
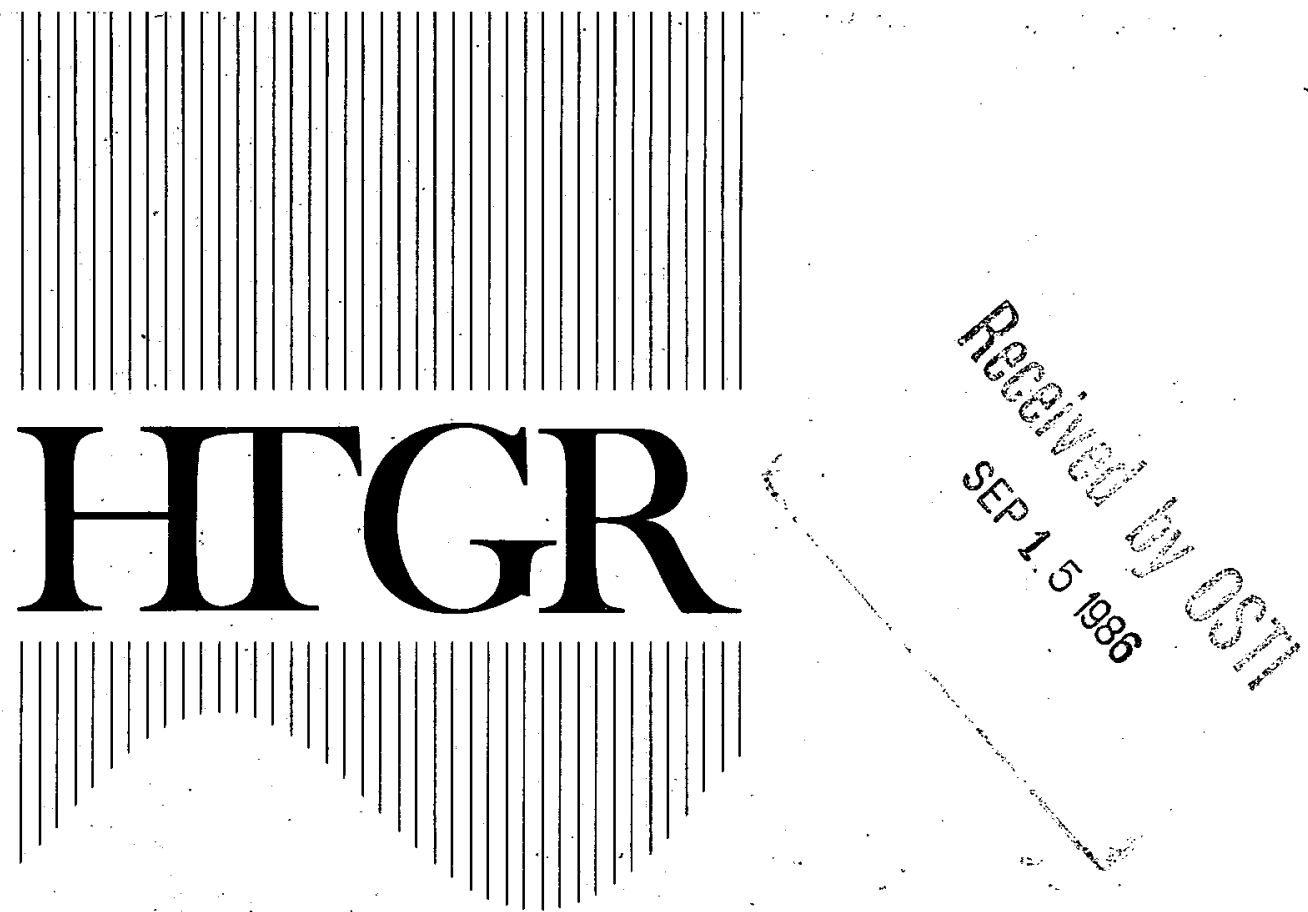

\title{
GRAPHITE TECHNOLOGY DEVELOPMENT PLAN
}

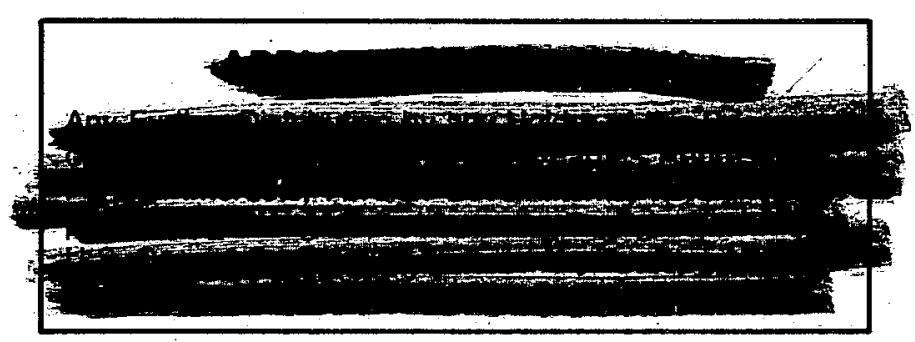

AUTHORS/CONTRACTORS

GA TECHNOLOGIES INC.

OAK RIDGE NATIONAL LABORATORY

DISTRIBUTION OF THIS DOCUMENT IS UNLMTTED

$$
\begin{aligned}
& \text { Pel nemo 3/15\%01-David steinman, } \\
& \text { Classirigigrion }
\end{aligned}
$$

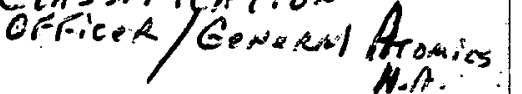

This do

ISSUED BY GA TECHNOLOGIES INC. FOR THE DEPARTMENT OF ENERGY PUST ICK Y RELEASABL CONTRACT DE-AC03-84SF11962 


\section{DISCLAIMER}

This report was prepared as an account of work sponsored by an agency of the United States Government. Neither the United States Government nor any agency Thereof, nor any of their employees, makes any warranty, express or implied, or assumes any legal liability or responsibility for the accuracy, completeness, or usefulness of any information, apparatus, product, or process disclosed, or represents that its use would not infringe privately owned rights. Reference herein to any specific commercial product, process, or service by trade name, trademark, manufacturer, or otherwise does not necessarily constitute or imply its endorsement, recommendation, or favoring by the United States Government or any agency thereof. The views and opinions of authors expressed herein do not necessarily state or reflect those of the United States Government or any agency thereof. 


\section{DISCLAIMER}

Portions of this document may be illegible in electronic image products. Images are produced from the best available original document. 

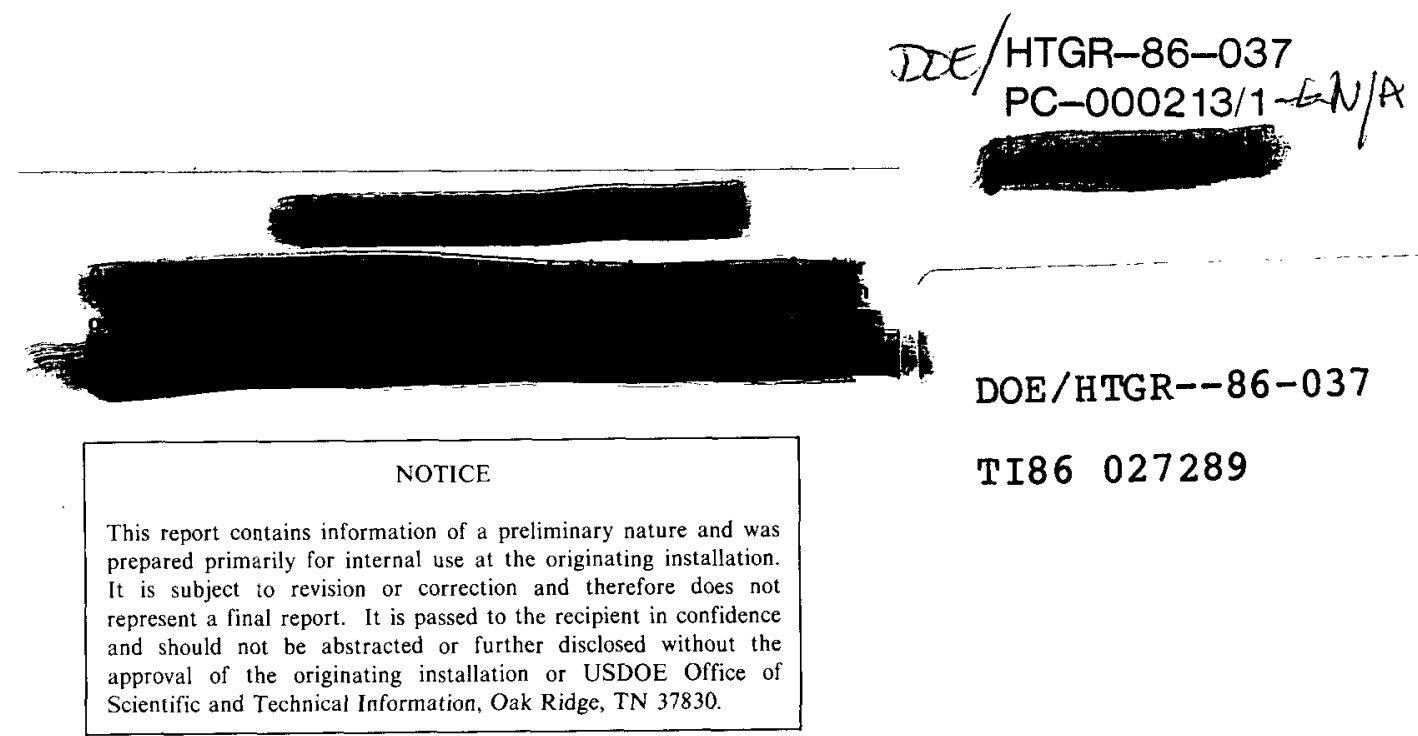

\section{GRAPHITE TECHNOLOGY DEVELOPMÉNT PLAN}

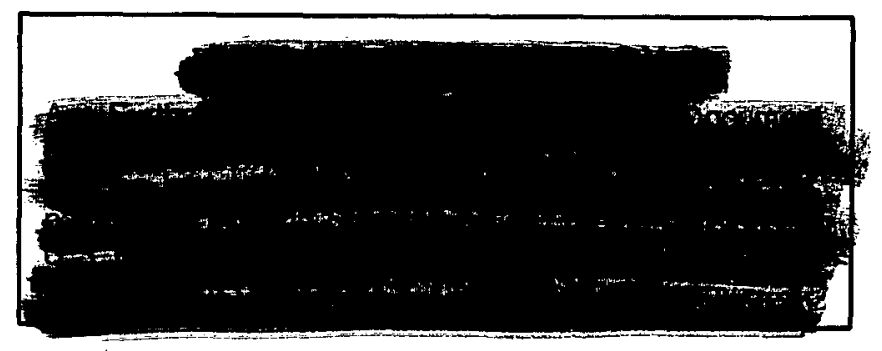

DOE/HTGR--86-037

TI86 027289

This report contains information of a preliminary nature and was prepared primarily for internal use at the originating installation. ent in confidence er disclosed without the approval of the originating installation or USDOE Office of Scientific and Technical Information, Oak Ridge, TN 37830.

\section{DISCLAIMER}

This report was prepared as an account of work sponsored by an agency of the United States Government. Neither the United States Government nor any agency thereof, nor any of their employees, makes any warranty, express or implied, or assumes any legal liability or responsibility for the accuracy, completeness, or usefulness of any information, apparatus, product, or process disclosed, or represents that its use would not infringe privately owned rights. Reference herein to any specific commercial product, process, or service by trade name, trademark, manufacturer, or otherwise does not necessarily constitute or imply its endorsement, recommendation, or favoring by the United States Government or any agency thereof. The views and opinions of authors expressed herein do not necessarily state or reflect those of the United States Government or any agency thereof.

\section{Issued By:}

GA Technologies Inc.

P.O. Box 85608

San Diego, California 92138

\section{This doovinent is PUBLICLY RELEASABLE}

DOE Contract No. DE-AC03-84SF11962

GA Project 6300

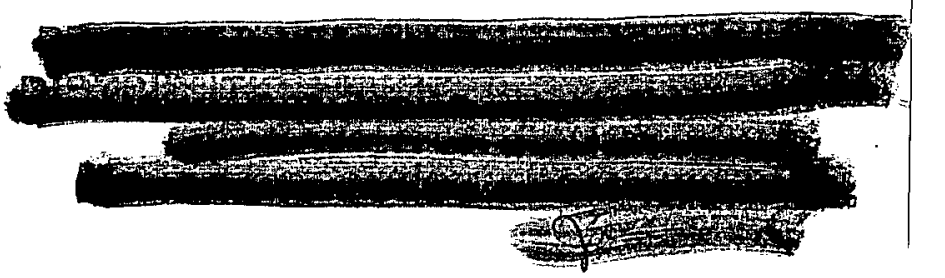




\section{PROJECT CONTROL DOCUMENT APPROVAL SUMMARY}

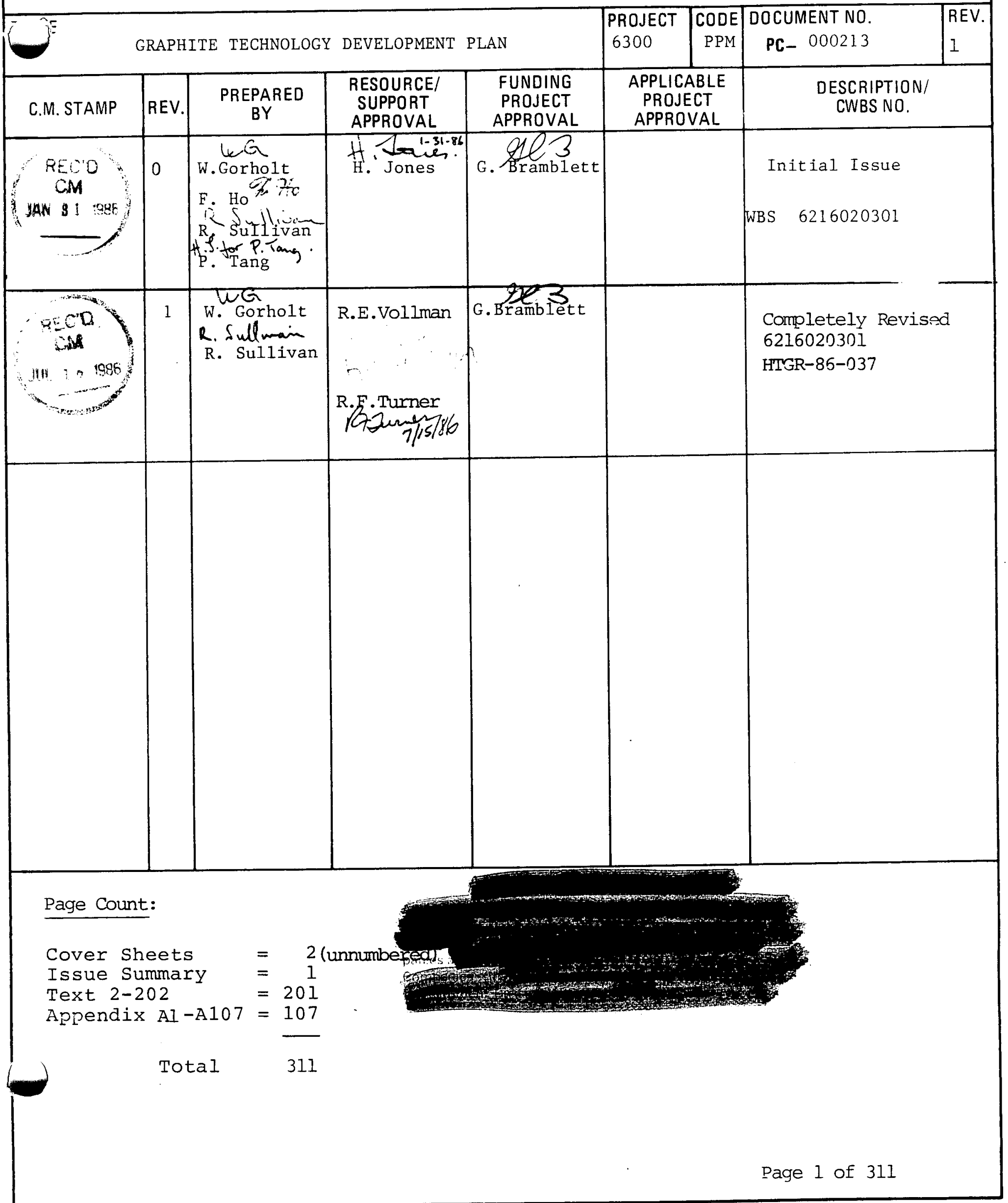




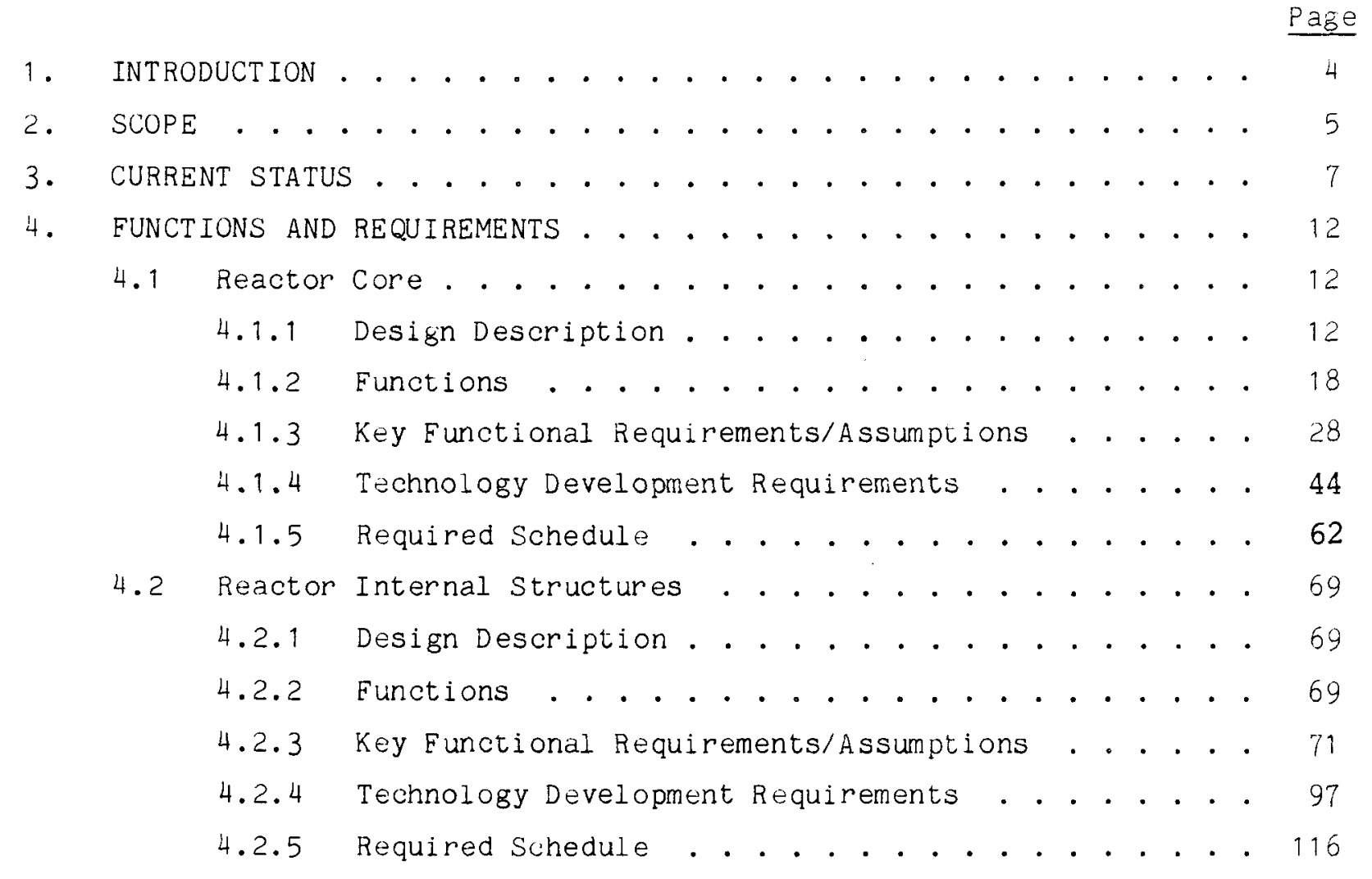

5. TECHNOLOGY DEVELOPMENT PLAN . . . . . . . . . . . . . . . . . 123

5.0 Introduction . . . . . . . . . . . . . . . 123

5.01 Core Support and Permanent Reflector . . . . . . 123

5.02 Core Components ............... 124

5.03 Organization of the Program Sub-Elements . . . . . 126

5.04 A Note on the Statistical Requirements....... 130

5.1 Permanent Graphite Components . . . . . . . . . . 134

5.1.1 Unaxial Mechanical Behavior and Thermal Expansivity

of 2020 Graphite . . . . . . . . . . . . 134

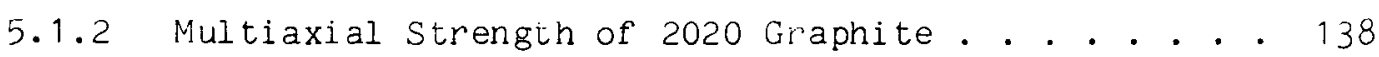

5.1.3 Fatigue and Miner's Law for 2020 Graphile . . . . i40

5.1.4 Irradiation Effects on Mechanical Properties of 2020 Graphite . . . . . . . . . . . . 145

5.1.5 Thermal Conductivity of 2020 Graphite . . . . . . . 147

5.1.6 Emissivity of 2020 Graphite . . . . . . . . . . . 151

5.1.7 Specific Heat of 2020 Graphice . . . . . . . . . . . 152

5.1.8 Corrosion Characteristics of 2020 Graphite. . . . 154

5.1.9 Procurement of Large Block 2020 Graphite

for Permanent Reflector . . . . . . . . . . 158 
5.2 Core Components . . . . . . . . . . . . . . . . 160

5.2.1 Mechanical Properties and Thermal Expansion of Unirradiated and Irradiated 4451 Graphite . . . . 160

5.2.2 Multiaxial Strength of H451 Graphite. . . . . . 166

5.2.3 Fatigue Strength and Miner's Law for H451 Graphite. 169 5.2.3 Addendum . . . . . . . . . . . 173

5.2.4 Irradiation-Induced Strain of H451 Graphite . . . 174

5.2.5 Irradiation-Induced Creep of 4451 Graphite . . . 178

5.2.6 Thermal Conductivity of H451 Graphite . . . . . 182

5.2.7 Emissivity of $H 451$ Graphite . . . . . . . . 183

5.2.8 Specific Heat of H451 Graphite.......... . 183

5.2.9 Statistics of Fracture Mechanics Properties of H451 Graphite............... . 184

5.2.10 Corrosion Characteristics of and Effects on H451 Graphite . . . . . . . . . . . . . 187

5.2.11 Validation of Design Methods for H451 Graphite Corrosion .. . . . . . . . . . . 191

5.3 Nondestructive Evaluation . . . . . . . . . . . . 194

5.3.1 Nondestructive Evailuation of Graphite . . . . . . 194

5.4 Time Schedules ................... . 196

5.5 Cost schedules................... 197 6. COMPONENT VALIDATION [LATER]

APPENDIX A: Design Data Needs . . . . . . . . . . . . . . A1 


\section{INTRODUCTION}

This document presents the plan for the graphite tochnology development required to support the design of the $350 \mathrm{MW}(t)$ Modular HTGR within the U.S. National Gas-Cooled Reactor Program. Besides descriptions of the required technology development, cost estimates, and schedules, the plan also includes the associated design functions and design requirements.

The plan follows the principles of the Integrated Approach which is a systematic method for establishing and documenting the design basis for a nuclear power plant in a "top down" manner. An essential element of the Integrated Approach is the Functional Analysis which identifies the functions and associated design requirements, first for the power plant as a whole, then for the systems, subsystems, components, and subcomponents in descending order. Appropriate design selections are also part of the Functional Analysis.

As the Functional Analysis evolves, it is necessary to show that the design requirements for each function have been met (or, as an interim measure, can be met) before proceeding to the subordinate functions. This is done through design analyses and trade studies where different design concepts are evaluated and the best concept selected. The selected design will then be checked against the design requirements with three possible results:

1. The design requirements are met on the basis of existing technology. In-those cases the Functional Analysis can proceed directly to the next level.

2. The design requirements are met (or, as an interim measure, are expected to be met) provided certain assumptions about nonexisting technology can be verified (examples of nonexisting technology are the actual values of material properties for the specific operating conditions and the validation of a design method). If this is the case, a need for technology is identified and included in the 
Technology Program. When the needed technology has been provided through the Technology Program, the provisionally satisfied requirements will be reexamined.

3. The design requirements are not met, in which case another design selection must be made.

The process is illustrated in Fig. 1-1.

While the process of showing compliance with the design requirements is a part of the design program, the tasks of verifying the assumptions belong to the technology program. The assumptions are thus the bridge between design and technology within the Integrated Approach. By tying the technology development to the design in this clear and direct manner, two purposes are served. First, by limiting the technology program to tasks which are established in direct response to design needs, unnecessary or excessive technology development is avoided. Secondly, by introducing a systematic method for identifying all the missing design data, the risk of defining an incomplete technology program has been greatly reduced.

\section{SCOPE}

The Graphite Technology Development Plan includes all the technology development necessary to support the design of the graphite components of the reactor core and of the reactor internal structures, except for those development needs which are not related to graphite characteristics but to other aspects of the reactor design; for example, flow passage configuration.

As discussed in Section 1 above, the plan is prepared in accordance with the principles of the Integrated Approach. Accordingly, the functions and their associated design requirements which generate needs for technology development are extracted from the function logic tree and included in the 


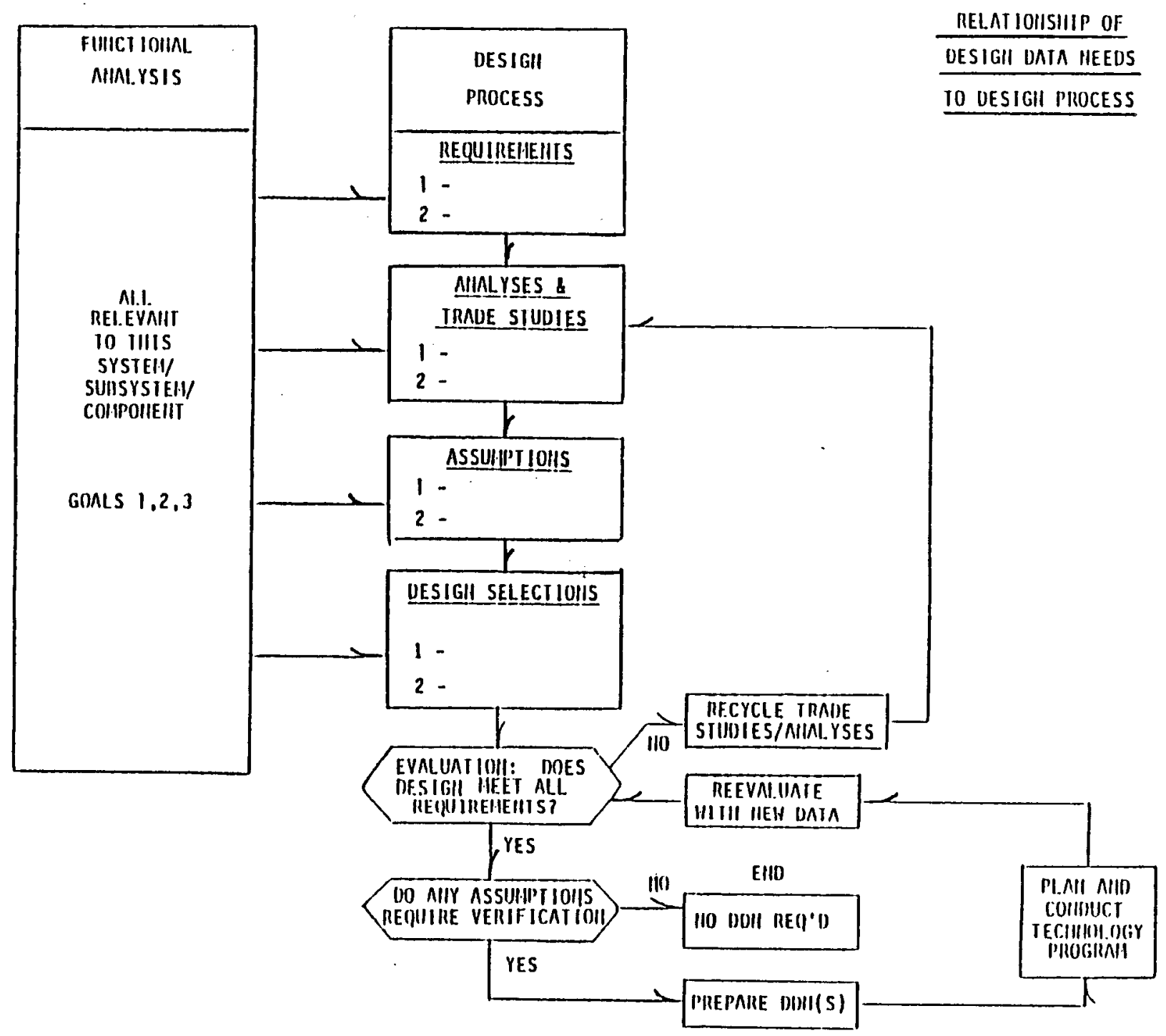

Figure 1.1 Logic Diagram For Design Process 
plan. This is done in Section 4 of the plan. Section 4 also includes detailed specifications of the data needs and schedules for when the data are needed.

While Section 4 defines the need for data from the designer's perspective, Sections 5 and 6 describe the proposed graphite technology program prepared in response to the needs. The program is divided into two parts, the materials program (sometimes referred to as the "Base Program") described in Section 5 and the component validation program described in section 6 .

The information in Section 4 is also contained in abbreviated form in the Design Data Needs or DDNs. A DDN is a summary level statement about a need for design data and is prepared to a specified format. The total collection of DDNs defines the required technology support for the entire $350 \mathrm{MW}(t)$ Modular HTGR program.] The relevant DDNs, i.e., the DDNs in the area of graphite technology, are-appended to the plan.

\section{CURRENT STATUS}

The status of the graphite development program is discussed in this section. The discussion is organized around the specific graphite components of the $350 \mathrm{MW}(\mathrm{t})$ Modular HTGR design. The specific graphite components are: (1) the fuel elements and the replaceable reflector elements of the reactor core, and (2) the core support blocks, the core support posts, and the permanent side reflector blocks of the reactor internal structures. Besides being organized around the specific components, the discussion is divided into the areas of materials development and characterization, materials modeling, and component validation testing.

In the area of the graphite materials development and characterization a considerable body of data has been established for both the core components and for the reactor internals components. The existing data were generated in a number of materials programs, including programs for developing improved grades of graphite, for characterizing mechanical and physical properties, for 
evaluating graphite fatigue behavior, and for assessing the effects of coolant impurities; specifically for:

1. Fuel Elements and Replaceable Reflector Elements. Grade H-451 graphite has been developed as a high-purity, specialty graphite for HTGR fuel and replaceable reflector elements. In addition to the materials development, extensive work has been accomplished on establishing the design data base for ${ }^{-H}-451$ graphite. Included in this work was irradiation testing involving four fully instrumented and additional partially instrumented capsules; this irradiation testing was done to determine the irradiation-induced dimensional changes and the irradiation effects on mechanical and physical properties of $\mathrm{H}-451$. Also, five irradiation creep experiments have been conducted. Additionally, an improved higher strength version of $\mathrm{H}-451$, designated $\mathrm{H}-451-\mathrm{I}$, has been partly developed. [This development work has been discontinued, since the higher strength graphite is not needed for the $350 \mathrm{MW}(t)$ Modular HTGR.]

The characterization of $\mathrm{H}-451$ has also included statistical analyses of the data base. Much of this statistical analysis has been in the area of tensile strength, where the data base includes tests from several production lots. Up to recently a Gaussian distribution was assumed. However, a recent detailed inspection of the tensile strength data has revealed a bimodal distribution with the lower mode attributable to fabrication flaws.

2. Reactor Internal Structures. For the core support posts, core support blocks, and permanent side reflectors, a high-strength, low-oxidation rate grade 2020 graphite has been selected. The design data base for 2020 graphite is not as well-established as for H-451, although much information has been obtained on this material. Considerable testing has been completed on 10-in. diameter 2020 billets for core support posts, but additional characterization will be required on large cross section material 
for core support blocks and permanent side reflectors. One large block of special 2020 graphite measuring 26 in. $\times 26$ in. $\times 39$ in. has been made and characterized. [Prior to the development of 2020 graphite grade PGX was the candidate material for the reactor internal structures. A large data base exists on this material.]

To address the concern for graphite oxidation, some accelerated oxidation tests have been completed on 2020 graphite. These tests were performed in a special test atmosphere of helium, hydrogen, and water vapor that is representative of reactor conditions. The tests indicated that the graphite-water reaction produces a surface-oriented oxidation profile, leaving unoxidized graphite as a core.

In the area of oxidation resistance, a problem with 2020 graphite has been the variability of its oxidation characteristics, apparently due to small differences in the raw materials and in the production process in graphite produced at different times. Guidelines have been worked out for correcting this problem by carefully controlling the raw materials going into 2020 graphite when it is produced for the HTGR program. Six logs of the special 2020 graphite have been made and partially evaluated. The first results of oxidation tests on these logs of the improved material are very encouraging with oxidation rates being in the same range or better than $\mathrm{H}-451$.

Besides the work specific to either the core components or the reactor internal structures, development work applicable to all the graphite components has also been performed. This includes statistical techniques for formulating sampling methods, acceptance criteria, and interproperty correlations. The work applicable to all the graphite components also includes nondestructive testing techniques; in this area three nondestructive test methods have been evaluated: radiography, sonic testing, and eddy current testing. Radiography has been used to detect high atomic number impurities and fabrication defects during the development of H-451-I and 
grade 2020 graphites. Sonic velocity and sonic attenuation measurements have been found to give good indications of the elastic modulus and the mean strength of billets of $\mathrm{H}-451-\mathrm{I}$, and eddy current testing has been investigated as a means of measuring the density profile in surface-oxidized core support graphites.

Much of the HTGR graphite material development work described in the preceding paragraphs was performed in the period from the early 1960 s through the mid- to late 1970s, when the graphite program emphasis was on new graphite development and data accumulation on existing graphites. During the same period, relatively low priority was given to the area of material modeling. Since then, towards the end of the 1970s, component designers became increasingly aware that graphite behavior in an HTGR environment was not well predicted by the existing material models and constitutive relations. Consequently, higher priority was given to development of better behavior models and failure theories.

The scope of this material modeling activity within the graphite technology program was to develop and verify multiaxial models for the mechanical behavior and failure characteristics of graphite under reactor conditions, including effects of material nonlinearity, load history dependence, and material inhomogeneity, to the extent necessary to achieve verified stress analysis methods.

As a result of the material modeling efforts, a nonlinear theory was developed for unirradiated graphite. This theory includes a nonlinear stress-strain relation and transverse isotropy. In addition, a multiaxial failure theory for graphite was proposed using a failure mechanism based on the Tsai-Wu quadratic strength criteria. To investigate the strain gradient effect on the constitutive relationship of graphite, a series of beam tests were performed on a coarse and on a fine grain graphite, H-451 and 2020, respectively. 
In parallel with the material development and material modeling activity, component testing has been performed for three different purposes: (1) to verify the design adequacy, (2) to generate design data, and (3) to verify analytical methods. One of the major test programs performed under the $2240 \mathrm{MW}(t)$ steam cycle program for the first of these three purposes was a series of static load capacity tests of the core support posts and seat assemblies. These tests showed that the recent design improvements increased the ultimate vertical compression load capacity and that the design requirements can be met. To supplement the results of that test program, an evaluation of the structural effects of oxidation on graphite core support components has been performed for Fort St. Vrain (FSV) components, and the results are being correlated with laboratory measurements on test specimens exposed in the FSV bottom reflector.

Further within the component validation area, tests to determine the buckling behavior of graphite posts with various length-to-diameter ratios have been completed. Parametric buckling design curves were derived from these tests. Tests have also been performed to determine the material and structural damping of post/seat assemblies for use in flow-induced vibration analyses.

To validate the seismic design methods, unirradiated graphite core components (fuel elements and replaceable reflector elements) have been subjected to mechanical tests that simulate seismic loads on the side faces of the elements and on the dowels. Both static and dynamic tests were performed. The results demonstrated the ability of the core to withstand the seismic loads.

Another source of data for validating design methods has been the use of FSV experience, specifically to verify the predicted behavior of the graphite core components in the reactor environment. Up to the present, fuel elements have been irradiated in the FSV reactor at fluences equivalent to about two years of full-power operation which corresponds to about $30 \%$ of their design lifetime. Components made from $\mathrm{H}-451$ graphite (the current reference 
material for the $350 \mathrm{MW}(t)$ core) have been licensed for FSV and have begun replacing the original $\mathrm{H}-327$ elements beginning with the segment 9 reload. Eight $\mathrm{H}-451$ fuel test elements also are currently under irradiation in FSV.

In 1982, two cracked elements were found during the post-service inspection of the spent FSV fuel elements. As part of a study to explain how and why the blocks cracked, finite element analyses were performed. These finite element analyses predicted the maximum stress at the location of the crack to be close to the minimum strength of the graphite material. Although code validation was not the prime purpose of the analysis, the good correlation between the analytical predictions and the observed behavior is nevertheless a result which strongly supports the validity of the finite element codes.

Additional irradiation experiments of multiple-holed configurations were performed in other reactors such as Peach Bottom (USA), Dragon (U.K.), and Osiris (France). These experiments indicate that present analytical methods for predicting irradiation-induced stresses are apparently conservative, although they also show that the predictions have significant uncertainties.

4. FUNCTIONS AND REQUIREMENTS

\subsection{Reactor Core}

\subsubsection{Design Description}

The primary components of the $350 \mathrm{MW}(t)$ modular nuclear steam supply system (NSSS) are contained in two pressure vessels (the reactor vessel and the steam generator vessel) as shown in Fig. 4.1. The reactor core is located in the reactor vessel, together with the permanent side reflector, the core support structure, the core barrel, and other components. The reactor core is an array of hexagonal prismatic graphite blocks as shown in Fig. 4.2. The core is divided into three approximately concentric regions; these are the central reflector, the active core, and the side reflector. 


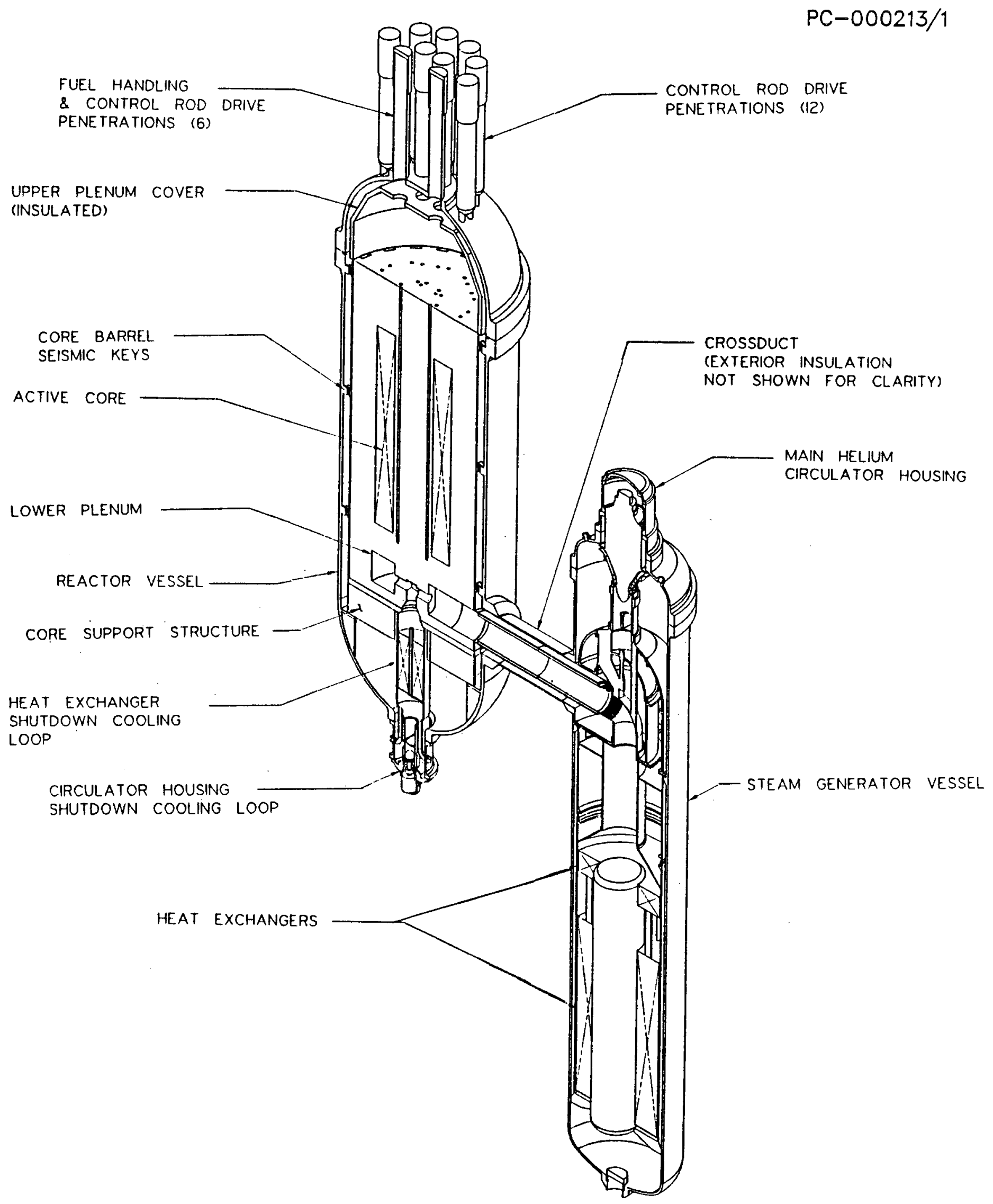

Figure 4.1 $350 \mathrm{MW}(\mathrm{t})$ Modular Nuclear Steam Supply System 


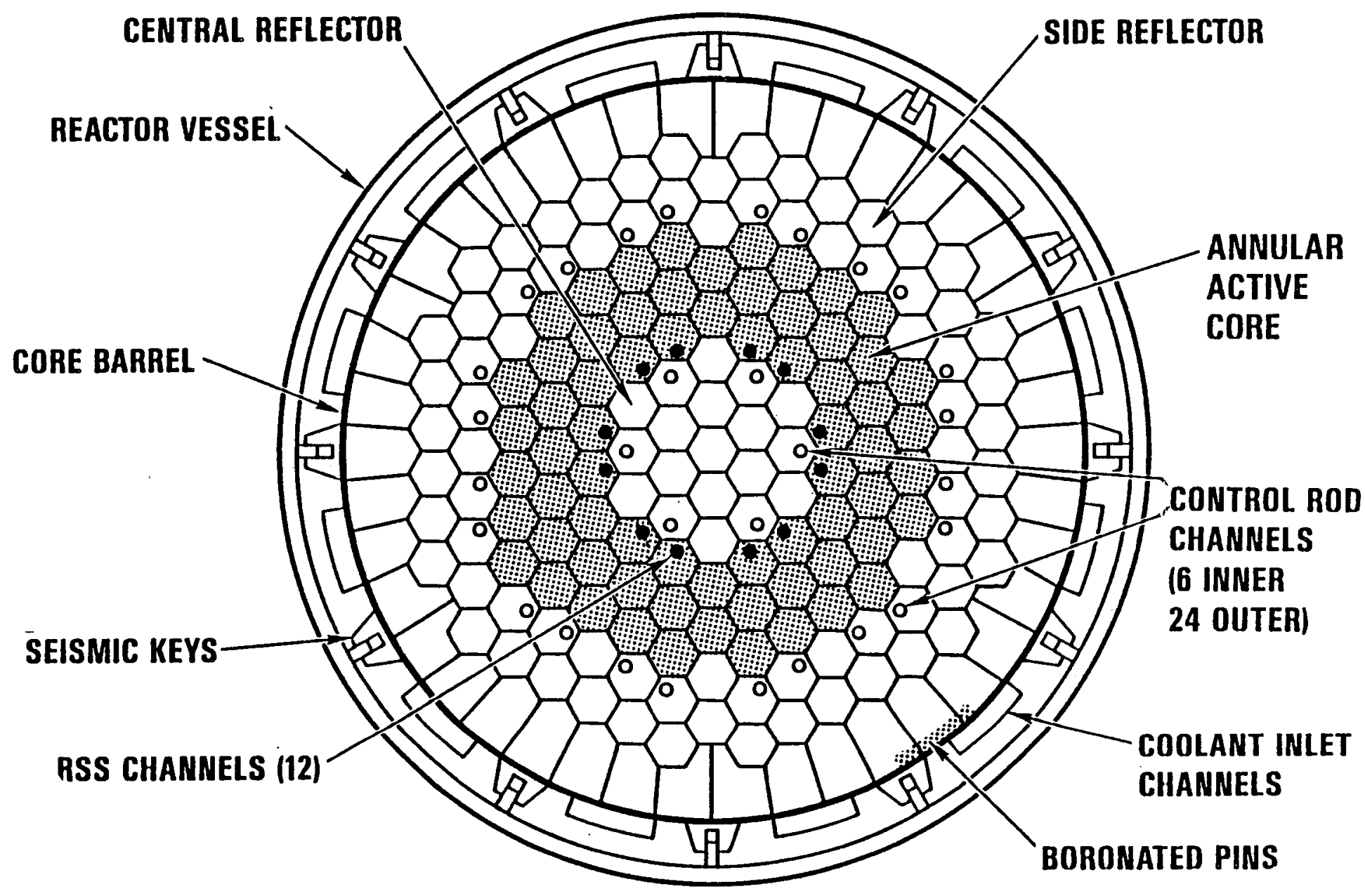

Figure 4.2 $350 \mathrm{MW}(t)$ Reactor Core Layout 
The top and bottom reflectors (above and below the active core) complete the array which is surrounded by the permanent side reflectors and rests upon a graphite core support structure.

The hexagonal elements all have a 14.2-in. $(36 \mathrm{~cm})$ flat-to-flat width and are made of graphite grade $\mathrm{H}-451$. The 31.2 -in. $(0.79 \mathrm{~m})$ high elements of the active core are referred to as fuel elements and have vertical holes through the element for coolant flow and blind holes for fuel rods as shown in Fig. 4.3. Some of the fuel elements have an additional large hole for insertion of reserve shutdown material.

When installed in the core, the elements are stacked in columns. The active core consists of 66 columns of fuel elements, stacked ten elements to the column. Twelve of the columns located adjacent to the central reflector have reserve shutdown channels and are therefore made up of the special fuel elements with the reserve shutdown holes. The volume of the active core is $59.23 \mathrm{~m}^{3}$; for a power rating of $350 \mathrm{MW}(t)$, this gives an average active core power density of $5.91 \mathrm{w} / \mathrm{cm}^{3}$. Half of the fuel columns are replaced every 18 months during reactor shutdown, except for an initial core cycle of two years.

The reflector elements consist of five types: (1) top, (2) central, (3) outer side (or radial), (4) bottom, and (5) bottom transition. The top reflector elements, of which there are two on top of each fuel column, are 31.2 in. $(0.79 \mathrm{~m})$ high and contain an array of coolant holes that allow coolant to pass through to the fuel elements directly below. The bottom reflector elements below the active core (see Fig. 4.4 ) are 15.6 in. ( $0.4 \mathrm{~m}$ ) high and have identical arrays of coolant holes as in the top reflector. Finally, at the very bottom of the columns are the transition blocks, which form the lowermost part of the bottom reflector. These blocks are also $15.6 \mathrm{in.}(0.4 \mathrm{~m}) \mathrm{high}$ and transfer the coolant from the bottom reflectors into six large holes in the flow distribution blocks directly below them. (The flow distribution blocks are part of Reactor Internal Structures described in Section 4.2 .1 below.) 


\section{ALL DIMENSIONS IN mm}
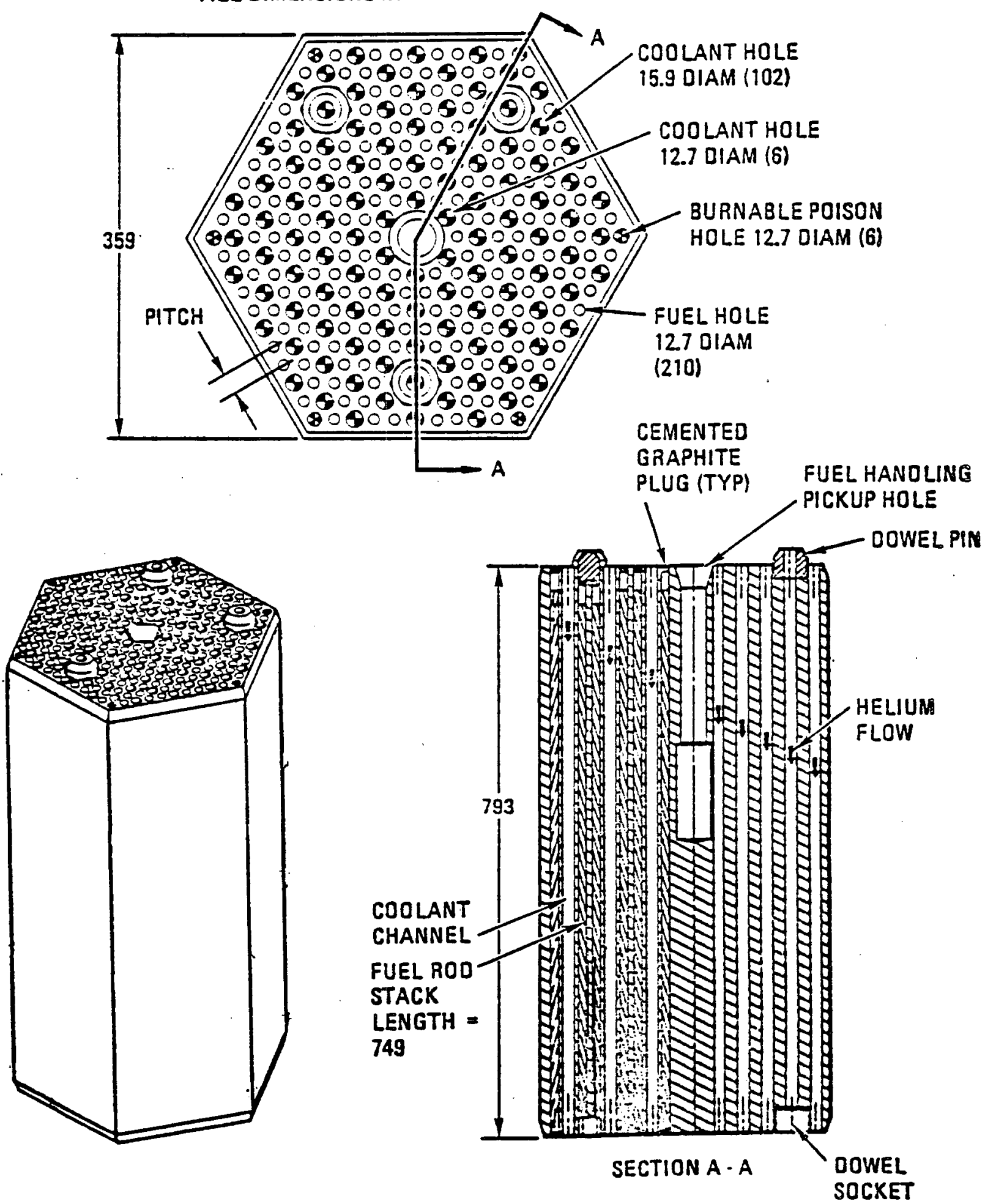

Figure 4.3 Standard Fuel Element 


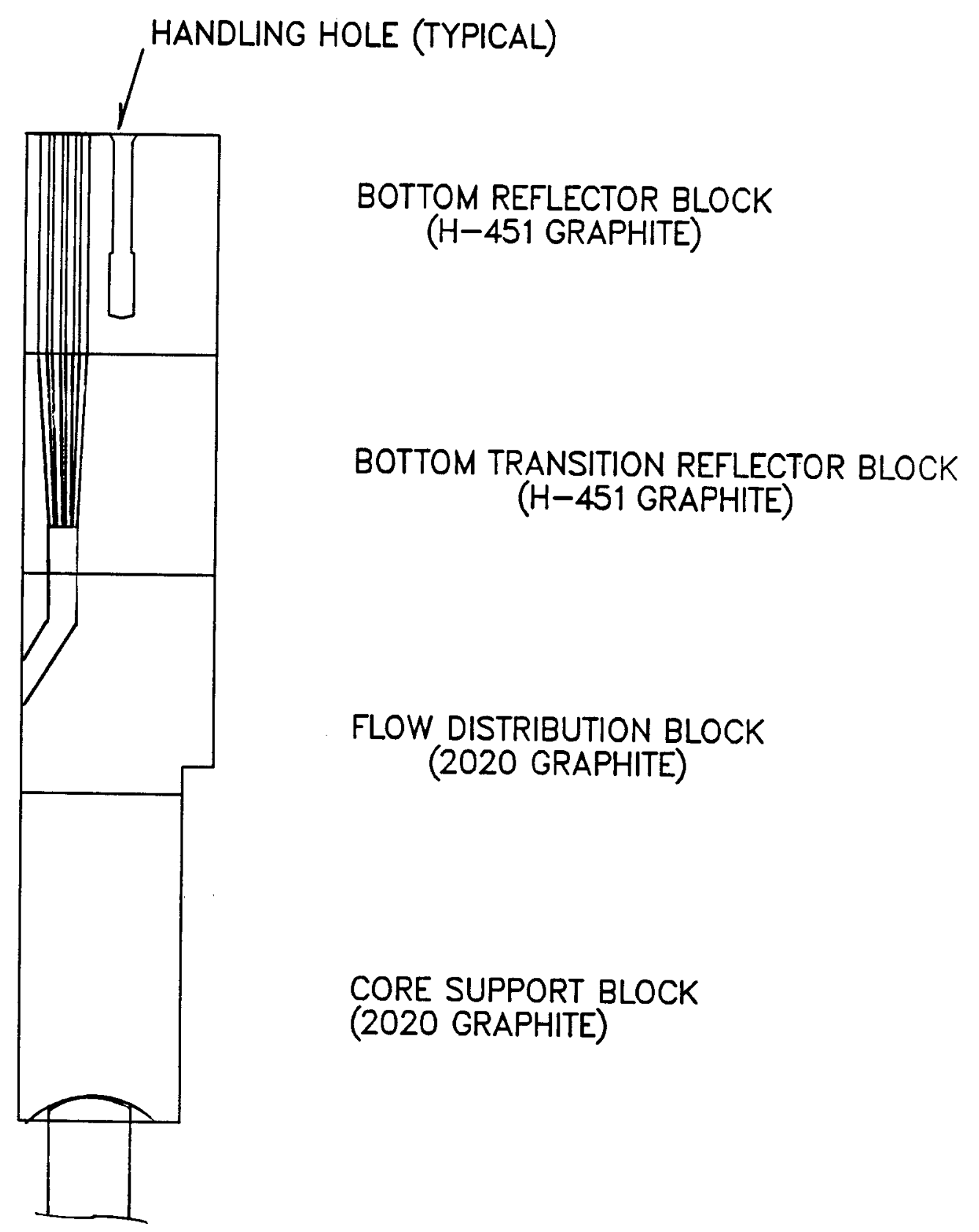

Figure 4.4 Bottom Reflector and Graphite Core Support Structure 
The replaceable outer side reflector consists of two rings of graphite columns of hexagonal elements without any fuel or coolant holes. As shown in the core layout in Fig. 4.2, control rod channels are situated in 24 of the columns of the innermost of the two rings. The columns of the central reflector consists of the same type of solid elements as the outer side reflector. Six of these columns have control rod channels.

\subsubsection{Functions}

The graphite core components consist of fuel elements and replaceable reflector elements. The functions which result in technology requirements for these components, as extracted from the functional tree, are discussed below.

4.1.2.1 Fuel Element Functions. The functions which result in technology requirements fall into the two general areas of structural support and geometrical alignment. The latter is needed for nuclear control and for heat transfer from the fuel rods through the graphite into the primary coolant. By name and number, the specific functions are:

Function No. 1.1.2.1.2.2.4, Maintain Fuel Element Structural Integrity:

This function assists in maintaining geometric alignment for both coolant flow passage and nuclear control. As shown in Fig. 4.5, it is a subfunction under Function 1.1.2.1.2.2, Maintain Core Coolant Passages Geometry and Function 1.1.2.1.2, Transfer Heat from Heat Transfer Surface to Primary Coolant.

Function No. 1.1.2.1.2.1.1, Control In-Core Gap Flow:

This function limits the flow between components of the core and helps reduce coolant exit temperature fluctuations. It is a subfunction under Function 1.1.2.1.2.1, Control Core Bypass Flow, as shown in Fig. 4.6. 


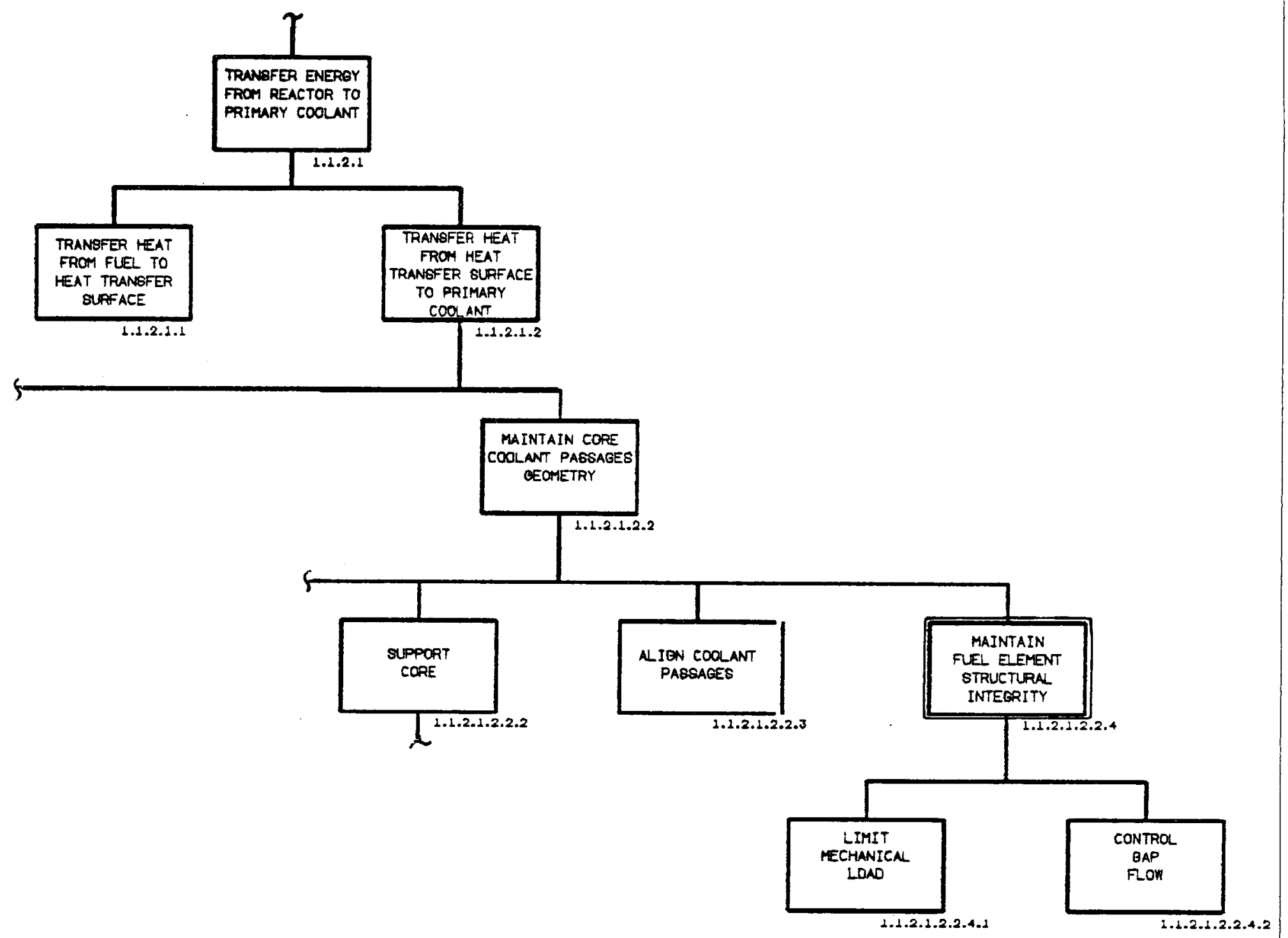

Figure 4.5 Partial Functional Tree for Core Components 


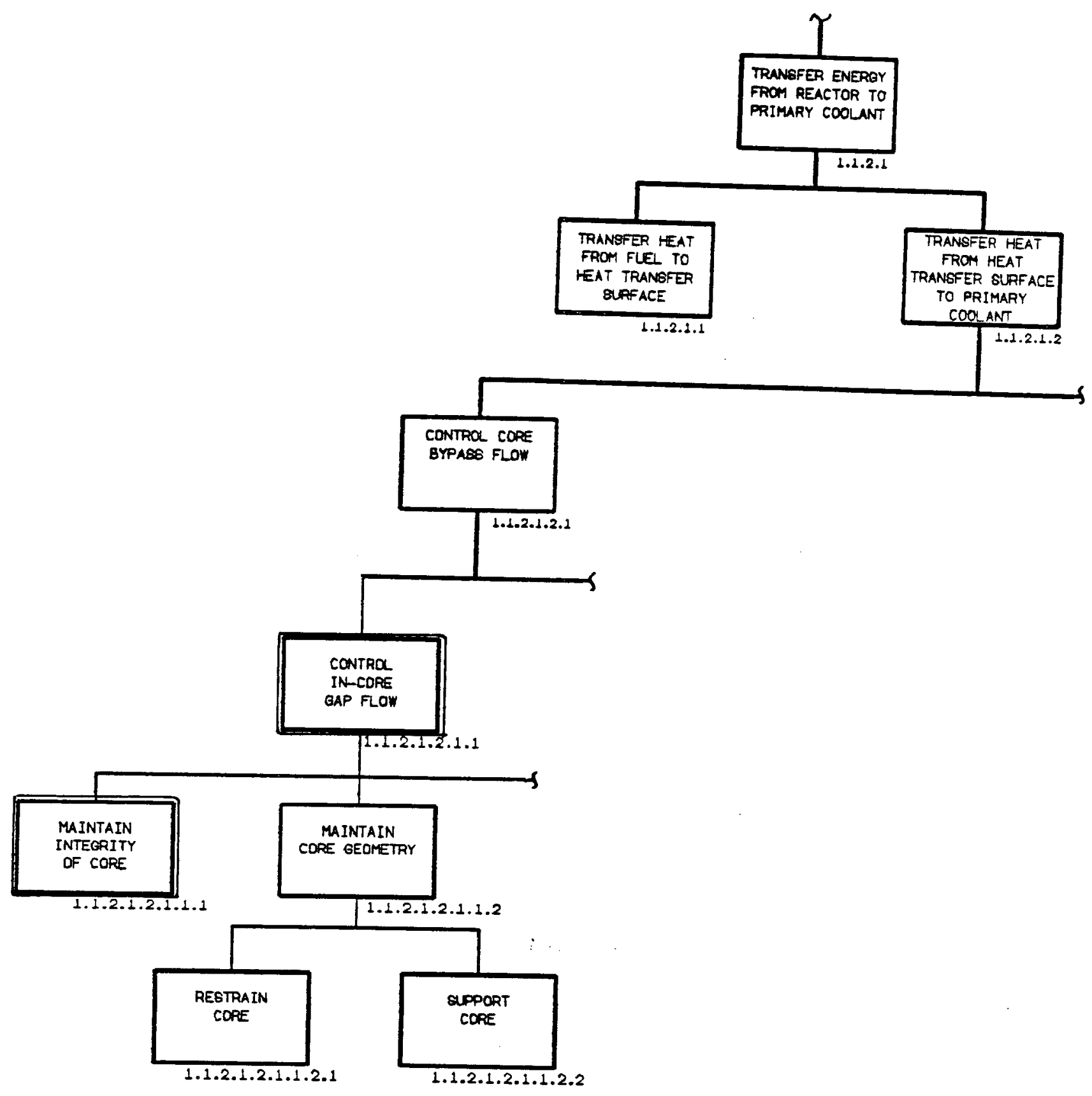

Figure 4.6 Partial Functional Tree for Core Components 
Function No. 1.1.2.1.2.1.1.1, Maintain Integrity of Core:

This function maintains the geometric alignment of the fuel columns to assist in controlling core bypass flow. It is a subfunction under Function 1.1.2.1.2.1.1, Control In-Core Gap Flow, as shown in Fig. 4.6 .

Function No. 1.1.2.1.1, Transfer Heat from Fuel to Heat Transfer Surface:

This function aids in the energy transfer from the fuel into the graphite fuel elements. It is one of two subfunctions under Function 1.1.2.1, Transfer Energy from Reactor to Primary Coolant as shown in Fig. 4.7 .

Function No. 1.1.2.1.2, Transfer Heat from Heat Transfer Surface to Primary Coolant:

This function aids the energy transfer from the fuel rods through the graphite into the helium coolant. It is the second of the two subfunctions under Function 1.1.2.1, Transfer Energy from Reactor to Primary Coolant, as shown in Fig. 4.7.

Function No. 2.1.2.1.2.4, Protect the Capability to Maintain Fuel Element Structural Integrity:

This function is one of the goal 2 functions which collectively are intended to limit the investment risk and to ensure the plant availability of $80 \%$. More specifically, this function assists in maintaining the capability to preserve core geometrical alignment for nuclear heat generation, heat transfer to the primary coolant, and nuclear control so as to limit the plant unscheduled downtime to $10 \%$. 


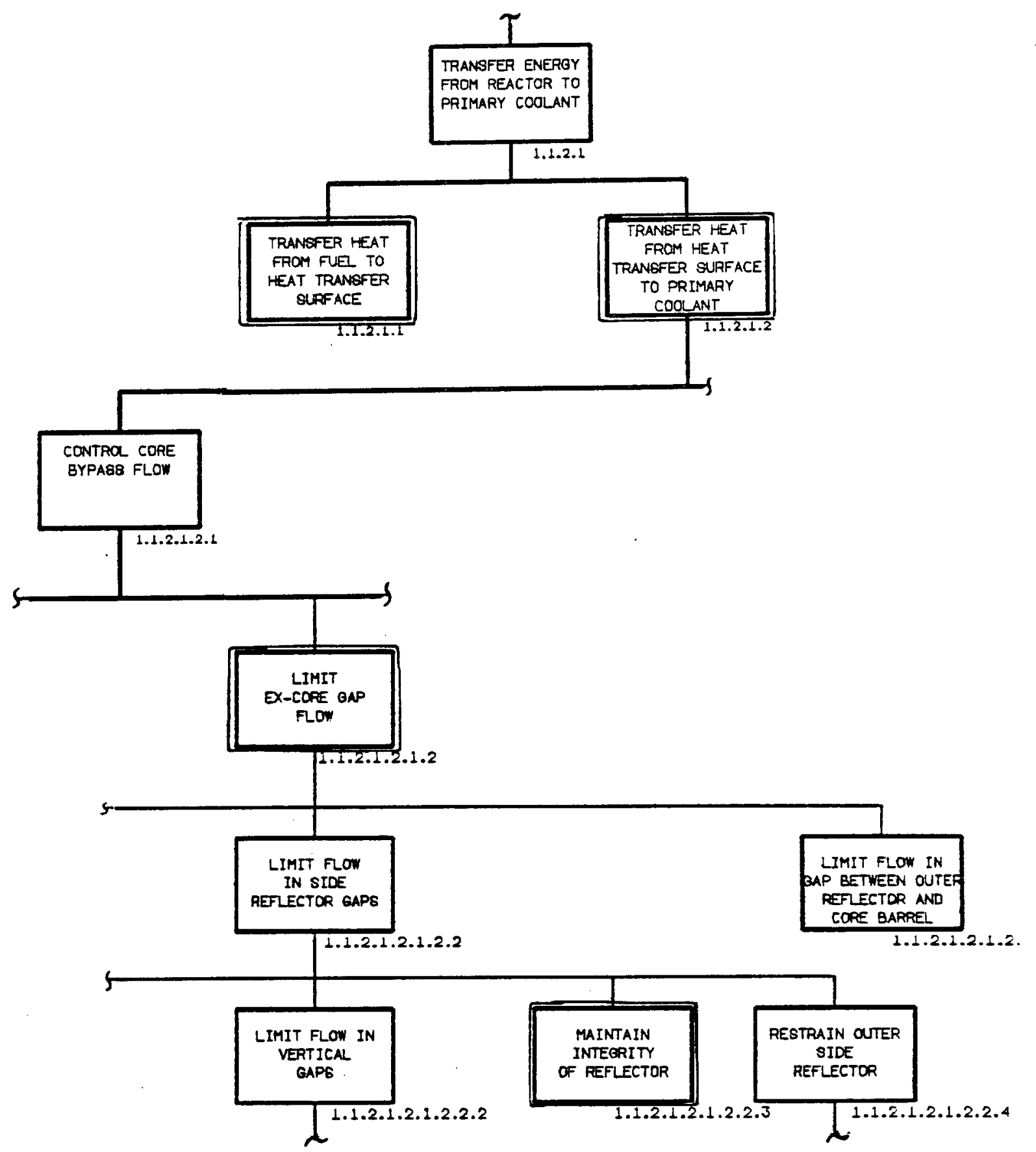

Figure 4.7 Partial Functional Tree for Core Components 
Function No. 2.1.2.1.2.2.2.2.2.2.4, Absorb Energy from Dropped Control Rod:

This function is one of the goal 2 functions which collectively are intended to limit the investment risk and to ensure the plant availability of $80 \%$. This function assists in protecting the core support structure from the unintended impact of a dropped control rod.

Function No. 3.1.1.2.1.1.2.2.1.1.1, Conduct Heat from Fuel to Core Graphite:

This function is one of the goal 3 functions which collectively maintain control of radionuclide release during unscheduled events. This function aids in in the energy transfer from the fuel into the core graphite. It is one of these subfunctions under Function $3 \cdot 1 \cdot 1 \cdot 2 \cdot 1 \cdot 1 \cdot 2 \cdot 2 \cdot 1 \cdot 1$, Conduct Heat from Core to Vessel wall.

Function No. 3.1.1.2.1.1.2.1.1.3.2.2, Maintain Integrity of RSS Fuel Element:

This function is a goal 3 function which assists in maintaining geometric alignment for both coolant flow passage and nuclear control. It is a subfunction under Function $3 \cdot 1 \cdot 1 \cdot 2 \cdot 1 \cdot 1.2 .1 .1 .3 .2$, Maintain RSS Channel Geometry.

4.1.2.2 Reflector Element Functions. As for the fuel elements (Subsection 4.1.2.1) the functions resulting in technology requirements are in the two general areas of structural support and geometrical alignment, the latter being for nuclear control and heat transfer. By name and number these functions are: 
Function No. 1.1.1.1.2.2.1.3, Maintain Integrity of Reflectors:

This function assists in preserving the geometrical alignment of the core which allows nuclear heat generation. It is a subfunction under: Function 1.1.1.1.2.2.1, Maintain Reflector Geometry, and Function $1.1 \cdot 1 \cdot 1 \cdot 2 \cdot 2$, Conserve Neutrons.

This function also has four subfunctions which collectively maintain the reflector geometry. As shown in Fig. 4.8, they are:

Function 1.1.1.1.2.2.1.3.1, Maintain Integrity of Top Reflectors Function 1.1.1.1.2.2.1.3.2, Maintain Integrity of Side Reflectors Function 1.1.1.1.2.2.1.3.3, Maintain Integrity of Bottom Reflectors Function $1 \cdot 1 \cdot 1 \cdot 1 \cdot 2 \cdot 2 \cdot 1 \cdot 3 \cdot 4$, Maintain Integrity of Central Reflectors

Function $1 \cdot 1 \cdot 1 \cdot 2 \cdot 2 \cdot 1 \cdot 1 \cdot 2$, Maintain Integrity of Reflector Control Element

This function assists in preserving the control rod channel geometry which allows nuclear control. It is a subfunction under Function 1.1.1.2.2.1.1, Maintain Control Rod Channel Geometry, as shown in Fig. 4.9 .

Function No. 1.1.2.1.2.1.2, Limit Ex-core Gap Flow:

This function aids in controlling the core bypass flow by maintaining geometrical alignment. It is a subfunction under Function 1.1.2.1.2.1, Control Core Bypass Flow. As shown in Fig. 4.7 , it has three subfunctions: 


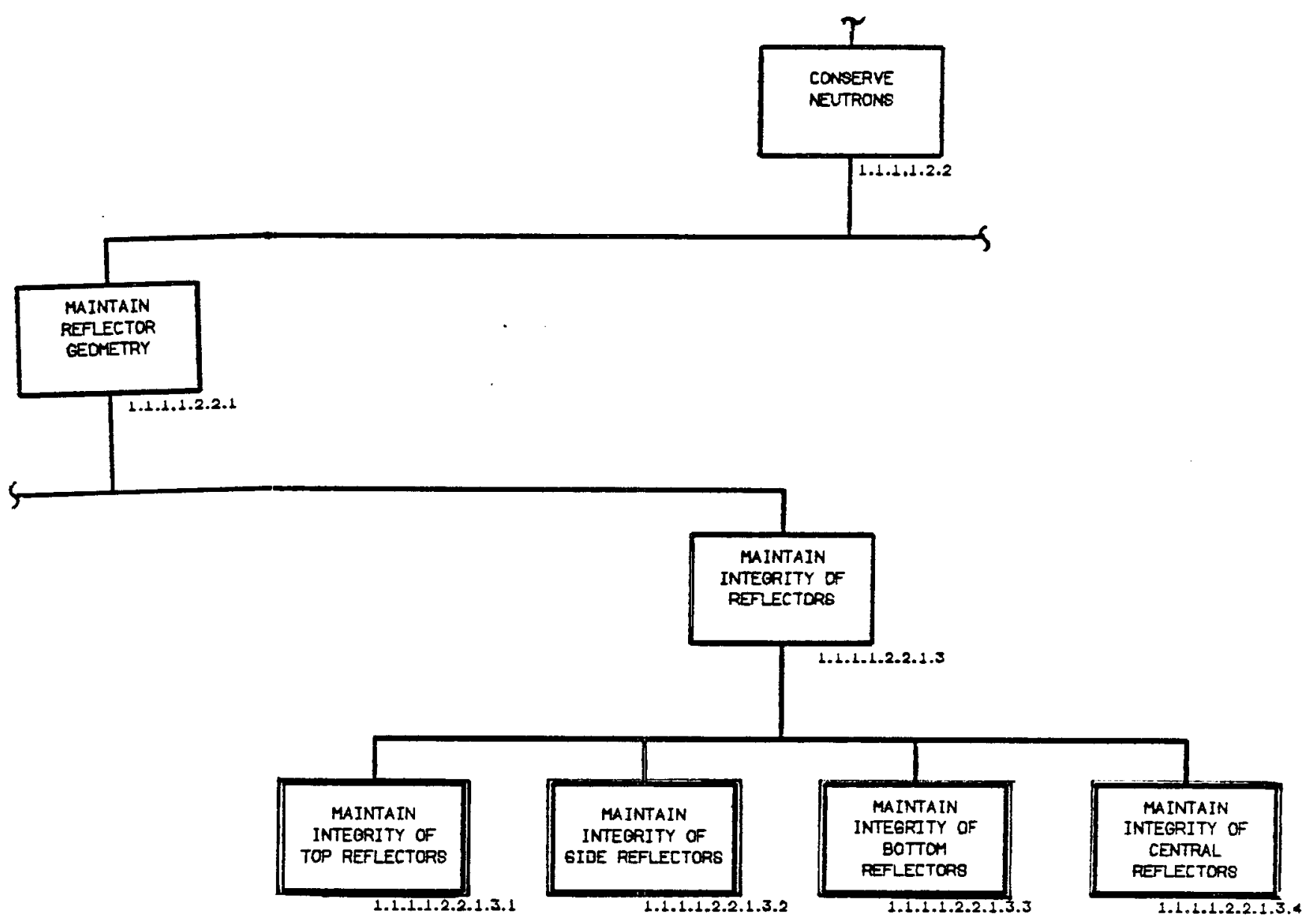

Figure 4.8 Partial Functional Tree for Core Components 


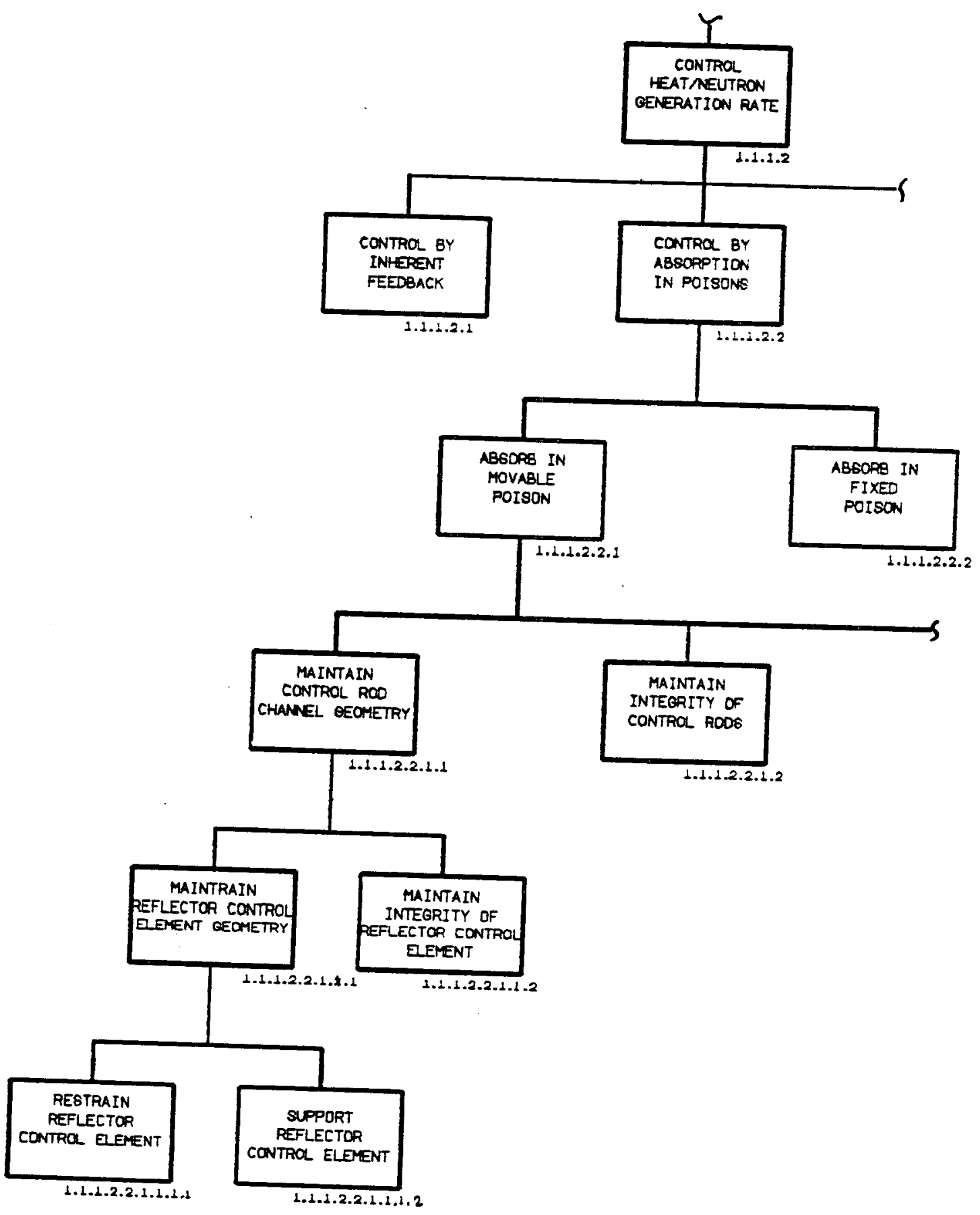

Figure 4.9 Partial Functional Tree for Core Components 
Function 1.1.2.1.2.1.2.1, Limit Flow in Central Reflector Function $1 \cdot 1 \cdot 2 \cdot 1 \cdot 2 \cdot 1 \cdot 2.2$, Limit Flow in Side Reflector Gaps Function 1.1.2.1.2.1.2.3, Limit Flow in Gap Between Outer Reflector and Core Barrel

Function No. 1.1.2.1.2.1.2.2.3, Maintain Integrity of Reflector:

This function assists in controlling the flow in the side reflector gaps by assuring structural integrity under Function 1.1.2.1.2.1.2.2, Limit Flow in Side Reflector Gaps, as shown in Fig. 4.7. It is similar to Function 1.1.1.1.2.2.1.3, Maintain Integrity of Reflectors, which, as discussed above, assists in maintaining geometrical alignment for nuclear heat generation.

Function No. 3.1.1.2.1.1.2.2.1.1.2, Conduct Heat Through Reflector

This function is one of the goal 3 functions which collectively maintain control of radionuclide release during unscheduled events. This function aids in the energy transfer from the core, through the reflectors, and out to the vessel wall. It is a subfunction under Function 3.1.1.2.1.1.2.2.1.1, Conduct Heat from Core to Vessel Wall.

Function No. 3.1.1.2.1.1.2.1.1.3.1.2, Maintain Integrity of Reflector Control Element

This function is a goal 3 function which assists in maintaining geometrtic alignment for both nuclear control and coolant flow passage and provides neutron shielding for the permanent reflectors. It is a subfunction under Function 3.1.1.2.1.1.2.1.1.3.1, Maintain Control Rod Channel Geometry. 


\subsubsection{Key Functional Requirements/Assumptions}

The requirements which bound the functions discussed above, and the assumptions necessary to satisfy these requirements are discussed below for the core components (fuel elements and replaceable reflector elements). These requirements are grouped into two categories:

1. Requirements which lead to a technology need (through an assumption), and

2. Requirements which define the operating environment.

\subsubsection{Core Component Requirements/Assumptions Resulting in Technology Needs.} The discussion that follows on the requirements and assumptions that result in technology needs will be divided up by the relevant functions, of which there are seven.

Function 1.1.2.1.1, Transfer Heat from Fuel to Heat Transfer Surface.

The heat transfer function is performed by containing the active fuel in cylindrical rods which are held in a staggered array in the fuel element graphite moderator surrounded by holes in which helium coolant flows to carry the heat away. Heat transfer is mainly radially away from the fuel rods, across a small stagnant helium gap, through the graphite moderator, to the primary coolant flowing through the holes surrounding the fuel rods. Requirement 2 of this function states that the maximum, time-averaged fuel temperature be less than $\left[1250^{\circ} \mathrm{C}\right.$ ] during normal operation. This requirement is Design Selection 4 (DS4) of Function 1.1.4.1.1.2.1.1.2, Retain Radionuclides with Particle Coatings. The satisfaction of this requirement involves thermal analyses which include the properties of thermal expansivity, thermal conductivity, emissivity, and specific heat for $\mathrm{H}-451$ graphite. These analyses are performed for the design conditions of the core which include spatially varying temperatures 
and fluences, and thus the above thermal properties are needed as functions of temperature and fast fluence. In the thermal analysis, the mean values of expansivity, conductivity, and specific heat are used. For the conceptual design, this information is obtained from the Graphite Design Data Manual. The specific values in this manual are, however, derived from a limited data base, which leads to the assumption:

a): The mean values of thermal expansivity, thermal conductivity, and specific heat given in the Graphite Design Data Manual for $\mathrm{H}-451$ graphite are valid.

The technology need related to this assumption is for a statistical data base such that the mean values of the above thermal properties can be sufficiently accurately established. The detailed needs are specified in Section 4.1.4.6.

In the case of emissivity, however, which has only a small effect on temperatures, a conservative practice is to use a lower bound to its value as found for carbon plates in standard heat transfer texts.

This leads to a second assumption:

b): The lower bound for the emissivity of $H-451$ graphite is 0.8 .

This assumption relates to the need for a data base on emissivity sufficient to determine the lower bound with a reasonable confidence. This need is also specified in Section 4.1.4.6.

Function 1.1.2.1.2.1.1, Control In-Core Gap Flow.

This function is performed by designing the fuel columns to limit the leakage flow at the horizontal joints between vertically adjacent blocks (cross flow) and by maintaining the vertical gaps between columns at minimum and maximum values. One of the purposes of 
controlling the gap flow is to prevent bistable column motion and minimize column thermal distortion. This function has two requirements that involve knowledge of graphite material data:

Requirement 1 states that the inter-element gaps at refueling be at least $[1 \mathrm{~mm}]$. This is DS2 of Function 1.3.5.2.1, Move Elements Between Core and Plenum.

Requirement 2 states that the in-core gap flow is less than $[1.5] \%$ and greater than $[1.0] \%$ total core flow. This is DS2 of Function 1.1.2.1.2.1, Control Core Bypass Flow.

The satisfaction of these two requirements in the design of the gaps between adjacent columns involves thermal and deformation analyses which includes the properties of expansivity, conductivity, specific heat, and irradiation induced dimensional change for H-451 graphite. These analyses are performed for the design conditions of the core which include spatially varying temperatures and fluences, and thus the above thermal and dimensional change properties are needed as functions of temperature and fast fluence. In the thermal analyses, the mean values of expansivity, conductivity, and specific heat are used. In the deformation analyses, the mean values of the expansivity and the irradiation-induced dimensional changes are used. For the conceptual design, this information is obtained from the Graphite Design Data Manual. The specific values in this manual are, however, derived from a limited data base, which for the thermal analyses leads to the same assumption discussed above:

c): The mean values of thermal expansivity, thermal conductivity, and specific heat given in the Graphite Design Data Manual for H-451 graphite are valid. 
This assumption is identical to Assumption a) above (but arrived at through another function). The related technology need is also the same as for Assumption a) and is discussed in section 4.1.4.6.

For the deformation analyses, the assumption is:

d): The mean values of the irradiation-induced dimensional changes given in the Graphite Design Data Manual for H-451 graphite are valid.

To validate this assumption, a statistical data base is needed for irradiation-induced dimensional changes given in the Graphite Design Data Manual for H-451 graphite. The details are specified in section 4.1 .4 .4 .

Function 1.1.2.1.2.2.4, Maintain Fuel Element structural Integrity.

This function is performed by designing the fuel elements so that stresses from all credible sources is limited to values which will ensure a high probability of functional success. Other than the limitation on peak neutron fast fluence of $[5] \times 10^{25} \mathrm{n} / \mathrm{m}^{2}$, no specific limitations are placed on fluence or on graphite temperature to limit stresses in the fuel elements. However, several design features are incorporated to achieve relatively smooth and uniform distributions of fast neutron fluence, temperature, and power within the fuel elements such as the use of radial and axial fuel zoning. In addition to control of the power distribution, the flow distribution in and around the fuel element is controlled to limit temperature gradients within the fuel element. In addition to stresses created by thermal and irradiation effects, the fuel elements are subjected to mechanical loads of gravity, fluid forces, and seismic events. Of these, only the seismic loads are significant, and even these are smaller than those due to thermal and irradiation effects. 
There are seven requirements that bound this function, six of which collectively lead to technology needs. They are:

Requirement 1. Operate over a three year design life with peak fluence less than [5] x $10^{25} \mathrm{n} / \mathrm{m}^{2}$ (E>29 fJ, HTGR). This requirement is DS3 of Function 1.1.1.1, Generate Nuclear Reactor Heat.

Requirement 2. Withstand $O B E$ and SSE seismic excitation of $0.15 \mathrm{~g}$ (OBE) and $0.30 \mathrm{~g}$ (SSE) ground acceleration as amplified by the response of the plant and vessel [TBD].

Requirement 3. Withstand a pressure differential of [5] psi vertically. This requirement is DS2 of Function 1.1, Maintain Safe Energy Production.

Requirement 4. Withstand mechanical loads due to deadweight, element-to-element interference, and fuel rod/element interaction. This requirement is DS2 of function 1.1.1.2, Control Heat/Neutron Generation Rate.

Requirement 6 . Operate in a primary coolant which has a total oxidant level below $10 \mathrm{ppm}$. This requirement is from DS3 of Function 1.1.2.2.2, Maintain Primary Coolant Conditions.

Requirement 7 . Meet duty cycles.

The satisfaction of these requirements leads to several assumptions about the material data. Fulfilling Requirements 1 and 7 involve performing thermal and irradiation stress analyses. The stress analysis is performed with a series of codes, the most important of which is the TWOD finite element code. This code calculates the principal stresses and the stress to strength ratio (the ratio between the principal stress and the mean value of the uniaxial 
strength of the material at the same location and for the same operating environment - the strength of graphite is a function of the location in the $\log$ and of temperature and fast fluence irradiation). The stress to strength ratios are then compared to the criteria developed under the Goal 2 Function 2.1.2.1.2.4 (see discussion below). This approach involves a simplification; although the state of stress in the graphite core components is three-dimensional, the acceptance criteria are based on the maximum stress failure theory which uses the uniaxial stress also for multiaxial stress conditions. This approach rests on the following assumption:

e): The maximum stress failure theory is a reasonable approximation for $\mathrm{H}-451$ graphite under a multiaxial state of stress.

The validation of this assumption requires the biaxial and triaxial failure surfaces such that the inaccuracies in using the maximum stress failure theory can be quantified. The detailed need is specified in Section 4.1.4.1.

In addition to the thermal properties and the irradiation-induced dimensional changes discussed previously, the analyses require knowledge of the elastic moduli, Poisson's ratio, and irradiation induced creep. Because the fuel elements are made from extruded graphite logs, their properties are anisotropic and data is required for both the radial and axial directions. In addition, because the elements are subjected to varying temperature and fast fluence fields, the changes in the properties are needed as functions of temperature and fast fluence. For the conceptual design, this information is obtained from the Graphite Design Data Manual. The specific values in this manual are, however, derived from a limited data base, which for the irradiation-induced dimensional change leads to the same assumption discussed earlier. 
Satisfying Requirements 2, 3, and 4 involve performing mechanical analyses utilizing knowledge of the spatially varying mechanical properties of the elastic moduli and Poisson's ratio. Requirement 2, withstand seismic excitations, imposes the most severe loads on the elements. These loads are determined analytically by the twodimensional MCOCO code which analyzes a vertical slice of the core subjected to the seismic response at the model boundaries. The accuracy of these predicted loads is unverified which leads to the assumption:

f): The seismic loads are conservatively predicted by the MCOCO computer code.

The validation of this assumption requires a data base on the integrity of the core components subject to a simulated earthquake of sufficient intensity that the analytical methods would predict structural damage. The detailed needs are specified in Section $4 \cdot 1 \cdot 4 \cdot 13$.

The structural adequacy of the element under these loads is assessed by static two-dimensional finite element analyses. The loads, however, are at best quasi-static, or dynamic, and the use of static analyses leads to the assumption:

g): The dynamic strength can be conservatively predicted with static finite element methods.

The technology need related to this assumption is for a data base on element failure loads that confirms the core components ability to withstand the loads imposed on them during a seismic event. This confirmation is performed by establishing that the analytical methods are conservative in predicting the dynamic strength. Because failure loads depend upon the state of residual stresses resulting from thermal and irradiation induced loads, data is needed for both fresh 
and irradiated elements. The specific technology need is discussed in Section 4.1.4.11.

The stresses induced by the seismic loads must be combined with any existing stresses resulting from the operating thermal and fast fluence time histories and the ability of the fuel element to withstand the combined effects must be evaluated. To what extent the seismic load capacity has been reduced by the presence of the residual stresses is not known, but it is believed that a linear combination of the stress fields is conservative. Thus, for simplicity during the conceptual design, the seismic and thermal and irradiation stress fields are combined under the assumption:

h): Thermal/irradiation stresses and seismic stresses can be linearly combined.

The detailed need for validating this assumption is also specified in Section $4.1: 4.11$.

Because these design conditions must be met throughout the component lifetimes for any core locations, the effects of temperature and fast fluence on the material properties must be properly accounted for. As in satisfying Requirements 1 and 7 , for the conceptual design, this information is obtained from the Graphite Design Data Manual. However, because the components are subjected to multiple stress cycles due to startups, shutdowns, flow-induced vibrations, and possible seismic events where each earthquake may cause several different stress waves, knowledge of the fatigue properties of $\mathrm{H}-451$ graphite is also required. The available data on fatigue behavior, however, is sparse especially on the applicability of Miner's Rule, the most widely used method for evaluating the cumulative effects of fatigue in metals. This leads to an additional assumption: 
i): Miner's rule for estimating the cumulative fatigue is applicable to H-451 graphite.

The validation of this assumption requires a data base including fatigue life as a function of stress amplitude for both constant amplitude load cycles and sequential series of cycles with different amplitudes. The detailed needs are discussed in section 4.1.4.2.

Meeting Requirement 6 involves evaluation of the effects of corrosion from trace impurities of water and other oxidants in the coolant on the elements ability to satisfy its design functions. Neutron moderation as well as bypass gap and coolant hole flows are effected by removal of carbon mass from the elements. In addition to weight loss, corrosion reduces the structural strength of graphite and affects other mechanical and thermal material properties such as Young's modulus, thermal conductivity, etc. The approach selected for the design of the graphite core components is to determine the weight loss or burnoff by analytical methods using the expected operational history. These methods must properly describe the corrosion which may be mass-transfer limited, chemical reaction limited, or a combination of both; consequently, both processes must be characterized and correlations describing the corrosion must be established. The specific values of these correlations are derived from a limited data base, which leads to the assumption:

j): The existing correlations for $\mathrm{H}-451$ graphite corrosion are accurate within a factor of [2] at [95]\% confidence.

The technology need related to this assumption is for a data base for correlations describing the corrosion of the graphite by coolant impurities during normal operation and water ingress events. The detailed needs are discussed in Section 4.1.4.8. 
In addition, evaluation of the structural effects of corrosion on the graphite require analyses for the various design conditions of the reactor environment. The accuracy of the design methods and computer codes utilized in calculating the corrosion for the MHTGR reactor operating conditions is relatively unknown which leads to an additional assumption:

k): The existing design methods and computer codes for calculating H-451 graphite corrosion are accurate within a factor of [3] at $95 \%$ confidence.

The validation of this assumption requires the verification of the integrated models and computer codes used to predict the graphite corrosion in the MHTGR core under both normal operation and during steam and air ingress events. The detailed needs are discussed in Section 4.1 .4 .15 .

These design methods and codes are used in conjunction with the corrosion correlations discussed above to examine the effects of corrosion on the graphite design properties. Any degradation of the strength and/or alteration of the other material properties must be properly accounted for in the design evaluation. This evaluation rests on a third assumption:

1): The existing data base is sufficient to predict the corrosion effects on $\mathrm{H}-451$ graphite within a factor of [2] at [95]\% confidence.

The technology need related to validating this assumption is the determination of the degradation of the material strength and alteration of the other material properties due to graphite corrosion. The detailed needs are given is Section 4.1.4.9. 
Finally, because of the inherent variability in the graphite due to small variations in the raw material and in the production process, product control is needed during the procurement to ensure that the production graphite has the same characteristics as the graphite used to establish the data base and that the strength requirements have been met. Nondestructive testing techniques developed by ORNL satisfy this need but the data base as of yet is too sparse to validate these techniques for use in product control of mass produced graphite. For the designer to assure that the design is structurally adequate for these future materials a required assumption is:

m): The production graphite will have the same properties as the design data base.

The validation of this assumption requires a data base sufficient to verify that nondestructive evaluation (NDE) techniques can be used for acceptance testing of mass produced graphite for core components and for writing product control specifications. The detailed needs are specified in Section 4.1.4.10.

Function 2.1.2.1.2.4, Protect the Capability to Maintain Fuel Element Structural Integrity.

The requirement bounding this function is a reliability goal allocated to the core from the top level Goal 2 investment risk targets. Design criteria are currently being developed using a probabilistic risk assessment (PRA) approach which will ensure that the replaceable graphite components, the hexagonal fuel and reflector elements, have met this reliability goal. The specific requirement is:

Requirement 1. The average equivalent full power hours lost per year due to failures to perform Function 1.1.2.1.2.2.4, Maintain Fuel Element Structural Integrity, shall be less than [TBD]. 
The development of the design criteria requires a statistical knowledge of the various thermal and mechanical graphite properties to determine the distribution of the variation of the properties about their mean values. If these distributions can be described in one of the convenient mathematical forms such as "normal distribution" or "log-normal distribution", statistically based analyses become more tractable. Using the statistical distributions of the graphite properties and probabilistic data about the operating conditions, thermal-hydraulic and stress analyses are then performed to establish the probability distribution functions for the predicted stresses. The probabilities of fuel element failures are then predicted and related to the reliability requirement through the PRA analysis. As in satisfying the Goal 1 requirements, failure states in the elements are evaluated using the maximum stress failure theory.

When performing the analyses for establishing the probability distributions of the predicted stress, statistical knowledge is needed of several material properties such as the thermal and mechanical properties, the driving forces of the differential irradiation-induced dimensional changes, and the relieving forces of the irradiation-induced creep. Some information on the statistical distribution of the material properties is contained in the Graphite Design Data Manual. This information, with interpolations and extrapolations, was used to estimate distribution functions for the conceptual design. In order to complete the criteria development, however, the existing data base must be augmented; especially in the area of creep properties. The estimates of the statistical. distribution functions were done on the basis of the following three assumptions:

$n)$ : The coefficients of variation given in the Graphite Design Data Manual are accurate to within [25]\%. 
$0)$ : Confidence limits on the mean value and standard deviation can be sufficiently determined through the $t$ and Chi-Square distributions, respectively.

p): Uncertainty in the estimation of the skewness of a distribution can be estimated by the uncertainty in the coefficient of variation.

These assumptions were made to ensure the mean value of the material data was well known and that enough data would be generated to determine the skewness of the distribution. The skewness is exceptionally important in determining which type of statistical function best represents the data.

The validation of these three assumptions requires material statistical data bases sufficient to accurately determine the coefficients of variation, mean values, and standard deviations of the thermal and mechanical properties. The detailed needs for the thermal properties are specified in Section 4.1.4.6 and for the mechanical properties in Sections 4.1.4.3, 4.1.4.4, and 4.1.4.5.

The calculations of fuel element failure probabilities include cracking analyses where the potential for a crack to initiate and progress is assessed. Damage is defined as cracks of such an extent that the functions of the fuel element are affected. These cracking analyses are done with the finite element codes on the basis of continuum mechanics; cracks are simply postulated to occur if the true stress exceeds the mean strength. this approach is considered reasonable for vertical cracks (i.e., cracks caused by the in-plane or horizontal stresses) and leads to the two assumptions:

q): The progression of vertical cracks, due to in-plane stresses, can be analyzed with continuum mechanics methods. 
r): The failure mode, i.e., the crack progression, can be predicted with the TWOD finite element code.

The validation of the first assumption requires a data base that defines the critical stress intensity factors and strain energy release rates for crack initiation, stable crack growth, and crack arrest for core component graphite. The detailed needs are specified in Section 4.1 .4 .7 .

To validate the second assumption, confirmation of the cracking analysis methods, sufficient data are needed relating to failure loads and modes for the core components subjected to combined static mechanical and thermal/irradiation loads. The detailed needs are specified in Section 4.1.4.12.

The crack progression approach based on continuum mechanics is considered reasonable for the analysis of vertical cracks due to the presence of the numerous fuel and coolant holes which function as crack arresters. For the analysis of horizontal cracks, however, fracture mechanics methods will be necessary. Since such methods are not yet available, the reliabilities predicted at the conceptual design stage do not include the potential for horizontal cracks. The justification for this simplification is contained in the assumption:

s): Horizontal cracks which need fracture mechanics methods are less probable than vertical cracks due to (1) lower stresses in the axial direction, and (2) only vertical cracks have been observed in FSV fuel elements.

The validation of this assumption requires the same data base discussed above for Assumption q) with the detailed needs specified in Section $4 \cdot 1 \cdot 4 \cdot 7$. 
Function 2.1.2.1.2.2.2.2.2.2.4, Absorb Energy From Dropped Control Rod.

This function has a Goal 2 reliability requirement allocated from the top level investment risk target from the plant availability goal of $80 \%$. To satisfy this requirement, it is necessary to protect the graphite core support structure from damage due to an accidentally dropped control rod. This protection is done with a crushable graphite insert in the bottom reflector block underneath the control rod channel. As the design of the shock absorbed has not yet been performed, the adequacy of the concept rests on the assumption:

t): A crushable graphite insert can absorb sufficient energy to protect the core support structure.

The validation of this assumption requires data to establish the energy absorption characteristics for three alternative designs of a crushable graphite shock absorber. The detailed need is discussed in section $4.1 .4 \cdot 14$.

Function 3.1.1.2.1.1.2.2.1.1.1, Conduct Heat From Fuel to Core Graphite.

This function is one of the goal 3 functions which collectively maintain control of radionuclide release during unscheduled events such as core heatup transients. Requirement 3 of this function states that the peak fuel temperature is to be less than $[1600]^{\circ} \mathrm{C}$ during core heatup transients. This requirement is DS3 of Function 3.1.1.2.1.1.2, Retain Radionuclides With Particle Coatings. This helps to limit radionuclide release. The satisfaction of this requirement involves thermal analyses which include the properties of thermal expansivity, thermal conductivity, specific heat, and emissivity for $\mathrm{H}-451$ graphite. These analyses are performed for the transient thermal states encountered during core heatup events which include spatially varying temperatures in the core components potentially any time during their design life. In the thermal 
analysis, the mean values of expansivity, conductivity, and specific heat are used. For the conceptual design, this information is obtained from the Graphite Design Data Manual. The specific values in this manual are, however, derived from a limited data base, which leads to the same assumptions a) and b) as in the goal 1 analyses but for an extended temperature range of up to $[1600]^{\circ} \mathrm{C}$. The technology needs related to these assumptions are found in Section 4.1.4.6.

Function $3 \cdot 1 \cdot 1 \cdot 2 \cdot 1 \cdot 1 \cdot 2 \cdot 1 \cdot 1 \cdot 3 \cdot 2.2$, Maintain Integrity of RSS Fuel Element.

This function is another of the the goal 3 functions which collectively maintain control of radionuclide release during unscheduled events such as core heatup transients. Requirement 1 of this function states the element must withstand Safe Shutdown Earthquake (SSE) seismic excitation of $0.3 \mathrm{~g}$ ground acceleration as amplified by the plant and vessel. Requirement 3 of this function states that the peak fuel temperature is to be less than $[1600]^{\circ} \mathrm{C}$ during core heatup transients. This requirement is DS3 of Function 3.1.1.2.1.1.2, Retain Radionuclides With Particle Coatings. This helps to limit radionuclide release. The satisfaction of these requirements involve thermal and mechanical analyses which include the properties of thermal expansivity, thermal conductivity, specific heat, emissivity, elastic moduli, Poisson's ratio, and material strength for H-451 graphite. These analyses are performed for the transient thermal states encountered during core heatup events which include spatially varying temperatures in the core components potentially any time during their design life. In these analyses, the mean values of the properties are used. For the conceptual design, this information is obtained from the Graphite Design Data Manual. The specific values in this manual are, however, derived from a limited data base, which lead to the same assumptions as in the goal 1 analyses but for an extended temperature range of up to $[1600]^{\circ} \mathrm{C}$. The technology needs related to these assumptions are found in section 4.1.4. for the various properties. 


\subsubsection{Core Component Requirements Defining the Operating Environment}

Function 1.1.2.1.1, Transfer Heat from Fuel to Heat Transfer Surface.

Requirement 2. Maximum, time-average fuel temperature $\leq\left[1250^{\circ} \mathrm{C}\right]$

during normal operation. This requirement is DS4 of Function

1.1.4.1.1.2.1.1.2, Retain Radio-nuclides with Particle Coatings.

This requirement creates a data need as discussed above in section

4.1.3.1. It also provides an upper limit on the service temperature of the graphite.

Function $1 \cdot 1 \cdot 2 \cdot 1 \cdot 2 \cdot 2 \cdot 4$, Maintain Fuel Element Structural Integrity

Requirement 1. Three year design life with peak fluence $<[5] \times 10^{25}$ $\mathrm{n} / \mathrm{m}^{2}$ (E>29 $\mathrm{fJ}, \mathrm{HTGR}$ ). This requirement is DS3 of Eunction 1.1.1.1, Generate Nuclear Reactor Heat.

Requirement 5. Ten-row hexagonal fuel element configuration with across flats dimension equal to $360 \mathrm{~mm}$ with 2 fuel/1 coolant hole in a triangular array with a pitch of $18.8 \mathrm{~mm}$. This is from DS1 of Function 1.1.2.1.1, Transfer Heat from Fuel to Heat Transfer Surface, and DS3 of Function 1.1.2.1.2, Transfer Heat from Heat Transfer Surface to Primary Coolant.

Requirement 6. Purify primary coolant in order to keep the level of impurities $\leq[10] \mathrm{ppm}$. This requirement is DS3 of Function 1.1.2.2.2, Maintain Primary Coolant Conditions.

\subsubsection{Technology Development Requirements}

The detailed statements of the data needed to verify the assumptions discussed in section 4.1 .3 are given here in 15 subsections. Subsections 4.1.4.1 through 4.1.4.10 pertain to graphite material development and 
characterization including mechanical, thermal, and chemical characteristics, while Subsections 4.1.4.11 through 4.1.4.14 pertain to component testing for structural/mechanical design purposes including methods validation tests. The final Subsection, 4.1.15, addresses validation of the graphite corrosion predictions. Each of these subsections starts with the associated assumption, for a direct connection to section 4.1.3. The data needs specified in each subsection are summarized in section 1.3 of the corresponding DDN (DDN's M.10.18.01 through M.10.18.14 and DDN M.10.01 which are included in Appendix A. Table 4.1 at the end of Section 4.1 .4 shows the correspondence between the DDNs and the subsections of 4.1.4. For completeness, the functions and assumptions are also included in Table 4.1)

All experimental work necessary for satisfying the technology development requirements must comply with the Quality Assurance criteria of 10CFR50 Appendix B.

The service conditions for the core components are listed below. These conditions apply to all the Subsections 4.1.4.1 through 4.1.4.15, except where otherwise stated.

1. Graphite Temperatures

Normal Operation: $300^{\circ} \mathrm{C}-950^{\circ} \mathrm{C}$

Shutdown: $120^{\circ} \mathrm{C}$

Core Heatup Events: $300^{\circ} \mathrm{C}-1600^{\circ} \mathrm{C}$

2. Fast Fluence

Maximum Fast Fluence: $5 \times 10^{25} \mathrm{n} / \mathrm{m}^{2}$ (E>29 $\mathrm{fJ}$, HTGR) The range of fast fluence and the corresponding service temperatures is given in Fig. 4.10. The shaded area in the figure covers all the combinations of fluences and irradiation temperatures. It should be noted, however, that the temperatures of the fuel elements vary during their operating life. For example, those fuel elements which experience a maximum fluence of $4.5 \times 10^{25} \mathrm{n} / \mathrm{m}^{2}$ at a temperature of about $550^{\circ} \mathrm{C}$ will have operated at higher temperatures earlier in 
their life. (Note that the core components may experience temperatures down to and including the shutdown temperature subsequent to the fast fluence exposure).

3. Primary Coolant Conditions

a) Pressure Range

Normal Operation: $63 \mathrm{~atm}$

Shutdown: 1 atm

Starting up-shutting down: 1-63 atm

b) Temperature Range

Normal Operation: $300^{\circ} \mathrm{C}$ core inlet, $687^{\circ} \mathrm{C}$ core outlet mixed mean $\left(100^{\circ} \mathrm{C}\right.$ higher in hot streaks)

Shutdown: $120^{\circ} \mathrm{C}$

Core Heatup Events: Up to $1400^{\circ} \mathrm{C}$

c) Oxidizing Impurites

Normal Operation:

[2] $\mathrm{ppm} \mathrm{H}_{2} \mathrm{O}$

[5] $\mathrm{ppm} \mathrm{CO}$

[2] $\mathrm{ppm} \mathrm{CO}_{2}$

[10] ppm maximum total oxidants

The above impurity levels are all maximum time averaged values. Moisture Ingress Conditions:

Total oxidants not to exceed [600] ppm days per year including normal operation.

\section{Air Ingress Events:}

\section{[Later]}

4.1.4.1 Multiaxial Strength of Graphite for Core Components. The data specified below are needed to validate Assumption e).

e): The maximum stress failure theory is a reasonable approximation for H-451 graphite under a multiaxial state of stress. 
PC $-000213 / 1$

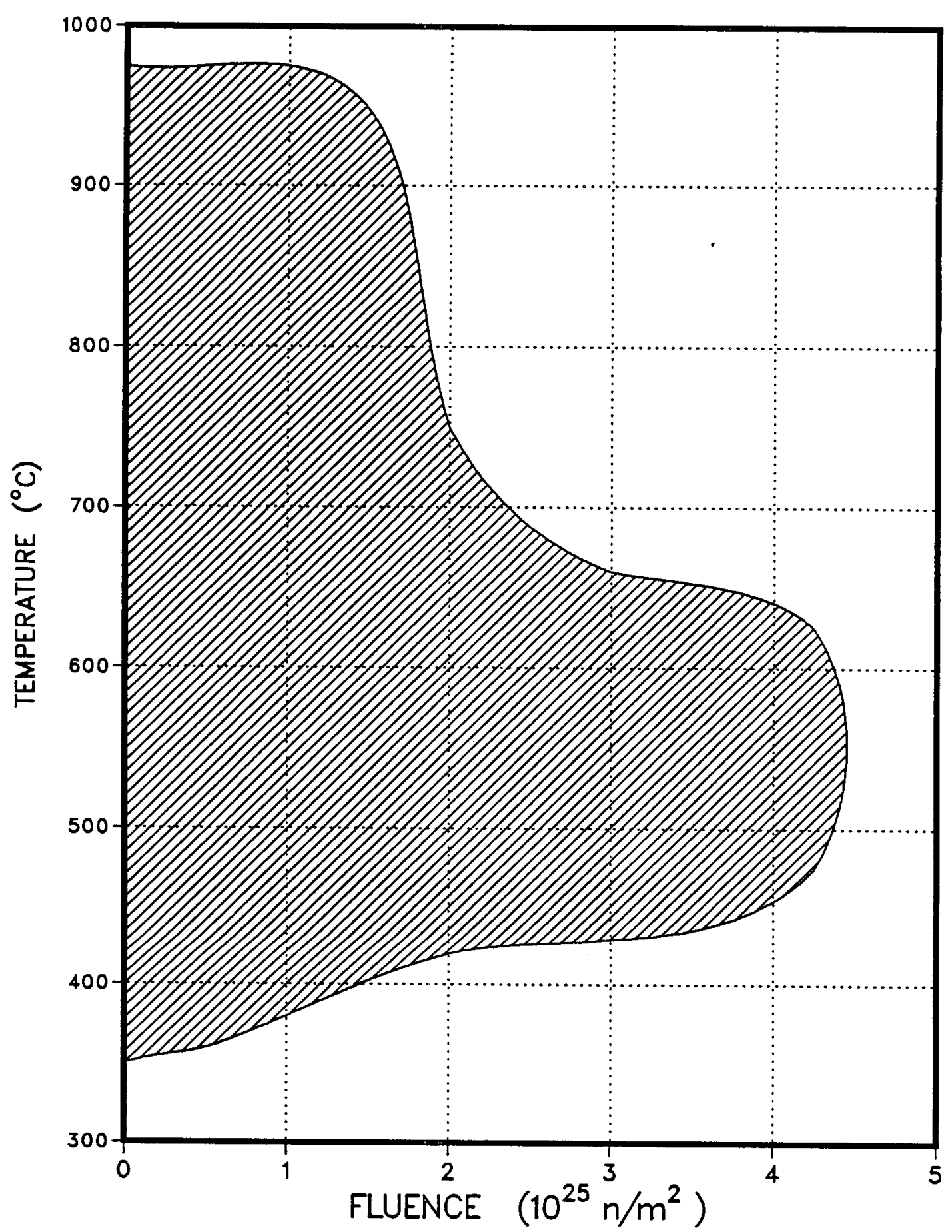

Figure 4.10 Estimated Temperature Versus Fluence Envelope for Fuel Element Graphite 
To quantify the uncertainty in the maximum stress failure theory, the failure surfaces for biaxial and triaxial stress conditions are needed, biaxially for tension-tension and tension-compression and triaxially for tension-tension-tension, tension-tension-compression, and tension-compressioncompression. For all combinations involving compression, the failure surface is not needed for compressive stresses beyond the uniaxial tensile strength because the maximum service stresses in compression are about the same as in tension. The specific needs are:

A) Biaxial Stress Field

A mean value failure surface in the form of a smooth, continuous curve as shown in Fig. 4.11 is assumed. The curve passes through the points representing the uniaxial strengths, as shown, and also through the points $A$ and $B$ in Fig. 4.11. Data are needed to show with [95\%] confidence that the distances $a$ and $b$ in Fig. 4.11 are at most $[15] \%$ and $[5] \%$, respectively, of the uniaxial tensile strength.

B) Triaxial Stress Field

For a triaxial stress field, the curve in Fig. 4.11 is assumed to extend to a smooth continuous surface passing through the points of uniaxial strength. In each octant there is a point corresponding to points $A$ or $B$, except extended to three dimensions. The data base must show with [95\%] confidence that the relative distance to these points measured from the plane through the uniaxial strength is at most:

$[20] \%$ in the first octant (all tension)

[15]\% in the second, fourth, and fifth octants (tension-tension-compression) 


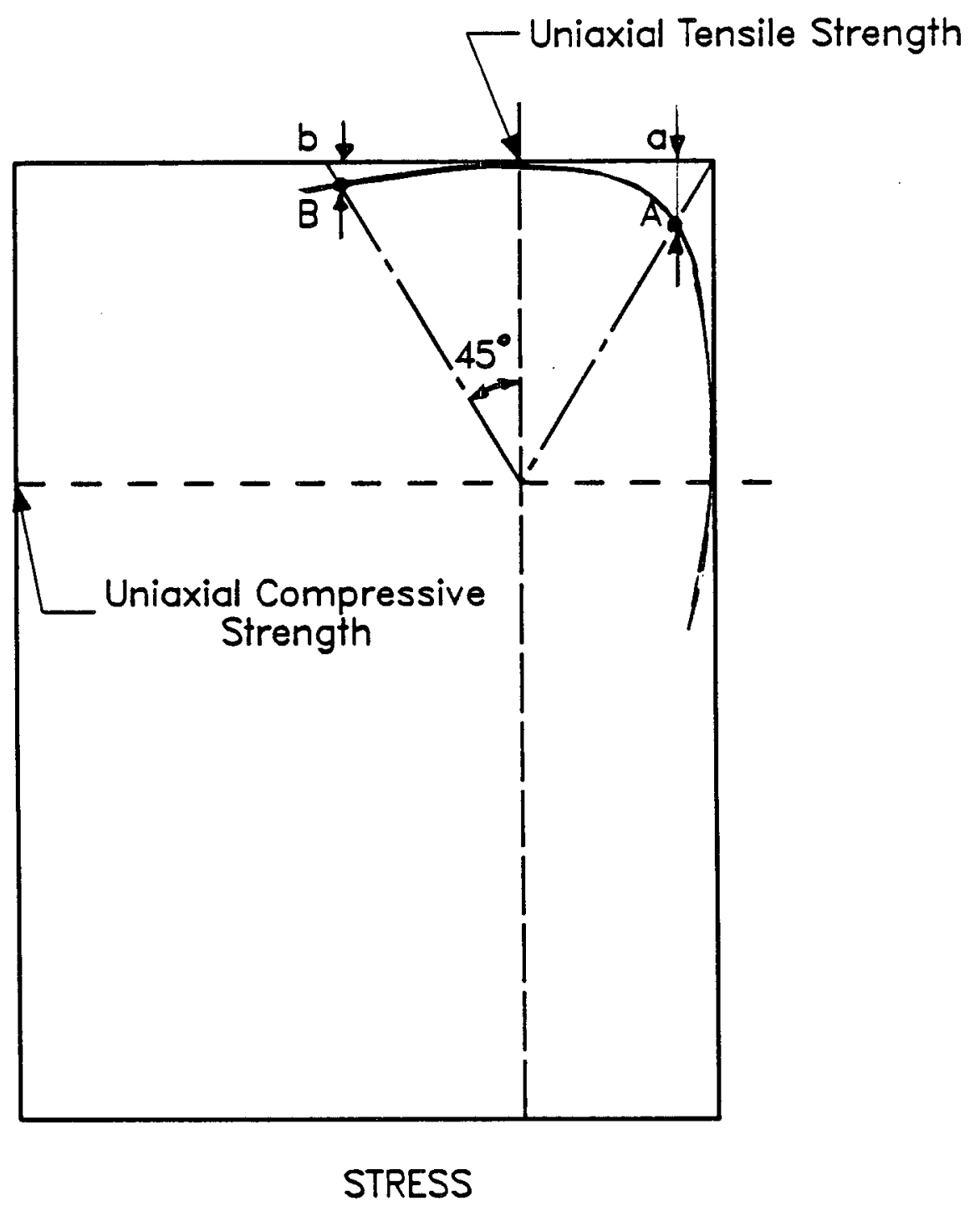

Figure 4.11 Assumed Biaxial Failure Surface 
[5]\% in the third, sixth, and eighth octants (tension-compression-compression)

The above data base is needed for unirradiated graphite at room temperature in a normal atmospheric environment. Additionally, a small number of data points are needed to determine the effects of the service conditions on the multiaxial failure strength. The service conditions are specified at the beginning of section 4.1 .4 .

4.1.4.2 Fatigue Data for Graphite for Core Components. The data specified below are needed to validate Assumption i).

i): Miner's rule for estimating the cumulative fatigue is applicable to H-451 graphite.

To validate Miner's rule for H-451 graphite, is it first necessary to estalbish the fatigue life as a function of stress amplitude under constant amplitude cyclic loading. The fatigue life data must include the effects of the mean stress during the stress cycles. For this purpose, data are needed for two different conditions.

a. Cycling between tension and equal compression (stress ratio of -1 ).

b. Cycling between tension and zero stress (stress ratio of 0 ).

For both conditions, the fatigue life is needed for the range between $10^{2}$ and $10^{5}$ cycles. The data base must be sufficient to determine the mean value of the fatigue strength within $\pm[6] \%$ at $[95] \%$ confidence.

Further, the fatigue life is needed for $\mathrm{H}-451$ graphite subjected to sequential series of cycles with different amplitudes. A small number of conditions (combinations of stress amplitudes) shall be tested. The combinations shall be selected such that the difference between varyingamplitude fatigue and constant amplitude fatigue can be established for the range between $10^{2}$ and $10^{5}$ cycles. 
The above data are needed for unirradiated graphite at room temperature in a normal atmospheric environment. Additionally, a limited number of data points are needed to determine the effects of the service conditions on the constant-amplitude fatigue life. The service conditions are stated at the beginning of Section 4.1.4.

4.1.4.3 Statistics of Mechanical Properties of Graphite for Core Components. The following statistical data base is needed to validate these three assumptions as they pertain to the mechanical properties.

n): The coefficients of variation given in the Graphite Design Data Manual are accurate to within $[25] \%$.

o): Confidence limits on the mean value and standard deviation can be sufficiently determined through the $t$ and Chi-Square distributions, respectively.

p): Uncertainty in the estimation of the skewness of a distribution can be estimated by the uncertainty in the coefficient of variation.

The data base must be sufficient to define the following mechanical properties of $\mathrm{H}-451$ graphite.

1. Tensile and compressive strengths.

2. Stress-strain relationships in tension and compression up to and including failure in tension and up to a compressive stress equal to the mean value of the tensile strength.

3. Transverse-to-longitudinal strain ratios (i.e., Poisson's ratios). 
The data base must include the following effects:

1. Orientation and location in billet.

2. Variation from billet to billet and from lot to lot.

3. Temperature ranging from shutdown temperature to the maximum service temperature.

4. Fast neutron irradiation up to the maximum fluence level. For ranges of fast fluences and corresponding service temperatures, see Fig. 4.10. (Note that the components may experience temperatures down to and including the shutdown temperature subsequent to the fast fluence exposure).

The data base must be sufficient to establish the mean values of the required properties within the following bounds with [95]\% confidence:

\begin{tabular}{|c|c|}
\hline Tensile strength: & $\pm[3] \%$ \\
\hline Compressive strength: & $\pm[10] \%$ \\
\hline Stress-Strain relationship: & $\begin{array}{l} \pm[8] \% \text { (for strain values above }[10] \% \\
\text { of mean ultimate strain) }\end{array}$ \\
\hline Poisson's Ratio: & $\pm[20] \%$ \\
\hline
\end{tabular}

In addition to the above statistical data base, information is also needed on the volume effect (especially on strength) and on the effects of the pressurized helium environment (Note that the effects of graphite corrosion are covered in Subsection 4.1.4.9).

The service conditions are stated at the beginning of Section 4.1.4.

4.1.4.4 Statistics of Irradiation-Induced Strain of Graphite for Core Components. The data specified below are needed to validate the three assumptions in Subsection 4.1 .4 .3 above, as these assumptions pertain to irradiation induced strain, and also to validate Assumption d). 
d): The mean values of the irradiation-induced dimensional changes given in the Graphite Design Data Manual for $\mathrm{H}-451$ graphite are valid.

A data base sufficient to define the irradiation-induced dimensional changes (i.e., irradiation strains) of $\mathrm{H}-451$ graphite as a function of fast fluence and irradiation temperatures is needed. The data base must cover the ranges of fast fluences and corresponding service temperatures given in Fig. 4.10. The following effects must be included:

1. Orientation and location in billet.

2. Variation from billet to billet and from lot to lot.

The data base must be sufficient to bound the mean values of the irradiation strains within $\pm[0.05] \%$ strain at $[95] \%$ confidence. Additionally, the data base must be such that the within billet correlation can be established with reasonable confidence. (The within billet correlation is important since the stresses in a fuel element depend on the spatial strain differences within the element. For example, if the strain of some point in the element is one standard deviation below the mean value, is it going to be one standard deviation below the mean value at all other points as well?)

4.1.4.5 Statistics of Irradiation Induced Creep of Graphite for Core Components. The data specified above are needed to validate the three assumptions in Subsection 4.1 .4 .3 above as these pertain to irradiation induced creep.

A data base sufficient to define the creep properties for $\mathrm{H}-451$ graphite over the range of fast neutron fluence and corresponding irradiation temperatures given in Fig. 4.10 is needed. The specific creep properties are:

1. Steady-state creep strain in tension and compression up to $1 \%$ creep strain. 
2. Transient (primary) creep strain.

3. Transverse-to-longitudinal strain ratios.

The data base must be sufficient to bound the mean values of the steady-state creep strain within $\pm[8] \%$ with $[95] \%$ confidence. The bound on the mean values of the other creep properties (items 2 and 3 ) is $\pm[20] \%$. In defining the required creep properties, the following effects need to be included:

1. Orientation and location in billet.

2. Variation from billet to billet, lot to lot.

In addition to the full statistical data base, a limited number of data points are needed to establish the effect of creep strain on tensile strength, Young's modulus, thermal expansivity, and thermal conductivity. Some data points are also needed to validate that the neutron flux level has no significant effects on the creep properties.

4.1.4.6 Statistics of Thermal Properties of Graphite for Core Components. The data base specified below is needed to validate the thermal properties related aspects of Assumptions $n$ ), 0 ), and $p$ ) (Subsection 4.1.4.3) and also Assumptions a) and b).

a): The mean values of thermal expansivity, thermal conductivity, and specific heat given in the Graphite Design Data Manual for H-451 graphite are valid.

b): The lower bound for the emissivity of $\mathrm{H}-451$ graphite is 0.8 .

A data base is needed to define thermal expansivity, thermal conductivity, emissivity, and specific heat for $\mathrm{H}-451$ graphite, including: 
1. Dependence on orientation and location in billet.

2. Variation from billet to billet and from lot to lot.

3. Temperature dependence within the range of normal operating temperatures given at the beginning of Section 4.1.4.

4. Dependence on fast neutron irradiation for the range of fluences and corresponding service temperatures given in Fig. 4.10.

The data base shall be sufficient to establish the mean values of the required thermal properties within the following bounds at [95\%] confidence:

$$
\begin{array}{ll}
\text { Expansivity: } & \pm[5] \% \\
\text { Conductivity: } & \pm[5] \% \\
\text { Specific Heat }: & \pm[10] \%
\end{array}
$$

For emissivity, [95]\% confidence is required that the lower bound of the property is $[0.80]$. A reasonable estimate of the mean value is also needed.

In addition to the above statistical data base, a limited number of data points are also needed to establish the effects on the thermal properties of temperatures down to the refueling temperature. These data points must also include material which have been irradiated at higher temperatures as specified above.

\subsubsection{Statistics of Fracture Mechanics Properties of Graphite for Core} Components. The data specified below are needed to develop fracture mechanics methods to validate Assumption $s$ ).

s): Horizontal cracks which need fracture mechanics methods are less probable than vertical cracks due to (1) lower stresses in the axial direction, and (2) only vertical cracks have been observed in FSV fuel elements. 
A data base is required to define the critical stress intensity factors $\left(K_{I C}\right)$ and strain energy release rates $\left(G_{I C}\right)$ for crack initiation, stable crack growth, and crack arrest for H-451 graphite. In defining these properties, the following effects need to be included:

1. Orientation and location in billet.

2. Variation from billet to billet and from lot to lot.

The data base shall be sufficient to bound the mean values of the stress intensity factors and strain energy release rates within $\pm[10] \%$ at $[95] \%$ confidence.

In addition to the full statistical data base which is only required for unirradiated material at room temperature in a normal atmospheric environment, a limited number of data points are needed to establish the effects of the operating environment on the fracture mechanics properties. The environmental conditions whose effects need to be established are:

1. Temperatures within the graphite service temperature range.

2. Fast neutron irradiation for the range of fluences and corresponding service temperatures given in Fig. 4.10 .

3. Pressurized helium (note that the effects of graphite oxidation are covered in Subsection 4.1.4.9).

The service conditions are specified at the beginning of Section 4.1.4.

4.1.4.8 Corrosion Characteristics of Core Components Graphite. The data described below are needed to validate Assumption $j$ ). 
j): The existing correlations for $\mathrm{H}-451$ graphite corrosion are accurate within a factor of [2] at [95]\% confidence.

Data describing the corrosion of $\mathrm{H}-451$ graphite by coolant impurities during normal operation and moisture ingress events are needed. The data base should be sufficient to characterize both the transport of coolant impurities and graphite corrosion products in $\mathrm{H}-451$ graphite and the intrinsic kinetics for the reaction of water and oxygen with H-451 graphite. To characterize the transport of coolant impurities in the graphite, the porosity, tortuosity, and permeability of the graphite must be determined. To characterize the reaction kinetics, the reaction rate must be determined as a function of temperature, impurity concentrations, system pressure, and time. In addition the effects of radiolysis and catalysis by graphite impurities and by fission metals on the reaction kinetics must be determined. Finally, the effects of partial graphite burnoff on both the mass transfer processes and the intrinsic reaction kinetics must be quantified. Sufficient data are needed to predict the burnoff within an accuracy of [2] with [95]\% confidence. The operating environment is specified at the beginning of section 4.1.4.

4.1.4.9 Corrosion Effects on Core Component Graphite Design Properties. The data specified below are needed to validate Assumption 1 ).

1): The existing data base is sufficient to predict the corrosion effects on H-451 graphite within a factor of [2] at [95]\% confidence.

The corrosion effects of concern to the mechanical design of the graphite core components are the degradations of the mechanical and thermal material properties. The quantification of this degradation will be done by by first predicting the burnoff from computer analysis (using the basic corrosion data from Subsection $4 \cdot 1.4 .8$ as input), then converting the predicted burnoff into the corresponding effects on the graphite design properties. To perform this conversion, the following data are needed: 
1. Effects of uniform burnoff on Young's modulus, tensile strength, compressive strength, irradiation-induced creep and dimensional change, fracture toughness, thermal conductivity, thermal expansivity, and specific heat.

2. Effects of nonuniform burnoff on these mechanical and thermal properties.

Sufficient data are needed so that changes in the mean values at the design properties can be determined as function of the burnoff rate within an accuracy of [2] with [95]\% confidence.

The service conditions are specified at the beginning of Section 4.1.4.

4.1.4.10 NDE Data for Core Graphite Specifications. The data discussed below are needed to validate Assumption $\mathrm{m}$ ).

m): The production graphite will have the same properties as the design data base.

The data base should be sufficient to validate nondestructive evaluation (NDE) techniques that can be used for acceptance testing of mass produced graphite for core components and for writing material control specifications. The NDE techniques must be sufficiently accurate to (1) detect flaws $>$ [2] mm in the billets used for the core components, and (2) determine the tensile strength of smaller specimens with an error no greater than $[10] \%$.

4.1.4.11 Confirm Fuel Element Dynamic Strength Predictions. The ability of the graphite core components to withstand the dynamic loads imposed during an earthquake is predicted on the basis of static finite element methods and linear combinations of thermal/irradiation and seismic stresses. This is done in accordance with Assumptions $g$ ) and $h$ ). 
8): The dynamic strength can be conservatively predicted with static finite element methods.

h): Thermal/irradiation stresses and seismic stresses can be linearly combined.

To validate these two assumptions, data are needed on the failure loads of H-451 fuel elements subjected to dynamically applied forces. The nature of the forces and their duration must be representative for the type of loads imposed on the fuel elements during earthquakes. Data points are needed for both virgin fuel elements and irradiated fuel elements with residual stresses resulting from long time exposure to temperatures and fluences comparable to the conditions in an HTGR core. The data base must be sufficient to establish with [95\%] confidence that the analytical methods are conservative, i.e., the mean values of the experimentally determined failure loads are higher than the corresponding analytical predictions.

The required data parameters and service conditions are given at the beginning of Section 4.1 .4 .

4.1.4.12 Confirm Fuel Element Failure Mode Predictions. As part of the effort to calculate the reliabilities of the fuel elements, a crack progression analysis is performed based on these two assumptions.

q): The progression of vertical cracks, due to in-plane stresses, can be analyzed with continuum mechanics methods.

r): The failure mode, i.e., the crack progression, can be predicted with the TWOD finite element code.

To confirm the cracking analysis methods, sufficient data are needed on the failure loads and failure modes of $\mathrm{H}-451$ fuel elements subjected to the combination of static mechanical and thermal irradiation loads. The thermal/irradiation stresses must be comparable to those developed in a 
typical fuel elements at shutdown conditions (due to creep there are residual stresses at shutdown of the same magnitude as the operating stresses). The specific data needed are:

1. Mechanical load at crack initiation.

2. Location of crack initiation.

3. Mechanical load at ultimate failure.

4. Crack path from initiation to ultimate failure.

The data base must be sufficient to establish with $95 \%$ confidence that the analytical methods are conservative, i.e., the mean values of the experimental data is higher than the corresponding analytical predictions.

4.1.4.13 Confirm Core Component Seismic Load Predictions. The data specified below are needed to validate Assumption $\mathrm{f}$ ).

f): The seismic loads are conservatively predicted by the MCOCO computer code.

To confirm the methods for predicting the seismic loads on $H-451$ fuel elements, the following data are required from suitable experiments:

1. The structural integrity of the fuel elements, i.e., whether the elements break or are otherwise structurally damaged after having been subjected to a simulated earthquake of an intensity for which the analytical methods would predict damage.

2. The relative impact velocities between the pairs of elements experiencing the highest impact loads in the simulated earthquake defined above.

Due to earlier difficulties in scaling experimental results, the data must be obtained in a full scale or nearly full scale experiment. The data base must be sufficient to establish with [95]\% confidence that the analytical methods 
are conservative; i.e., the analytically predicted loads are higher than the actual loads.

Data are only needed for unirradiated fuel elements at room temperature in a normal atmospheric environment.

4.1.4.14 Validate Control Rod Shock Absorber Characteristics. The data specified below are needed to validate Assumption $t$ ).

t): A crushable graphite insert can absorb sufficient energy to protect the core support structure.

Data are needed to establish the absorption characteristics for three design alternatives, as specified by the designer, of a crushable graphite shock absorber. (The absorption characteristic is the energy absorbed in crushing action, expressed as a percentage of the total kinetic energy in the falling body.) For each of the three alternatives, a sufficient data base must be established to provide [95]\% confidence that the mean value of the data base is at most [20]\% different from the true mean value. (Provided the data confirms that all three alternatives are adequate, the designer will select the most cost effective of the three alternatives.)

The above data are needed for unirradiated crushable graphite at room temperature in a normal atmospheric environment. Additionally, a small number of data points are needed to determine the effects of the service conditions on the absorption characteristics.

The service conditions are specified at the beginning of section 4.1.4. The characteristics of the dropped control rod are:

Weight of Rod: [180] lb

Max. Drop Height: [32] ft 
4.1.4.15 Validate Design Methods for Graphite Corrosion. The amount and effects of graphite corrosion are predicted with computer codes using data specified in 4.1.4.8 and 4.1.4.9 as input. These computer codes are assumed to be valid as expressed in Assumption $k$ ).

k): The existing design methods and computer codes for calculating $\mathrm{H}-451$ graphite corrosion are accurate within a factor of [3] at 95\% confidence.

Validation of the integrated models and computer codes used to predict graphite corrosion in the HTGR core under normal operation and during steam and air ingress events is needed in order to assure that the predictive methods are accurate to within a factor of [3] at 95\% confidence. Particular attention must be given to transport of coolant impurities in fuel element graphite and to effect of catalysis by graphite impurities and fission metals. The data base used for code validation must be independent from the data from which the individual correlations in the overall design method (effective diffusivities, reaction kinetics, etc.) were originally derived (Subsection 4.1.4.9), in accordance with software standard IEEE Standard 730-1984 and software definitions in NUREG-0856. The service conditions are given at the beginning of Section 4.1 .4 .

The functions and assumptions and the resulting technology needs for the core components are summarized in Table 4.1. The technology needs are stated in the table in terms of the titles of the corresponding Design Data Needs or DDNs and the associated subsections of section 4.1 .4 (see section 2 above for a discussion of the relationship between the DDN's and this plan).

\subsubsection{Required Schedule}

Figure 4.12 shows the required technology development schedule for the reactor core components. The required data are divided into a preliminary and a final data base, corresponding to the preliminary and the final design phases, respectively. The schedule requirements for the final data base are summarized in the respective Section 4 of DDN M.10.18.01 through DDN M.10.18.14 and DDN M.10.01 (included in Appendix A). 


\section{TABLE 4.1}

PC-000213/1

\section{FUNCTIONS/ASSUMPTIONS RESULTING \\ IN TECHNOLOGY NEEDS \\ FOR CORE COMPONENTS}

Function

F1.1.2.1.2.2.4

Maintain Fuel Element Structural Integrity

\section{F2.1.2.1.2.4}

Protect the Capability to Maintain Fuel Element Structural Integrity

\section{F1.1.2.1.2.2.4}

Maintain Fuel Element Structural Integrity

\section{F2.1.2.1.2.4}

Protect the Capability to Maintain Fuel Element Structural Integrity
Assumption

k) The existing design methods and computer codes for calculating $\mathrm{H}-451$ graphite corrosion are accurate within a factor of [3] at $95 \%$ confidence.

e) The maximum stress failure theory is a reasonable approximation for H-451 graphite under multiaxial state of stress

i) Miner's rule for estimating the cumulative fatigue is applicable to $\mathrm{H}-451$ graphite.

n) The coefficients of variation given in the Graphite Design Data Manual are accurate to within $[25] \%$.

o) Confidence limits on the mean value and standard deviation can be sufficiently determined through the $t$ and Chi-Square distributions, respectively.

p) Uncertainty in the estimation of the skewness of a distribution can be estimated by the uncertainty in the coefficient of variation.

\section{DDN No./ DDN Title}

Section No.

\section{M.10.01}

4.1.4.15

M.10.18.01

4.1.4.1

M.10.18.02

4.1.4.2

M.10.18.03

4.1.4.3

\section{Statistics of Mechanical Properties of Graphite \\ Core Components}

Validation of Design M
for Graphite Corrosion

Multiaxial Strength of Graphite for Core Components

Fatigue Data for Graphite for Core Components 
Function

F1.1.2.1.2.2.4

Maintain Fuel Element

Structural Integrity

F2.1.2.1.2.4

Protect the Capability to Maintain Fuel Element Structural Integrity

F2.1.2.1.2.4

Protect the Capability to Maintain Fuel Element Structural Integrity
Assumption

d) The mean values of the irradiation-induced dimesnional changes given in the Graphite Design Data Manual for H-451 graphite are valid.

n) The coefficients of variation given in the Graphite Design Data Manual are accurate to within $[25] \%$.

o) Confidence limits on the mean value and standard deviation can be sufficiently determined through the $t$ and Chi-Square distributions, respectively.

p) Uncertainty in the estimation of the skewness of a distribution can be estimated by the uncertainty in the coefficient of variation.

n) The coefficients of variation given in the Graphite Design Data Manual are accurate to within $[25] \%$.

o) Confidence limits on the mean value and standard deviation can be sufficiently determined through the $t$ and Chi-Square distributions, respectively.

p) Uncertainty in the estimation of the skewness of a distribution can be estimated by the uncertainty in the coefficient of variation.

\section{DDN No. DDN Title}

Section No.

M.10.18.04

4.1.4.4

Statistics of Irradiation-Induced Strain of Graphite Core Components

M.10.18.05

Statistics of Irradiation-Induced Creep of Graphite Core Components 
TABLE 4.1 (CONTINUED)

PC-000213/1

Function

F1.1.2.1.1

Transfer Heat from Fuel to Heat Transfer Surface

F2.1.2.1.2.4

Protect the Capability to Maintain Fuel Element Structural Integrity

\section{F2.1.2.1.2.4}

Protect the Capability to Maintain Fuel Element Structural Integrity
Assumption

a) The mean values of thermal expansivity, thermal conductivity, and specific heat given in the Graphite Design Data Manual for H-451 graphite are valid.

b) The lower bound for the emissivity of $\mathrm{H}-451$ graphite is 0.8 .

n) The coefficients of variation given in the Graphite Design Data Manual are accurate to within [25]\%.

o) Confidence limits on the mean value and standard deviation can be sufficiently determined through the $t$ and Chi-Square distributions, respectively.

p) Uncertainty in the estimation of the skewness of a distribution can be estimated by the uncertainty in the coefficient of variation.

q) The progression of vertical cracks (due to to radial stresses) can be analyzed with continuum mechanics methods.

s) Horizontal cracks which need fracture mechanics methods are less probable than vertical cracks due to (1) lower stresses in the axial direction, and (2) only vertical cracks have been observed in FSV fuel elements.
DDN No. DDN Title

Section No.

M.10.18.06

Statistics of Thermal Properties of Graphite for Core Components
M.10.18.07

4.1.4.7
Statistics of Fracture Mechanics Properties of Graphite For Core Components 
TABLE 4.1 (CONTINUED)

PC-000213/1

Function

F1.1.2.1.2.2.4

Maintain Fuel Element Structural Integrity

F1.1.2.1.2.2.4

Maintain Fuel Element Structural Integrity

F2.1.2.1.2.4

Protect the Capability to Maintain Fuel Element Structural Integrity

F1.1.2.1.2.2.4

Maintain Fuel Element

Structural Integrity

F1.1.2.1.2.2.4

Maintain Fuel Element Structural Integrity

F2.1.2.1.2.4

Protect the Capability to Maintain Fuel Element Structural Integrity
Assumption

j) The existing correlations for H-451 graphite corrosion are accurate within a factor of [2] at [95]\% confidence.

1) The existing data base is sufficient to predict the corrosion effects on $\mathrm{H}-451$ graphite within a factor of [2] at [95]\% confidence.

1) The existing data base is sufficient to predict the corrosion effects on $\mathrm{H}-451$ graphite within a factor of [2] at [95]\% confidence.

m) The production graphite will have the same properties as the design data base.

g) The dynamic strength can be predicted with static finite element methods.

h) Thermal/irradiation stresses and seismic stresses can be linearly combined.

r) The failure mode, i.e., the crack progression can be predicted with the TWOD finite element code.
DDN No. DDN Title

Section No.

M.10.18.08 Corrosion Characteristics

4.1.4.8 Of Core Components

Graphite

M.10.18.09 Corrosion Effects On

4.1.4.9 Core Component Graphite Design Properties

M.10.18.10

NDE Data for Core

4.1.4.10

Graphite Specifications

M.10.18.11

Validate Fuel Element

4.1.4.11

Dynamic Strength

Predictions

M.10.18.12

Validate Fuel Element

4.1.4.12

Failure Mode Predictions 
TABLE 4.1 (CONCLUDED)

Function

F1.1.2.1.2.2.4

Maintain Fuel Element

Structural Integrity

F2.1.2.1.2.2.2.2.2.2.4

Absorb Energy from

Dropped Control Rod
Assumption

f) The seismic loads are correctly predicted by the MCOCO computer code.

t) A crushable graphite insert can absorb sufficient energy to protect the core support structure.
DDN No. DDN Title

Section No.

M.10.18.13

4.1.4.13

M.10.18.14

4.1.4.14

\section{Validate Control Rod}

Shock Absorber

Characteristics 
Years after the Start of the Preliminary Design Phase

DDN M.10.18.1 Multiaxial Strength of Graphite for Core Components

DDN M.10.18.2 Fatigue Data for Graphite for Core Components

DDN M.10.18.3 Statistics of Mechanical Properties of Graphite for Core Components

DDN M.10.18.4 Statistics of Irradiation Induced Strain of Graphite Core Components

DDN M.10.18.5 Statistics of Irradiation Induced Creep of Graphite Core Components

DDN M.10.18.6 Statistics of Thermal Properties of Graphite Core Components

DDN M.10.18.7 Statistics of Fracture Mechanics Properties of Graphite Core Components

DDN M.10.18.8 Corrosion Characteristics of Core Components Graphite

DDN M.10.18.9 Corrosion Effects on Core Component Graphite Design Properties

DDN M.10.18.10 NDE Data for Core Graphite Specifications

DDN M.10.18.11 Validate Fuel Element Dynamic Strength Predictions

DDN M.10.18.12 Validate Fuel Element Failure Mode Predictions

DDN M.10.18.13 Validate Core Component Seismic Load Predictions

DDN M.10.18.14 Validate Control Rod Shock Absorber Characteristics

DDdN M.10.01 Validate Design Methods for Graphite Corrosion

Fig. 4.12 Technology Development Schedule for Reactor Core Components

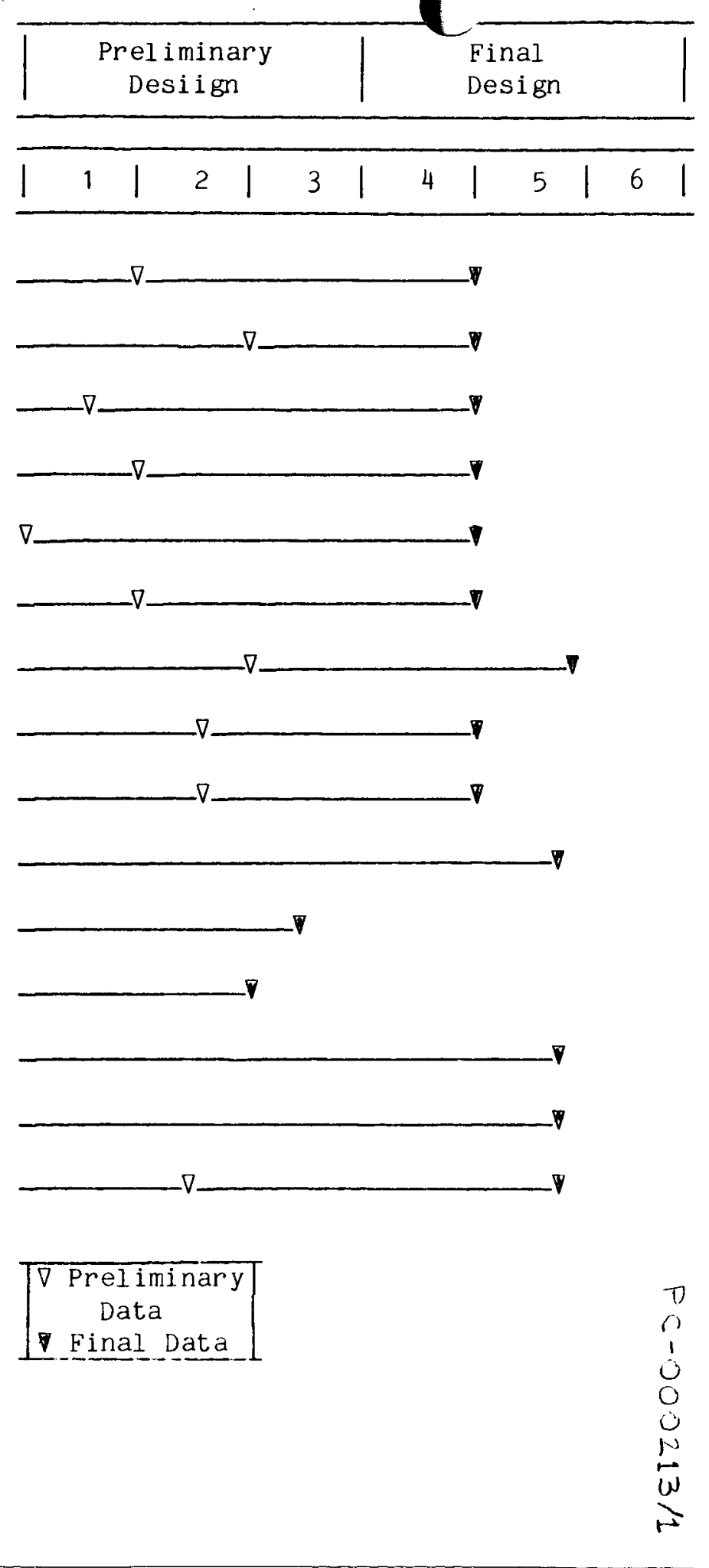

Fig. 4.12 DEVELOPPENT SCHEDULE 


\subsection{REACTOR INTERNAL STRUCTURES}

\subsubsection{Design Description}

The reactor internal graphite components consist of the permanent side reflector and the graphite core support structure (GCSS), both made of graphite Grade 2020. Forty-two columns of permanent side reflector (PSR) blocks surround the core as shown in the core layout view in Fig. 4.2 and the vertical view in Fig. 4.13. The permanent side reflector blocks are irregular in shape since their insides interface with the hexagonal outer side reflectors of the reactor core while their outsides form a smooth cylindrical outer periphery that abuts the core barrel. The PSR blocks are approximately 20 inches wide by 20 inches deep by 27 inches high $(0.51 \mathrm{~m} \times 0.51 \mathrm{~m} \times 0.69 \mathrm{~m})$.

The permanent side reflector extends vertically from the bottom of the plenum elements downward to circumscribe the GCSS. The GCSS consists of a layer of flow distribution blocks (immediately below the bottom transition reflectors of the reactor core as shown in Fig. 4.4), a layer of post blocks, 7 inch diameter cylindrical posts, and a lower plenum floor (LPF). The graphite LPF rests on alumina pads which, in turn, rest upon a metallic core support structure. The same metallic structure also supports the permanent side reflector.

The posts create the lower plenum which receives the primary coolant helium exiting the core, mixes the coolant and channels it to the hot duct.

\subsubsection{Functions}

The functions which result in technology requirements for the PSR and GCSS are discussed below. 


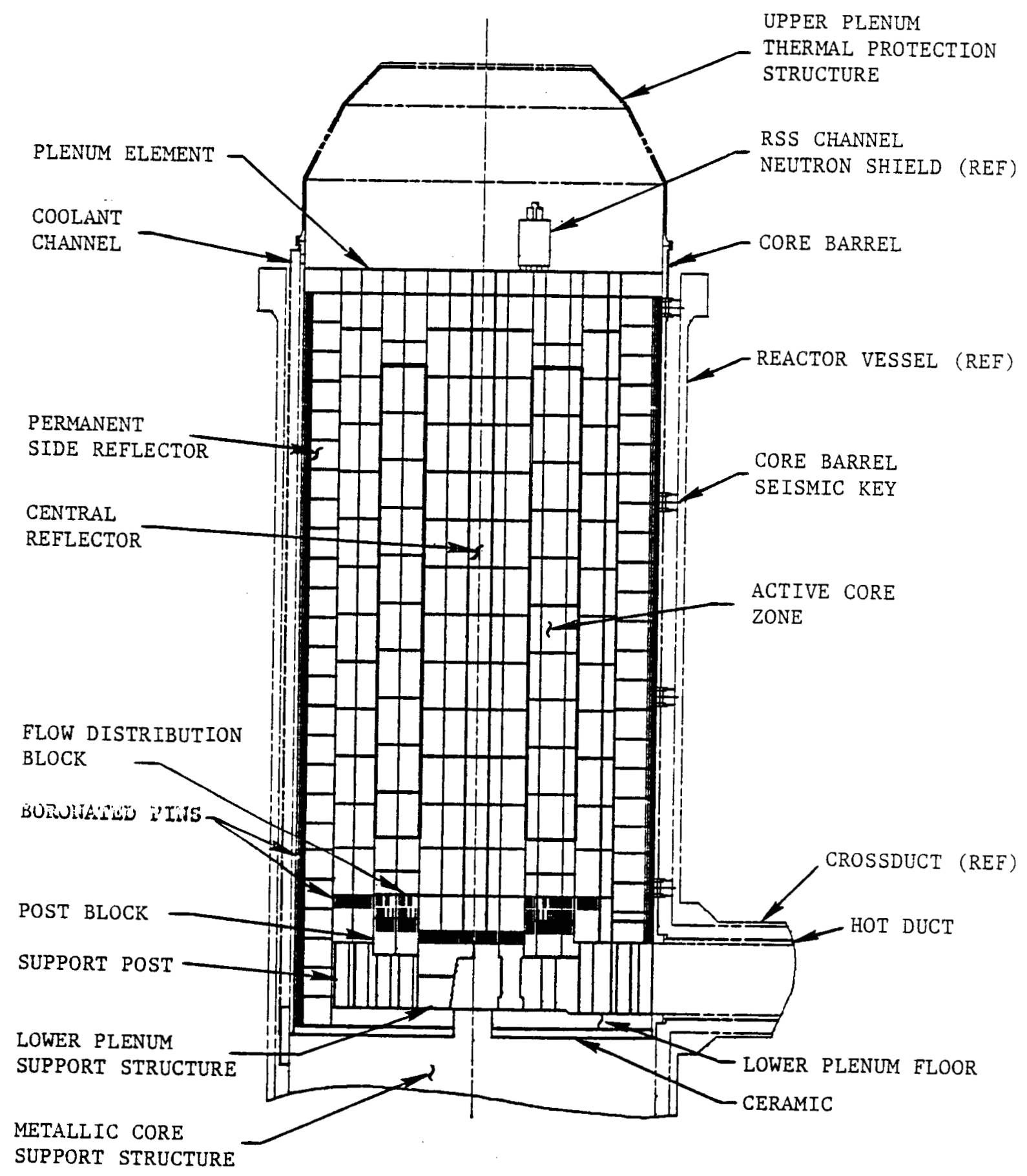

Figure 4.13 $350 \mathrm{MW}(t)$ Reactor Vessel Vertical View 
4.2.2.1 Graphite Core Support Component Functions. The design requirements discussed in Section 4.2 .3 .1 result from the need to satisfy the function to maintain integrity of the Graphite Core Support Structure [F1.1.2.1.2.2.2.2.2]. How this function ties into the functional analysis tree is shown in Fig. 4.14 for Goal 1*. This function assists in supporting the core $[F 1 \cdot 1 \cdot 2 \cdot 1 \cdot 2 \cdot 2.2]^{*}$ which is described in section 4.1.1. Thus, it is necessary to maintain the integrity of the GCSS to support any portion of the core such as the reflectors $[\mathrm{F} 1 \cdot 1 \cdot 1 \cdot 1 \cdot 2 \cdot 2 \cdot 1 \cdot 2]$.

It is also required to maintain integrity of the GCSS to assist in achieving the Goal 3 functions of supporting reflector control elements [F3.1.1.2.1.1.2.1.1.3.1.1.2] supporting RSS fuel elements $[F 3 \cdot 1 \cdot 1 \cdot 2 \cdot 1 \cdot 1 \cdot 2 \cdot 1 \cdot 1 \cdot 3 \cdot 2 \cdot 1.2]$ and supporting the core $[F 3 \cdot 1 \cdot 1 \cdot 2 \cdot 1 \cdot 1.2 \cdot 1 \cdot 1 \cdot 3 \cdot 3]$.

4.2.2.2 Permanent Side Reflector Component Functions. The design requirements discussed in section 4.2 .3 .2 result from the need to satisfy the functions to maintain the integrity of the Side Reflectors [F1.1.1.2.2.1.3.2] to conduct heat through the reflector $[F 3 \cdot 1 \cdot 1 \cdot 2.1 \cdot 1 \cdot 2.2 .1 .1 .2]$ and to limit flow in the side reflector gaps [F1.1.2.1.2.1.2.2]. How the goal 1 functions tie into the functional analysis tree is shown in Figs. 4.14, 4.15, and 4.16.

\subsubsection{Key Functional Requirements/Assumptions}

The requirements which bound the functions discussed above, and the assumptions necessary to satisfy these requirements, are discussed below for the core support components and the permanent side reflector components.

\footnotetext{
*Goal 1 is to Maintain Plant Operation. The associated functions for Goal 2, Maintain Plant Protection, are also applicable.

* This function also appears in other parts of the tree [i.e., F1.1.2.1.2.1.1.2.2] however, for simplicity, only one typical portion of the function analysis tree is given in this report.
} 


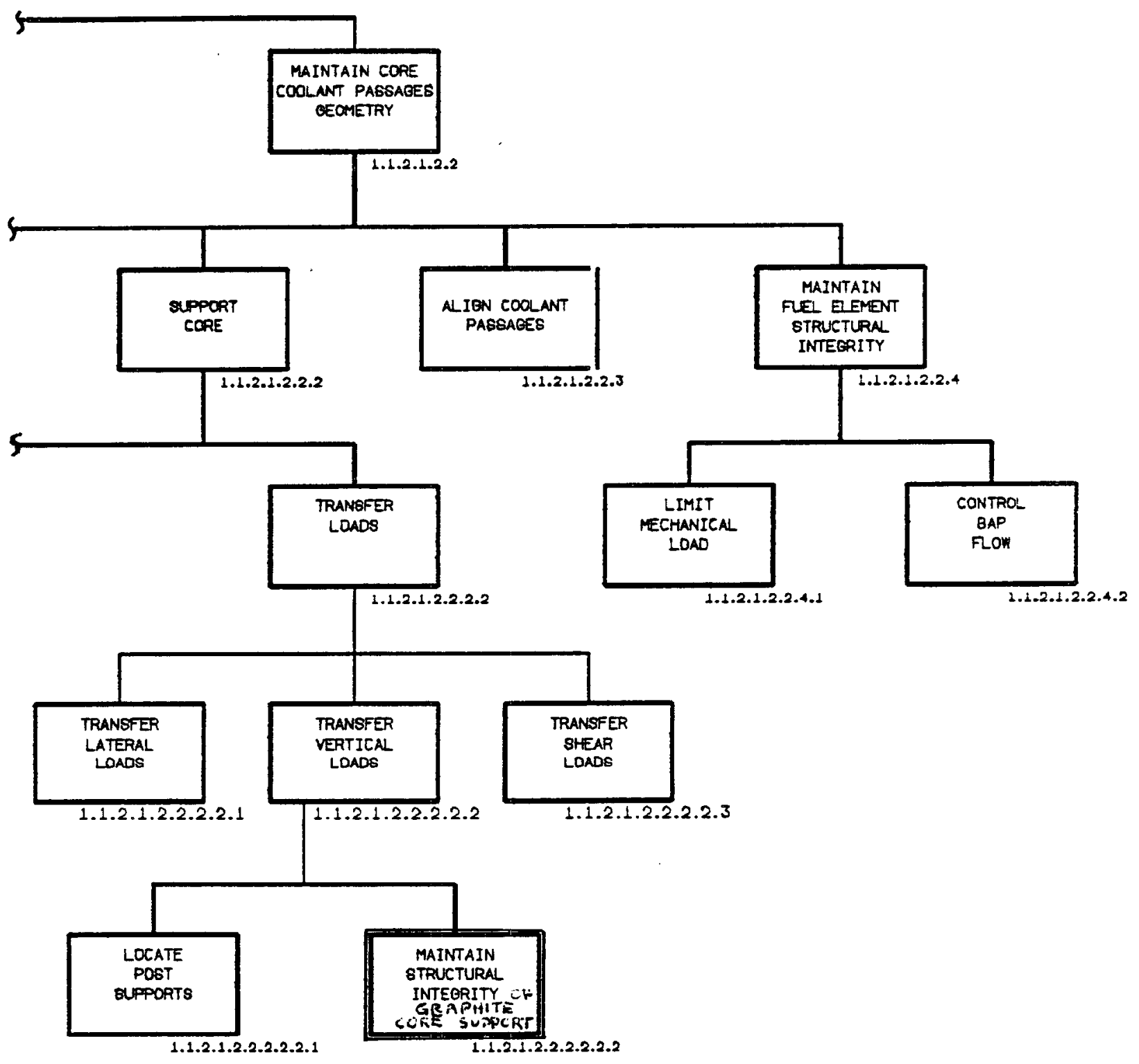

Figure 4.14 Partial Functional Tree for Permanent Components 


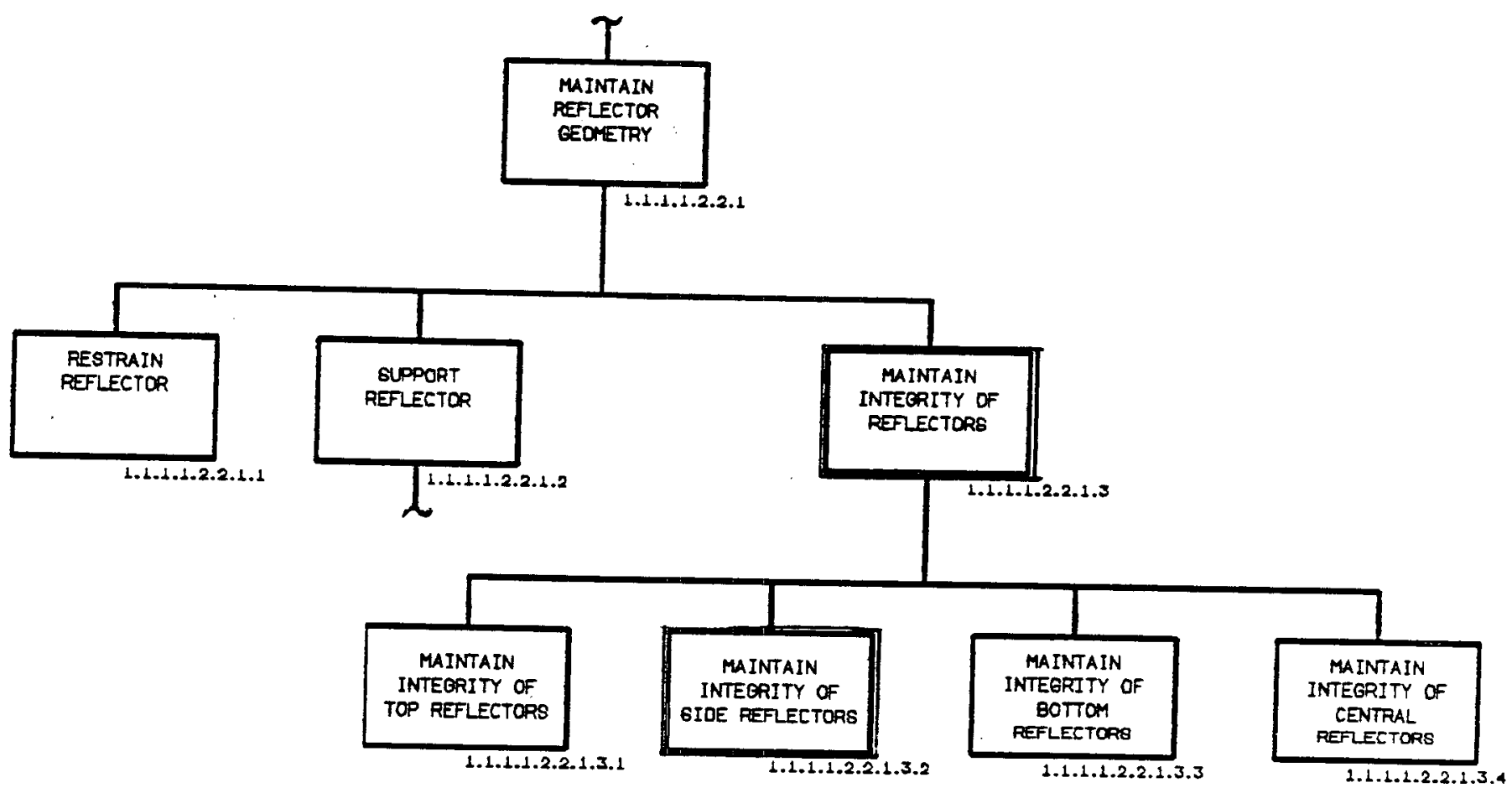

Figure 4.15 Partial Functional Tree for Permanent Components 


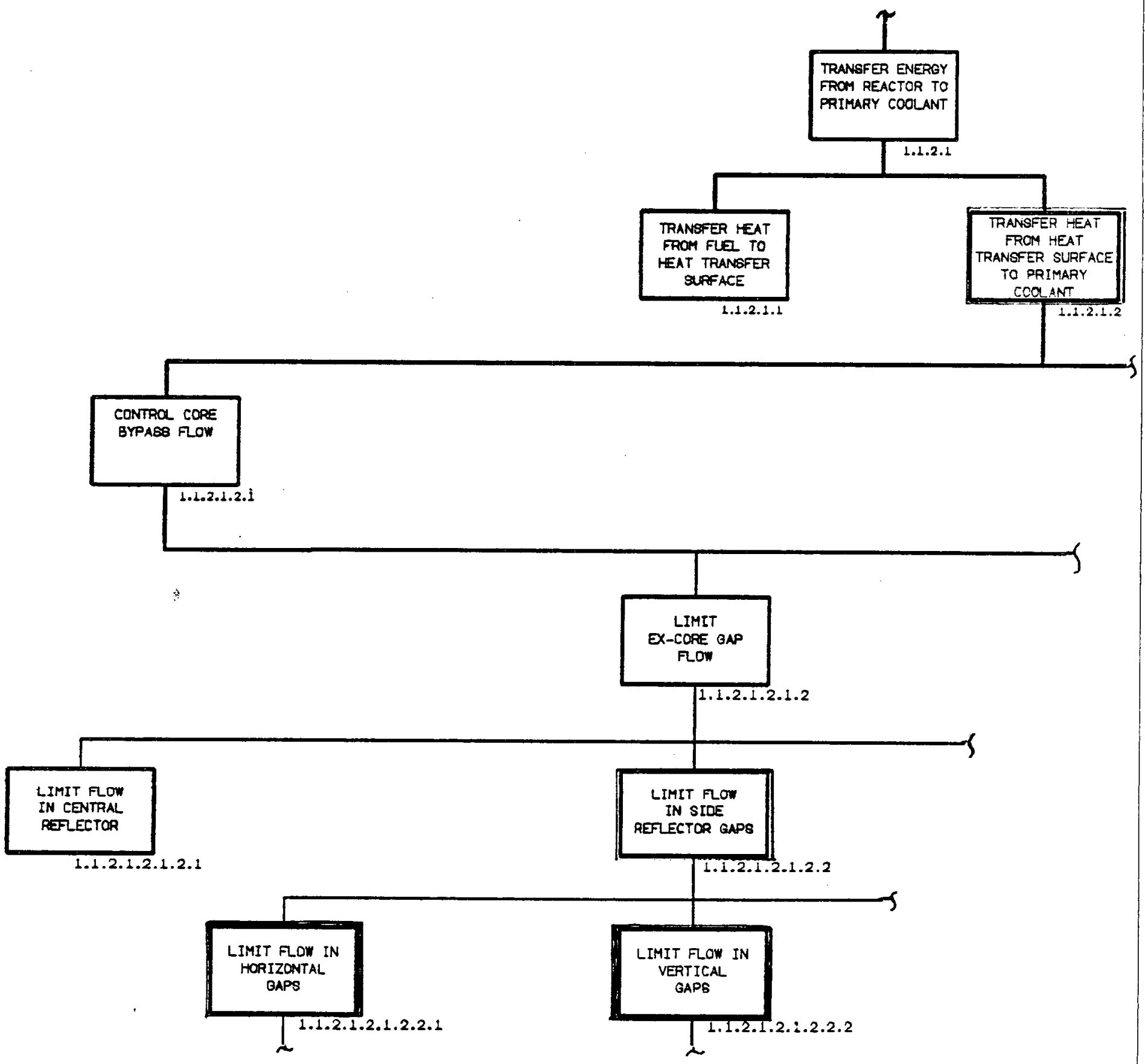

Figure 4.16 Partial Functional Tree for Permanent Components 


\subsubsection{Core Support Component Requirements/Assumptions Resulting in}

Technology Needs. This section presents a discussion on the requirements and assumptions resulting in technology needs for the graphite core support structure (GCSS). These requirements, which are listed in Table 4.2, are those which must be satisfied to adequately ensure that the GCSS maintains at structural integrity. This is ensured by designing the GCSS so that all induced stresses are below the design allowables.

Requirement 1 indicates that the GCSS must withstand an operational life of at least $280,000 \mathrm{~h}$ (i.e., 40-yr $\times 7008 \mathrm{~h} / \mathrm{yr}$ ). During this time it must accommodate temperatures from $316^{\circ} \mathrm{C}$ to $800^{\circ} \mathrm{C}$ (Req. 2.1) while exposed to primary coolant (Req. 6) and irradiation (Req. 7). Under these conditions the GCSS is stressed by thermal and mechanical induced loads.

Stresses are induced thermally by temperature gradients in the GCSS. These occur during steady-state conditions because of variations in the temperature of the gas exiting the core (Req. 2.1) and during temperature transients (Req. 2.2). These variations may occur many times during the life of the plant (Req. 3). Each time there is a change in the temperature condition of the GCSS, there is a change in its thermally-induced stress. It follows that the GCSS must be designed to withstand the number of cycles indicated in Req. 3 for load changes as well as for relatively rapid temperature transients like in a reactor trip.

Stresses are induced mechanically by the dead weight of components, the axial pressure drop across these components, and by seismic events (Req. 5). The pressure load and seismic loads given in Req. 5 result from Req. 2.4 and 4.1, respectively. The pressure load can cycle up to 25,750 times between the value given in Req. 5 to almost zero, due to the load changes indicated in Req. 3. The load associated with the OBE may occur $[<1000]$ times during a single seismic event. 
TABLE 4.2

REQUIREMENTS LEADING TO TECHNOLOGY NEEDS FOR THE GCSS

Requirement

No.

1. Design as a permanent installation free of maintenance during life of the plant.

1.1 The operational life shall be 40 years.

1.2 Availability allocation $\geq 7008$ effective full power $h / y r$ average operating time.

2. Accommodate the temperature, pressure and flow of the primary coolant.

2.1 Accommodate the temperatures of gas entering GCSS:

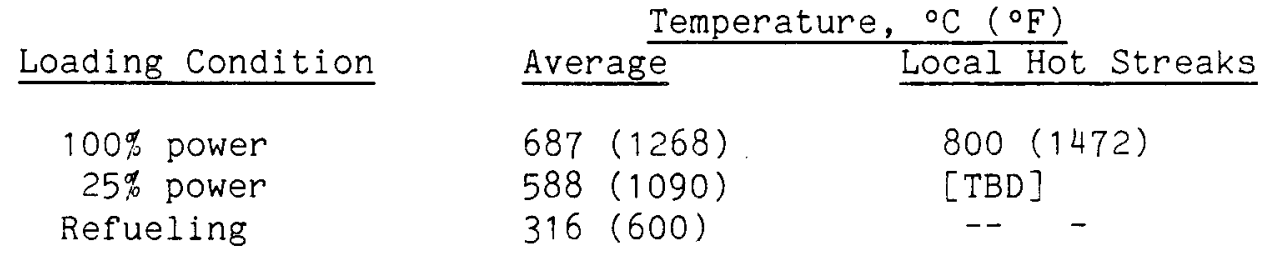

2.2 Accommodate temperature transients resulting from a reactor trip from $100 \%$ power $-688^{\circ} \mathrm{C} / \mathrm{h}$ for $1 / 2 \mathrm{~h}$.

2.3 Primary coolant pressure is 63 atm at rated power and 1 atm of shutdown.

2.4 Core pressure drop:

5 psi at rated power

0.6 psi at $25 \%$ power

-0 psi at shutdown

2.5 Accommodate a maximum primary coolant flow rate of $566,100 \mathrm{~kg} / \mathrm{h}$ $(1,248,100 \mathrm{lb} / \mathrm{h})$ at rated power.

3. Meet plant duty cycles:

Condition

- Load changes - $100 \%$ to as low as 25\% power and back to higher power

- Load changes shutdown to power operation

- Reactor trip
Number of Cycles

25,400

350

120 
TABLE 4.2 (continued)

- Operational Basis Earthquake (OBE) 1

O Safe Shutdown Earthquake (SSE) 1

4. Accommodate design seismic loads.

4.1 Accommodate OBE loads with a maximum horizontal ground acceleration of $0.15 \mathrm{~g}$.

4.2 Accommodate SSE loads with a maximum vertical ground acceleration of $0.30 \mathrm{~g}$.

5. Withstand the maximum vertical design loads per core columns, which are (1b).

$\begin{array}{lccc} & \begin{array}{c}\text { Flow } \\ \text { Distribution } \\ \text { Block }\end{array} & \begin{array}{c}\text { Support } \\ \text { Block }\end{array} & \text { Post } \\ \text { Deadweight } & {[4000]} & {[4250]} & {[4500]} \\ \text { Delta } P \text { at rated power } & {[1000]} & {[1050]} & {[1100]} \\ \text { OBE } & {[4000]} & {[4250]} & {[4500]}\end{array}$

6. Be compatible with the primary coolant.

6.1 The primary coolant is helium with chemical impurities as specified in Table 4.3.

7. Accommodate design irradiation levels.

7.1. The maximum fast ( $E>29 \mathrm{fJ}$ ) fluence to the permanent graphite core support structure is $\left[\begin{array}{llll}1 & \times & 10^{24} & \mathrm{n} / \mathrm{m}^{2}\end{array}\right]$. 
TABLE 4.3

"LONG TERM" EXPECTED AND DESIGN PRIMARY COOLANT IMPURITIES

\begin{tabular}{ccc}
\hline $\begin{array}{l}\text { Chemical } \\
\text { Impurities }\end{array}$ & $\begin{array}{c}\text { Expected } \\
\text { ppmv }\end{array}$ & $\begin{array}{c}\text { Design } \\
\text { ppmv }\end{array}$ \\
\hline $\mathrm{H}_{2} \mathrm{O}$ & 0.5 & 2 \\
$\mathrm{CO}_{2}$ & 1 & 2 \\
$\mathrm{CO}$ & 2 & 5 \\
$\mathrm{H}_{2}$ & 3 & 10 \\
$\mathrm{CH}_{4}$ & 0.1 & 2 \\
$\mathrm{~N}_{2}$ & 2 & 10 \\
\hline
\end{tabular}

(a) The ppmv signifies part per million in volume. At rated power the design pressure is approximately $918 \mathrm{psi}(63 \mathrm{~atm})$. Note $0.5 \mathrm{ppmv} \times 63$ atm $=$ $31.5 \mu \mathrm{atm}$. 
Fulfilling these requirements involves performing thermal and mechanical load analysis requiring knowledge of the thermal properties, elastic moduli, Poisson's ratio, and material strength. When these properties are not known with sufficient confidence, assumptions about their values have to be made. The rest of this section discusses why the requirements listed lead to assumptions which need to be verified.

The GCSS stresses are limited to a percentage of the "minimum ultimate strength" of the graphite which is defined in probabilistic terms (99\% survivability at a confidence level of 95\%). In the evaluation of the conceptual design, it was found that in order to meet the stress limits it is necessary for the core support graphite to have a minimum ultimate tensile strength of [2400] psi and a minimum ultimate compressive strength of [3000] psi. The material selected as reference material, namely Stackpole Grade 2020, has not been adequately characterized, especially for the log sizes needed for the core support components. Accordingly, the following assumption was made:

a): Grade 2020 graphite can be manufactured in the size needed for the core support structure with minimum ultimate strengths of [2400] psi in tension and [3000] psi in compression.

The technology need related to the assumption is for a statistical data base such that the above properties can be established to the ASME code subsection $\mathrm{CE}$ statistical requirements. The detailed needs are specified in Section 4.2 .4 .1 .

Subsection CE of the ASME Code specifies the use of mean values for the thermal and elastic properties. The values for the thermal properties of expansivity, specific heat, and conductivity and the mechanical properties of elastic moduli and Poisson's ratio are obtained from the Graphite Design Data Manual for the conceptual design, but this data base is too sparse for preliminary and final design which lead to the additional assumptions. 
b): The mean values of thermal expansivity, thermal conductivity, and specific heat given in the Graphite Design Data Manual for 2020 graphite are valid.

The technology need related to this assumption is for a statistical data base such that the mean values of the above thermal properties can be sufficiently accurately established. The detailed needs are specified in Section 4.2 .4 .13 .

c): The lower bound for the emissivity of 2020 graphite is 0.8 .

This assumption relates to the need for a data base on emissivity sufficient to determine the lower bound with a reasonable confidence. This needs is also specified in Setion $4 \cdot 2 \cdot 4 \cdot 13$.

d): The mean values for the elastic properties of Young's modulus and Poisson's ratio given in the Graphite Design Data Manual for 2020 graphite are valid.

This assumption relates to the need for a data base on Young's modulus and Poisson's ratio sufficient to determine its mean value. The detailed needs are specified in section 4.2.4.9.

To reduce the time and cost of analyses, linearly elastic methods are used. This is done even though 2020 graphite exhibits nonlinear stress strain behavior over the full range between compressive and tensile failure. This is justified because the design allowable stresses are significantly less than the failure stress and, over the range of allowable. stresses, the graphite stress-strain behavior is relatively linear. However, the use of such methods has not been verified for graphite and leads to the assumption:

e): The use of simplified linear elastic stress analysis methods to show compliance with required stress limits is valid. 
Validation of this assumption requires strength data to confirm that the ultimate load capacity of the GCSS is adequate. The detailed needs are specified in $4.2 \cdot 4.21$.

The evaluation of the GCSS is done on the basis of the maximum stress failure theory which is a simplified approximation for failure of graphite in multiaxial stress states. The maximum stress failure theory states that failure will occur when one of the three principal stress components at a point in a body reaches either the uniaxial tensile strength or the uniaxial compressive strength. The use of this theory is permitted by the draft Subsection CE of the ASME code, but is known to be unconservative for graphite. The degree of nonconservatism needs to be quantified so that an adequate safety margin can be ensured. Thus the use of this theory is based upon the assumption:

f): The maximum stress failure theory is a reasonable approximation for 2020 graphite under a multiaxial state of stress.

The technology need related to this assumption is to generate data to bound inaccuarcies associated with the maximum stress failure theory. The detailed needs are specified in 4.2 .4 .3$.

Because of inherent variability in the graphite due to small variations in the raw material and in the production process, product control is needed during the procurement to ensure that the production graphite has the same characteristics as the graphite used to establish the data base and that the strength requirements have been met. Nondestructive testing techniques developed by ORNL satisfy this need, but the data base as of yet is too sparse to validate these techniques for use in product control of mass produced graphite. For the designer to assure that the design is structurally adequate for these future materials a required assumption is:

g): The production graphite will have the same properties as the design data base. 
To validate this assumption NDE techniques must be established to be sufficiently accurate to insure satisfactory properties of the graphite used to make the GCSS. The detailed needs are specified in 4.2.4.20.

Cyclic stresses in the GCSS need to be evaluated to establish that they are within design allowables. The design allowable cyclic stresses are based on design fatigue curves determined by a statistical analyses of the data such that the specimen survival probability is $99 \%$ at a confidence level of $95 \%$. These curves need to be in the form of constant life diagrams (also referred to as modified Goodman diagrams). Values for the curve are given for 2020 graphite in the Graphite Design Data Manual for survival to $10^{5}$ cycles under uniaxial cyclic loading in air at ambient temperature. Additional data are needed to verify that these design values are valid for the HTGR service condition. It is being assumed that:

h): The cycle fatigue endurance limits for 2020 graphite specified in the Graphite Design Data Manual are valid.

The technology need related to this assumption is for a statistical data base such that the cyclic fatigue limits can be established with sufficient accuracy. The detailed needs are specified in 4.2.4.5.

Subsection $C E$ of the code specifies that accumulated fatigue damage shall be evaluated using Miner's rule. This rule specifies that structural damage is a linear function of the number of cycles to failure and that the total fraction of available life is the summation of damage fractions for different amplitudes of accummulated stress cycles. It is also expected that incipient failure will occur when the sum of all the damage fractions is 1 (or 100\%). Miner's rule is the most widely used method for evaluating the cumulative effects of fatigue in metals. The attractiveness of this method is that it is simple to use, fits in with the maximum stress failure theory, and data may be obtained from simple axially loaded push-pull tests on specimens. However, the applicability of Miner's rule has not yet been validated for 2020 graphite. This leads to the assumption: 
i): Miner's rule for estimating the cumulative fatigue is applicable to 2020 graphite.

The validation of this assumption requires a data base including fatigue life as a function of stress amplitude for both constant amplitude load cycles and sequential series of cycles with different amplitudes. The detailed needs are discussed in Section 4.2.4.7.

The effects of radiation (Req. 6) on the design properties must be accounted for in the design evaluation. Under irradiation, the minimum ultimate tensile strength increases as does the modulus. However, these effects are expected to be small which leads to the assumption:

$j)$ : The effects of radiation on 2020 graphite mechanical properties are negligible.

The technology need related to this assumption is for data sufficient to show to a high confidence that the effects of design irradiation levels on selected mechanical properties are negligible. The detailed needs are specified in Section 4.2.4.11.

Under irradiation, the conductivity typically decreases which leads to larger differential temperatures and consequently larger thermal stresses. These effects are expected to be minimal and lead to the assumption:

k): The effects of radiation on 2020 graphite thermal properties are negligible.

The technology need related to this assumption is for data sufficient to show to a high confidence the effects of design irradiation levels on the mean value of selected thermal properties. The detailed needs are specified in Section $4 \cdot 2 \cdot 4 \cdot 15$. 
The high temperature primary coolant may contain water vapor and other trace impurities such as carbon monoxide and carbon dioxide as given by Req. 6. Meeting Req. 6 involves evaluation of the effects of corrosion, from water vapor and other oxidants in the coolant, on the components ability to satisfy its design functions.

There are two kinds of steam-corrosion of concern. The first is a localized corrosion caused by clumping of catalysts, usually metals, within the graphite often called "worm-holing." This type of corrosion is not acceptable for the GCSS and is prevented by the removal or dispersal of catalytic impurities in the core support graphite. The second type of corrosion is a more homogenous one and is proportional to the macroscopic water concentration in the pores of the graphite. This is the type dealt with in the design. Both kinds of corrosion remove carbon atoms from the graphite thus lowering the density. This reduction is often referred to as "burnoff" and is usually expressed as a percentage reduction in density or weight. Associated with this burnoff is a reduction in strength and stiffness of the component. The time it takes to obtain a given level of burnoff is dependent on the steam graphite reaction rate which is highly dependent on the concentration of moisture in the primary coolant, and the graphite temperature. The steam-graphite reaction rates of core support graphite are high enough to generally result in surface burnoff. The amount of burnoff anticipated is then calculated and allowed for in the design. This leads to the assumption:

1): Graphite corrosion is limited to a maximum depth of [2] $\mathrm{mm}$.

The technology need related to this assumption is for sufficient data to confirm with a high confidence that any significant corrosion of the graphite core support components is limited to a maximum depth of [2] $\mathrm{mm}$ below the exposed surface. The detailed needs are specified in Section 4.2.4.17. 
4.2.3.2 Permanent Side Reflector Component Requirements/Assumptions Resulting in Technology Needs. The following discussion on the requirements and assumptions resulting in technology needs for the permanent reflector components is divided up by the relevant functions of which there are only four.

Function $3 \cdot 1 \cdot 1 \cdot 2 \cdot 1 \cdot 1 \cdot 2 \cdot 2 \cdot 1 \cdot 1.2$, Transfer Heat Through Reflector. To ensure that the temperature of the fuel does not exceed design temperature allowables, heat has to be removed from the core. During a postulated event involving the loss of all forced circulation (also called a conduction cooldown) a major portion of this heat is removed by conduction through the side reflector. As a result it is necessary to ensure that the thermal conductivity of PSR is sufficiently high such that:

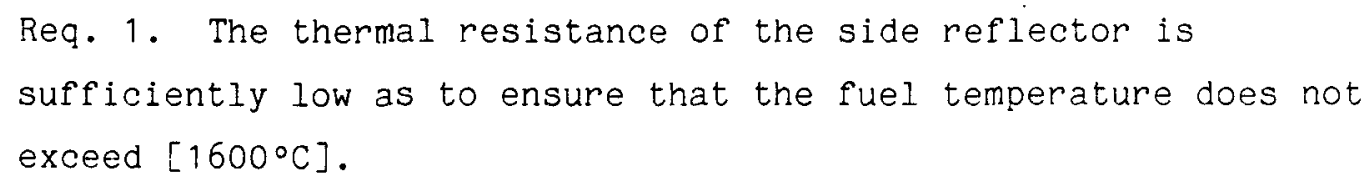

This requirement has been shown to be satisfied by performing thermal analysis using the mean values of the thermal conductivity and specific heat given in the Graphite Design Data Manual and by assuming an emissivity of 0.8 for the PSR graphite. However, the specific values in the Graphite Design Data Manual were derived from a limited data base, which leads to the assumptions:

b): The mean values of thermal expansivity, thermal conductivity, and specific heat given in the Graphite Design Data Manual for 2020 graphite are valid.

The technology need related to this assumption is for a statistical data base such that the mean values of the above thermal properties can be established with sufficient accuracy. The detailed needs are included in Section 4.2.4.14. 
c): The lower bound for the emissivity of 2020 graphite is 0.9 .

This assumption relates to the need for a data base on emissivity sufficient to determine the lower bound with a reasonable confidence. The need is detailed in section 4.2.4.14.

Function $1 \cdot 1 \cdot 2 \cdot 1 \cdot 1 \cdot 2 \cdot 1 \cdot 2 \cdot 2 \cdot 3$, Limit Flow in Side Reflector Gaps

This function is performed by designing the permanent reflector components such that the gaps between side reflector columns are maintained between minimum and maximum values to control the flows through them to low levels. Requirement 1 limits the ex-core gap flow to less than $[6.5] \%$. Satisfying this requirement involves thermal and deformation analyses which utilize the properties of expansivity, conductivity, and specific heat for 2020 graphite. These analyses are performed for the design conditions of the permanent reflector which include spatially varying temperatures; thus, the above thermal properties are needed as functions of temperature. In the thermal analyses, the mean values of expansivity, conductivity, and specific heat are used. In the deformation analyses, the mean values of the expansivity are used. For the conceptual design, this information is obtained from the Graphite Design Data Manual. The specific values in this manual are, however, derived from a limited data base which leads to the assumption:

b): The mean values of thermal expansivity, thermal conductivity, and specific heat given in the Graphite Design Data Manual for 2020 graphite are valid.

The replaceable reflectors shield the permanent components from significant neutron radiation exposure. However, the effects of low levels of radiation on the thermal properties must be included in the 
design evaluation. Under irradiation, the conductivity typically decreases which leads to larger differential temperatures and consequently larger thermal stresses. These effects are expected to be minimal and lead to the assumption:

k): The effects of radiation on 2020 graphite thermal properties are negligible.

The technology need related to this assumption is for data sufficient to show to a high confidence the effects of design levels on the mean values of selected thermal properties. The detailed needs are specified in Section 4.2.4.16.

Function 1.1.2.1.2.1.2.2.1, Limit Flow in Horizontal Gaps Function $1.1 \cdot 2 \cdot 1 \cdot 2 \cdot 1 \cdot 2 \cdot 2.2$, Limit Flow in Vertical Gaps

These two functions are performed primarily by limiting the total number of vertical and horizontal gaps around the core through the use of large blocks as permanent reflectors. Requirement 1 of the first function states that the flow in the horizontal reflector gaps is less than [TBD]\% of the circulator flow rate. Similarly, Requirement 1 of the second function states that flow in vertical reflector gaps is less than $[T B D] \%$ of the circulator flow rate. These large blocks are not routinely produced for 2020 graphite which leads to the assumption:

m): Large grade 2020 graphite blocks are available.

To validate the assumption a process must be identified for producing 2020 graphite in billet sizes need for the PSR in sufficient quantities and with satisfactory properties. The detailed needs are specified in Section 4.2.4.19. 
Function $1 \cdot 1 \cdot 1 \cdot 2 \cdot 2 \cdot 1 \cdot 3 \cdot 2$ Maintain Integrity of Side Reflector

The requirements listed in Table 4.4 are those which must be satisfied to adequately ensure that the PSR maintains its structural integrity. This is ensured by designing the PSR so that all induced stresses are below the design allowables of Req. 1.

Requirement 1 indicates that the PSR must withstand an operational Iife of at least $280,000 \mathrm{~h}$ (i.e., 40-yr times at $7008 \mathrm{~h} / \mathrm{yr}$ ). During this time it must accommodate temperatures from $116^{\circ} \mathrm{C}$ to $800^{\circ} \mathrm{C}$ (Req. 2.1) while exposed to primary coolant (Req. 6) and irradiation (Req. 7). For shorter durations $(400 \mathrm{~h}$ ) the PSR must accommodate temperatures to $900^{\circ} \mathrm{C}$ (Req. 5). Under these conditions the PSR is stressed by thermal and mechanical induced loads.

Stresses are induced thermally by temperature gradients in the PSR. These occur during steady-state conditions because of variations in the temperature of the gas exiting the core (Req. 2.1) and during temperature transients (Req. 2.2). These may occur many times during the life of the plant (Req. 3). Each time there is a change in temperature condition of the PSR, there is a change in its thermally-induced stress. It follows that the PSR must be designed to withstand the number of cycles indicated in Req. 3 for load changes as well as for relatively rapid temperature transients like in a reactor trip and cooldown.

Stresses are induced mechanically by the radial pressure drop across the PSR and during seismic events (Reqs. 2.4 and 4). The pressure load can cycle up to 25,750 times between the maximum value given in Req. 2.4 to almost zero due to load changes indicated in Req. 3. The load associated with the OBE may occur many times during a single seismic event. 
TABLE 4.4

REQUIREMENTS LEADING TO TECHNOLOGY NEEDS FOR PSR

Requirement

No.

1. Design as a permanent installation free of maintenance during life of the plant.

1.1 The operational life shall be 40 years.

1.2 Availability allocation $\geq 7008$ effective full power $h / y r$ average operating time.

2. Accommodate the temperature, pressure and flow of the primary coolant.

2.1 Accommodate the temperatures of gas:

\begin{tabular}{|c|c|c|c|}
\hline \multirow[b]{3}{*}{ Loading Condition } & \multicolumn{3}{|c|}{ Temperature, ${ }^{\circ} \mathrm{C}\left({ }^{\circ} \mathrm{F}\right)$} \\
\hline & Core & Core & \\
\hline & Inlet & Outlet & Local Hot Streaks \\
\hline $100 \%$ power & $200(500)$ & $687(1268)$ & $800(1472)$ \\
\hline 25\% power & $234(490)$ & $588(1090)$ & {$[\mathrm{TBD}]$} \\
\hline Refueling & $116(240)$ & $316(600)$ & -- \\
\hline
\end{tabular}

2.2 Accommodate temperature transients resulting from a reactor trip from $100 \%$ power $-688^{\circ} \mathrm{C} / \mathrm{h}$ for $1 / 2 \mathrm{~h}$.

2.3 Primary coolant pressure is 63 atm at rated power and 1 atm of shutdown.

2.4 Core pressure drop:

5 psi at rated power

0.6 psi at $25 \%$ power

-O psi at shutdown

2.5 Accommodate a maximum primary coolant flow rate of $566,1000 \mathrm{~kg} / \mathrm{h}$ $(1,248,100 \mathrm{lb} / \mathrm{h})$ at rated power.

3. Meet plant duty cycles:

Condition Number of Cycles

- Load changes - $100 \%$ to as low as $25 \%$ power and back to higher power

- Load changes shutdown to power operation

o Reactor trip

$$
25,400
$$

350

120 


\section{TABLE 4.4 (continued)}

- Operational Basis Earthquake (OBE) 1

- Safe Shutdown Earthquake (SSE)

4. Accommodate design seismic loads.

4.1 Accommodate OBE loads with a maximum horizontal ground acceleration of $0.15 \mathrm{~g}$.

4.2 Accommodate SSE loads with a maximum vertical ground acceleration of $0.30 \mathrm{~g}$.

5. Accommodate design temperature during a depressurized conduction cooldown of up to $900^{\circ} \mathrm{C}$ for $400 \mathrm{~h}$.

6. Be compatible with primary coolant.

6.1 The primary coolant is helium with chemical impurities as specified in Table 4.3 .

7. Accommodate design irradiation levels.

7.1. The maximum fast $(E>29 \mathrm{fJ})$ fluence to the PSR is $\left[2 \times 10^{20} \mathrm{n} / \mathrm{cm}{ }^{2}\right]$. 
Fulfilling these requirements involves performing thermal and mechanical load analysis requiring knowledge of the thermal properties, elastic moduli, Poisson's ratio, and material strength. When these properties are not known with sufficient confidence, assumptions about their values have to be made. The rest of this section discusses why the requirements listed lead to assumptions which need to be verified.

The PSR stresses are limited to a percentage of the "minimum ultimate strength" of the graphite which is defined in probabilistic terms ( $99 \%$ survivability at a confidence level of $95 \%$ ). In the evaluation of the conceptual design, it was found that in order to meet the stress limits it is necessary for the core support graphite to have a minimum ultimate tensile strength of [1950] psi and a minimum ultimate compressive strength of [2400] psi. The material selected as reference material, namely Stackpole Grade 2020, has not been adequately characterized, especially for the log sizes needed for the core support components. Accordingly, the following assumption was made:

n): Grade 2020 graphite can be manufactured in the size needed for the permanent reflector components with minimum ultimate strengths of [1950] psi in tension and [2400] psi in compression.

The technology need related to the assumption is for a statistical data base such that the above properties can be established to the ASME code subsection $C E$ statistical requirements. The detailed needs are specified in Section 4.2 .4 .2 .

Subsection CE of the ASME Code specifies the use of mean values for the thermal and elastic properties. The values for the thermal properties of expansivity, specific heat, and conductivity and the elastic properties of elastic moduli and Poisson's ratio are obtained from the Graphite Design Data 
Manual for the conceptual design, but this data base is too sparse for preliminary and final design which lead to the additional assumptions.

b): The mean values of thermal expansivity, thermal conductivity, and specific heat given in the Graphite Design Data Manual for 2020 graphite are valid.

The technology need related to this assumption is for a statistical data base such that the mean values of the above thermal properties can be sufficiently accurately established. The detailed needs are specified in Section $4.2 \cdot 4 \cdot 14$.

c): The lower bound for the emissivity of 2020 graphite is 0.8 .

This assumption relates to the need for a data base on emissivity sufficient to determine the lower bound with a reasonable confidence. This needs is also specified in Setion 4.2 .4 .14 .

d): The mean values for the elastic properties of Young's modulus and Poisson's ratio given in the Graphite Design Data Manual for 2020 graphite are valid.

This assumption relates to the need for a data base on Young's modulus and Poisson's ratio sufficient to determine its mean value. The detailed needs are specified in section 4.2.4.10.

To reduce the time and cost of analyses linearly elastic methods are used. This is done even though 2020 graphite exhibits nonlinear stress strain behavior over the full range between compressive and tensile failure. This is justified because the design allowable stresses are significantly less than the failure stress and, over the range of allowable stresses, the graphite stress-strain behavior is relatively linear. However, the use of such methods has not been verified for graphite and leads to the assumption: 
e): The use of simplified linear elastic stress analysis methods to show compliance with required stress limits is valid.

To validate this assumption requires strength data to confirm that the analytically predicted ultimate load capacity of the PSR is adequate. The detailed needs are specified in 4.2.4.22.

The evaluation of the PSR is done on the basis of the maximum stress failure theory which is a simplified approximation for failure of graphite in multiaxial stress states. The maximum stress failure theory states that failure will occur when one of the three principal stress components at a point in a body reaches either the uniaxial tensile strength or the uniaxial compressive strength. The use of this theory is permitted by the draft Subsection CE of the ASME code, but is known to be unconservative for graphite. The degree of nonconservatism needs to be quantified so that an adequate safety margin can be ensured. The use of this theory is based upon the assumption:

f): The maximum stress failure theory is a reasonable approximation for 2020 graphite under a multiaxial state of stress.

The technology need related to this assumption is to generate data to bound inaccuarcies associated with the maximum stress failure theory. The detailed needs are specified in 4.2.4.4.

Because of inherent variability in the graphite due to small variations in the raw material and in the production process, product control is needed during the procurement to ensure that the production graphite has the same characteristics as the graphite used to establish the data base and that the strength requirements have been met. Nondestructive testing techniques developed by ORNL satisfy this need, but the data base as of yet is too sparse to validate these techniques for use in product control of mass produced graphite. For the designer to assure that the design is structurally adequate for these future materials a required assumption is: 
g): The production graphite will have the same properties as the design data base.

To validate this assumption NDE techniques must be established to be sufficiently accurate to insure satisfactory properties to the graphite used to make the PSR. The detailed needs are specified in 4.2.4.20.

Cyclic stresses in the PSR need to be evaluated to establish that they are within design allowables. The design allowable cyclic stresses are based on design fatigue curves determined by a statistical analyses of the data such that the specimen survival probability is $99 \%$ at a confidence level of $95 \%$. These curves need to be in the form of constant life diagrams (also referred to as modified Goodman diagrams). Values for the curve are given for 2020 graphite in the Graphite Design Data Manual for survival to $10^{5}$ cycles under uniaxial cyclic loading in air at ambient temperature. Additional data are needed to verify that these design values are valid for the HTGR service condition. It is being assumed that:

h): The cycle fatigue endurance limits for 2020 graphite specified in the Graphite Design Data Manual are valid.

The technology need related to this assumption is for a statistical data base such that the cyclic fatigue limits can be established with sufficient accuracy. The detailed needs are specified in 4.2.4.6.

Subsection $C E$ of the code specifies that accumulated fatigue damage shall be evaluated using Miner's rule. This rule specifies that structural damage is a linear function of the number of cycles to failure and that the total fraction of available life is the summation of damage fractions for different amplitudes of accummulated stress cycles. It is also expected that incipient failure will occur when the sum of all the damage fractions is 1 (or 100\%). Miner's rule is the most widely used method for evaluating the cumulative effects of fatigue in metals. The attractiveness of this method is that it is 
simple to use, fits in with the maximum stress failure theory, and data may be obtained from simple axially loaded push-pull tests on specimens. However, the applicability of Miner's rule has not yet been validated for 2020 graphite. This leads to the assumption:

i): Miner's rule for estimating the cumulative fatigue is applicable to 2020 graphite.

The validation of this assumption requires a data base including fatigue life as a function of stress amplitude for both constant amplitude load cycles and sequential series of cycles with different amplitudes. The detailed needs are discussed in Section 4.2.4.8.

The effects of radiation (Req. 6) on the design properties must be accounted for in the design evaluation. Under irradiation, the minimum ultimate tensile strength increases as does the modulus. However, these effects are expected to be small which leads to the assumption:

j): The effects of radiation on 2020 graphite mechanical properties are negligible.

The technology need related to this assumption is for data sufficient to show to a high confidence that the effects of design irradiation levels on selected mechanical properties are negligible. The detailed needs are specified in Section 4.2.4.12.

Under irradiation, the conductivity typically decreases which leads to larger differential temperatures and consequently larger thermal stresses. These effects are expected to be minimal and lead to the assumption:

k): The effects of radiation on 2020 graphite thermal properties are negligible. 
The technology need related to this assumption is for data sufficient to show to a high confidence the effects of design irradiation levels on the mean value of selected thermal properties. The detailed needs are specified in Section $4 \cdot 2 \cdot 4 \cdot 16$.

The high temperature primary coolant may contain water vapor and other trace impurities such as carbon monoxide and carbon dioxide as given by Req. 6. Meeting Req. 6 involves evaluation of the effects of corrosion, from water vapor and other oxidants in the coolant, on the components ability to satisfy its design functions.

There are two kinds of steam-corrosion of concern. The first is a localized corrosion caused by clumping of catalysts, usually metals, within the graphite often called "worm-holing." This type of corrosion is not acceptable for the PSR and is prevented by the removal or dispersal of catalytic impurities in the core support graphite. The second type of corrosion is a more homogenous one and is proportional to the macroscopic water concentration in the pores of the graphite. This is the type dealt with in the design. Both kinds of corrosion remove carbon atoms from the graphite thus lowering the density. This reduction is often referred to as "burnoff" and is usually expressed as a percentage reduction in density or weight. Associated with this burnoff is a reduction in strength and stiffness of the component. The time it takes to obtain a given level of burnoff is dependent on the steam graphite reaction rate which is highly dependent on the concentration of moisture in the primary coolant, and the graphite temperature. The steam-graphite reaction rates of core support graphite are high enough to generally result in surface burnoff. The amount of burnoff anticipated is then calculated and allowed for in the design. This leads to the assumption:

1): Graphite corrosion is limited to a maximum depth of [2] $\mathrm{mm}$.

The technology need related to this assumption is for sufficient data to confirm with a high confidence that any significant corrosion of the graphite 
core support components is limited to a maximum depth of [2] $\mathrm{mm}$ below the exposed surface. The detailed needs are specified in Section 4.2.4.18.

\subsubsection{Technology Development Requirements}

This section gives detailed statements of the data needs introduced in the discussion of the design requirements and the assumptions in section 4.2.3. The term "specified minimum ultimate strength $\left(\mathrm{S}_{u}\right)$ " used in this Section means the minimum strength as established from statistical treatment of ultimate strength data such that the survival probability is $99 \%$ at a confidence level of $95 \%$. This is the definition used in the ASME Code Section III, Division 2, Subsection CE, "Design Requirements for Graphite Core Supports," draft, April 1984.

This section is divided into 22 subsections. Subsections 4.2.4.1 through 4.2.4.20 pertain to graphite material development and characterization. including mechanical, thermal, and chemical characteristics, while Subsections 4.2.4.21 and 4.2.4.22 pertain to component testing for structural/mechanical design purposes. (The needs specified in each of these subsections are summarized in Section 1.3 of the corresponding DDN (DDNs M.10.17.01 through M.10.18.22, which are included in Appendix A). Table 4.5 at the end of Section 4.2 .4 shows the correspondence between the DDNs and the subsections. For completeness, the functions and assumptions are also included in Table 4.5.)

All experimental work necessary for satisfying the technology development requirements must comply with the Quality Assurance criteria of 10CFR50, Appendix B.

The reference material for the core support components is SC-2020 graphite in two cylindrical billet sizes:

1. [7] in. diameter $x$ [48] in. length for core support posts. 
2. [17] in. diameter $x$ [48] in. length for core support blocks and lower plenum floor blocks.

An alternative is to use only the larger size (17 in. diameter) and machine several posts from each biliet; however, for the purposes of this Graphite Technology Program Plan it will be assumed that the two billet sizes will be used.

The reference material for the permanent side reflector is also SC-2020 graphite but of rectangular billet size [20.5] in. square $x$ [39] in. length.

The required minimum values of $\mathrm{S}_{\mathrm{u}}$ are:

$\begin{array}{lll} & \text { Tension } & \text { Compression } \\ \text { Core Support Graphite } & {[2400] \text { psi }} & {[3000] \text { psi }} \\ \text { Permanent Reflector Graphite } & {[1950] \text { psi }} & {[2400] \text { psi }}\end{array}$

The service conditions for the reactor internal components are listed below. These conditions apply to all the Subsections 4.2.4.1 through 4.2.4.23, except where otherwise stated.

1. Graphite Temperatures

Power Production:

Core support blocks: $[300]^{\circ} \mathrm{C}$ to $[800]^{\circ} \mathrm{C}$

Core support posts: $[300]^{\circ} \mathrm{C}$ to $[800]^{\circ} \mathrm{C}$

Permanent side reflector: $[300]^{\circ} \mathrm{C}$ to $[500]^{\circ} \mathrm{C}$

Shutdown: $120^{\circ} \mathrm{C}$

Loss of forced circulation: $[900]^{\circ} \mathrm{C}$ maximum

2. Fast Fluence

Maximum fast fluence ( $\mathrm{E}>29 \mathrm{fJ}, \mathrm{HTGR}$ ):

Core support blocks: $\left[\begin{array}{lll}1 & x & 10^{20}\end{array}\right] \mathrm{n} / \mathrm{cm}^{2}$

Core support posts: $\left[\begin{array}{lll}1 & x & 10^{19}\end{array}\right] \mathrm{n} / \mathrm{cm}^{2}$

Permanent side reflector: $\left[2 \times 10^{20}\right] \mathrm{n} / \mathrm{cm}^{2}$ 
3. Primary Coolant Conditions

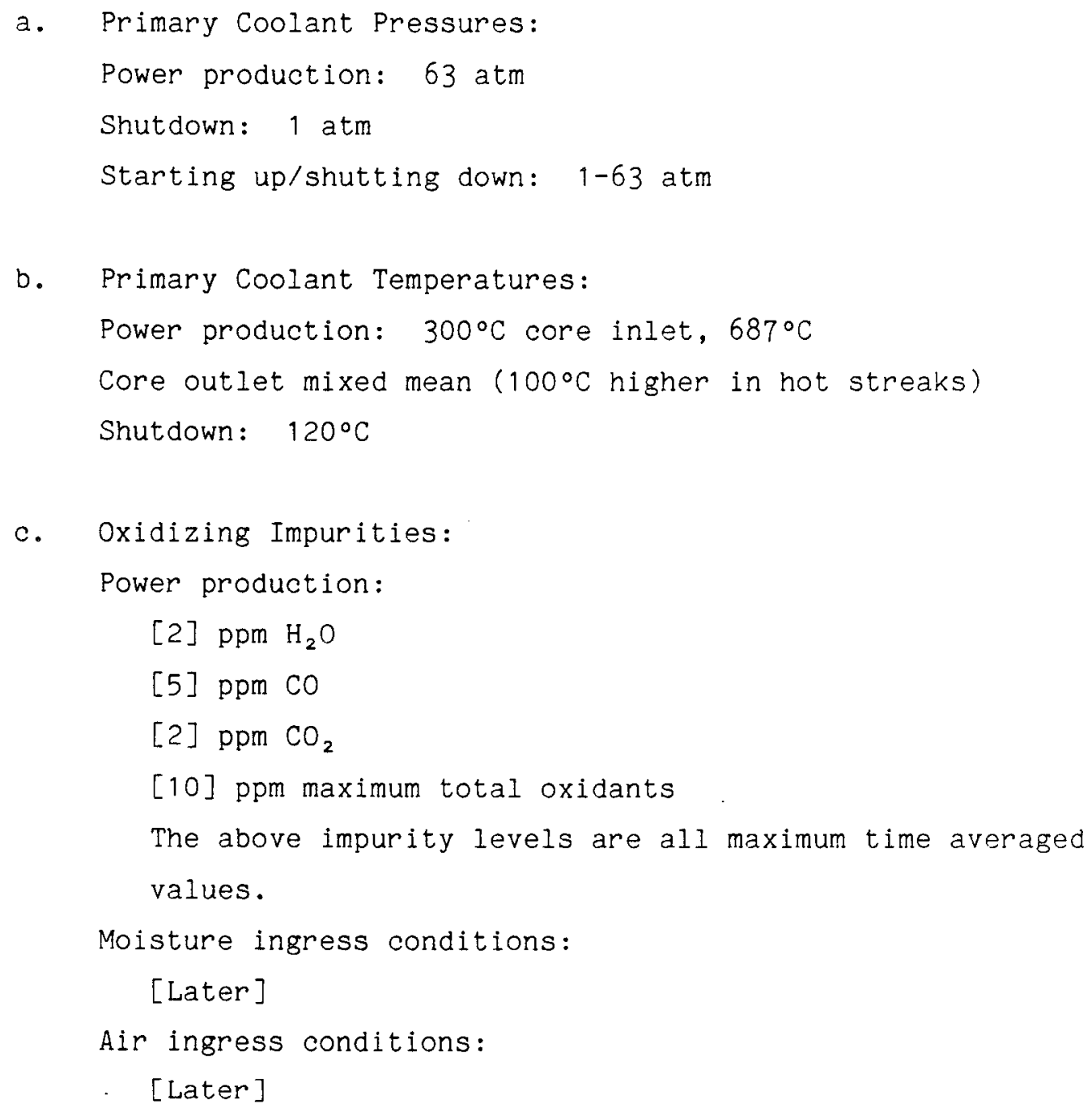

4.2.4.1 Uniaxial Strength Data Base for Core Support Graphite. The data specified below are needed to validate assumption a):

a): Grade 2020 graphite can be manufactured in the size needed for the core support structure with a minimum ultimate strengths of [2400] psi in tension and [3000] psi in compression.

Sufficient uniaxial strength data are required to determine the specified minimum ultimate strength $\left(S_{u}\right)$ to the ASME Code Subsection CE statistical requirements. The minimum values of $S_{u}$ required for core support graphite are 
[2400] and [3000] psi for tensile and compressive strength, respectively. The current reference material for the core support components is SC-2020 graphite. The sizes of the logs are given at the beginning of section 4.2 .4 .

The full statistical data base is needed for unirradiated graphite at room temperature in a normal atmospheric environment. $\mathrm{S}_{\mathrm{u}}$ derived from this data base shall include spatial and orientational variabilities and variabilities from billet to billet and lot to lot.

Expected small increases of strength due to the pressurized helium environment and due to the temperature varying within the operating temperature range need to be confirmed by additional data. The temperature and pressure conditions are given at the beginning of section 4.2.4. (The structural effects due to oxidation and fast neutron fluence are covered in Sections 4.2 .4 .17 and 4.2 .4 .11 , respectively.)

4.2.4.2 Uniaxial Strength Data Base for Permanent Reflector Graphite. The data specified below are needed to validate Assumption $n$ ):

n): Grade 2020 graphite can be manufactured in the size needed for the permanent side reflector with a minimum ultimate strength of [1950] psi in tension and [2400] psi in compression.

Sufficient uniaxial strength data are required to determine the specified minimum ultimate strength $\left(S_{U}\right)$ to the ASME Code Subsection CE statistical requirements. The minimum values of $S_{u}$ required for permanent reflector graphite are [1,950 psi] and [2400 psi] for tensile and compressive strength, respectively. The current reference material for the permanent reflector blocks is SC-2020 graphite. The size of the $\log$ is given at the beginning of Section 4.2.4.

The full statistical data base is needed for unirradiated graphite at room temperature in a normal atmopsheric environment. $\mathrm{S}_{\mathrm{u}}$ derived from this 
data base shall include spatial and orientational variabilities and variabilities from billet to billet and lot to lot.

Expected small increases of strength due to the pressurized helium environment and due to the temperature varying within the operating temperature range need to be confirmed by additional data. The temperature and pressure conditions are given at the beginning of section 4.2.4. (The structural effects due to oxidation and fast neutron fluence are considered in Sections 4.2 .4 .18 and 4.2 .4 .12 , respectively.)

4.2.4.3 Multiaxial Strength of Graphite for Core Support. The graphite core support components are designed on the basis of the maximum stress failure theory in accordance with Assumption $\mathrm{f}$ ).

f): The maximum stress failure theory is a reasonable approximation for 2020 graphite under a multiaxial state of stress.

This theory is known to result in unconservative predictions for the failure of graphite, but is nevertheless permitted by the code, since the safety factors are sufficiently high to give an adequate margin against failure. To ensure the safety margin; inaccuracy in the maximum stress failure theory must be bounded. Accordingly, the failure surfaces for biaxial and triaxial stress conditions are needed, biaxially for tension-tension and tension-compression and triaxially for tension-tension-tension, tensiontension-compression, and tension-compression-compression. For all combinations involving compression, the failure surface is not needed for compressive stresses beyond the uniaxial tensile strength. The specific needs are:

A) Biaxial Stress Field

A mean value failure surface in the form of a smooth, continuous curve as shown in Fig. 4.11 is assumed. The curve passes through the points representing the uniaxial strengths, as shown, and also 
through the points $A$ and $B$ in Fig. 4.11. Data are needed to show with [95\%] confidence that the distances $a$ and $b$ in Fig. 4.11 are at most $[15] \%$ and [5]\%, respectively, of the uniaxial tensile strength.

B) Triaxial Stress Field

For a triaxial stress field, the curve in Fig. 4.11 is assumed to extend to a smooth continuous surface passing through the points of uniaxial strength. In each octant there is a point corresponding to points $A$ or $B$, except extended to three dimensions. The data base must show with [95\%] confidence that the relative distance to these points measured from the plane through the uniaxial strength is at most :

$[20] \%$ in the first octant (al] tension)

$[15] \%$ in the second, fourth, and fifth octants (tension-tension-compression)

$[5] \%$ in the third, sixth, and eighth octants (tension-compression-compression)

The above data base is needed for unirradiated graphite at room temperature in a normal atmospheric environment and must be applicable to the billet sizes used for the core support components. Additionally, a small number of data points are needed to determine the effects of the service conditions on the multiaxial failure strength. The service conditions are specified at the beginning of Section 4.2 .4 .

4.2.4.4 Multiaxial Strength of Graphite for Permanent Reflector. The permanent reflector components are designed on the basis of the maximum stress failure theory in accordance with Assumption f). 
f): The maximum stress failure theory is a reasonable approximation for 2020 graphite under a multiaxial state of stress.

This theory is known to result in unconservative predictions for the failure of graphite. To ensure an adequate safety factor, the inaccuracy in the maximum stress failure theory must be bounded. Accordingly, the failure surfaces for biaxial and triaxial stress conditions are needed, biaxially for tension-tension and tension-compression and triaxially for tension-tensiontension, tension-tension-compression, and tension-compression-compression. For all combinations involving compression, the failure surface is not needed for compressive stresses beyond the uniaxial tensile strength. The specific needs are:

A) Biaxial Stress Field

A mean value failure surface in the form of a smooth, continuous curve as shown in Fig. 4.11 is assumed. The curve passes through the points representing the uniaxial strengths, as shown, and also through the points $A$ and $B$ in Fig. 4.11. Data are needed to show with [95\%] confidence that the distances $a$ and $b$ in Fig. 4.11 are at most $[15] \%$ and $[5] \%$, respectively, of the uniaxial tensile strength.

B) Triaxial Stress Field

For a triaxial stress field, the curve in Fig. 4.11 is assumed to extend to a smooth continuous surface passing through the points of uniaxial strength. In each octant there is a point corresponding to points $A$ or $B$, except extended to three dimensions. The data base must show with [95\%] confidence that the relative distance to these points measured from the plane through the uniaxial strength is at most : 
$[20] \%$ in the first octant (all tension)

$[15] \%$ in the second, fourth, and fifth octants

(tension-tension-compression)

[5]\% in the third, sixth, and eighth octants

(tension-compression-compression)

The above data base is needed for unirradiated graphite at room temperature in a normal atmospheric environment and must be applicable to the billet size used for the permanent reflector components. Additionally, a small number of data points are needed to determine the effects of the service conditions on the multiaxial failure strength. The service conditions are specified at the beginning of Section 4.2 .4 .

\subsubsection{Fatigue Strength of Graphite for Core Support Components. The data} specified below are needed to validate Assumption $h$ ).

h): The cyclic fatigue endurance limits for 2020 graphite specified in the Graphite Design Data Manual are valid.

A fatigue strength data base sufficient to construct a Design Fatigue Diagram for the core support graphite is needed. The Design Fatigue Diagram is defined in the draft of Subsection CE of the ASME Code Section III, Division 2. The data base must be sufficient to establish a [95]\% confidence that the sample mean of the data base does not differ from the corresponding mean values of the population by more than [10]\%.

The data base must include:

1. Up to $10^{5}$ cycles.

2. Stress ratio, $R$ (ratio between the minimum and maximum stresses during a cycle) ranging from $[-1]$ to $[+1]$. 
3. Dependence on orientation and location in billet and on variation from billet to billet.

The data base must be valid for the different billet sizes used for the core support components. The billet sizes are given at the beginning of Section 4.2.4.

In addition to the data base necessary for constructing the Design Fatigue Diagram, a limited number of data points are needed to establish the effects of the operating environment. The service conditions are given at the beginning of section 4.2 .4 .

4.2.4.6 Fatigue Strength of Graphite for Permanent Reflector Components. The data specified below are needed to validate Assumption $h$ ) (see 4.2.4.5). A fatigue strength data base sufficient to construct a Design Fatigue Diagram for the permanent side reflector graphite is needed. The Design Fatigue Diagram is defined in the draft of Subsection CE of the ASME Code Section III, Division 2. The data base must be sufficient to establish a [95]\% confidence that the sample mean of the data base does not differ from the corresponding mean values of the population by more than $[10] \%$.

The data base must include,

1. Up to $10^{5}$ cycles

2. Stress ratio, $\mathrm{R}$ (ratio between the minimum and maximum stresses during a cycle) ranging from $[-1]$ to $[+1]$

3. Dependence on orientation and location in billet and on variation from billet to billet.

The data base must be valid for the billet size used for the permanent reflector blocks. The billet size is given in the beginning of section 4.2.4. 
In addition to the data base necessary for constructing the Design Fatigue Diagram, a limited number of data points are needed to establish the effects of the operating environment (specified at the beginning of Section 4.2 .4 .

4.2.4.7 Miner's Law for Graphite for Core Support Components. The fatigue analysis of the graphite core support components is done on the basis of Miner's Rule in accordance with Assumption i).

i): Miner's rule for estimating the cumulative fatigue is applicable to 2020 graphite.

To validate the applicability of Miner's Rule, data are needed on the cumulative fatigue strength of core support graphite subjected to sequential series of stress cycles with different amplitudes. The number of cases (i.e., combinations of stress amplitudes) shall be selected such that a valid comparison can be made between the measured cumulative fatigue life and the cumulative fatigue life predicted by applying Miner's rule to the constant amplitude fatigue data established in Subsection 4.2.4.5. The comparison must be valid for the range up to $10^{5}$ cycles.

A sufficient data base is needed to determine the difference between the mean value of the constant amplitude fatigue life (i.e., number of cycles to failure) and the mean value of the varying amplitude fatigue life with [95]\% confidence.

The data base must be valid for the two different billet sizes used for the core support components (see the beginning of Section 4.2.4).

\subsubsection{Miner's Law for Graphite for Permanent Reflector Components. The} fatigue analysis of the permanent reflector components is done on the basis of Miner's rule in accordance with Assumption i) (see 4.2.4.7). To validate the applicability of Miner's Rule, data are needed on the cumulative fatigue 
strength of permanent reflector graphite subjected to sequential series of stress cycles with different amplitudes. The number of cases (i.e., combinations of stress amplitudes) shall be selected such that a valid comparison can be made between the measured cumulative fatigue life and the cumulative fatigue life predicted by applying Miner's rule to the constant amplitude fatigue data established in Subsection 4.2.4.6. The comparison must be valid for the range up to $10^{5}$ cycle.

A sufficient data base is needed to determine the difference between the mean value of the constant amplitude fatigue life (i.e., number of cycles to failure) and the mean value of the varying amplitude fatigue life with [95]\% confidence.

The data base must be valid for the billet size used for the permanent reflector components (see the beginning of Section 4.2.4).

4.2.4.9 Elastic Properties Data Base for Core Support Graphite. The data specified below are needed to validate Assumption d).

d): The mean values for the elastic properties of Young's modulus and Poisson's ratio given in the Graphite Design Data Manual for 2020 graphite are valid.

A Young's modulus and Poisson's ratio data base is needed for the graphite grade SC-2020 used for the core support components. Young's modulus is obtained from the stress-strain curve as defined in subsection CE of the ASME Code, Section III.

The data base shall include data on spatial and orientational variabilities as well as variabilities from billet to billet and lot to lot.

The data base must be valid for the two billet sizes used for the core support components and must be sufficient to establish with [95]\% confidence 
that the sample mean differs from the mean value of the population by at most $\pm[10] \%$ for Young's modulus and $\pm[25] \%$ for Poisson's ratio.

The statistical data base is needed for unirradiated graphite at room temperature in a normal atmospheric environment. Some additional data points are needed to confirm the expected small changes in the properties due to the operating temperatures and due to the pressurized helium environment (note that irradiation effects are covered in subsection 4.2.4.11 and corrosion effects in Subsection 4.2.4.17).

The environment in which the core support structure operates and the billet sizes needed for the graphite core support components are given in the beginning of section 4.2 .4 .

4.2.4.10 Elastic Properties Data Base for Permanent Reflector Graphite. The data specified below are needed to validate Assumption d) (see 4.2.4.9). A Young's modulus and Poisson's ratio data base is needed for the permanent reflector graphite. Young's modulus is obtained from the stress-strain curve as defined in Subsection CE of the ASME Code, Section III.

The data base shall include data on spatial and orientational variabilities as well as variabilities from billet to billet and lot to lot.

The data base must be valid for the billet size used for the permanent reflector components and must be sufficient to establish with [95]\% confidence that the sample mean differs from the mean value of the population by at most $\pm[10] \%$ for Young's modulus and $\pm[25] \%$ for Poisson's ratio.

The statistical data base is needed for unirradiated graphite at room temperature in a normal atmospheric environment. Some additional data points are needed to confirm the expected small changes in the properties due to the operating temperatures and due to the pressurized helium environment (note that irradiation effects are covered in Subsection 4.2.4.12 and corrosion effects in Subsection 4.2.4.18). 
The environment in which the permanent reflector operates and the billet size needed for the permanent reflector blocks are given in the beginning of Section 4.2.4.

\subsubsection{Irradiation Effects on Mechanical Properties of Core Support}

Graphite. The data specified below are needed to validate Assumption $j$ ).

$j)$ : The effects of radiation on 2020 graphite mechanical properties are negligible.

Data are needed to establish the effect of low levels of fast fluence on Young's modulus, Poisson's ratio, and the strength of the core support graphite. The data base must be sufficient to establish a [95]\% confidence that the effects of irradiation are to (1) increase the specified minimum ultimate strength (see Section 4.2.4.1) and (2) change the mean value of Young's modulus by less than $[10] \%$ and the mean value of Poisson's ratio by less than [25]\% (see Section 4.2.4.9). The required data base must be valid for the two different billet sizes used for the core support components.

To the extent the effects of irradiation are not as assumed as above, the data base must be sufficient to: (1) determine any decrease in the minimum strength with [95]\% confidence, and (2) determine the changes in the mean values of Young' modulus and Poisson's ratio within $\pm[5] \%$ and $\pm[20] \%$, respectively, also with $[95] \%$ confidence.

The data base for the low level irradiation effects must be valid for an irradiation temperature range of $[600]^{\circ} \mathrm{C}$ to $[800]^{\circ} \mathrm{C}$ in combination with a fluence range from zero to the maximum fluences given at the beginning of Section 4.2.4. The data base must also include the effects of the range of service temperatures and helium pressures on the irradiated material.

4.2.4.12 Irradiation Effects on Mechanical Properties of Permanent Reflector Graphite. The data specified below are needed to validate Assumption $j$ ). 
$j)$ : The effects of radiation on 2020 graphite thermal properties are negligible.

Data are needed to establish the effect of low levels of fast fluence on Young's modulus, Poisson's ratio, and the strength of the permanent reflector graphite. The data base must be sufficient to establish a [95]\% confidence that the effects of irradiation are to (1) increase the specified minimum ultimate strength (see Section 4.2.4.1) and (2) change the mean value of Young's modulus by less than [10]\% and the mean value of Poisson's ratio by less than [25]\% (see section 4.2.4.9). The required data base must be valid for the billet size used for the permanent reflector blocks.

To the extent the effects of irradiation are not as assumed as above, the data base must be sufficient to: (1) determine any decrease in the minimum strength with [95]\% confidence, and (2) determine the changes in the mean values of Young' modulus and Poisson's ratio within $\pm[5] \%$ and $\pm[20] \%$, respectively, also with $[95] \%$ confidence.

The data base for the low level irradiation effects must be valid for the following combination of irradiation temperatures and range of fluences:

$\begin{array}{cr}\text { Fast Fluence, } \mathrm{n} / \mathrm{cm}^{2} & \text { Irradiation Temperat } \\ 1 \times 10^{19} & {[260 \text { to } 425]} \\ 5 \times 10^{19} & {[280 \text { to } 475]} \\ {[2] \times 10^{20}} & {[300 \text { to } 425]}\end{array}$

The data base must also include the effects of the range of service temperatures and helium pressures on the irradiated material. (The service conditions are given at the beginning of Section 4.2.4.)

4.2.4.13 Thermal Properties of Core Support Graphite. The data specified below are needed to validate Assumptions $b$ ) and $c$ ). 
b): The mean values of thermal expansivity, thermal conductivity, and heat given in the Graphite Design Data Manual for 2020 graphite are valid.

c): The lower bound for the emissivity of 2020 graphite is 0.8 .

Data are needed on the thermal expansivity, thermal conductivity, emissivity, and specific heat of graphite for the core support components. The data base shall be sufficient to determine the mean values of the required properties within the following bounds with [95]\% confidence:

$$
\begin{array}{ll}
\text { Expansivity: } & \pm[5] \% \\
\text { Conductivity: } & \pm[5] \% \\
\text { Specific Heat: } & \pm[10] \%
\end{array}
$$

For emissivity, [95]\% confidence is required that the lower bound of the property is [0.80]. An estimate of the mean value is also needed.

The data base must be valid for the two different billet sizes used in the design of the graphite core support components (see the beginning of Section 4.2.4), and must include the dependence on orientation and location in the billet and the variation from billet to billet and lot to lot.

The data base must cover the range of service temperatures given at the beginning of section 4.2.4. Some data points are also needed to determine the effects of the pressurized helium environment and in the case of thermal conductivity, the effects of graphite corrosion.

4.2.4.14 Thermal Properties of Permanent Reflector Graphite. The data specified below are needed to validate Assumptions b) and c) (see 4.2.4.13). Data are needed on the thermal expansivity, thermal conductivity, emissivity, and specific heat of graphite for the permanent reflector blocks. The data base shall be sufficient to determine the mean values of the required properties within the following bounds with [95]\% confidence: 


$$
\begin{array}{ll}
\text { Expansivity: } & \pm[5] \% \\
\text { Conductivity: } & \pm[5] \% \\
\text { Specific Heat: } & \pm[10] \%
\end{array}
$$

For emissivity, [95]\% confidence is required that the lower bound of the property is $[0.80]$. An estimate of the mean value is also needed.

The data base must be valid for the billet size used in the design of the permanent reflector components (see the beginning of Section 4.2.4), and must include the dependence on orientation and location in the billet and the variation from billet to billet and lot to lot.

The data base must cover the range of service temperatures given at the beginning of Section 4.2.4. Some data points are also needed to determine the effects of the pressurized helium environment and in the case of thermal conductivity, the effects of graphite corrosion.

4.2.4.15 Irradiation Effects on Thermal Properties of Core Support Graphite. The data specified below are needed to validate Assumption $k$ ).

k): The effect of radiation on 2020 graphite thermal properties are negligible.

Data are needed to confirm the effects of low levels of fast fluence on the thermal expansivity, thermal conductivity, and specific heat of the core support graphite. In the cases of expansivity and specific heat, only small effects are expected. For these properties the data base must be sufficient to establish a [95]\% confidence that the irradiation does not change the mean values by more than $[10] \%$. In the case of conductivity the change to the mean value is expected to be larger; for this property, the change must be determined within $\pm[5] \%$ with $[95] \%$ confidence. The required data base must be valid for the two different billet sizes used in the design of the core support components (see the beginning of section 4.2.4). 
Confirmation of the low level irradiation effects must cover an irradiation temperature range of $[600]^{\circ} \mathrm{C}$ to $[800]^{\circ} \mathrm{C}$ in combination with a range from zero to the maximum fluences given at the beginning of Section 4.2.4. The data base must also include the effects of the range of service temperatures and helium pressures on the irradiated material.

\subsubsection{Irradiation Effects on Thermal Properties of Permanent Reflector} Graphite. The data specified below are needed to validate Assumption $k$ ) (see 4.2.4.15) for the permanent reflector graphite.

Data are needed to confirm the effects of low levels of fast fluence on the thermal expansivity, thermal conductivity, and specific heat of the permanent reflector graphite. In the cases of expansivity and specific heat, only small effects are expected. For these properties, the data base must be sufficient to establish a [95]\% confidence that the irradiation does not change the mean values by more than [10]\%. In the case of conductivity, the change of the mean. value is expected to be larger; for this property, the change must be determined within $\pm[5] \%$ with $[95] \%$ confidence. The required data base must be valid for the billet size used in the design of the permanent reflector blocks (see the beginning of section 4.2.4).

Confirmation of the low level irradiation effects must cover the following combinations of irradiation temperature and fast fluences:

$\begin{array}{cc}\text { Fast Fluence, } \mathrm{n} / \mathrm{cm}^{2} & \text { Irradiation Temperature, }{ }^{\circ} \mathrm{C} \\ 1 \times 10^{19} & {[260-425]} \\ 5 \times 10^{19} & {[280-475]} \\ {[2] \times 10^{20}} & {[300-425]}\end{array}$

The data base must also include the effects of the range of service temperatures and helium pressures on the irradiated material.

4.2.4.17 Corrosion Characteristics of Core Support Graphite. The data specified below are needed to validate Assumption 1). 
1): Graphite corrosion is Iimited to a maximum depth of [2] $\mathrm{mm}$.

Data are needed to confirm with [95]\% confidence that any significant corrosion of the graphite core support components is limited to a maximum depth of [2] $\mathrm{mm}$ below the exposed surface. (Significant corrosion is defined as a reduction in strength by more than [10]\%.) The confirmation must include the effects of the operating environment, both for normal operation and for the specified moisture ingress conditions, and must be valid for the actual graphite components of the core support structure (see the beginning of Section 4.2 .4 for the service conditions). To the extent these effects are significant, catalysis by graphite impurities and by fission metals must be included.

4.2.4.18 Corrosion Characteristics of Permanent Reflector Graphite. To validate Assumption 1 ), data are needed to confirm with [95]\% confidence that any significant corrosion of the permanent reflector components is limited to a maximum depth of [2] $\mathrm{mm}$ below the exposed surface. (Significant corrosion is defined as a reduction in strength by more than [10]\%.) The confirmation must include the effects of the operating environment, both for normal operation and for the specified moisture ingress conditions, and must be valid for the actual permanent reflector blocks (see the beginning of section 4.2.4 for the service conditions). To the extent these effects are significant, catalysis by graphite impurities and by fission metals must be included.

4.2.4.19 Confirm Large Size Graphite for Permanent Reflector. The process described below is needed to validate Assumption $m$ ).

m): Large grade 2020 graphite blocks are available.

The process for producing graphite grade 2020 in the billet size specified at the beginning of Section 4.2 .4 is needed, so that the ability to supply permanent reflector block in sufficient quantities and with consistent properties can be ensured. The process must be such that all the billets 
produced have the required minimum ultimate strength (see Section 4.2.4.2). If grade 2020 in the large billet size does not have the required properties, an alternative material must be developed.

4.2.4.20 NDE Data for Reactor Internals Graphite Specifications. The data specified below are needed to validate Assumption $g$ ).

g): The production graphite will have the same properties as the design data base.

Data is needed to validate NDE techniques and write material control specifications for the procurement of graphite for reactor internal structures. The NDE techniques must be sufficiently accurate to (1) detect flaws $>$ [2] $\mathrm{mm}$ in the billets used for the reactor internals components, and (2) determine the tensile strength of smaller specimens with an error no greater than $[10] \%$ with $[95] \%$ confidence.

4.2.4.21 Confirm Strength of Graphite Core Support. The data specified below are needed to validate Assumption e).

e): The use of simplified linear elastic stress analysis methods to show compliance with required limits is valid.

Room temperature strength data are required to confirm that the analytically predicted ultimate load capacity of the graphite core support structure under vertical loads is adequate. The design to be confirmed will be that selected and shown to meet the required stress limits by analysis during conceptual and preliminary design. Data are also required on the load at which initial cracking occurs, if different from the ultimate load.

\subsubsection{Confirm Lateral Strength of Permanent Side Reflector. The data} specified below are needed to validate Assumption e) (see 4.2.4.21) for the permanent side reflector. Room temperature strength data are required to confirm that the analytically predicted ultimate shear load capacity of the 
graphite keyway in the PSR under lateral shear loads is adequate. The design to be confirmed will be that selected and shown to meet the required stress limits by analysis during conceptual and preliminary design.

The functions and assumptions and the resulting technology needs for the permanent graphite components are summarized in Table 4.5. The technology needs are stated in the table in terms of the corresponding Design Data Needs or DDNs and the associated subsection of section 4.2.4.

\subsubsection{Required Schedule}

Figure 4.17 shows the required technology development schedule for the reactor internals components. The figure gives the detailed schedules for the preliminary and the final data base as needed for the preliminary and the final design phases, respectively. The schedule requirements for the final data base are summarized in the respective Section 4 of DDN M.10.17.01 through DDN M.10.18.24 (included in Appendix A). 
TABLE 4.5

PC-000213/1

\section{FUNCTIONS/ASSUMPTIONS RESULTING \\ IN TECHNOLOGY NEEDS \\ FOR PERMANENT COMPONENTS}

Function

F1.1.2.1.2.2.2.2.2.2

Maintain Integrity of Graphite Core Support

F1.1.1.1.2.2.1.3.2

Maintain Integrity of Side Reflectors

F1.1.2.1.2.2.2.2.2.2

Maintain Integrity of Graphite Core Support

F1.1.1.1.2.2.1.3.2

Maintain Integrity of of Side Reflector
Assumption

a) Grade 2020 graphite can be manufactured in the size needed for the core support structure with minimum ultimate strengths of [2400] psi in tension and [3000] psi in compression.

n) Grade 2020 graphite can be manufactured in the size needed for the permanent reflector components with minimum ultimate strengths of [1950] psi in tension and [2400] psi in compression.

f) The maximun stress failure theory is a reasonable approximation for 2020 graphite under a multiaxial state of stress.

f) The maximun stress failure theory is a reasonable approximation for 2020 graphite under a multiaxial state of stress.
DDN No. DDN Title

Section No.

M.10.17.01

4.4.4.1

Uniaxial Strength Data Base For Core Support Graphite

M.10.17.02

4.2.4.2

M.10.17.03

M.10.17.04

4.2.4.4
Uniaxial Strength Data Base For Permanent Reflector Graphite

Multiaxial Strength of Graphite For Core Support

Multiaxial Strength of Graphite For Permanent Reflector 
Function

F1.1.2.1.2.2.2.2.2.2

Maintain Integrity of Graphite Core Support

F1.1.1.1.2.2.1.3.2 Maintain Integrity of of Side Reflector

F1.1.2.1.2.2.2.2.2.2

Maintain Integrity of Graphite Core Support

\section{F1.1.1.1.2.2.1.3.2 \\ Maintain Integrity of Side Reflector}

F1.1.2.1.2.2.2.2.2.2 Maintain Integrity of Graphite Core Support

F1.1.1.1.2.2.1.3.2 Maintain Integrity of Side Reflector
Assumption

h) The cycle fatigue endurance limits for 2020 graphite specified in the Graphite Design Data Manual are valid.

h) The cycle fatigue endurance limits for 2020 graphite specified in the Graphite Design Data Manual are valid.

i) Miner's rule for estimating the cumulative fatigue is applicable to 2020 graphite.

i) Miner's rule for estimating the cumulative fatigue is applicable to 2020 graphite.

d) The mean values for the elastic properties of Young's modulus and Poisson's ratio given in the Graphite Design Data Manual for 2020 graphite are valid.

d) The mean values for the elastic properties of Young's modulus and Poisson's ratio given in the Graphite Design Data Manual for 2020 graphite are valid.
DDN No. DDN Title

Section No.

M.10.17.05

4.2.4.5

M.10.17.06

4.2.4.6

M.10.17.07

4.2.4.7

Miner's Law for Graphite For Core Support Components

M.10.17.08

4.2.4.8

M.10.17.09

M.10.17.10

Elastic Properties Data Base For Permanent Reflector Graphite 
Function

F1.1.2.1.2.2.2.2.2.2

Maintain Integrity of Graphite Core Support

F1.1.1.1.2.2.1.3.2

Maintain Integrity of Side Reflector

F1.1.2.1.2.2.2.2.2.2

Maintain Integrity of Graphite Core Support

F1.1.1.1.2.2.1.3.2

Maintain Integrity of Side Reflectors

F3.1.1.2.1.1.2.2.1.1.2 Conduct Heat Through Reflector
Assumption

j) The effects of radiation on 2020 graphite mechanical properties are negligible.

j) The effects of radiation on 2020 graphite mechanical properties are negligible.

b) The mean values of thermal expansivity, thermal conductivity, and specific heat given in the Graphite Design Data Manual for 2020 graphite are valid.

c) The lower bound for the emissivity of $\mathbf{2 0 2 0}$ graphite is $\mathbf{0 . 8}$.

b) The mean values of thermal expansivity, thermal conductivity, and specific heat given in the Graphite Design Data Manual for 2020 graphite are valid.

c) The lower bound for the emissivity of 2020 graphite is 0.8 .

b) The mean values of thermal expansivity, thermal conductivity, and specific heat given in the Graphite Design Data Manual for 2020 graphite are valid.

c) The lower bound for the emissivity of 2020 graphite is 0.8 .
DDN No.

Section No.

\section{M.10.17.11}

4.2.4.11

M.10.17.12

4.2.4.12

M.10.17.13

4.2.4:13

M.10.17.14

4.2.4.14

\section{DDN Title}

Irradiation Effects on Mechanical Properties of Core Support Graphite

Irradiation Effects on Mechanical Properties of Permanent Reflector Graphite

Thermal Properties of Core Support Graphite

Thermal Properties of Permanent Reflector Graphite 
Function

F1.1.2.1.2.2.2.2.2.2

Maintain Integrity of

Graphite Core Support

F1.1.1.1.2.2.1.3.2

Maintain Integrity of

Side Reflectors

F1.1.2.1.2.2.2.2.2.2

Maintain Integrity of

Graphite Core Support

F1.1.1.1.2.2.1.3.2

Maintain Integrity of

Side Reflectors

F1.1.2.1.2.1.2.2.1

Limit Flow in Horizontal

Gaps

F1.1.2.1.2.1.2.2.2

Limit Flow in Vertical

Gaps
Assumption

k) The effects of radiation on 2020 graphite thermal properties are negligible.

k) The effects of radiation on 2020 graphite thermal properties are negligible.

1) Graphite corrosion is limited to a maximum depth of [2] mm.

1) Graphite corrosion is limited to a maximum depth of [2] $\mathrm{mm}$.

m) Large grade 2020 graphite blocks are available.
M.10.17.17

4.2.4.17

DDN No.

Section No.

M.10.17.15

4.2.4.15

M.10.17.16

4.2.4.16

M.10.17.18

4.2.4.18

M.10.17.21

4.2.4.19
DDN Title

Irradiation Effects on Thermal Properties of Core Support Graphite

Irradiation Effects on Thermal Properties of Permanent Side Reflector Graphite

Corrosion Characteristics of Core Support Graphite

Corrosion Characteristics of Permanent Reflector Graphite

Confirm Large Size Graphite For Permanent Reflector 
Function

F1.1.2.1.2.2.2.2.2.2

Maintain Integrity of Graphite Core Support

F1.1.1.1.2.2.1.3.2

Maintain Integrity of Side Reflectors

F1.1.2.1.2.2.2.2.2.2

Maintain Integrity of Graphite Core Support

F1.1.1.1.2.2.1.3.2

Maintain Integrity of Side Reflector
Assumption

g) The production graphite will have the same properties as the design data base.

g) The production graphite will have the same properties as the design data base.

e) The use of simplified linear elastic stress analysis methods to show compliance with required stress limits can be validated.

e) The use of simplified linear elastic stress analysis methods to show compliance with required stress limits can be validated.
DDN No. DDN Title

Section No.

M.10.17.22

4.2.4.20

NDE Data For Reactor Internals Graphite Specifications

M.10.17.23

4.2.4.21

Confirm Strength of Graphite Core Support

M.10.17.24

Confirm Lateral Strength

4.2.4.22 of Permanent Reflector 


\section{YEARS AFTER THE START OF THE PRELIMINARY DESIGN PHASE}

DDN M.10.17.1 Uniaxial Strength of Core Support Graphite DDN M.10.17.2 Uniaxial Strength of Permanent Reflector Graphite

DDN M.10.17.3 Multiaxial Strength of Core Support Graphite

DDN M.10.17.4 Multiaxial Strength of Permanent Reflector Graphite

DDN M.10.17.5 Fatigue Strength of Core Support Graphite

DDN M.10.17.6 Fatigue Strength of Permanent Reflector Graphite

DDN M.10.17.7 Miner's Law for Core Support Graphite

DDN M.10.17.8 Miner's Law for Permanent Reflector Graphite

DDN M.10.17.9 Young's Modulus of Core Support Graphite

DDN M.10.17.10 Young's Modulus of Permanent Reflector Graphite

DDN M.10.17.11 Irradiation Effect on Mechanical Properties of C S Graphite DDN M.10.17.12 Irradiation Effect on Mechanical Properties of $\mathrm{P} R$ Graphite DDN M.10.17.13 Thermal Properties of Core Support Graphite

DDN M.10.17.14 Thermal Properties of Permanent Reflector Graphite

DDN M.10.17.15 Irradiation Effects on Thermal Properties of C S Graphite

DDN M.10.17.16 Irradiation Effects on Thermal Properties of $P$ R Graphite

DDN M.10.17.17 Corrosion Characteristics of C S Graphite

DUN M.10.17.18 Corrosion Characteristics of $P R$ Graphite

DDN M.10.17.19 Confirm Large Size Graphite for Permanent Reflector

DDN M.10.17.20 NDE Data for Material Specifications

DDN M.10.17.21 Confirm Strength of Core Support

DDN M.10.17.22 Confirm Lateral Strength of PSR

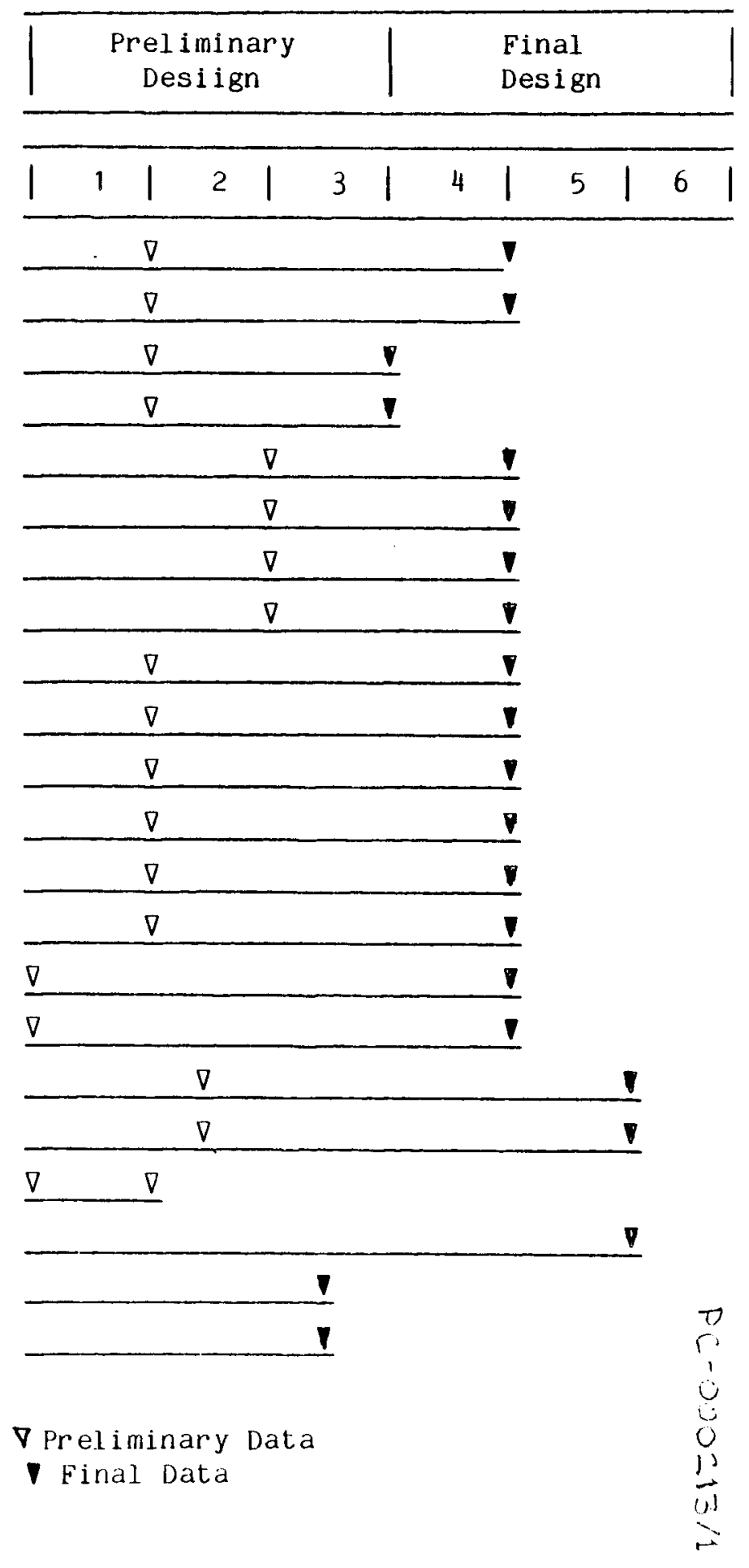




\section{TECHNOLOGY DEVELOPMENT PLAN}

\subsection{Introduction}

The base technology program evolves from the technical data needs described in Section 4.1 .4 (core components) and section 4.2 .4 (permanent reflector and core-support components) of Section 4. The design philosophy between the two sections is quite different in that a draft design code exists for the permanent core-support structures (ASME Code, Section III, Division 2, Subsection $\mathrm{CE}$ ), whereas the core components are being designed with the possibility of local material failure being an included statistical event. This distinction in design philosophies obviously carries over into the required data needs to be furnished by the Technology Development Program. We consider the general implications of these data requirements in the following Sections 5.01 ihrough 5.04 .

\subsection{Core Support and Permanent Reflector}

The ASME draft code specifies the design methodology in detail but is less definitive in the data requirements. In general, the data requiremenis may be characterized as a survival probability (tolerance limit) for failure criteria, and a mean-value definition for properties utilized in the constitutive equation, this latter not being numerically defined. The tolurance limits are specifically set as $99 \%$ survival with $95 \%$ confidence, with further safety factors applied depending on the type of service. The resulting data base requirements are described in section 5.1 following.

This development of the detailed data base requirements and their acquisition is the first real attempt to place the ASME Code into practical operation. Two types of deficiency in the code have become evident. The first is the lack of recognition by the code of the variability in graphite at ail levels of scale, viz., within a billet, from billet to billet, and from lot to lot. This is further compounded by the anisotropy of the graphite. The second deficiency in the code is deliberate and probably unavoidabie to a 
large degree, the data requirements arising from "environmental effects." These include the material damage due to neutron flux and steam corrosion.

In the development of the individual program elements making up Sections 5.1 , the sections describing the approach to the data acquisition have been preceded in many cases by one or more premises. These arise from either the interpretation of the Code when the Code is deficient or to an assumption on the expected form of the data which leads to a simplification and reduction in costs of the data base. If either type of premise proves incorrect, the program element will necessarily need revision.

The service conditions for the various permanent core components vary slightly depending on their site and function in the core. A general requirement is that the quality of the data be assured by conformance with 10CFR50, Appendix B. Specific data paramecers and service conditions are given in Table 5.1. The base technology program subelements have been designed to envelop the entire range of service conditions for each of the components, and the conditions of $\mathrm{T}$ able 5.1 have not been explicitiy reptated in the individual subsections under section 5.1 below.

\subsection{Core Components}

As noted above, the design of the core components is not governed by an extant code and furthermore must include fracture of the material as a statistically occurring event with finice probability. The statistical requirements imposed by Section 4 are directed entirely on bounding meanvalues on the basis of estimated sensitivities. At this stage of design, it is the only reasonable basis for which a statistical requirement can be laid down. However, we have anticipated in section 5.2 below that the various failure criteria must eventually be framed in terms of survival probabilities (tolerance limits) and have planned the program accordingly. This provides a particularly difficult situation in terms of fatigue life, which is explicitly addressed in the specific program sub-elements dealing with fatigue life and Miner's law. 
TABLE 5.1.

DATA PARAMETERS AND SERVICE CONDITIONS

FOR PERMANENT GRAPHITE COMPONENTS

\section{Tensile Compressive}

A. Specified minimum ultimate strength, psi:

Core support posts Core support blocks

[2400]

[2400]

$[3000]$

Permanent reflector

[1950]

B. Maximum point stress, psi:

Core support posts

Core support blocks

Permanent reflector

[ 800$]$

[ 800$]$

[1000]

[650]

[ 800$]$

C. Graphite temperature range, ${ }^{\circ} \mathrm{C}$ :

Minimum

Maximum

[ 120]

[900]

D. Operating atmosphere:

Primary coolant

Coolant pressure range

Impurity levels, ppm:

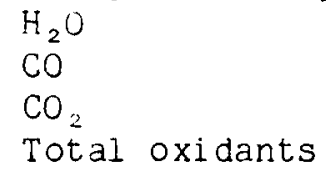

Total oxidants

Helium

[1-65] atm

[2]

[5]

[2]

$<$ [10] but not to exceed

600 ppm-days per year

E. Neutron fluence, neutrons $/ \mathrm{cm}^{2}$

( $\mathrm{C}>29 \mathrm{fJ}$, HTGR spectrum):

Core support posts, maximum

Core support blocks, maximum

Permanent reflector, maximum

$\left[2 \times 10^{20}\right]$
$\left[2 \times 10^{20}\right]$
$\left[2 \times 10^{20}\right]$ 
The development of the data bases for the core components is not only a complex statistical problem but also is complicated by the relatively highneutron-fluence levels involved. Consequently, the cost of the program under the core components is of much greater magnitude.

The service conditions for the core components are given in Table 5.2 and are not repeated in the various subsections of section 5.2 below. A general requirement is conformance with 10CFR50, Appendix $B$, to ensure the quality of the data.

\subsection{Organization of the Program Sub-Elements}

The organization of Section 4 and its associated Design Data Needs (UDNS) is determined by the functional analysis and its assumptions. Section 5 is organized in accordance with the logical grouping of concurrent work p.lans with such efforts on occasion addressing parts of one or more sections of Section 4 or its associated DDNs.

As a case at point, consider section 4.2.4.3 and its associated DDN M.10.17.13, which is an umbrella requirement on thermal properties. The properties of interest are thermal expansion, thermal conductance, emissivity, and specific heat. The methods of measurements differ considerably among the four, and each is found in Section 5 at a separate work element. Emissivity and specific heat are considered separately and disposed of as requiring no further data acquisition on the basis of their universal character. Thermal conductivity occurs as a separate subprogram, and its unique requirements are defined therein. Thermal expansivity is found under the subprogram involving mechanical properties, since it is determined along with and in some cases on the same specimens as those used in the mechanical properties determinations whether irradiated or unirradiated.

The explicit relationships between the graphice technology plan as given in this section to the requirements given in section 4 and the associated DDNs are given in the accompanying Tables 5.3 and 5.4 . The direct connection to 
TABLE 5.2.

DATA PARAMETERS AND SERVICE CONDITIONS FOR CORE COMPONENTS

A. Graphite temperature range, ${ }^{\circ} \mathrm{C}$ Shutdown

Minimum normal operation

300

Maximum normal operation

950

B. Neutron fluence, neutrons $/ \mathrm{cm}^{2}$ ( $E>29 \mathrm{fJ}, \mathrm{HTGR}$ spectrum)

(See Fig. 4.10 for details of temperature and fluence conditions)

C. Operating atmosphere

see Table 5.1 
TABLE $5 \cdot 3$.

GRAPHITE 2020 PROGRAM ELEMENTS AS RELATED TO SECTION 4 REQUIREMENTS

\begin{tabular}{|c|c|c|c|}
\hline Section 4 & DDNa & Subject & Section 5 \\
\hline $\begin{array}{l}4.2 .4 .1 \\
4.2 \cdot 4 \cdot 2\end{array}$ & $\begin{array}{l}M .10 .17 .01 \\
M .10 .17 .02\end{array}$ & Uniaxial Strengths & 5.1 .1 \\
\hline $\begin{array}{l}4 \cdot 2 \cdot 4 \cdot 3 \\
4 \cdot 2 \cdot 4 \cdot 4\end{array}$ & $\begin{array}{l}M .10 .17 .03 \\
M .10 .17 .04\end{array}$ & Multiaxial Strengths & 5.1 .2 \\
\hline $\begin{array}{l}4.2 .4 .5 \\
4.2 .4 .6\end{array}$ & $\begin{array}{l}M .10 .17 .05 \\
M .10 .17 .06\end{array}$ & Fatigue Strengths & 5.1 .3 \\
\hline $\begin{array}{l}4.2 \cdot 4 \cdot 7 \\
4.2 \cdot 4 \cdot 8\end{array}$ & $\begin{array}{l}M .10 .17 .07 \\
M .10 .17 .08\end{array}$ & Miner's Law & 5.1 .3 \\
\hline $\begin{array}{l}4.2 .4 .9 \\
4.2 .4 .10\end{array}$ & $\begin{array}{l}M .10 .17 .09 \\
M .10 .17 .10\end{array}$ & Elastic Properties & 5.1 .1 \\
\hline $\begin{array}{l}4.2 .4 .11 \\
4.2 .4 .12\end{array}$ & $\begin{array}{l}M .10 .17 .11 \\
M .10 .17 .12\end{array}$ & $\begin{array}{l}\text { Radiation Effects on } \\
\text { Mechanicals }\end{array}$ & 5.1 .4 \\
\hline $\begin{array}{l}4.2 \cdot 4 \cdot 13 \\
4.2 .4 .14\end{array}$ & $\begin{array}{l}M .10 .17 .13 \\
M .10 .17 .14\end{array}$ & $\begin{array}{l}\text { Thermal Properties: } \\
\text { Expansivity } \\
\text { Conductivity } \\
\text { Emissivity } \\
\text { Specific Heat }\end{array}$ & $\begin{array}{l}5.1 .1 \\
5.1 .5 \\
5.1 .6 \\
5.1 .7\end{array}$ \\
\hline $\begin{array}{l}4.2 \cdot 4 \cdot 15 \\
4.2 \cdot 4 \cdot 16\end{array}$ & $\begin{array}{l}M .10 .17 .15 \\
M .10 .17 .16\end{array}$ & $\begin{array}{l}\text { Radiation Effects on } \\
\text { Thermal Properties: } \\
\text { Expansivity } \\
\text { Conductivity } \\
\text { Emissivity } \\
\text { Specific Heat }\end{array}$ & $\begin{array}{l}5.1 .1 \\
5.1 .5 \\
5.1 .6 \\
5.1 .7\end{array}$ \\
\hline $\begin{array}{l}4.2 \cdot 4 \cdot 17 \\
4 \cdot 2 \cdot 4 \cdot 18\end{array}$ & $\begin{array}{l}M .10 .17 .17 \\
M .10 .17 .18\end{array}$ & $\begin{array}{l}\text { Corrosion } \\
\text { Characteristics }\end{array}$ & 5.1 .8 \\
\hline 4.2 .4 .19 & $M .10 .17 .21$ & $\begin{array}{l}\text { Large Block } \\
\text { Avail } b_{\perp} \text { lity }\end{array}$ & 5.1 .9 \\
\hline $4 \cdot 2 \cdot 4 \cdot 20$ & $M .10 \cdot 17.22$ & $\begin{array}{l}\text { Nondestructive } \\
\text { Evaluation }\end{array}$ & 5.3 .1 \\
\hline
\end{tabular}

a Please compare this table with Table 4.5 for relationship of DDNs to functional requirements. 
TABLE 5.4 .

GRAPHITE H451 PROGRAM ELEMENTS AS RELATED TO SECTION 4 REQUIREMENTS

\begin{tabular}{|c|c|c|c|}
\hline Section 4 & DDNa & Subject & Section 5 \\
\hline 4.1 .4 .1 & $M .10 .18 .01$ & Multiaxial Strength & 5.2 .2 \\
\hline 4.1 .4 .2 & $M .10 .18 .02$ & Fatigue & 5.2 .3 \\
\hline $4 \cdot 1 \cdot 4 \cdot 3$ & $M .10 .18 .03$ & $\begin{array}{l}\text { Tensile Strength } \\
\text { Compressive Strength } \\
\text { Stress/Strain } \\
\text { Poisson's Ratio }\end{array}$ & 5.2 .1 \\
\hline 4.1 .4 .4 & $M .10 .18 .04$ & Irradia. Distortion & 5.2 .4 \\
\hline 4.1 .4 .5 & M.10.18.05 & Irradiation Creep & 5.2 .5 \\
\hline 4.1 .4 .6 & $M .10 .18 .06$ & $\begin{array}{l}\text { Thermal Conductivity } \\
\text { Emissivity } \\
\text { Specific Heat } \\
\text { Thermal Expansion }\end{array}$ & $\begin{array}{l}5.2 .6 \\
5.2 .7 \\
5.2 .8 \\
5.2 .1\end{array}$ \\
\hline $4 \cdot 1.4 .7$ & $M .10 .18 .07$ & Fracture Mechanics & 5.2 .9 \\
\hline 4.1 .4 .8 & $M .10 .18 .08$ & Corrosion & $5 \cdot 2 \cdot 10$ \\
\hline 4.1 .4 .9 & M.10.18.09 & $\begin{array}{l}\text { Corrosion Effects on: } \\
\text { Strength } \\
\text { Irradia. Distort. } \\
\text { Creep } \\
\text { Thermal Conduc. } \\
\text { Specific Heat } \\
\text { Fracture Mechan. }\end{array}$ & $\begin{array}{l}5.2 .1 \\
5.2 .4 \\
5.2 .5 \\
5.2 .0 \\
5.2 .8 \\
5.2 .9\end{array}$ \\
\hline $4.1 .4 \cdot 10$ & M.10.18.10 & Nondestruc. Evaluation & 5.3 .1 \\
\hline $4 \cdot 1 \cdot 4 \cdot 15$ & $M .10 .10 .01$ & Validate Corrosion & 5.2 .11 \\
\hline
\end{tabular}

\footnotetext{
a Please compare this table with Tabie 4.1 for relationship of DDNs to functional requirements.
} 
the functional analysis is given in the referenced Tables 4.1 and 4.2 of Section 4.

\subsection{A Note on the Statistical Requirements}

Section 4 places a number of requirements on the statistical quality of the information to be developed by the Base Technology Program. These fall into three general cases and are expressed more or less in the following words:

Two-Sided Bound: The mean value shall be determined within an error bound of $\pm \varepsilon \%$ with $\gamma \%$ confidence.

One-Sided Bound: The mean value shall be determined to lie not above (below) an error bound of $-\varepsilon \%(+\varepsilon \%)$ with $r \%$ confidence.

Tolerance Limit: The data base shall provide assurance the material will survive $P \%$ of the time with confidence $\gamma$.

Each of these statements imposes a restriction on the minimum number of specimens which must be contained in the samplings. Obviously, this requirement sharply affects the philosophy by which the various data bases are determined as well as their costs, and forces us where possibie to estimate the needed sampling sizes.

We first restate the above three requirements in the formal lenguage of statistics:

Two-Sided Bound: The sample mean shall lie within the interval $\pm \varepsilon \%$ of the population mean with $95 \%$ conf idence.

One-Sided Bound: The sample mean shall lie above (below) the population mean minus (plus) $\varepsilon \%$ with $95 \%$ confidence.\} 
Tolerance Limit: The lower bound shall be determined such that $\mathrm{P} \%$ of the population falls above this bound with $95 \%$ confidence.

Even as stated precisely, the first two objectives cannot be met. The problem is that we never know the population mean in principle. We may only draw statistical inferences on its location, but in terms of the sample mean and its statistical character. Thus, the first two requirements can only be interpreted as follows:

Two-Sided Bound: The population mean shall lie within the interval $\pm \varepsilon \%$ of the sample mean with $95 \%$ confidence.

One-Sided Bound: The population mean shali lie above (below) the sample mean minus ( $p l$ us) $\varepsilon \%$ with $95 \%$ confidence.

In this form, as long as we deal with normal distributions, these two requirements can be calculated quantitatively on the basis of central $t$ statistics; the third requirement on a tolerance limit is handled by the noncentral $\tau$ distribution.

The required sample size is most easily determined for a sample drawn at random only once and complete in itself, and the results for this case we shall explicitly tabulate here. For more involved situations, such as (for example) regression or variance analyses, the required sample size can be much larger. The coefficient of variance (COV) is defined as the sample standard deviation divided by the sample mean. As one would expect, the more uncertain the population is (the larger the COV) the larger the sample size must be in order to determine the mean precisely (small s). The results for the first type of requirement ( $t w o-s i d e d$ bound on the sample mean) are given in Tabie 5.5. We generally expect the CoVs for graphite to lie in the 0.10 to 0.15 range, sometimes up to 0.20. Clearly, as the COV approaches the upper ends of this expected range, attaining high precision requires an exorbitant amount of data. 
TABLE 5.5 .

SAMPLE SIZES $n$ REQUIRED TO TRAP THE POPULATION MEAN

WITHIN $\pm \Sigma$ OF THE OBSERVED MEAN AT $95 \%$ CONFIDENCE LEVEL

\begin{tabular}{|c|c|c|c|c|c|}
\hline $\mathrm{COV}$ & $\varepsilon=$ & $8 \%$ & $5 \%$ & $3 \%$ & $2 \%$ \\
\hline 0.05 & & 4 & 7 & , & 27 \\
\hline 0.10 & & 9 & 18 & 45 & 99 \\
\hline 0.15 & & 16 & 37 & 99 & 219 \\
\hline 0.20 & & 27 & 64 & 173 & 387 \\
\hline 0.25 & & 40 & 99 & 270 & 603 \\
\hline 0.30 & & 57 & 141 & 387 & 867 \\
\hline
\end{tabular}

The application of the second requirement (one-sided bound) only partially alleviates the situation. The results are given in Table 5.6 for the lower bound and would be identical for an upper bound by changing the wording accordingly. Both Tables 5.5 and 5.6 are "robust," that is, small departures from a normal population do not seriously affect the results.

TABLE 5.6 .

SAMPLE SIZES $\rightarrow$ REQUIRED FOR THE POPULATION MEAN

TO EXCEED THE OBSERVED MEANSLESS $\varepsilon$ AT A 95\% CONFIDENCE LEVEL

\begin{tabular}{lrrrr} 
Cov & $e=8 \%$ & $5 \%$ & $3 \%$ & $2 \%$ \\
\hline 0.05 & 4 & 5 & 10 & 19 \\
0.10 & 7 & 14 & 33 & 70 \\
0.15 & 12 & 26 & 70 & 154 \\
0.20 & 19 & 45 & 122 & 274 \\
0.25 & 29 & 70 & 190 & 424 \\
0.30 & 40 & 100 & 272 & 610
\end{tabular}

The situation is quite different for the third requirement (colerance limit). A straight application of the noncentral $t$ distribution yields the 
results of Table 5.7. The tolerance limits are requested only for failure criteria, say (for example) the tensile strength. To use Table 5.7, let us take the mean strength as determined from a fifty-fold sampling to be 1000 psi with a COV of 0.15 , that is, a standard deviation of 150 psi. At the point $\mathrm{n}=50, \mathrm{COV}=0.15$ we find the value 0.571. We conclude that $99 \%$ of the population will exceed a strength of 571 psi with $95 \%$ confidence.

TABLE 5.7 .

RATIO OF THE LOWER BOUND \& TO THE SAMPLE MEAN $\bar{x}$ WHICH IS EXCEEDED BY 99\% OF THE POPULATION WITH 95\% CONFIDENCE FOR A SAMPLE OF SIZE $r$. THE VALUES FOR $\eta=\infty$ ARE THE LIMIT APPRUACHED WHEN THE SAMPLE MEAN AND STANDARD DEVIATION (HENCE, THE COV) ARE COMPLETELY KNOWN.

\begin{tabular}{|c|c|c|c|c|c|c|c|c|c|}
\hline \multirow[b]{2}{*}{$\mathrm{COV}$} & \multicolumn{9}{|c|}{$\ell^{\prime} \bar{x}$} \\
\hline & $\eta=$ & 3 & 4 & 5 & 10 & 50 & 100 & 500 & $\infty$ \\
\hline 0.05 & & 0.473 & 0.648 & 0.713 & 0.801 & 0.857 & 0.866 & 0.876 & 0.884 \\
\hline 0.10 & & & 0.296 & 0.426 & 0.602 & 0.714 & 0.732 & 0.752 & 0.767 \\
\hline 0.15 & & & & 0.139 & 0.403 & 0.571 & 0.598 & 0.628 & 0.651 \\
\hline 0.20 & & & & & 0.204 & 0.428 & 0.464 & 0.504 & 0.534 \\
\hline 0.25 & & Inacce & ssible & & & 0.285 & 0.330 & 0.380 & 0.418 \\
\hline 0.30 & & & & & & 0.142 & 0.196 & 0.256 & 0.301 \\
\hline
\end{tabular}

A hint of the problem with this naive approach is indicated by the region noted as inaccessible. In this region we have moved so deeply into the tail of the population distribution that the strength limit is negative. The flaw, of course, is that a normal distribution cannot properiy represent a variable which is intrinsically positive. But we may carry the logid further: whatever distribution is assumed to represent the property, that representation must be valid over the population percentage of interest, here being $P=99 \%$. This leads to quite a different sample size requirement which is specified by so-called order statistics. As a rule of thumb, the requirement is that the sample size be given by 


$$
\mathrm{n}=\frac{100}{100-\mathrm{P} \%}
$$

where $P$ is the fraction of the population exceeding the lower bound. For $P=99 \%$, this requires $n=100$. Thus Table 5.7 is not the requirement unless we restrict our attention to $n \geq 100$. This obviously excludes the inaccessible region: we would never assume a distribution function which would predict negative strengths at any significant level of probability.

In developing the following sections on the base program elements, the expected COVs are estimated on either existing data bases for the graphite in question or on bases for graphites of similar structure and manufacturing history. In the several cases where such data does not exist, we have simply had to make an educated guess to establish a sampling plan and its associated $\cos \tau$.

\subsection{Permanent Graphite Components}

\subsubsection{Uniaxial Mechanical Behavior and Thermal Expansivity of 2020 Graphite}

\section{1 .1 .1 References}

This program element is responsive to sections 4.2.4.1 and 4.2.4.2 (uniaxial strength), Sections 4.2.4.9 and 4.2.4.10 (elastic properties) and a portion of Sections 4.2.4.13 and 4.2.4.14 (chermal expansion). Corresponding DDNs are M.10.17.01, M.10.17.02, M.10.17.09, M.10.17.10, and parts of $M .10 .17 .13$ and $M .10 .17 .14$.

This program element is prerequisite to the requirements of Sections 4.2.4.3 and 4.2.4.4 (multiaxial strengths), Sections 4.2.4.5 and 4.2.4.6 (fatigue), Sections 4.2.4.7 and 4.2.4.8 (Miner's Law), and Sections $4 \cdot 2 \cdot 4 \cdot 11$ and 4.2.4.12 (irradiation effects). 
Before any extended data base is determined, prior decision on material must be made as required under section 4.2.4.19 (large block availability).

\section{1 .1 .2 Data Needed}

The design criteria to be met are those of ASME Code, Section III, Division 2, Subsection CE, which is here applied in the form of a designallowable point stress equal to one-third the minimum tensile strength, the latter to be defined as the strength at which $99 \%$ of the population $P$ will exceed said minimum at $\gamma=95 \%$ confidence. Three types of billets are to be examined:

1. Cylindrical, $254 \mathrm{~mm} \phi$ by $1.98 \mathrm{~m}$ length (core support post).

2. Cylindrical, $432 \mathrm{~mm} \phi$ by $1.22 \mathrm{~m}$ length (core support biocks).

3. Rectangular, $666 \mathrm{~mm}$ by $660 \mathrm{~mm}$ by $1.00 \mathrm{~m}$ (permanent reflector block).

Design allowables are 800 psi (core support) and 650 psi (reflector) from ambient to $900^{\circ} \mathrm{C}$.

Young's moduli, as defined by the Code, shall be determined to provide mean values known to $\pm 5 \%$ at $95 \%$ conf idence.

Thermal expansivity shall be determined to provide mean values of the differential coefficient of expansion to $\pm 5 \%$ at $95 \%$ confidence.

All data shall recognize the variability within and between billets and from lot to lot, and will be dependent on orientation.

\section{$5 \cdot 1.1 .3$ Approach}

The following premises are taken:

1. The Code is silent on the point within a billet at which the $P=99 \%, Y=95 \%$ tolerance limit is to be applied. We shall 
interpret this to apply to the general region within which the minimum tensile strengih occurs.

2. Volume (Weibull) effects will be identified by means of tensile, flexural, and brittle-ring strengths covering a range of about four orders of magnitude in critical stress volume. Since a weibull exponent of the order of 15 is expected, about ten isodensity specimens will be required for each of the five volume levels.

3. Sampling plans assume billet symmetry is $\mathrm{C}_{4 \mathrm{v}}$, or higher (with local transverse isotropy), and have been truncated accordingly for planning purposes.

4. Although present information is not conclusive, correlation with density is assumed.

5. Although not specifically asked for, data on Poisson's ratio and cyclic stress-strain curves to failure on selected specimens will be obtained at negligible additional cost.

6. Because of the method of manufacture, lot-to-lot variability can be established only by procuring occasional billets over an extended period of time. This requirement is based on the necessity of obtaining lot samplings from multiple coke procurements by the manuf acturer.

7. The tolerance limit specification is mild. Implicit within it, however, is the hidden presumption that the population is normally distributed. To validate the assumption of normality requires a sampling of the order of 100 specimens at one or more points in the program. If normality is violated, the sampling requirement will increase. 
With these premises, the planned program is as follows:

Once production is known to be under control, a sampling of four of each billet type will be made to determine the within-billet symmetries, and for one or two billets more detailed measurements will be made to ascertain the symmetry class in detail. This should require the order of 100 strength measurements per billet except for detailed mappings where about twice that number of specimens will be required. These specimens will be sufficient to establish within-billet and between-billet variances and the Weibull and density correlations.

Young's modulus and Poisson's ratio will be determined on a modicum of specimens and this information exurapolated to the entire billet from symmetry and density.

High-iemperature strengths will be determined statistically, but only to the degree necessary to state the mean strength at any temperature of interest is equal to or greater than the room temperature value with $95 \%$ confidence. About twenty specimens in two sets, each set to be measured at one of two temperatures, will be selected on the basis of symmetry and density to establish bounds on the strength and moduli.

It is not believed that hydrostatic pressure has any effect on strength unless the pressure approaches the breakthrough point for liquid intrusion, something of the order of $1000 \mathrm{~atm}$. This point can be settled from the literature and no direct experiments are planned.

Thermal expansion coefficients generally are of the form

or

$$
\alpha=\alpha_{0}+\alpha_{1} \Delta T \quad \text { (differential) }
$$

$$
\left.\alpha=\alpha\left(T_{0}\right)+\frac{\alpha_{1}}{2} \Delta T \text { (mean, } T_{0} \text { to } T_{0}+\Delta T\right)
$$

The coefficients $\alpha_{0}$ and $\alpha_{1}$ will be determined so that $\alpha$ is known to $\pm 5 \%$ with 95\% confidence over the temperature range of interest. This will require 
something over fifty specimens to determine the density correlation and to smooth out effects of residual strains in the specimen.

Subsequent procurements will be made on the basis of two billets of each type per year for approximately four years to establish a rough estimate of lot-to-lot variability. Testing of these lots will be selective and only sufficient to establish approximate stability of the population.

Nondestructive evaluations (sonic and eddy current) will be carried out concurrently as the program proceeds to establish correlations and to simpiify the sampling requirements.

\section{1 .1 .4 Schedule}

The initial evaluation will require one year; subsequent lot evaluations will require an additional three years.

5.1 .1 .5 Costs

$$
\begin{aligned}
\text { First year: } & \$ 300,000 \\
\text { Following three years: } & \$ 100,000
\end{aligned}
$$

\section{1 .2 Multiaxial Strength of 2020 Graphite}

\section{1 .2 .1 References}

This program element is responsive to the data needs expressed in Sections 4.2.4.3 and 4.2.4.4. Corresponding DDNs are M.10.17.03 and M.10.17.04.

The development of a work $\_$ng data base from Program Element 5.1 .1 is a prerequisite to this $\in l$ ement. 


\section{1 .2 .2 Datia Needed}

Multiaxial strength data are needed to establish how much much the actual strength of 2020 graphite under multiaxial stresses deviates below the strength predicted by the maximum stress theory of failure. For all combinations involving compression, data are not needed for compressive stresses beyond the uniaxial tensile strength. The data base must be sufficient to establish with $95 \%$ confidence that each point on the "mean value" failure surface differs from the population mean value by no more than $5 \%$.

Three types of billets are to be examined:

1. Cylindrical, $0.25 \mathrm{~m}$ diam by $1.98 \mathrm{~m}$ length (core support post).

2. Cylindrical, $0.43 \mathrm{~m}$ diam by $1.22 \mathrm{~m}$ length (core support blocks).

3. Rectangular $0.66 \mathrm{~m}$ by $0.66 \mathrm{~m}$ by $1.00 \mathrm{~m}$ (permanent reflector block).

\subsubsection{Approach}

The following premises are taken:

1. The multiaxial failure surface for 2020 graphite is similar to the failure surfaces of graphites that have been studied by previous investigators. Therefore, for biaxial stress-states the maximum deviation below the maximum principal stress theory of failure can be expected to occur at equal biaxial tension or possibly at the point where there is equal tension and compression.

2. Weibull size effects completely characterized on uniaxial specimens applies to the multiaxial behavior.

With these premises, the planned program is as follows:

Correlations between NDE measurements and uniaxial strength under the uniaxial strength study will be used to select specimen sets that will 
minimize the effects of material variability. Thin-walled tubular specimens will be tested under internal pressure combined with axial loading to produce the following ratios of circumferential to axial stress: $0: 1,1: 1,2: 1,1: 0$, 1: 1. Approximately 20 specimens will be tested under each of the stressstates for each of the three billet sizes.

Theoretical studies will be done to determine what triaxial stress-states that might be encountered in an HTGR would be expected to produce the maximum deviations below the maximum principal stress theory of failure. If necessary, test methods will then be developed for running tests in the critical regions of triaxial stress space. Such tests are extrenely difficult to perform and will be developed only if the information is extremeiy vital.

If significant environmental effects are found in the 4451 investigations, testing may become necessary to determine if there are similar effects in 2020 graphite.

\section{1 .2 .4 Schedule}

These tests will require two years. Because of the reliance placed on the uniaxial and NDE data base for specimen selection, it cannot start until they are well along.

\section{1 .2 .5 Costs}

$\$ 200,000$.

\subsubsection{Fatigue Strength and Miner's Law for 2020 Graphite}

\section{1 .3 .1 References}

This program element is responsive to the requirements of Sections 4.2.4.5 and 4.2.4.6 (fatigue strength), and 4.2.4.7 and 4.2.4.8 (Miner's Law). Corresponding DDNs are M.10.17.5, M.10.17.6, M.10.17.7, and M.10.17.8. 
A working data base from Program Element 5.1 .1 is prerequisite to this program element.

\section{1 .3 .2 Data Needed}

A fatigue data base sufficient to construct a Design Fatigue Diagram* is needed for 2020 graphite. The data must be sufficient to establish the Design Fatigue Diagram providing the maximum allowable stress amplitude at which $99 \%$ of the specimens will survive for the specified number of cycles at a $95 \%$ confidence level for a specified ratio of minimum to maximum stress.

The data base must include:

1. Adequate fatigue data to define a tolerance limit of $99 \%$ surviva 1 at $95 \%$ confidence from $10^{2}$ to $10^{5}$ cycles.

2. Stress ratio, $R$ (ratio of minimum to maximum stress during a cycie) ranging from $[-1]$ to $[+1]$.

3. Dependence on orientation and location within billet and on variation from billet to billet.

4. Effect of the operating environment, that is, pressure, oxidation, neutron fluence. These will generally be nonstatistical and performed only where effects are expected.

*As defined in the draft of Subsection CE of the ASME Code. It must be pointed out that the code is deficient in defining how the tolerance limit is to be determined and, in fact, the results presented in Figs. I-1 and I-2 of the code are obtained by incorrect statistical procedures. In this regard, see the discussion under section 5.2 .3 for the core components. 
The data base must aiso be shown to be valid for the different billet sizes used in the core support components. These are:

1. Cylindrical, $0.25 \mathrm{~m}$ diam by $1.98 \mathrm{~m}$ length (core support post).

2. Cylindrical, $0.43 \mathrm{~m}$ diam by $1.22 \mathrm{~m}$ length (core support blocks).

3. Rectangular $0.66 \mathrm{~m}$ by $0.66 \mathrm{~m}$ by $1.00 \mathrm{~m}$ (permanent reflector biocks).

5.1 .3 .3 Approach

Some uniaxial push-pull fatigue tests in air have been performed at ambient temperature in both the axial and radial directions on specimens taken from a single billet of conventional grade 2020 . The stress ratio $R$ varied from -2 and 0 , and 40 to 50 specimens were tested for each orientation and stress ratio to a maximum of $10^{5}$ cycles. These data can be used to give direction to the test program; however, the data base needs to be expanded and possibly extended to include the nuclear grade 2020. While 2020 is a fairly uniform graphite, the effects of billet position, density, and lot-to-lot variability need to be demonstrated.

The accuracy of Miner's Law and the effect of stress volume on the fatigue behavior are two uncertainties in the fatigue data base. The fatigue characteristics of graphite are such that the slope of the $S / N$ curve is very shallow. This implies that Miner's Law, if it is applicable, will be difficult to demonstrate in view of the variability of strength. However, the important aspect of Miner's Law that a large number of low stress ampiitude cycles will not appreciably affect the strength of the material can be demonstrated with a modest program. The effect of stress volume on the Design Fatigue Diagram will require a larger test program. Testing must inclide uniaxial specimens and flexural specimens with various stress volumes in significant numbers to be statistically significant.

The following premises are used to define the details of the planned program:

1. Stress homology at the tensile end of the cycle exists. 
2. The predictions of the statistical analyses are to be performed in accordance with the ASTM procedure E 739-80, including cautions on the sample size.*

3. Due to the flatness of the $S / N$ curves, errors due to Miner's Law not being followed will be small.

4. The tests will be performed only within the $r$ ange of $R-1$ and +1 since values below $R=-1$ have not been encountered in the reactor design.

5. The fatigue testing program design assumes that variance homogeneity exists over the $\mathrm{S} / \mathrm{N}$ curves.

With these premises the planned program is as follows:

1. Review past results and procedures.

2. Using the homologous stress assumption, the nuclear 2020 graphite will be compared to past results. All three sizes of billets will be evaluated in the axial direction with an $\mathrm{R}$ ratio of [0]. The core support post cylinders will be further tested in the radial. direction and with an $R$ ratio of $[-1]$. Careful sampling with respect to prior NDT and destructive evaluations will be done to determine the effects of position and density on the results. This program will require the fatigue testing of at least 200 specimens each from the core support billets and the permanent reflector blocks. The number tested from the core support post billets will be at least 800 specimens.

*This premise addresses the deficiency in the Code but does not address the question of their correctness for the intended end use. 
3. The effect of stress volume will be determined by fatigue testing on additional larger-size uniaxial specimens with an $R$ ratio of -1 taken from the core support post billets. Also, tests in fluence using three sizes of brittle rings giving a stress volume ratio of greater than 10 will also be performed on specimens from the core support post billets. The number of tests here will be at least 400 .

4. The evaluation of Miner's Law as a design methodology will be accomplished by two means, first, an extended cyciing at a low stress level followed by cycling at high stress levels and, second, by a ramp method. The first technique presumably demonstrates that long application of low stresses does not affect life, the second provides an integratable form of experiment where failure is certain.

For the first approach a group of specimens will be cycled to $n=10^{5}$ at, say, 90\% of the 99/95 tolerance limit used for the Goodman diagram at the $10^{5}$ cycle level. The set will then be further cycled at various stress leveis leading to failures at $n<10^{5}$, and this mean-life curve compared to one without the low stress pre-cycling. According to Miner's Law, the two mean-life curves will be undetectably different.

The second series involves continuously increasing the stress level with each cycle until failure occurs. The mean-life in this case is also deducible from integrating across the modified Goodman diagram. Since the rate of stress increase can be varied over several orders of magnitude, this becomes a sensitive test of Miner's Law.

\section{1 .3 .4 Schedule}

The schedule of fatigue testing is predicated on the completion of the NDE and uniaxial testing of the 2020 billets.

1. Review of past results and procedures--4 months. 
2. Demonstrate consistency of nuclear 2020 to previous 2020 results-12 months.

3. Determine the effect of stress volume--6 months.

4. Evaluate applicability of Miner's Law--4 months.

This schedule assumes that the necessary fatigue testing equipment can be dedicated to the program for a full period of 24 months.

\section{$5.1 \cdot 3 \cdot 5$ Costs}

$\$ 600 K$.

\subsubsection{Irradiation Effects on Mechanical Properties of 2020 Graphite}

\section{$5 \cdot 1.4 .1$ References}

This program element is responsive to the requirements of Sections 4.2.4.11 and 4.2.4.12 and the corresponding DDNs numbered M.10.17.11 and $M .10 \cdot 17 \cdot 12$.

Prerequisite to this program element is a working data base from element 5.1.1.

\section{1 .4 .2 Data Needed}

Data are needed to establish the effect of low levels of fast fluence on Young's modulus and on the strength of the core support graphite. The data base must be sufficient to establish a $[95] \%$ confidence that the effects of irradiation are to (1) increase the specified minimum ultimate strength, and (2) change the mean value of Young's modulus by less than [10]\% with $95 \%$ confidence. If the change in modulus exceeds $10 \%$, then the change shall be 
determined within $\pm 5 \%$ at $95 \%$ confidence. The required data base must be valid for the three billet sizes of 2020 graphite used for core support components and permanent reflector blocks.

\section{1 .4 .3 Approach}

The data base established for uniaxial strength (DDN M.10.17.01) will furnish the base 1 ine statistical data for 2020 graphite. The determination of the effect of irradiation on the mechanical properties will assume underlying functional relationships. This testing program must therefore include sampling procedures to assure that the two groups of specimens to be irradiated are representative of material having average propertites and material having extreme values.

The following premises are taken:

1. The experimental plan will also recognize the significance of increasing confidence by exiending the total irradiation fluence.

2. Brittle-ring strength is representative of the strength of the material.

3. Young's-modulus changes, as defined by the code, can be correlated to those measured by sonic techniques.

4. The COV is constant or monotonically decreases.

The following program is proposed:

1. Two irradiation experiments to be run in the BSR reactor, one at $300^{\circ} \mathrm{C}$ and the second at $650^{\circ} \mathrm{C}$, to maximum fluence levels of $2.5 \times 10^{20}(\mathrm{E}>29 \mathrm{f})$. Each experiment will contain approximately 400 brittle-ring specimens for evaluation. (Within che inside diameter of each stack of brittle-ring specimens are to be placed thermal-conductance and expansion specimens.) 
2. The sonic modulus of each brittle-ring specimen and each thermalconductance and expansion specimen will be measured.

\section{1 .4 .4 Schedule}

The schedule is predicated on the prior nondestructive evaluation and destructive evaluation of the 2020 billets. It is also predicated on the availability of a suitable irradiation testing facility.

Both irradiation experiments: $1 \frac{1}{2}$ years.

5.1 .4 .5 Costs

$\$ 600 \mathrm{~K}$.

\section{1 .5 Thermal Conductivity of 2020 Graphite}

\section{1 .5 .1 References}

This program element is responsive to sections 4.2.4.13 through 4.2.4.16 as they apply to thermal conductivity. Corresponding DDN numbers are M.10.17.13 through M.10.17.16.

A prerequisite to this element is the materiai decision required under Section 4.2.4.19 (1arge block availability).

\section{1 .5 .2 Data Needed}

Mean value of the thermal conductivity within $5 \%$ at $95 \%$ confidence over the temperature range 20 to $900^{\circ} \mathrm{C}$ for both oxidized and unoxidized graphite and at fluences up to $2.5 \times 10^{20}$ neutrons $/ \mathrm{cm}^{2}$ ( $\mathrm{E}>29 \mathrm{fJ}$ ) at $300^{\circ} \mathrm{C}$ and at $650^{\circ} \mathrm{C}$ irradiation temperature. The environment is 65 bar helium with $10 \mathrm{ppm}$ total oxidants for 32 full-power years. 


\section{1 .5 .3 Approach}

The thermal conductivity/diffusivity relationship has been repeatedly verified for bulk graphites and has been recently extended even to fibrous carbon insulating materials. We accept as a basic premise without need for further verification the ability to calculate thermal conductivity from diffusivity measurements.

The effect of gas conductivity within the pores will be extremely small and calculatable on basic principles above one atmosphere total pressure. Thus, only sub-atmospheric measurements are required to verify and bound the theoretical calculation.

Thermal conductance in graphite is well understood at least phenomenologically. Above $20 \mathrm{~K}$ heat transport is entireiy dominated by lattice waves (phonons). In ordinary bulk graphites there is a transition in mechanism at or just below room temperature, representing the change in dominance from a phonon-imperfection scattering mechanism to a phonon-phonon scattering mechanism.

The thermal conductivity reaches a maximum in the transition region, being limited below by the the specific heat (number of phonons) and above by the increased phono-phonon scattering. The latter is very well represented by an exponential decrease in thermal conductivity.

The third and final component of thermal conductivity is infrared (photon) transfer in the pores of the graphite. In insulating porous materials, the infrared component is just detectable at temperatures of $1000 \mathrm{~K}$, and this at a bulk density of onl y $0.2 \mathrm{Mg} / \mathrm{m}^{3}$. Thus, this mechanism is of no importance in the present situation, except possibiy for oxidized material. 
We may anticipate a three- to five-fold decrease in therma conductance due to the very low fluences required for this material. This is due to lattice vacancies pushing the transition temperature to and above room temperature, as well as the rapid increase. In the number of imperfections in the lattice. Thus, we have iittle recourse but to determine the data base empirically. It is fortunate this can be achieved by diffusivity rather than direct determination of the conductance.

The mechanical property degradation due to oxidation can be handled by discounting the surface layer as nonexistent (see section 5.1.8). This cannot be done for the thermal conductivity, for which this layer acts as an insulating medium. This can serve to reduce thermal stresses during transients, but can al so lead to higher internal temperatures. To establish whether such effects are of concern, uniformly oxidized specimens of 2020 graphite will be measured for thermal diffusivity. Since minimum densities of the order of $0.5 \mathrm{Mg} / \mathrm{m}^{3}$ lead to powdering and therefore removal of the oxidizing surface, it is again not anticipated that the infrared component of conductivity will be significant.

5.1 .5 .4 Work Scope

The anticipated program is phased to define the experimental parameters of interest before irradiations are conducted.

Phase 1: Determine the temperature dependence on the thermal conductivity to establish the transition zone and gas pressure dependence.

Phase 2: Determine the statistical character and density correlation at an elevated temperature near the minimum temperature range of interest.

Phase 3: Perform the necessary irradiation and oxidation experiments to obtain the required information on a correlative basis. 
Phase 1 is obviously a pair of scoping experiments and will require presumably no more than three specimens with the order of 20 data points per specimen. Phase 2 determination of the statisticai characteristics, including density and orientation correlations, will require between 40 and 100 specimens depending on the variance encountered and the numerical value of the correlations. It is expected that these measurements will be performed at three temperatures in order to obtain the confidence interval as a function of temperature. For the third phase, three irradiations are anticipated in order to cover the strong reduction in conductivity over the temperatures and fluences required. This would involve about 30 cylindrical specimens of 0.5-in. diam by 0.25-in. height. Because of this small specimen size, these can easily be included with the mechanical properties irradiation capsules. A similar number of oxidized specimens will also be required.

\section{1 .5 .5 Schedule}

Total elapsed time, three years, as follows:

5.1.5.5.1 Phase 1. Twel ve months for experiments and theoretical analysis.

5.1.5.5.2 Phase 2. Six months.

5.1.5.5.3 Phase 3. Two years including capsule construction and specimen turnaround.

5.1 .5 .6 Costs

Irradiation costs are included under 5.1.4; other costs: $\$ 185 \mathrm{~K}$. 


\section{1 .6 Emissivity of 2020 Graphite}

\section{$5 \cdot 1.6 .1$ References}

This program element is responsive to sections 4.2.4.13 through 4.2.4.16 as they pertain to emissivity; DDN numbers M.10.17.13 and M.10.17.14 also apply .

\subsubsection{Data Needed}

The requirement is for the emissivity to be determined so that the population mean differs from the sample mean by no more than 10\%. This property does not significantly depend on graphite grade or other variables as long as the material is a normal artificial graphite. Grade $2020 \mathrm{falls}$ in this category.

\section{1 .6 .3 Approach}

The critical variable for total emissivity is surface condition, with emissivity being lowest for highly polished surfaces and highest for the crater of an arc operating at the sublimation temperature (3900 $\mathrm{K}$ at $1 \mathrm{~atm})$. Values for three graphites in the same class as 2020 are known, the grades being Great Lakes H1LM and H3LM and Speer 7100. The latter is probably closest in structure to stackpole grade 2020. Results for total normal emissivity are:

\begin{tabular}{llll} 
Surface & H1 LM & H3LM & 7100 \\
\hline Polished & 0.802 & 0.808 & 0.800 \\
Machined & 0.852 & 0.852 & 0.847
\end{tabular}

and are temperature-independent from 1000 to $3000^{\circ} \mathrm{C}$, the range investigated. For comparison, the arc crater emissivity is 0.894 . 
We therefore conclude the emissivity of 2020 graphite for any surface, machined or rougher, is bounded by

$$
0.85>\varepsilon>0.90 \text {. }
$$

This is well within the required quality for the data base, and no further experimental data acquisition is necessary.

\section{1 .6 .4 Schedule}

None required.

5.1 .6 .5 Costs

None.

\subsubsection{Specific Heat of 2020 Graphite}

\section{1 .7 .1 References}

This program element is responsive in part to sections 4.2.4.13, 4.2.4.14, 4.2.4.15, and 4.2.4.16. Also see DDN numbers M.10.17.13, $M .10 .17 .14, M .10 .17 .15$, and $M .10 .17 .16$.

\section{$5 \cdot 1 \cdot 7 \cdot 2$ Data Needed}

Mean value of the specific heat within $5 \%$ at $95 \%$ confidence over the temperature range 20 to $900^{\circ} \mathrm{C}$ for both oxidized and unoxidized graphite and at fluences up to $2.5 \times 10^{20}$ neutrons $/ \mathrm{cm}^{2}$ ( $\mathrm{E}>29 \mathrm{fJ}$ ) at $300^{\circ} \mathrm{C}$ and $650^{\circ} \mathrm{C}$ irradiation temperature. The environment is 65 bar helium with $10 \mathrm{ppm}$ coial oxidants for 32 full-power years. 


\subsubsection{Approach}

The specific heats of all grades of graphite which have been examined do not vary from an unweighted average value by more than $2.5 \%$. The range of values within a given grade of graphite approaches the experimental precision of measurement. On this basis no experimental data on 2020 graphite is required; assumption of the average graphite specific heat curve as being characteristic of 2020 graphite will not lead to an error in excess of $2.5 \%$.

The effect of oxidation on the specific heat is undetectable. The preferential removal of the binder carbon is attributable to surface access rather than a change in atomic binding energy. Hence, the specific heat attributable to the binder phase is undetectably different than that due to the filler phase.

At the temperatures and fluences required here, the stored energy release rate will be much smaller than 0.01 cal $/ 8 \mathrm{~K}$ and thus negligible compared to the specific heat.

We conclude no experimental work is required and at most a Iiterature survey is needed to justify use of the average graphite specific heat curve.

\section{$5 \cdot 1 \cdot 7.4$ Work Scope}

Literature survey.

\section{$5 \cdot 1 \cdot 7.5$ Schedule}

Three man-months effort.

5.1 .7 .6 Cost

$\$ 30 \mathrm{~K}$. 


\subsubsection{Corrosion Characteristics of 2020 Graphite}

\section{1 .8 .1 References}

This program element is responsive to the Graphite Technology Development Plan Sections 4.2.4.17 and 4.2.4.18 (DDN numbers M.10.17.17 and M.10.17.18).

Prerequisite to this program element is a decision under Section 4.2.4.21 ( 1 arge block availability).

\subsubsection{Data Needed}

Data to confirm that significant corrosion of these components is limited to a skin depth of $2 \mathrm{~mm}$ over the lifetime of the reactor. Significant corrosion is defined as that amount of corrosion that would result in a strength loss of $10 \%$ or more. The confirmation is required at a $95 \%$ conf idence level.

\section{$5 \cdot 1.8 .3$ Approach}

This program task requires the confirmation that the loss in minimum tensile strength of core support or permanent reflector graphite shall not exceed 10\% for material greater than $2 \mathrm{~mm}$ from the geometric surface with $95 \%$ confidence. In the reference DDNs "skin depth" is used to indicate that depth for which strength loss is not significant. It is to be distinguished from oxidation depth, that depth at which the oxidation is $1 / e$ of that at the geometric surface. Because the oxidation rate of the principal candidate material (Stackpole 2020) is extremely low under temperature and impurity levels of the reactor, oxidation effects over the lifetime of the reactor may reach several centimeters. However, the weight loss is expected to be less than $0.1 \%$. Only in regions of hot streaking where the temperature might reach $50^{\circ} \mathrm{C}$ or more above the nominal design temperature is oxidation expected to reach values of more than one or two percent, but here the oxidation is limited to a superficial region of 1 or $2 \mathrm{~mm}$ depth from the surface. 
The following premises are taken:

1. A normal distribution of properties is assumed. To validate this assumption usually requires of the order of 100 specimens to be tested. We accept the premise that for oxidation kinetics studies more than one condition may be studied, and the results obtained under numerous conditions of oxidant level and temperature may be grouped as a single population, that is, the variance under any conditions of measurement is the same.

2. Langmuir-Hinshelwood Kinetics will apply to the new production runs of 2020 graphite and that the statistical character of the oxidation and strength loss parameters will be dominated by the chemical kinetics of the material.

3. Air or oxygen ingress will be controlled by start-up procedures. This will result in a limited and calculable incremental corrosion, limited in extent. Therefore, no additional data base for this condition is required.

Two types of data are therefore required for the chosen graphite and/or its contingent alternate, Union Carbide's recently developed TS1792 material. These data are:

1. Confirmatory studies on the oxidation rate of presently produced 2020 graphite as well as characterization of this material adequately to permit the use of calculated extrapolations for the period and down to the temperature and impurity levels expected in the reactor.

2. Confirmatory studies on strength loss of the material with oxidation. 
Although both the strength loss and oxidation characteristics of similar graphites have been well established, a sufficient number of specimens must be included to yield a 95\% confidence that the strength loss will not exceed the specified amount in $99 \%$ of the cases for this material.

Catalytic effects have been observed in some earlier studies of oxidation of 2020 graphite. The program task therefore requires ascertaining the uniformity and purity of newly produced billets of 2020 and sufficient studies to permit calculation of oxidation depths for various conditions including those expected in the reactor. Because oxidation rates and extents for reactor conditions are expected to be too small for laboratory studies to be conducted in reasonable time periods, accelerated conditions will be used.

These preliminary studies and calculations are then to be subject to test for those conditions that are accessible to laboratory study. The studies of this task are consequently phased in four parts:

1. Mapping and determination of density and chemical properties of newly produced 2020 billets.

2. Comparative oxidation studies at one atmosphere total pressure to establish parameters needed for modeling.

3. Testing selected samples at high pressure to confirm the calculated skin depths under moderately accelerated conditions.

4. Measurements of strength loss of oxidized specimens to conf irm that no abnormal or unexpected strength loss with oxidation is evident.

The work to be carried out in these four phases is described as follows:

1. Mapping of billets for both these studies and quality assurance during later production runs requires dissecting chosen billets and obtaining specimens for analysis, tests, archiving, and other 
studies. Density and chemical analysis are the principal tests that are used to characterize uniformity of properties in a billet.

2. Oxidation studies at one atmosphere pressure and diffusion measurements provide data to assure that the models (originally developed for H451 graphite) are being appropriately used for the present material. Sufficient specimens are to be tested to yield $95 \%$ confidence levels for the kinetic relationship.

3. Measurements of oxidation profile (oxidation depth) shall be performed at high pressures in GAT's high-pressure test 100p. The conditions chosen will be moderately accelerated from the conditions expected in the reactor, both for temperature and moisture levels in order to achieve a measurable oxidation level in the few months available for laboratory tests.

4. Selected specimens will be uniformly oxidized and tested for strength to establish the relation between strength loss and corrosion extent to the $95 \%$ conf idence level for this material.

The final confirmation of skin depth calculations for the reactor condition must be performed in the reactor itself. For this reason it is recommended that a surveillance program be designed that will permit not only a control over the purity of production runs of graphite during construction but aiso intermittent monitoring of the extent of corrosion in specimens mounted in the reactor, for example, the bottom reflector block and the bottom transition reflector block at certain locations in the reactor.

\section{1 .8 .4 Schedule}

The initial sampling and billet mapping will require six months after receipt of reference material. Oxidation studies at one atmosphere would begin after the mapping and would require an additional two and one-half years. Strength measurements and correlation with oxidation would begin after the mapping and require one year. 
5.1 .8 .5 Costs

$$
\begin{array}{ll}
\text { First year: } & \$ 150,000 \\
\text { Second year: } & \$ 200,000 \\
\text { Third year: } & \$ 150,000
\end{array}
$$

\subsubsection{Procurement of Large Block 2020 Graphite for Permanent Reflector}

\subsubsection{References}

This program element is responsive to Section 4.2 .4 .21 and the associated UDN number M.10.17.21.

This program element involves a decision on material and is prerequisite to all other program elements involving the core support and, potentially, the permanent reflector components.

\subsubsection{Data Needed}

The reference DDN requires assurance be obtained that the requisite billet size $(660 \mathrm{~mm} \times 660 \mathrm{~mm} \times 990 \mathrm{~mm}$ ) with satisfactory properties can be made available when required. This also involves establishment of specifications and demonstration of process control to assure reproducible material for the purpose of both reactor procurement and data base acquisition.

\section{1 .9 .3 Approach}

At the present time two vendors are potential candidates to meet the material requirements: Stackpole Corporation with their 2020 graphite and Union Carbide Carbon Products Division with their grade TS-1792. The situation at this time is as follows: 
Stackpole 2020 as normally produced is an impure graphite with both cataiysts and inhibitors present in variable amounts. The problem appears to be on its way to correction but will require confirmation by us. This grade of graphite is not normally produced as a commercial materiai in the size here specified.

Union Carbide TS-1792 is produced in the requisite size routinely. The manuf'acturer claims to have no abnormal impurity problem and to obtain properties equal to or superior to stackpole 2020 we have not verified this at ORNL.

The approach here is to verify both the reproducibility and process control along with satisfactory properties under the procurements for data base acquisition for the 2020 graphite and necessarily involving continuing close contacts with the manufacturer. As a backup to protect against the event siackpole fails to obtain adequate process and product control, a cursory examination of the Union Carbide material will be made.

5.1 .9 .4 Schedule

The schedule for establishing the availability of the $660 \mathrm{~mm} \times 660 \mathrm{~mm} \times 990 \mathrm{~mm}$ billets is that of the associated data bases. Material from Union Carbide is on hand and can be examined most economically as the 2020 data base is acquired.

\section{1 .9 .5 Costs}

The only additional program costs involve the cursory examination of grade TS-1792: \$20K. 


\subsection{Core Components}

5.2.1 Mechanical Properties and Thermal Expansion of Unirradiated and Irradiated $\mathrm{H} 451$ Graphite

\subsubsection{References}

This program element is responsive to the Technology Requirements of Section 4.1.4.3 (mechanical properties) and to parts of sections 4.1.4.6 (thermal expansivity) and 4.1 .4 .9 (effects of oxidation on mechanical properties). The corresponding DDN numbers are M.10.18.03, M.10.18.06, and M.10.18.09.

This program element is prerequisite to any detailed work on multiaxial strengths (Program Element 5.2.2), fatigue (5.2.3), and fracture mechanics $(5.2 .9)$.

An unstated but implied prerequisite to this program element is the mapping of billets and the overall planning of sampling requirements for the entire program on the core components.

\section{2 .1 .2 Data Needed}

The data base should be sufficient to define the tensile and compressive strengths, Poisson's ratio, and stress-strain relationship in accordance with appropriate ASTM standards for H-451 graphites, including the effects of:

1. Orientation and location in billet.

2. Variation within and between billets and variation from lot to lot.

3. Temperature ranging from ambient to the maximum service temperature.

4. Specimen or stress size.

e. Neutron fluence. 
Sufficient data from testing as received H451 to establish with 95\% confidence that the following mean values differ from the population mean by less than indicated below.

$\begin{array}{llll}\text { Tensile strength } & \pm 3 \% & \text { Stress-strain relationship } & \pm 8 \% \\ \text { Compressive strength } & \pm 5 \% & \text { Poisson's ratio } & \pm 20 \% \\ \text { Thermal expansion } & \pm 5 \% & & \end{array}$

\section{2 .1 .3 Approach}

The following premises are taken:

1. Volume (Weibull) effects will be identified by means of tensile, flexural, and brittle-ring strengths covering a range of about four orders of magnitude in critical stress volume. Since a weibull exponent of the order of 15 is expected, about 10 isodensity specimens will be required for each of the 5 volume levels.

2. Sampling plans assume billet symmetry is $\mathrm{C}_{4 \mathrm{v}}$, or higher (with local iransverse isotropy), and have been truncated accordingly for planning purposes.

3. Correlation with density has been found to date and will persist.

4. Although not specifically asked for, data on Poisson's ratio and cyclic stress-strain curves to failure on selected specimens will be obtained at negligible additional cost.

5. Although tolerance limits are not specifically requested, knowledge of the distribution density function for strength is implied. This is a sufficient condition to permit tolerance limits to be determined and the sampling plans are so determined.

6. The specification on knowledge of the stress-strain relationship is incomplete. If $\sigma$ is the stress and $\varepsilon$ the strain, then we interpret 
the requirement to be that the sample mean value $\bar{\varepsilon}$ be known to within $8 \%$ of the population mean over the range:

$$
0.1 \leq \bar{\varepsilon} / \bar{\varepsilon}_{u} \leq 1
$$

where $\bar{\varepsilon}_{u}$ is the ultimate mean strain.

7. For the interpretation of the thermal expansion specification, see Section $5.1 \cdot 1.3$ above.

With these premises, the planned program is as follows:

A significant number of tensile tests have been made on unirradiated $\mathrm{H} 451$ at room temperature and do furnish a fairly good description of the variability of H451. The results of this testing program may, however, be flawed in several respects that need to be clarified. First, the procedure used to tenșile test the graphite has never been demonstrated to yield representative tensile strengths. There could be a significant negative bias on both the mean and the variability resulting from the test procedures. While these tensile-test procedures may be more than adequate for proof testing or for material qualification, the designer needs the real tensile strength of the material. It must be demonstrated that these data do not place an undue burden on the designer.

A second impediment in the data is the combined effect of a restrained sampling plan and the lack of additional testing to obtain correlations between other physical properties such as density. The ability to use density-corrected strengths would yield more accurate estimates of the intrinsic variability in tensile strength. This is essential to vaidily describe the bimodal characteristics of fracture.

There also exists some compressive and flexurai test results which need to be examined. The compressive strength test results are probably adequate since failure will always be in tension. However, the stress-strain 
relationships in compression are needed in the analysis and these are not available. The flexural strength and stress-strain relationship do need to be correlated to the tensile properties. The tensile-flexural relationships are important in that they yield relevant procedures for resolving the effect of stress volume on strength. The stress-volume effect has not been cieariy described for grade $\mathrm{H} 451$ graphite.

There is also a fairly'large number of irradiated specimens that have been tensile tested. Most of the specimens were irradiated at $900^{\circ} \mathrm{C}$ with much smaller numbers at $600^{\circ} \mathrm{C}$ and $750^{\circ} \mathrm{C}$. These data need to be statistically evaluated to determine the $l \in v e l$ of confidence in the results. A preliminary estimate is that additional specimens irradiated at $600^{\circ} \mathrm{C}$ and $750^{\circ} \mathrm{C}$ will be needed to yield the necessary level of confidence in the temperature range of greatest concern. It would also be relevant to evaluate the effect of irradiation on the flexural and brittle-ring strength in comparison to the tensile strength results. This would yield additional information on the combined effects of irradiation and stress-volume and give credibility to using these simpler tests to evaluate additional lots of 4451 graphite.

There is no doubt that the tensile strength increases with increasing temperature; however, the elastic modulus also increases. Some graphites experience a reduction in the fracture strain with increasing temperature with a minimum around $900^{\circ} \mathrm{C}$. The alteration in the stress-strain behavior with iemperature should be determined.

The effect of oxidation on the strength of H451 graphite has been fairly well evaluated in several test programs with similar results. These results should be consolidated and statistically treated to demonstrate the confidence levels in the results. It is likely that no further testing will be required.

It is not believed that hydrostatic (pneumatic) pressure has any effect on the strength unless the pressure approaches the breakthrough point for Iiquid intrusion, something of the order of $1000 \mathrm{~atm}$. This point can be settled from the literature and no direct experiments are planned. 
It is essential that the test program use a carefully derived sampling plan based on nondestructive evaluations (NDE) to satisfy the above requirements. This is doubly important to integrate the NDE results with the destructive results to establish acceptance criterion of future material. It will also allow maximum utilization of the few billets of 4451 remaining for evaluation.

\section{2 .1 .4 Work Scope}

1. Confirmation of tensile test procedure to yield actual tensile strength:
a. 100 specimens with glued ends tests at room temperature.
b. 100 specimens using ASTM 749 test procedures.
c. 100 specimens using rigid load-train.

These tests will be performed to obtain full stress-strain results. The test material will be carefully selected from the biocks to yield as low a variability as possible.

2. Comparison of tensile strength to flexure, brittle-ring and compressive test results.
a. 100 flexural bars of two sizes each.
b. 100 brittle ring specimens of 3 sizes each.
c. 40 compressive specimens.

These specimens to be selected from the blocks to obtain the maximum degree of variability. Corresponding tensile specimens will be selected for comparative results. 
3. The tensile strength at elevated temperatures:

a. 100 specimens tested at $600^{\circ} \mathrm{C}$.

b. 100 specimens tested at $900^{\circ} \mathrm{C}$.

These specimens are to be selected to represent H451 as closely as possible. Representative stress-strain behavior will be obtained.

4. The effect of irradiation on tensile strength:

a. 150 brittle-ring specimens irradiated at $600^{\circ} \mathrm{C}$ to $5 \times 10^{21}$ neutrons $/ \mathrm{cm}^{2}$ ( $\mathrm{E}>29 \mathrm{fJ}$ ) and at $900^{\circ} \mathrm{C}$ to $3 \times 10^{21}$ each and tested at temperatures of $600^{\circ} \mathrm{C}$ and $900^{\circ} \mathrm{C}$ as well.

These specimens will be selected to represent 4451 or as closely as possible. Full stress-strain behavior will be obtained.

5. The variability within a block and between blocks:

a. 100 axial specimens block from five blocks.

b. 100 radial specimens block from five blocks.

c. 100 tangential specimens block from five blocks.

These specimens will be selected using NDE results to assure that the specimen strength volume distribution is equal to the block volume strength distribution.

The sampling procedures must also be coordinated with the demands of other test programs such as the evaluation of fracture toughness, fatigue, and other irradiation programs. 


\section{2 .1 .6 Schedule}

The schedule of the testing must be predicated upon: first, the NDE for the full-size blocks for sampling, and second, the confirmation of the tensile-test procedure.

1. Initial sampling plan for tensile test evaluation--1 month.

2. Tensile test evaluation-4 months.

3. Final sampling plan--2 months.

4. Tensile strength within and between block variability--6 months.

5. Flexural, brittle ring, and compressive testing--4 months.

6. Elevated temperature testing--4 months.

7. Tests of irradiated specimens--9 months.

Total program--2+ years.

As noted above, this program is predicated upon NDE and a confirmation of the tensile-test procedure. Depending on the equipment availability, this could add as much as a year to the overall program. The data will not be available for preliminary design, but should be available for final design. It should also be recognized that additionai testing of the new H451 graphite will be required to demonstrate the applicability of these results.

\section{2 .1 .7 Costs}

$\$ 550 \mathrm{~K}$.

\subsubsection{Multiaxial Strength of 4451 Graphite}

\subsubsection{References}

This program eiement is responsive to the data requirements of Section 4.1.4.1 and the corresponding DDN number M.10.18.01. 
Prerequisite to this program element is a working data base on uniaxial mechanical properties from Section 5.2.1 above. Also prerequisite and of critical importance are a working data base and satisfactory theoretical treatment of fracture mechanics in graphite (Section 5.2.9 below).

It is also responsive to DDN number M.10.18.01.

\subsubsection{Data Needed}

Biaxial and triaxial strength data are needed to establish the "mean value" failure surface for 4451 graphite. For all combinations involving compression, data are not needed for compressive stresses beyond the uniaxial tensile strength. The data base must be sufficient to establish with $95 \%$ confidence that each point on the "mean value" failure surface differs from the population mean value by no more than $5 \%$.

This "mean value" failure surface is only needed for unirradiated graphite at ambient temperature in a nominal atmospheric environment.

Additionally, a limited number of data points are needed to determine the effects of the service conditions on the multiaxial failure strength.

\subsubsection{Approach}

The following premises are taken:

1. The laws of fracture mechanics and the flaws in graphite govern fracture in graphite.

2. The principle of independent action for multiaxial stress states as applied by investigators such as Batdorf and Gyekenyesi is applicable to graphite.

3. The inherent flaws in graphite can be characterized. 
With these premises, the planned program is as follows:

Because of the infinite number of multiaxial stress states, a theoretical approach based on fracture mechanics and the principle of independent action for multiaxial stress states will be used to minimize the amount of testing required to develop a multiaxial failure surface for 4451 graphite. Consideration must be given to size effects. A limited amount of testing will be done to verify the accuracy of the theoretical approach in the biaxial domain. If the reactor design calculations demonstrate a critical need for triaxial data, and if the theoretical extrapolation is deemed uncertain for the design needs, then measurements in the triaxial domain will be attempied. It must be recognized that such measurements in general are difficuit, expensive, and notoriously unreliable.

Correlations between NDE measurements and uniaxial strength under the uniaxial strength study will be used to select specimen sets that will minimize the effects of material variability. A set of thin-wailed tubular specimens of a constant gage volume will be tested under internal pressure combined with axial loading to produce the following ratios of circumferential-to-axial stress: $0: 1,1: 1,2: 1,1: 0,1:-1$. Approximately 40 specimens will be tested under the $1: 1$ and $1:-1$ stress states, and approximately 100 specimens will be cested at the other three stress states. One hundred specimens of each of two additional gage volumes will be tested under the 2:1 stress state.

Effects of environment will be determined from uniaxial data using the theoretical model of multiaxial strength. If necessary, a limited number of specimens will be tested to validate the environmental effects.

\section{2 .2 .4 Schedule}

The analytical development and testing will require four years. 


\section{2 .2 .5 Costs}

$\$ 700 \mathrm{~K}$.

\subsubsection{Fatigue Strength and Miner's Law for H451 Graphite}

\subsubsection{References}

This program eiement is responsive to the requirements of Section 4.1.4.2 of the Technical Development Plan and its associated DDN number M.10.18.02.

Prerequisite to this program element is a working data base from Section 5.2 .1 .

This program eltment is a prerequisite to the development of a data base under the multiaxial strength studies (Section 5.2.2).

\subsubsection{Data Needed}

The following data are required:

1. Fatigue life from $10^{2}$ to $10^{5}$ cycles as a function of stress amplitude for $\mathrm{H} 451$ graphite for constant stress amplitude cyciic loading. The load cycling will be of two types, between equal tension and compression (stress ratio-1) and between tension and no stress (stress ratio 0 ).

2. Eatigue life for H451 graphite subjected to sequential series of cycles with different stress amplitudes. The test series will be designed to validate Miner's law for fatigue.

3. The effect of stress gradient and stress volume on the fatigue strength of graphite. 
The data shall be sufficient to assure that the population mean is within $6 \%$ of the sample mean at a $95 \%$ confidence level.

4. A limited number of fatigue tests on irradiated material to assure that the effect of irradiation does not decrease the fatigue life of the graphite.

Data Parameters/Service Conditions:

1. Service temperature range: $220^{\circ} \mathrm{C}$ to $900^{\circ} \mathrm{C}$.

2. Maximum fluence: $5 \times 10^{25}$ neutrons $/ \mathrm{m}^{2}(E>29 \mathrm{fJ})$.

3. Operating Environment: Helium at 1 to 63 atm pressure. Total oxidizing impurities $<10 \mathrm{ppm}$.

4. Maximum number of load cycles from plant cycles: [TBD].

5. Maximum number of load cycles from seismic vibrations: [TBD].

\subsubsection{Approach}

Some uniaxial push-pull fatigue tests have been performed on axlal and radial specimens of $H 451$ at room temperature. The stress ratios ( $R$ ) in this series varied from [-1] to [0] and were conducted to a maximum of $10^{5}$ cycles. The statistical analysis used was based on the ASME Code, Subsection CE, to describe the survival of graphite using Code design procedures. However, the core components are not using Code design procedures; therefore, the statistical analysis must be reexamined. This will be done by heavily weighing the ASTM Standard Operating Practice E739 for the statistical analysis more relevant to the design requirements of the core components. At first glance, it seems that more fatigue tests will be needed to yield data with adequate confidence limits. It is certain that block position, density, and lot-to-lot variability need to be examined to assure that the concept of stress homology applies to fatigue. The number of irradiated specimens tested is fairly 
small; however, the small number may be adequate to assure that irradiation does not decrease the fatigue strength.

As in the case of the permanent graphite grade 2020, the major areas of uncertainty are in the establishment of the adequacy of Miner's law and the effect of stress volume. The approach to evaluate 4451 will be identical to that described for 2020 in section 5.1.4.

The following premises are used to define the details of the planned program:

1. Stress homology at the tensile end of the cycle exists.

2. The predictions of the statistical analyses are to be performed in accordance with ASTM procedure E739-80, including cautions on the sample size.

3. Due to the flatness of the $S / N$ curves, errors due to Miner's law not. being followed will be small.

4. The requirements set extreme values for $R$ of -1 and +1 . No measurements are currently planned outside this range.

5. The fatigue-testing program design assumes that variance homogeneity exists over the $\mathrm{S} / \mathrm{N}$ curves.

6. The data base is to be used only to establish bounds on the mean and is not valid for extrapolation to tolerance limits. The lifing of this premise will multiply the sampling requirements by a factor of five.

The program will be as follows:

1. A statistical study of past fatigue results. Please see the attached addendum. 
2. A test series to demonstrate the adequacy of Miner's law.

a. Fatigue of specimens where the stress amplitude/cycle is increased at varying rates.

b. Fatigue of specimens at a subcritical stress level followed by fatigue at a critical level.

These two types of testing are described in more detail in Section $5 \cdot 1 \cdot 3 \cdot 3$ above.

3. A testing program to demonstrate that the statistics of fracture determined from uniaxial testing are applicable for fatigue.
a. Fatigue testing of specimens with a larger stress volume than used in section (b) above.
b. Fatigue testing of brittle ring specimens of various sizes to yield stress volume differences.

\subsubsection{Schedule}

The schedule of fatigue testing is predicated by the nondestructive evaluation and destructive testing program.

1. Statistical study of fatigue data-4 months.

2. Study of Miner's Law--8 months.

3. Study of the fracture statistics--12 months.

Overall program--2 years.

\section{$5 \cdot 2 \cdot 3 \cdot 7$ Costs}

$\$ 175 K$. 
ADDENDUM TO 5.2 .3$.

THE STATISTICAL INTERPRETATION OF FATIGUE DATA

The statistical interpretation of fatigue data to define lifetime is fraught with difficulties and extensive literature exists on the subject. The problem centers to a large degree on the fact that one searches for a relationship between two statistics (strength and life), both of which are inherently statistical due to the material and not due to random errors of measurement. The consequence is that two functional relationships exist, one treating average strength as a function of life and the other treating average Iife as a function of strength. This leads to an uncertainty ellipse in a two-dimensional space (rather than the commonly encountered case of an uncertainty interval along a line). Thus, there are an infinite number of ways to calculate a confidence interval or tolerance 1 imit depending on how the data are to be used. This type of problem is termed a Type S-1 regression analysis. In our case, the problem is further complicated in that the experiment of treating life as the independent variable is inaccessibie to us.

This S-1 type of problem with its attendant difficulties can be circumvented if we assume homology, that is, the fatigue strength can be normalized by dividing it by the ordinary tensile strength. Such a procedure can hopefully be used if the fatigue cycles of interest are physicaily dominated by the tensile portion of the cycle. If such is the case and the normalization is valid, then the statistical character of the fatigue strength may presumably be attributed to the statistical character of the tensile strength and the normalized fatigue strength is no longer a statistic. This procedure reduces the regression to a functional (type $F-1$ ) rather than statistical (type S-1) analysis. In actual fact, the tensile strength of a fatigue specimen cannot be directly measured without destroying the specimen; thus, only an imputed value can be obtained by other means, say nondestructive sonic techniques. Thus, the normalized fatigue strength remains a statistic but only in the sense of measurement errors (Lype F-2 regression). Whether type $\mathrm{F}-1$ or type $\mathrm{F}-2$, however, the regression analysis leads only to a single 
functional relationship between the normalized strength and $l$ if $\in$, and the uncertainty ellipsoid possesses only one inherent uncertainty, the other uncertainty axis being attributable to errors of measurement.

Further, available evidence suggests the error of measurement induced by the normalization of the fatigue strength may be small compared to the inherent uncertainty in life. If true, then the F-2 analysis reduces back to an F-1 type, the uncertainty ellipse collapses to a line, and ordinary interval estimates of confidence or tolerance levels apply and are unique. Thus, we arrive at the stated premises here and in the earlier section 5.1 .3 that homology exists and that we stay within the tensile-dominated regime, that is, $\mathrm{R} \geq-1$.

If the foregoing is true, then the modified Goodman diagram (constant life diagram) can be uniquely constructed at a stated confidence or iolerance level, and thus provides an interpolative method for unmeasured values of $R$ or Iife. And, at this point, the potential use of Miner's law to handle variable cycle amplitudes becomes available and its validity may be properly studied.

In the case of the permanent graphite (Section 5.1.3), we are at least covered by the safety factors, and incomplete or improper handling of the data may not be serious. Here in the core components, such as design safety factors are not imposed, and the data analysis must be correct. In this regard, the cautions of ASTM procedure E739 come into play and must be 1 ifted by goodness-of-fit tests, establishment of variance homogeneity, and proper handing of truncated or censored data sets.

\subsubsection{Irradiation-Induced Strain of 4451 Graphite}

\subsubsection{References}

This program element is responsive to requirements of section 4.1 .4 .4 and its associated DDN number M.10.18.04. It is also responsive to section 4.1.4.9 (DDN number M.10.18.09) with regard to the effects of oxidation on the irradiation-induced dimensional distortion. 


\subsubsection{Data Needed}

The irradiation-induced dimensional changes of H451 graphite as a function of fluence and temperature are needed, including:

1. Dependence on orientation, location in the billet.

2. Variation from lot to lot, billet to billet.

3. Dependence on the state of oxidation of the graphite.

Sufficient data are required for a $95 \%$ confidence level that the mean of the data base does not differ from the population mean by more than $[1] \%$.

\section{2 .4 .3 Approach}

There is a considerable amount of data on irradiation dimensional changes of $\mathrm{H} 451$ graphite at temperatures from $550^{\circ} \mathrm{C}$ to $1300^{\circ} \mathrm{C}$. These data were obtained from experiments run in the Oak Ridge Research Reactor (ORR), High FIUx Isotope Reactor (HFIR), and at Petten. All of the OG (in the URR) experimental data were obtained from experiments where the temperature was uncontrolled and fluctuated with the control rod position. The temperature fluctuations were as much as $\pm 50^{\circ} \mathrm{C}$ or higher in the exireme positions. The HFIR irradiations are also uncontrolled; however, because of the control rod configuration the temperature fluctuations are considerably less. The major uncertainties in the HFIR irradiations are the actual irradiation temperatures and the effect of the high flux on the irradiation damage in the graphite. The lower-temperature HFIR irradiation experiments can be estimated with good accuracy using the annealing characteristics of SiC and the graphite specimen itself. The higher temperatures must be calculated. The dimensional changes of control specimens in creep experiments from both the ORR and Petten represent results from well controlled experiments and should be used as basei ine data for comparison.

The existing data for H451, at first glance, appears to be adequate for design purposes. All of the irradiation data should be consolidated, weighted 
for experimental uncertainties, and compared to yield unified design data. These data can then be statistically treated to determine if further irradiation testing is warranted. The combined effect of irradiation and oxidation has not been examined, and this question should also be addressed. Studies in the United Kingdom have not yielded definitive results with regard to the dimensional changes of oxidized irradiated graphite. Also, studies at ORNL have shown that changes in graphite density have only mild influence on irradiation growth. The results of these studies should be consolidated to estimate the maximum possible effect of oxidation on irradiation growth, and, in combination with sensitivity studies, a decision made if an irradiation experiment on oxidized material is warranted.

The following premise is made:

1. Single-specimen standard deviation over the fluence range of interest is $0.02 \%$ strain. Specimens from multiple sources provide an estimate of the standard deviation of $\geq 0.2 \%$ strain. Both are based on the assumpiion that the data were correctly represented by a polynomial (with fluence as the independent variable) whose degree (apparently three) is determined by goodness-of-fit tests.

2. The observed correlations between bulk density and thermal expansivity will persist as the data base expands.

The implications of the above premise are that a reasonable attainable precision on the mean over the full life required is:

1. $0.05 \%$ strain with 50 specimens per temperature.

2. $0.03 \%$ strain with 180 specimens per temperature.

In view of an accuracy of about $0.02 \%$ strain for the measurenent of the specimen distortion, a requirement for greater precision does not appear to be cost effective. In view of the above, the following program is proposed: 
1. Consolidation and oritical review of all H451 graphite irradiation growth data.

2. Consolidation and review of the effect of density variation (including oxidation) on irradiation growth.

3. Since all irradiation experiments provide dimensional data, no further experiments for that specific purpose are required. Obviously, however, the dimensional data base will continue to grow as further irradiation experiments are conducted.

\subsubsection{Schedule}

1. If no further irradiations are indicated--6 months.

2. If an oxidation experiment is required--18 months. (Considerable lead time will be required to generate the oxidized specimens.)

This schedule is adequate to meet the preliminary design schedule if no further irradiations are indicated. If an oxidation experiment is deemed necessary, the lead time for oxidation and the preparation of the new irradiation facility in HFIR will cause at least six months to a year overrun in the preliminary design schedule. Eventually, however, an irradiation experiment using the 4451 graphite from the graphite procurement for the reactor must be performed to demonstrate that the design data is still applicable.

\section{2 .4 .5 Costs}

1. No further irradiation--\$60K.

2. With one oxidation irradiation experiment-- $\$ 250 \mathrm{~K}$. 


\subsubsection{Irradiation-Induced Creep of H451 Graphite}

\subsubsection{References}

This program element is responsive to the requirements of the Technology Development Plan under section 4.1 .4 .5 and its corresponding DDN number M.10.18.05. It is aiso responsive to that portion of section 4.1.4.9 (DDN M.10.18.09) dealing with corrosion ef fects on creep.

This program is closely associated with Program Elements 5.2.4 for irradiation-induced distortion and 5.2.10 for oxidation effects and requires correlated planning with these.

\section{2 .5 .2 Data Needed}

The following data are needed for H451 graphite:

1. Creep strain divided by stress versus fluence relationship for specimens loaded in tension to $1-1 / 2 \%$ and in compression to $2 \%$ or more.

2. Poisson's ratio under creep.

3. Effect of temperature, fluence, and flux.

4. Recovery of creep strains.

5. Effect of temperature change on creep.

6. Effect of change of compression to tension.

7. Effect of material variability (orientation, location in billet, etc.). 
8. Effect of creep strain on physical properties: Young's Modulus, Poisson's Ratio, tensile strength, thermal expansivity, and thermal conductivity.

Sufficient data are required to provide mean values known to $[ \pm 8] \%$ at $[95] \%$ confidence.

\section{2 .5 .3 Approach}

Creep experiments in the Oak Ridge Research Reactor at $600^{\circ} \mathrm{C}$ and $900^{\circ} \mathrm{C}$ have both operated long enough to have obtained a maximum graphite exposure of greater than $4.5 \times 10^{21}$ neutrons $/ \mathrm{cm}^{2}$ ( $\mathrm{E}>29 \mathrm{fJ}$ ). The maximum compressive creep strains obtained were $2 \%$ at $600^{\circ} \mathrm{C}$ and $3 \%$ at $900^{\circ} \mathrm{C}$. The compressive stresses in the ORNL experiments were fairly high, 13.8 and 20.7 MPa compared to the tensile creep stress at Petten of only $6 \mathrm{MPa}$. The Petten tensilt creep experiment at $900^{\circ} \mathrm{C}$ has achieved a fluence of $1.2 \times 10^{22}$ neutrons $/ \mathrm{cm}^{2}$ (E $>29 \mathrm{fJ}$ ) and will reach a final $1.5 \times 10^{22}$ neutrons $/ \mathrm{cm}^{2}$ ( $\mathrm{E}>29 \mathrm{fJ}$ ) by mid-1986. The tensile creep strain will be in the order of $1-1 / 2 \%$. The ORNL experiments have 20 axial specimens and two radial specimens loaded under the two stress levels at each temperature. Four of the axial specimens were from a separate block of $\mathrm{H} 451$ and two of these had a higher density and Young's modulus than the main group of specimens. The $900^{\circ} \mathrm{C}$ Petten experiment has four specimens of axial 4451 from the same block as the larger group of compressive ORNL specimens.

These data have basically covered the range needed for the HTR design with the exception of tensile creep at the lower temperatures. The effect of creep strain on many of the physical properties has been measured on the compressive creep specimens but not on the tensile creep specimens. Also, because of the specimen geometry, Poisson's ratio measurements under tensile creep are not very reliable. All of the specimens have been tested under constant temperature and stress with the exception of four ORNL compression specimens that were unloaded for an irradiation experiment cycle co measure the recovery of primary creep. The data have not been consolidated and statistically ana $\perp$ yed. 
There are preliminary indications of a wide difference in the tensile and compressive creep characteristics from Petten and URNL experiments. This discrepancy needs to be clarified either through experiment analysis or by additional tensile experiments at oak Ridge. The level of confidence in the H451 tensile creep data can be enhanced with the addition of the creep data obtained from experiments performed by KFA and UKAEA on other grades of graphite. Both have active creep programs and cooperative interaction will be very beneficial to our HTGR program.

Irradiation experiments are still needed to confirm the creep behavior of $\mathrm{H} 451$ under tension at the lower temperature range of $500^{\circ} \mathrm{C}$ to $600^{\circ} \mathrm{C}$. Experiments need to be devised in particular to determine the effect of the temperature change on creep and that of stress reversal on creep. The effect of tensile and compressive creep on thermal conductivity and strength both need to be measured while most physical properties under tensile creep need to be measured.

To furnish the data needed, the following irradiation experiments will at least be needed:

1. A low temperature $\left(600^{\circ} \mathrm{C}\right)$ tensile-creep experiment series.

2. An experiment where the temperature is cycled.

3. An experiment where the stress is reversed.

Additional irradiation experiments may be needed if the statistical analysis indicated the desired confidence levels have not been achieved. Ail of the creep experiments will run to $5 \times 10^{21}$ neutrons $/ \mathrm{cm}^{2}$ ( $\mathrm{E}>29 \mathrm{fJ}$ ) and contain a minimum of $20 \mathrm{H} 451$ specimens for statistical relevance. Compressive specimens will come from existing 4451 specimens and the new blocks used to evaluate the tensile strength of $H 451$ (DDN M.10.18.03). The tensile creep specimens will all be taken from the new material. 
Also, post-irradiation testing procedures to measure the effect of creep on physical properties need to be devised in particular for tensile creep specimens.

\section{2 .5 .4 Schedule}

1. Temperature cycling creep experiment under compression--two HFIR cycles in the new removable beryllium (RB) facilities--9 months. (The specimens will be recycled after the first temperature.)

2. A low-temperature tensile creep experiment--two HFIR cycies in the RB facility--12 months. (Two experiments where the specimens will be recycled in at least two steps.)

3. A stress reversal experiment--two HFIR cycles in the RB facility-9 months. (The specimens will be recycled after the first loading.)

4. Consolidation and statistical analysis of available creep data-4 months.

5. Postirradiation tensile, thermal conductivity and other physical properties--10 months.

These schedules do not allow for design and construction of the capsules and the RB irradiation facility. It is expected that at least a one-year lead time will be required to design and construction.

Total program without additional experiments--4 years.

Program with each additional experiment-- +6 months.

\section{2 .5 .5 Costs}

$\$ 4,000 \mathrm{~K}--e a c h$ additional experiment, if required, will cost approximately $\$ 500 \mathrm{~K}$. 


\subsubsection{Thermal Conductivity of 4451 Graphite}

\subsubsection{References}

This Program Element is in response to section 4.1 .4 .6 and the associated DDN number M.10.18.06 as they pertain to thermal conductivity.

\subsubsection{Data Needed}

Mean value of the thermal conductivity within [5]\% at [95]\% contidence over the temperature range of $120^{\circ} \mathrm{C}$ to $900^{\circ} \mathrm{C}$ for both oxidized and unoxidized graphite and at fluences up to $5 \times 10^{25}$ neutrons $/ \mathrm{m}^{2}$ ( $\mathrm{E}>29 \mathrm{fJ}$ ) at temperatures of $400^{\circ} \mathrm{C}$ to $900^{\circ} \mathrm{C}$. The environment is 65 bar helium with $10 \mathrm{ppm}$ total oxidants for 32 full-power years.

\section{2 .6 .3 Approach}

The approach here is identical to that described for 2020 graphite except for the larger range of fluences and temperatures. Please see section $5 \cdot 1 \cdot 5 \cdot 3$.

\section{2 .6 .4 Work Scope}

The same work scope applies here as for 2020 graphite. Please see Section $5 \cdot 1 \cdot 5 \cdot 4$.

\section{2 .6 .5 Schedule}

The same elapsed-time schedule applies here as for the 2020 graphite. Please see section $5 \cdot 1 \cdot 5.5$. 
5.2 .6 .6 Costs

Irradiation costs are included under section 5.2.1. Other costs: \$240K.

\subsubsection{Emissivity of H451 Graphice}

\subsubsection{References}

This Program Element is in response to Section 4.1.4.6 and the associated DDN number M.10.18.06 as they apply to emissivity.

\subsubsection{Data Needed}

This program element is subject essentially to the same considerations as those for emissivity of 2020 graphite. See Section 5.1.6.2.

\subsubsection{Approach}

See section 5.1.6.3. In the present instance, H451 graphite is structurally similar to H3LM graphite.

\section{2 .7 .4 Schedule}

None required.

$5 \cdot 2 \cdot 7 \cdot 5$ Costs

None.

\subsubsection{Specific Heat of 4451 Graphite}

\subsubsection{References}

This Program Element is in response to section 4.1.4.6 and the associated DDN number M.10.18.06 as they pertain to specific heat. 
5.2 .8 .2 Data Needed

This program element is subject essentially to the same considerations as those for specific heat of 2020 graphite. See Section 5.1.7.2.

\section{2 .8 .3 Approach}

See Section $5 \cdot 1 \cdot 7 \cdot 3$.

5.2 .8 .4 Schedule

Three man-months effort.

5.2 .8 .5 costs

None. Cost is included under Section 5.2.6.6.

\subsubsection{Statistics of Fracture Mechanics Properties of H451 Graphite}

5.2.9.1 References

This program element is responsive to Section 4.1 .4 .7 of Chapter 4 and the associated DDN number M.10.18.07. It also covers the fracture mechanics aspects of Section 4.1 .4 .9 (oxidation effects) and its DDN number M.10.18.09.

Prerequisite to the detailed development of this work is the resolution of the probability density function under Program Element 5.2.1.

This program element is also prerequisite to the deveiopment of a theoretical model for multiaxial strength (Program Element 5.2.2).

\section{2 .9 .2 Data Needed}

The critical stress intensity factors $\left(\mathrm{K}_{\mathrm{IC}}\right)$ and strain energy reiease rates $\left(G_{I c}\right)$ for crack initiation, stable crack growth, and crack arrest are needed for $H 451$ graphite including: 
1. The effects of orientation and location in billet.

2. Variation within and between billets and variation from iot to lot.

3. The effect of irradiation.

4. The ef fect of temperature.

5. The effects of helium containing oxidants.

The data base shall be adequate to assure that the sample mean is within $10 \%$ of the population mean with a $95 \%$ confidence level.

\section{2 .9 .3 Approach}

Some static $K_{I c}$ measurements have been made on production graphite using the chevron-notched short-rod specimen geometry. Although fracture toughness measurements have less scatter than conventional testing, the number of specimens of H451 tested was too small to yield statistically significant resuits. There have also been fracture toughness measurements made on oxidized and irradiated H451. The number of specimens rested in these studies was aiso fairly small. Many more specimens need to be tested to yield statistically significant results.

It should be pointed out that the assumption that linear elastic fracture mechaniCS (LEFM) applies to graphite is in doubt. There exists reasonable evidence that the elastic energy of fracture is only a fraction of the total energy of fracture. The failure of graphite by elastic-plastic fracture with an increasing energy of fracture with crack depth would lead to lower calculated fracture probabilities for the prismatic fuel element. Studies to separate the energies of fracture and more clearly describe the fracture characteristics are needed. A detailed description is particularly important in studying the effects of the different variables upon the fracture toughness.

While there are standard specimens (short rod, compact tension, notched beam, double cantilever) for measuring and evaluating the fracture toughness 
of materials, it would be desirable if the specimen test results were validated by testing full scale models. Full-size slices of prismatic fuel elements will be tested with artificiaily flawed sections, yielding results for comparison with results calculated using existing codes.

\section{2 .9 .4 Work Scope}

1. The development of automated fracture toughness methods to allow quick separation of elastic and plastic energies of fracture. Confirmation or correlation of fracture toughness measurements made by testing short-rod, compact tension, and notched bar specimens.

2. The establishment of a data base.

a. Within billet variability.

b. Lot to lot variability.

3. The effect of variables.

a. Orientation (Billet symmetry assumed to be $C_{\infty h}$ with transverse i sotropy).
(1) Radial-axial* specimens.
(2) Axial-radial specimens.
(3) Radial-radial specimens.

b. Oxidation.

c. Irradiation.

d. Temperature.

* Normal to fracture surface is in radial direction but crack propagating in axial direction. 


\subsubsection{Schedule}

The schedules are predicated on the NDE and destructive evaluation of the sample billets to be used.

1. Test development--6 months.

2. Data base--6 months.

3. Effect of variabies.
a. Orientation--2 months.
b. Oxidation- -12 months.
c. Irradiation- -12 months.
d. Temperatur $e^{*--12}$ months.

Uverall program--3 years.

\section{2 .9 .6 Costs}

$\$ 800 \mathrm{~K}$.

\subsubsection{Corrosion Characteristics of and Effects on 4451 Graphite}

\subsubsection{References}

This program element is responsive to sections $4 \cdot 1.4 .8$ and $4 \cdot 1.4 .9$ of the Graphite Technology Develpment Plan and to DDN numbers M.10.18.08 and M.10.18.09. The scope of this element includes determining the oxidation characteristics of the graphite and the preparation of specimens for the various property measurements. The actual measurements of mechanical properties and thermal expansion are included in Program Element 5.2.1, irradiation effects in 5.2.4 and 5.2.5, thermal conductance in 5.2.6, and fracture behavior in 5.2.9.

\footnotetext{
*Requires development of high-temperature testing apparatus.
} 
Prerequisite to this program element are working data bases for the relevant unoxidized material properties.

This program element is prerequisite to the validation tests described in 5.2 .11 .

\section{$5 \cdot 2 \cdot 10.2$ Data Needed}

Data are needed to describe the corrosion of 4451 by impurities in the coolant during normal operation of the reactor. The burn-off is to be predicted to within a factor of two with $95 \%$ confidence. Data for both the intrinsic kinetics of reaction of graphite with moisture and for transport of impurity gases in the graphite are required. The effect of catalysis by graphite impurities and fission metals on the reaction kinetics must be addressed as must the effect of radiolysis.

A second task relating corrosion weight loss to changes in physical properties is to be addressed in part here for sample preparation and in part elsewhere relative to testing. Properties to be measured as a function of burnoff are tensile strength, compressive strength, Young's modulus, irradiation-induced distortion and creep, fracture behavior, thermal conductance, and thermal expansion. No measurements are contemplated on specific heat since it is unaffected (see Program Element 5.2.8 above). Effects of nonuniform burnoff on properties will be examined only to the extent necessary to justify analytical treatment by integration over the uniform burnoff results.

\section{$5 \cdot 2 \cdot 10.3$ Approach}

This program task requires that the burn-off of core component graphite be correlated to corrosion conditions in order for a prediction to be made of the burn-off (weight loss) and corrosion penetration profile in the graphite.

We interpret the prediction confidence and accuracy requirement to be that sufficient data shall be taken to ensure that the calculated burnoff 
(weight loss) shall not be less than one-half of the oxidation actually achieved in the reactor for any depth, with $95 \%$ confidence.

A significant fact for this material is that the data base on which the corrosion of $\mathrm{H} 451$ is presently predicted is based on preproduction matericil. Newly produced material must be shown to have comparabie properties of purity and corrosion rate.

The following premises are taken:

1. A normal distribution of properties is assumed. To validate this assumpion usually requires the testing of about 100 specimens. We accept the premise that for oxidation kinetics studies more than one condition may be studied and the results obtained may be grouped as a single population, that is, the variance under any condition of measurement is the same.

2. Langmuir-Hinshelwood kinetics will apply to the new production runs of this material as was estabiished for the preproduction material.

3. Air or oxygen ingress will be controlled by start-up procedures. This will result in a limited and calculable incremental corrosion. Therefore, no additional data base associated with oxygen oxidation is needed.

4. If steam enters the reactor, it is presumed that the event will be of limited duration during shutdown procedures and that those procedures will control the event to yield an incremental, limited, and calculable corrosion.

5. Transport of iron or other species in the reactor will not produce catalytically active sites on the graphite. 
6. Porosity, tortuosity, and permeability of the graphite are not specifically needed in order to calculate the corrosion expected. Rather, only an effective diffusivity is required.

In the approach to be used here, some specimens obtained after biliet mapping for chemical composition and density measurement would be oxidized uniformly and the rate of oxidation measured to determine the agreement with the kinetic equation derived from the earlier data. Diffusion measurements will be made to permit the calculation of expected corrosion amounts and profiles at elevated pressures. Specimens will be tested in the High Pressure Test Loop at GAT, and the results will be compared to those calculated with calculated oxidation characteristics for these conditions.

For the purposes of functional needs associated with maintaining control of flow characteristics, the attrition depth of graphite is the most important parameter. For the period of one reloading cycle no attrition is expected, based on the earlier graphite corrosion studies. However, catalysis by impurities, fission products, or adventitiously deposited material in the reactor could alter the corrosion rate significantly. Impurities are under control of a continuing quality assurance procedure. Because $H 451$ is a purified graphite, catalytically active materials are not expected or permitted.

Fission product catalysis will be examined in this program task elcment by a literature study of expected fission product contaminants to identify those that are catalytically active and then to bound the effect of their presence using oxidation rate comparisons of exposed graphite materials.

Radiolysis is to be addressed by a literature study in an effort to define and bound the effect of this parameter for moisture oxidation. In the event of an ambiguous result, experimental procedures will be developed to simulate a radiation field using radiof requency excitation under conditions of moisture corrosion to limit or bound this parameter's effect. 
Specimens are to be produced with differing extents of uniform oxidation for physical testing. These tests will be performed as part of other program elements.

\section{$5 \cdot 1.10 .4$ Schedule}

The initial sampling and billet mapping will require six months after receipt of the graphite. Oxidation studies at one atmosphere and at higher pressure would begin after the mapping and would require two and one-half years. Specimen preparation for physical testing would begin after the mapping and requires six months.

\section{1 .10 .4 Costs}

$$
\begin{array}{ll}
\text { First year: } & \$ 300,000 \\
\text { Second year: } & \$ 350,000 \\
\text { Third year: } & \$ 300,000
\end{array}
$$

\subsubsection{Validation of Design Methods for 4451 Graphite Corrosion}

\section{2 .11 .1 References}

This program element is responsive to section 4.1.3.1, Assumption 5, of the Graphite Development Program Plan and to DDN number M.10.10.01.

The essential completion of Program Element 5.2.10 is prerequisite to this validation test in order to predict the outcome prior to the experiment and to determine the sensitivity of measurement required to discriminate between the prediction and actual results.

\subsubsection{Data Required}

Validation of the integrated models and computer codes used to predict graphite corrosion in the HTGR core under normal operation and during steam 
and air ingress events are needed. The specified accuracy is within a factor of three with 95\% confidence. Attention must be given to transport, catalysis by graphite impurities and fission products, and the chemical kinetics determining the corrosion behavior.

\section{2 .11 .3 Approach}

The corrosion of graphite for the core graphite $\mathrm{H} 451$ is predicted by means of a model that uses a kinetic equation based on $H 451$ and a diffusivity parameter that characterizes the transport properties of the graphite for the oxidant. Several codes have been used for various purposes. The existing calculational codes need to be evaluated for appropriateness for caiculation of both surface burnoff and profile of oxidation, which are the two necessary aspects of a calculational method. Appropriate or applicable codes then need to be compared and their predictions compared with the results from oxidizing the $\mathrm{H} 451$ in a reactor environment in order to validate the design methods for precision and accuracy. It is recognized that the validation study must be based on a different data base than the data used for the original correlations that produced the model and codes.

The following piemises are taken:

1. The specification of requiring assurance that the predictive methods are accurate to within a factor of three is interpreted as meaning that the prediction shall not be less than one-third the values resulting from corrosion in a reactor environment to the $95 \%$ confidence level.

2. Both fuel blocks and an appropriate log of environmental or chemical exposure conditions from $H 451$ materials in the Fort St. Vrain reactor are available for examination.

3. Graphite specimens from operating reactors are to be studied in this task. It is presumed that samples the graphite may be examined without requiring a hot cell. 
4. Radiolytic effects and neutron effects will be negligible relative to the permitted range for the predictions. If this is not the case, additional data of neutron exposure can be made available for the specimens of this study.

The approach to be used will examine successive diametral cuts from portions of numerous sections of fuel blocks from the reactor, and will produce density gradients for the resultant corrosion. These data will be normalized to similar data from archived H451. Metrology of the fuel blocks will be conducted to assess the presence of any attrition of the coolant channel.

Additional chemical studies are to be performed to assess the presence of catal ytically active materials.

Additional specimens of graphite from a reactor environment will be subjected to oxidation studies to determine if any enhancernent of oxidation rate occurred due to the reactor exposure.

\section{2 .11 .4 Schedule}

Specimens will be obtained and assayed in the first year following the availability of suitable specimens. Precision machining will be conducted in the second year as will sensitive chemical analysis of the coolant channel surfaces.

\section{2 .11 .5 Costs}

Shipment, fuel removal, disposal: $\$ 250,000$

First year: $\$ 30,000$

Second year: $\$ 70,000$

Third year: $\$ 50,000$ 


\subsection{Nondestructive Evaluation}

\subsubsection{Nondestructive Evaluation of Graphite}

\section{$5.3 .1 .1 \quad$ References}

This program element is responsive to Graphite Technology Development Requirements $4 \cdot 1 \cdot 4 \cdot 10$ and 4.2.4.22. It is also responsive to DDNs M.10.17.22 and $\mathrm{M} .10 .18 .10$.

\section{3 .1 .2 Data Needed}

Data is needed to validate nondestructive evaluation (NDE) and write material control specifications for the procurement of graphite for reactor internal structures. The NDE techniques must be sufficiently accurate to determine the mean strength of a graphite billet within $[10] \%$ at a $[95] \%$ confidence level. Billets containing large variations in strength or large disparate flaws shall also be identified.

Conditions Required: the data will be obtained at ambient conditions.

\section{3 .1 .3 Approach}

It is the purpose of the Nondestructive Evaluation Program to fully evaluate the complete billet. This is in contrast to conventional sampling and strength testing of billets yielding only the strength of the small sampled region and an implication of the strength of the overall billet. Currently, three methods of nondestructive testing are being utilized, falling generally in the areas of radiography, acoustic response, and eddy-current response. All three have been extensively used to guide the development of improved graphites and to assure that sampling plans are made to represent either mean values or extreme values within the normally expected range for the property and material under investigation. Experience from the successful application of NDE to DOD specialty graphite repeatedly demonstrated that the NDE techniques should be developed along with the material when possible. 
This is due to two facts: First, sensitivity of the NDE methods is a function of the characteristics of the material, and hence each method must be fine-tuned to the grade being examined. Second, various deficiencies in the material, both physical and chemical, usually show most frequently in the early stages of development. Thus, at this stage the use of these methods serves both a diagnostic and calibration purpose.

Sonic techniques of three types (velocity, attenuation, and disparate reflection) are used primarily to assess the graphite quality. Experience has shown that from the sonic velocity and attenuation measurenents, the tensile strength can be calculated on the basis of fracture mechanics concepts with the reliability to predict both the mean values and their variance. The billet evaluation is total rather than core drilled sample or an end slice thus yields data unrestricted by the sampling procedure. This means, however, that the test apparatus must collect and manage a very large amount of data from each billet. Thus, automatic computer-driven and data collection is a necessary development of the test procedure.

Eddy current techniques only permit a measurement of the electricai conductivity within a finite distance of the surface. The results are used primarily to insure the uniformity of the block. The conductivity also reflects the overall degree of graphitization of the graphite which in turn will reflect in the uniformity of irradiation response. It is certain that a conductivity specification for the graphites will be written to assure the overall quality of the graphite. The measurement will either be an eddy-current value or from standard voltage drop techniques used for evaluating graphite electrodes.

The NDE development must be done concurrently with the destructive testing program for calibration of results. The preliminary NDE evaluations, while not absolutely quantitative, will furnish direction for rational sampling plans for all of the testing programs including irradiation experiments. 
The necessary hardware has been purchased for the automatic evaluation system. The equipment must be interfaced and sof tware written before graphite blocks can be evaluated. Once this has been accomplished, large-size blocks can be evaluated.

\section{3 .1 .4 Schedule}

Interficing and writing software-- 6 months.

Debugging system and demonstration of capabilities-- 6 months.

\section{$5 \cdot 3 \cdot 1 \cdot 5$ Costs}

$\$ 100 \mathrm{~K}$ for system development only.

\subsection{Time Schedules}

Approximate time schedules for the various program elements are shown in Fig. 5.1 (Permanent Components) and Fig. 5.2 (Removabie Core Components). These schedules are aimed at substantially completing the work by the end of FY 1991, thus placing virtually all information in the hands of the deslgner at the beginning of the second year of final design. These schedules are also consistent with providing necessary data for the PSSAR ( 10 be issued at mid-FY 1989) and the FSAR (end FY-1993). The schedule will also permit initiation of negotiations to purchase graphite as early as FY 1991, if desired.

It will be noted that time-lines of Figs. 5.1 and 5.2 are only very roughly similar to the elapsed time given in the previous sections for the individual program elements. This is due largely to the interlocking of the various program elements to other controlling events, such as irradiation capsules and availability of fuel blocks from the Fort st. Vrain reactor. The program also assumes a continuing collaboration with the Federal Republic of Germany, particularly in the area of irradiation-induced creep. 
The program for FY 1986 through FY 1989 has been laid out in some detail, this period covering the development of the data base for preliminary design as well as that required for preparation of the PSSAR. This detailed program plan aiong with the major events occurring during the period are shown in Figs. 5.3 (Permanent Components) and 5.4 (Repiaceable Core Components). It will be noted that this schedule requires the current FY 1986 program be redirected at mid-year to permit timely decisions on material and billet mapping in order for data acquisition to begin in early FY 1987.

\subsection{Cost Schedules}

Program costs by element are presented in Table 5.8 and by year in Table 5.9. The year costs for FY 19861989 have been caiculated in some detail on the basis of item-by-item cost estimates; those for succeeding years are relatively crude. It will be noted that the program peaks in FY 1988 as irradiation facilities and capsules proceed through construction and into use.

As has been noted earlier, the various program elements have been framed around certain assumptions (premises) which, if found to fail, could in some cases push the program costs upwards from the estimates given here. The program element of most uncertainty is that for radiation-induced creep (5.2.5). This property is the single most important factor in the constitutive equations, leading to stress relaxation during reactor operation but stress enhancement at shutdowns. As it stands, the creep program assumes continuing collaboration with the FRG as well as initiation of irradiations in the new reflector positions (HRB*) in the HFIR. Lack of commutative additivity due to exiernally changing stress or varying radiation temperature would have a severe impact on costs. 
Fig. 5.1. General time schedule for technology development: Permanent Components

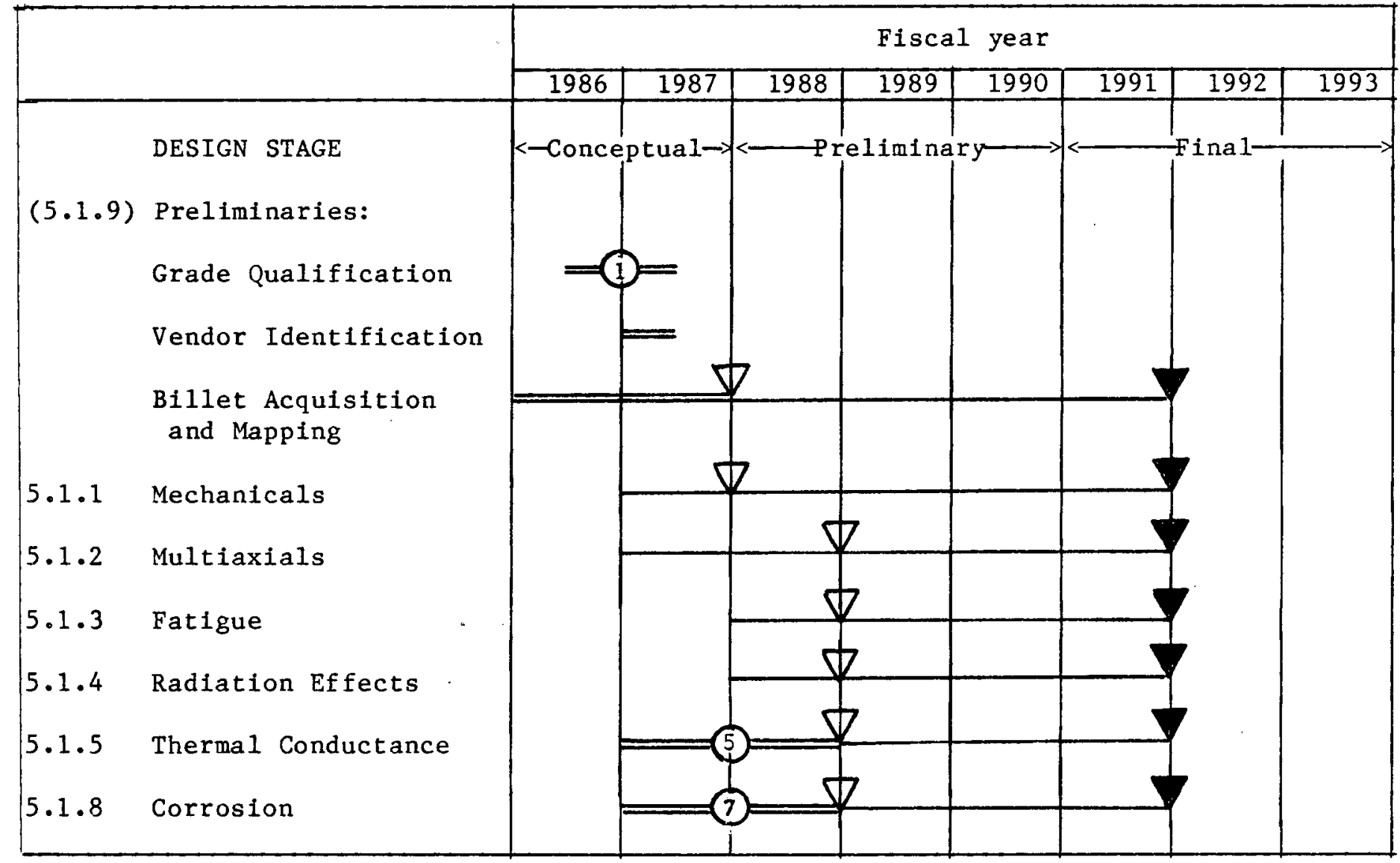

Symbols: $\nabla$ Preliminary Data Base Supplied.

$\checkmark$ Final Data Base Supplied.

- Program Element where preliminary data base is nonexistent and of high priority.

(x) Designer's Priority for preliminary data. 
Fig. 5.2. General time schedule for technology development: Core Components

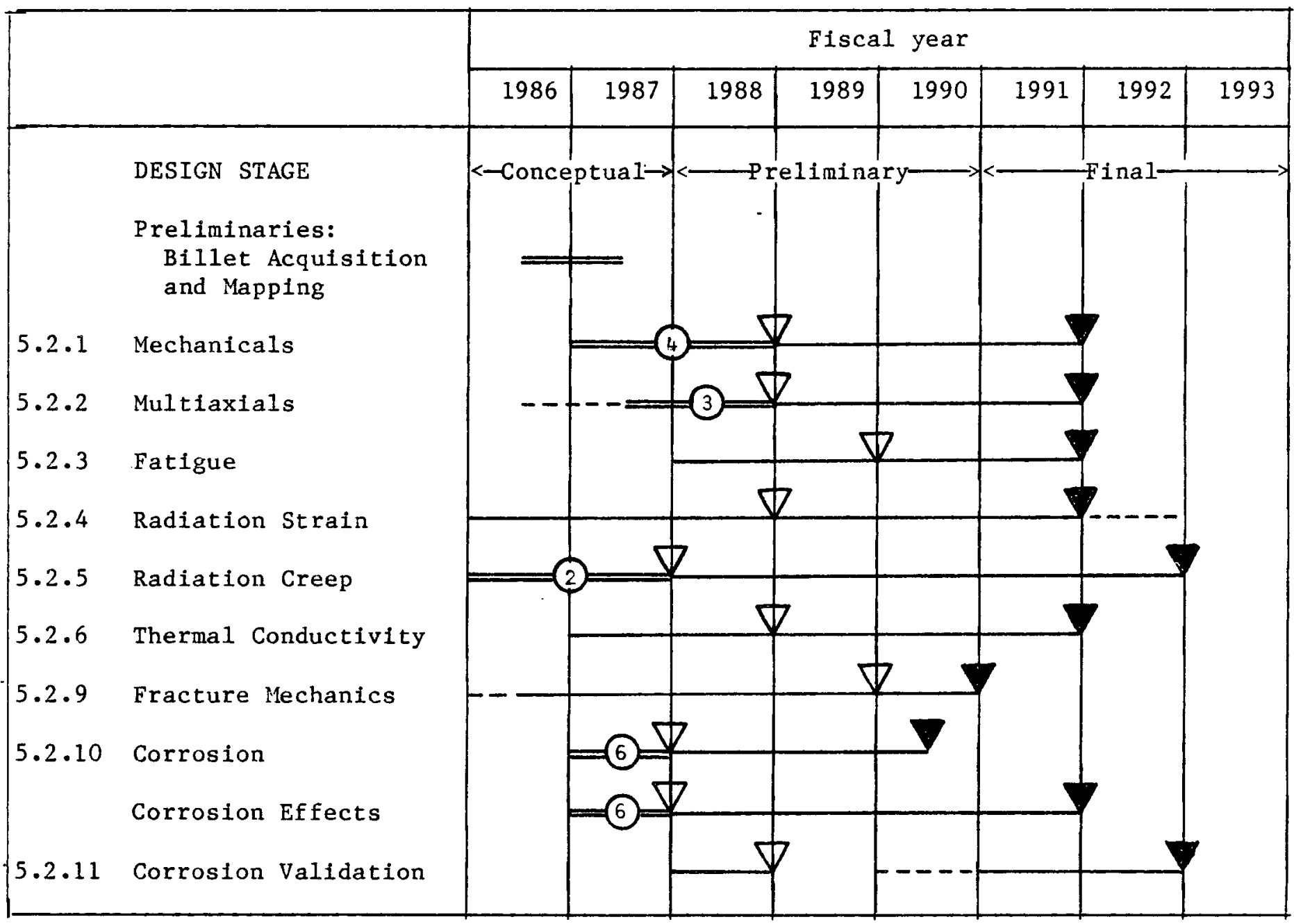

Symbols: $\nabla$ Preliminary Data Base Supplied.

$\checkmark$ Final Data Base Supplied.

- Program Element where preliminary data base is nonexistent and of high priority.

(8) Designer's Priority for preliminary data. 
Fig. 5.3. Technology Development Program Detail, FY 1986-1989: Permanent Components

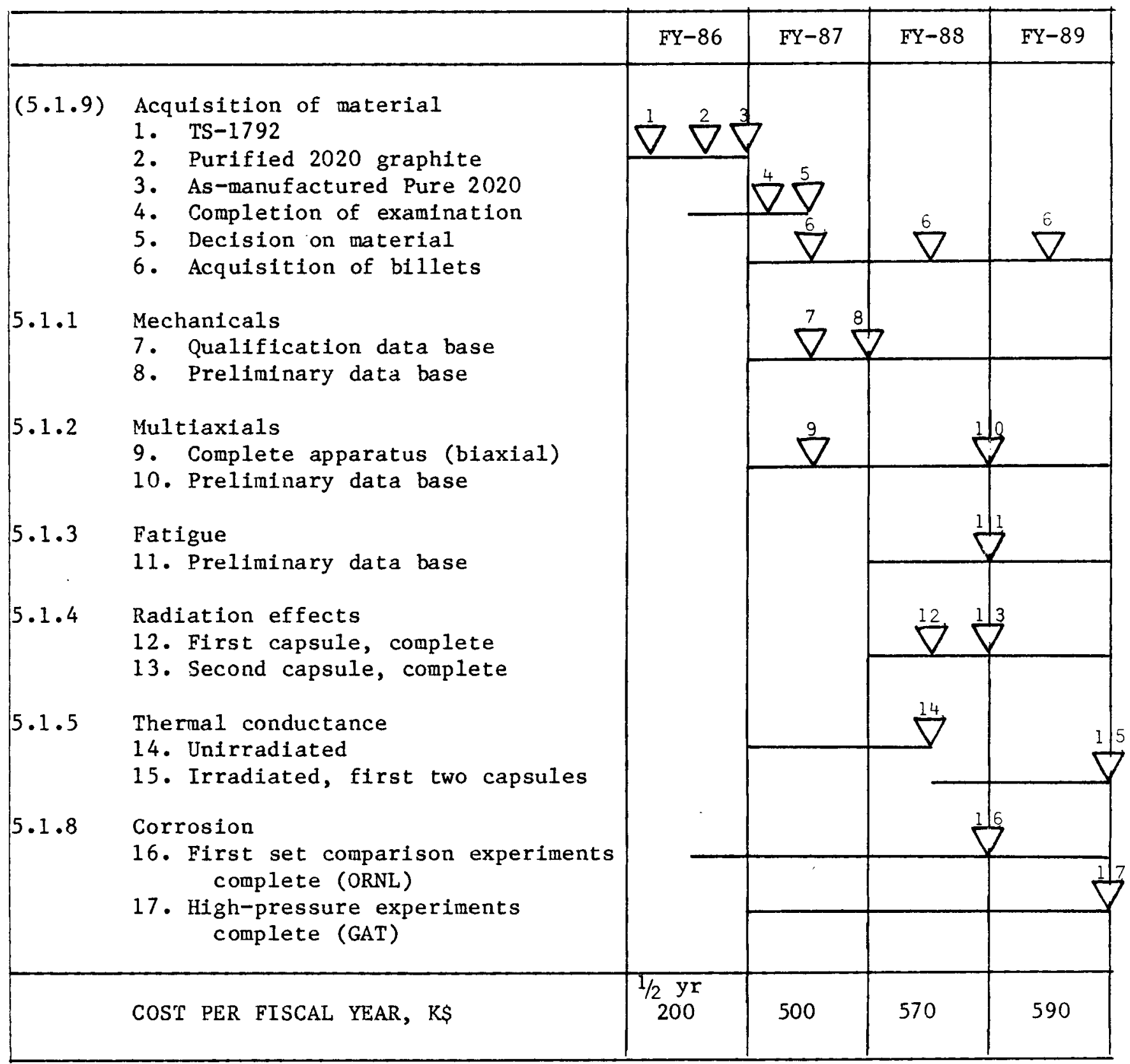


Fig. 5.4. Technology Development Program Detail, FY 1986-1989: Replaceable Core Components

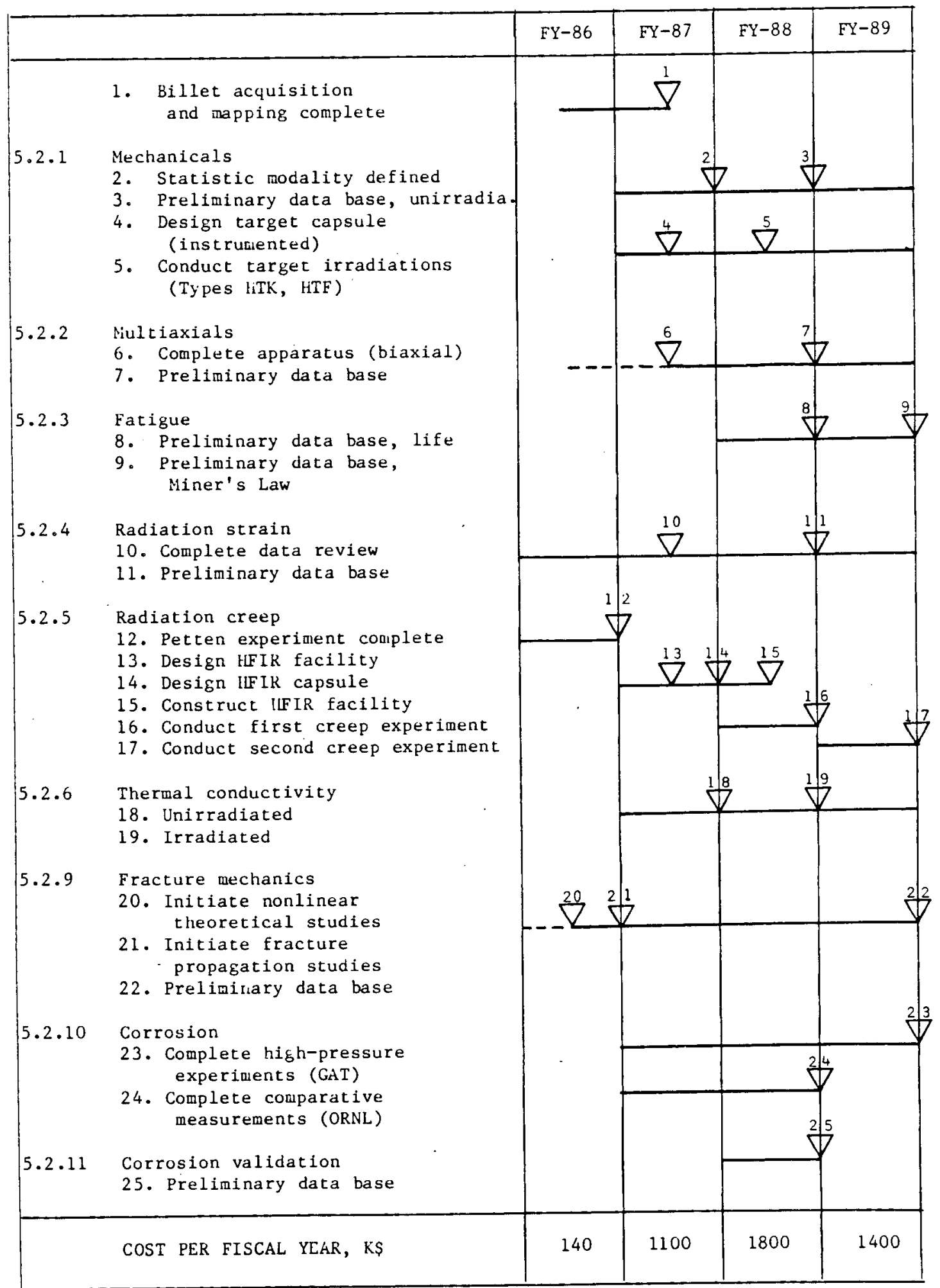


Table 5.8. Graphite technology development plan: Cost by Program Element

Program Element

5.1 Permanent Graphite Components

5.1.1 Unaxial Mechanicals

5.1.2 Multiaxial Strength

5.1.3 Fatigue Strength

5.1.4 Irradiation Effects

5.1.5 Thermal Conductivity

5.1.6 Emissivity

5.1 .7 Specific Heat

5.1 .8 Corrosion

5.1.9 Procurement
$\underline{\mathrm{K} S(1986) \quad \mathrm{KS}(1986)}$

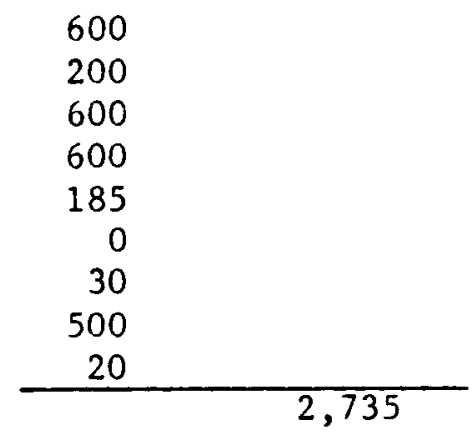

5.2 Core Components

5.2.1 Mechanical Properties 550

5.2.2 Multiaxial Strength 700

5.2.3 Fatigue Strength 175

5.2 .4 Irradiation Strain 250

5.2.5 Irradiation Creep 4,000+

5.2.6 Thermal Conductivity 240

5.2.7 Emissivity

5.2.8 Specific Heat

5.2.9 Fracture Mechanics 800

5.2.10 Corrosion Characteristics 950

5.2.11 Corrosion Validation 400

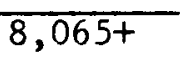

5.3 Nondestructive Evaluation

TOTAL

100

$10,900+$ 
PC-000213/1

APPENDIX A

DESIGN DATA NEEDS 


\author{
VALIDATION OF DESIGN METHODS FOR GRAPHITE CORROSION \\ DDN $M .10 .01$ \\ PROJECT NUMBER 6300
}

PLANT: $4 \times 350 \mathrm{MW}(\mathrm{t})$ Moduiar HTGR/System: 10

1. REQUIREMENT OR DESIGN FEATURE REQUIRING EXPERIMENTAL DATA OR VALIDATION TESTING

The design methods and codes used to predict the extent of corrosion of graphite components by coolant impurities must be validated to have the specified predictive accuracies for normal operating conditions and for moisture ingress transients.

Associated data needs: DDNs M.10.18.08 and M.10.18.09.

1.1 Summary of Function Number/Title/Assumptions

E1.1.2.1.2.2.4 "Maintain Fuel Element Structural Integrity," Assumption 7: The existing design methods and computer codes for calculating H-451 graphite corrosion are accurate within a factor of [3] at $95 \%$ confidence.

1.2 Current Data Base Summary

Calculational methods have been developed to predict graphite corrosion in a HTGR environment. These methods include the computer codes GOP, OXIDE, CSBBO, and HYDROBURN. The codes are based on the current data base on corrosion of various graphites developed in a laboratory environment. The validity of the models for graphite corrosion in the HTGR environment have not been thoroughly assessed al though limited comparisons with surveillance data from FSV have been made with apparent good success.

1.3 Data Needed

Validation of the integrated models and computer codes used to predict graphite corrosion in the HTGR core under normal operation and during steam and air ingress events are needed in order to assure that the predictive methods are accurate to within [3x] at 95\% confidence. Particular attention must be given to transport of coolant impurities in fuel element graphite and to effect of catalysis by graphite impurities and fission metals. The data base used for code validation must be independent from the data from which the individual correlations in the overall design method (effective diffusivities, reaction kinetics, etc.) were originally derived, in accordance with sof tware standard IEEE Standard 730-1984 and software definitions in NUREG-0856. Quality assurance must be in accordance with the requirements for Quality Assurance Level $I$. 
1.4 Data Parameters/Service Conditions

The service conditions are given below:

a. Normal Operation

Environment

Hel ium

Maximum fast fluence ( $E>29$ fJ HTGR)

$\left[5 \times 10^{21}\right] \mathrm{n} / \mathrm{cm}^{2}$

Maximum gamma flux

$[\mathrm{TBD}] \mathrm{MEV} / \mathrm{cm}^{2}-\mathrm{s}$.

Primary coolant temperature range

$[120 \text { to } 700]^{\circ} \mathrm{C}$

Fuel element temperature range

$[120-950]{ }^{\circ} \mathrm{C}$

Reflector element temperature range

$[120-900]{ }^{\circ} \mathrm{C}$

Maximum time averaged coolant impurity levels

[2] $\mathrm{ppm} \mathrm{H}_{2} \mathrm{O}$

[5] $\mathrm{ppm} \mathrm{CO}$

[2] $\mathrm{ppm} \mathrm{CO}_{2}$ Total oxidants

$<$ [10] ppm maximum but not to exceed

[600] ppm days per year

Helium coolant pressure

$1-63 \mathrm{~atm}$

b. Moisture Ingress Conditions

Environment

Helium

Coolant pressure range

$1-63 \mathrm{~atm}$

Fuel element temperature range

$[120-300]{ }^{\circ} \mathrm{C}$

Reflector element temperature range

$[120-300]{ }^{\circ} \mathrm{C}$

Core support temperature range

$[120-900]{ }^{\circ} \mathrm{C}$

Range of coolant impurity levels

[TBD] $\mathrm{ppm} \mathrm{H}_{2} \mathrm{O}$

[TBD] $\mathrm{ppm} \mathrm{CO}$

[TBD] $\mathrm{ppm} \mathrm{CO}_{2}$

Total Oxidants [TBD]

\section{DESIGNER'S ALTERNATIVES}

The following alcernatives have been considered:

2.1 Complete the design on the basis that the methods are acceptable without validation. 
2.2 Eliminate the need to validate the design methods by including sufficient margin in the design to account for the uncertainties.

2.3 Impose tighter tech specs on primary coolant oxidant leveis.

2.4 Use a higher purity, more corrosion-resistant graphite.

3. SELECTED APPROACH AND EXPLANATION

The selected approach is to obtain a data base on the corrosion of graphite components in support of code validation under conditions expected in a modular HTGR. Alternative 2.1 would involve the risk of rejection in licensing. Alternative 2.2 may require excessively large margins in the design to account for uncertainties in the design methods. Alternative 2.3 would have an adverse effect on plant availability. Alternative 2.4 would lead to large increases in the development costs.

4. SCHEDULE REQUIREMENTS

Preliminary data by [3/89], six months prior to PSSAR submittal (9/89) and final data by [9/92], one year prior to FSSAR submittal (9/93).

5. PRIORITY

$2 \mathrm{H}$

6. FALLBACK POSITION AND CONSEQUENCES OF NONEXECUTION

A combination of Alternatives $2.1,2.2$, and 2.3 , with the necessity of added conservatism in the design to compensate for calculational uncertainties. A weakened licensing position will result from this uncertainty. Another consequence of nonexecution will likely be unnecessarily restrictive tech specs on primary coolant impurities with an attendant adverse impact on plant availability.
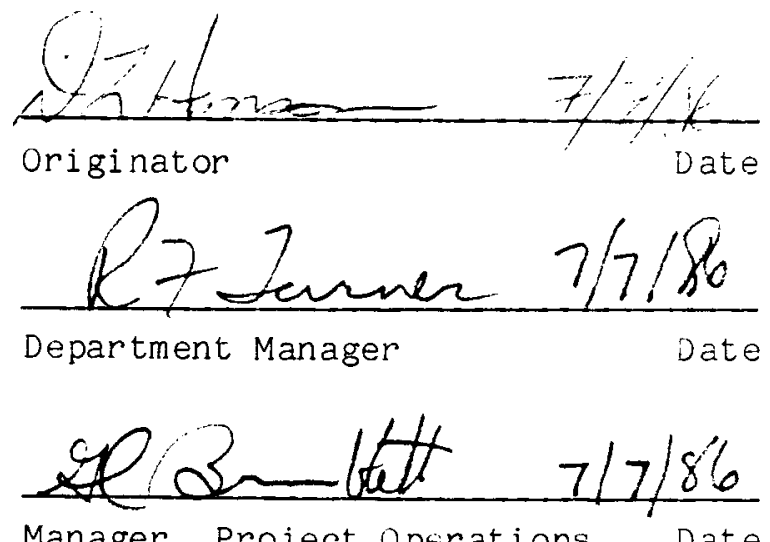

Manager, Project operations Date 
UNIAXIAL STRENGTH DATA BASE FOR CORE SUPPURT GRAPHITE

DDN M.10.17.01

PROJECT NUMBER 6300

PLANT: $4 \times 350 \mathrm{MW}(\mathrm{t})$ Modular HTGR/System: 10

1. REQUIREMENT OR DESIGN FEATURE REQUIRING EXPERIMENTAL DATA OR VALIDATION TEST ING

The graphite core support (CS) structure is designed to meet the stress limits of the ASME Code, Section III, Div. 2, Subsection CE. The codis gives the stress limits as a percentage of the "minimum ultimate strength" which is defined in probabilistic terms (99\% survivability at a confidence level of $95 \%$ ).

Associated data needs: DDN M.10.17.11.

\subsection{Summary of Function/Title/Assumptions}

F1.1.2.1.2.2.2.2.2.2, "Maintain Integrity of Graphite Core Support."

Assumption 3: Grade 2020 graphite can be manufactured in the size needed for the core support structure with minimum ultimat strengths of [2400] psi in tension and [3000] psi in compression.

\subsection{Current Data Base Summary}

The current reference material is 2020 graphite. Uniaxial strength (tensile, compressive, and flexural) data has been obtained in air at room temperature on axial and radial specimens from 49 standardproduction billets, $254 \mathrm{~mm}$ (10 in.) in diameter and $1.98 \mathrm{~m}$ (78 in.) long. A few strength measurements have been made on standardproduction 2020 graphite at temperatures up to $1500^{\circ} \mathrm{C}$ in an inert atmos phere.

A purified grade of 2020 graphite has been investigated to improve corrosion resistance. For the purified grade 2020 graphite, uniaxial strength measurements have been made in air at ambient temperature on axial and radial specimens from two standardproduction billets and one large rectangular billet with $660 \mathrm{~mm} x$ $660 \mathrm{~mm} \times 1.00 \mathrm{~m}$ (26 in. $\times 26$ in. $\times 39$ in.).

The current data base is judged adequate for conceptual design but needs to be increased for preliminary and final design. 
1.3 Data Needed

A uniaxial strength data base sufficient to meet the ASME Code statistical requirements is needed. Quality assurance must be in accordance with the requirements for Quality Assurance Level I. The data must be valid for 2020 graphite in two billet sizes:

a. Small cylindrical billet, $[178 \mathrm{~mm}$ (7 in.) $]$ in diameter and [1.22 $\mathrm{m}$ (48 in.)] long for core support posts.

b. Large cylindrical billet, [432 mm (17 in.)] in diameter and [1.22 $\mathrm{m}$ (48 in.)] long for core support blocks.

The data base must include data on:

a. Dependence on orientation, location in billet.

b. Variation from billet to billet and lot to lot.

The full statistical data base is needed at room temperature only. Some additional data points are needed to determine the effects of service temperatures. (Note that irradiation effects are covered by DDN M.10.17.11.)

\subsection{Data Parameters/Service Conditions}

a. Specified minimum ultimate strength, psi

Tensile

Compressive

[2400]

[3000]

b. Maximum point stress in core support components, psi

Tensile

[800]

Compressive

[1000]

c. Service temperature range, ${ }^{\circ} \mathrm{C} /{ }^{\circ} \mathrm{F}$

Minimum

$[120 / 248]$

Maximum

[900/1652]

d. Operating environment

Primary coolant

Hel i um

Pressure range

1 to 63 atmos

e. Radiation environment

Maximum fast neutron fluence ( $E>29 \mathrm{fJ}$, HTGR)

$$
\left[\begin{array}{lll}
1 & \times & 10^{2}
\end{array}\right] \mathrm{n} / \mathrm{cm}^{2}
$$




\section{DESIGNER'S ALTERNATIVES}

The following alternative has been considered:

2.1 Use the exisiting incomplete data base and include sufficient design margin to account for the uncertainties.

3. SELECTED APPROACH AND EXPLANATION

The selected approach is to obtain a statistically significant uniaxial strength data base for 2020 graphite in the billet sizes used for the case support components.

Design alternative 2.1 was rejected because it would result in 1 arger structural cross sections, higher primary loop pressure drop, lower plant operating efficiency, and higher operating costs.

4. SCHEDULE REQUIRMENTS

The final data are needed by [9/91], one year after the start of the final design phase $(9 / 90)$.

5. PRIORITY

$1 \mathrm{M}$

\section{FALLBACK POSITION AND CONSEQUENCES OF NONEXECUTION}

Design alternative 2.1 would be used resulting in larger structural sizes. This would cause additional primary coolant loop pressure drop which would reduce plant operating efficiency and increase operating costs. In addition, licensing difficulties may be encountered when trying to convince the NRC that the approach has adequate safety margin in light of limited data.

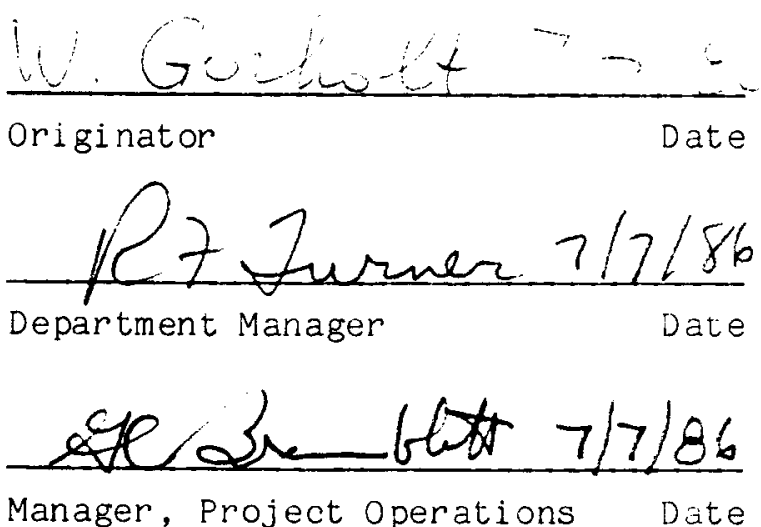


UNIAXIAL STRENGTH DATA BASE FOR PERMANENT REFLECTOR GRAPHITE

DDN M.10.17.02

PROJECT NUMBER 6300

PLANT: $4 \times 350 \mathrm{MW}(\mathrm{t})$ Modular HTGR/System: 10

1. REQUIREMENT OR DESIGN FEATURE REQUIRING EXPERIMENTAL DATA OR VALIDATION TESTING

The permanent side reflector (PSR) is designed to meet the stress limits of the ASME Code, Section III, Div. 2, Subsection CE. The code gives the stress limits as a percentage of the "minimum ultimate strength" which is defined in probabilistic terms ( $99 \%$ survivability at a confidence level of $95 \%$ ).

Associated data needs: DDN M.10.17.12.

\subsection{Summary of Function/Title/Assumptions}

F1.1.1.1.2.2.1.3.2, "Maintain Integrity of Side Reflectors."

Assumption 3: Grade 2020 graphite can be manufactured in the size needed for the permanent reflector components with minimum ultimate strengths of [1950] psi in tension and [2400] psi in compression.

1.2 Current Data Base Summary

The current reference material is 2020 graphite. Uniaxial strength (tensile, compressive, and flexural) data has been obtained in air at room temperature on axial and radial specimens from 49 standardproduction billets, $254 \mathrm{~mm}$ (10 in.) in diameter and $1.98 \mathrm{~m}$ (73 in.) long. A few strength measurements have been made on standardproduction 2020 graphite at temperatures up to $1500^{\circ} \mathrm{C}$ in an inert atmosphere.

A purified grade of 2020 graphite has been investigated to improve corrosion resistance. For the purified grade 2020 graphite, uniaxial strength measurements have been made in air at ambient temperature on axial and radial specimens from two standardproduction billets and one large rectangular billet of dimensions $660 \mathrm{~mm} \times 660 \mathrm{~mm} \times 1.00 \mathrm{~m}$ (26 in. $\times 26$ in. $\times 39$ in.).

The current data base is judged adequate for conceptual design but needs to be increased for preliminary and final design. 
1.3 Data Needed

A uniaxial strength data base sufficient to meet the ASME Code statistical requirements is needed. Quality assurance must be in accordance with the requirements for Quality Assurance Level I.

The data base must include data on:

a. Dependence on orientation and location in billet.

b. Variation from billet to billet and lot to lot.

The full statistical data base is needed at room temperature only. Some additional data points are needed to determine the effects of the service temperatures. (Note that irradiation effects are covered by DDN M.10.17.12.)

1. 4 Data Parameters/Service Conditions

a. Specified minimum ultimate strength, psi

Tensile

Compressive

[1950]

[2400]

b. Maximum point stress in PSR, psi

Tensile

Compressive

c. Service temperature range, ${ }^{\circ} \mathrm{C} /{ }^{\circ} \mathrm{F}$

Minimum

$[120 / 248]$

Maximum

[500/932]

d. Operating environment

Primary coolant

Hel i um

Pressure range

1 to 63 atmos

e. Radiation environment

Maximum fast neutron fluence ( $E>29 \mathrm{fJ}$, HTGR)

$\left[2 \times 10^{2} \mathrm{l}\right] \mathrm{n} / \mathrm{cm}^{2}$ 


\section{DESIGNER'S ALTERNATIVES}

The following aiternative has been considered:

2.1 Use the existing incomplete data base and include sufficient design margin to account for the uncertainties.

3. SELECTED APPROACH AND EXPLANATION

The selected approach is to obcain a statistically significant uniaxial strength data base for 2020 graphite in the billet size needed for the permanent side reflector blocks.

Design al ternative 2.1 was rejected because it would result in larger structural cross sections, larger outside diameter of the PSR, larger core cavity diameter, and higher capital costs.

4. SCHEDULE REQUIRMENTS

The final data are needed by [9/91], one year after the start of the final design phase $(9 / 90)$.

5. PRIORITY

$2 \mathrm{M}$

6. FALLBACK POSITION AND CONSEQUENCES OF NONEXECUTION

Design alternative 2.1 would be used resulting in larger structural sizes. This would cause the outer diameter of the permanent side reflector to increase resulting in a larger core cavity diameter and higher capital cost. In addition, licensing difficulties may be encountered when trying to convince the NRC that the approach has adequate safety margin in light of 1 imited data.
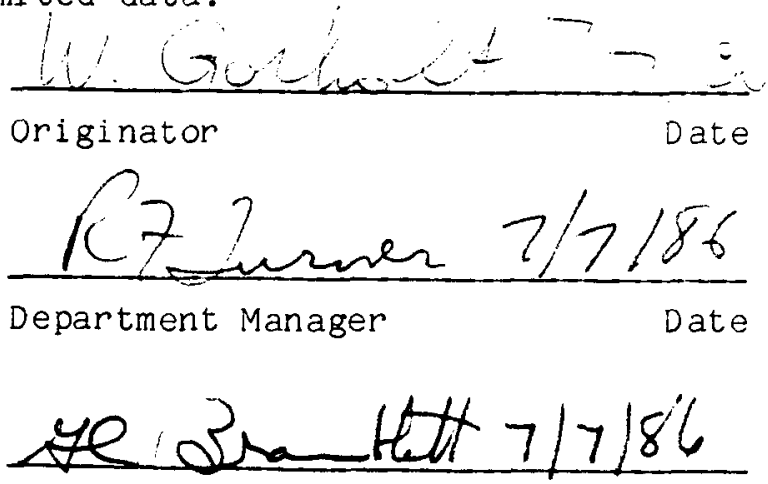

Manager, Project operations Date 
MULTIAXIAL STRENGTH OF GRAPHITE FOR CORE SUPPORT

DDN M.10.17.03

PROJECT NUMBER 6300

PLANT: $4 \times 350 \mathrm{MW}(\mathrm{t})$ Modular HTGR/System: 10

1. REQUIREMENT OR DESIGN FEATURE REQUIRING EXPERIMENTAL DATA OR VALIDATION TESTING

The conceptual design of the core support structure has been done on the basis of the maximum stress failure theory which is a simplified approximation whose uncertainty needs to be quantified. If the uncertainty is large, a more accurate theory will then be developed.

Associated data needs: DDN M.10.17.01.

1.1 Summary of Function/Title/Assumptions

F1.1.2.1.2.2.2.2.2.2, "Maintain Integrity of Graphite Core Support." Assumption 2. The maximum stress failure theory is a reasonable approximation for 2020 graphite under a multiaxial state of stress.

1.2 Current Data Base Summary

Exploratory biaxial stress tests were performed in 1980 on core support graphite. The tests yielded a limited number of biaxial stress data points. These are not sufficient to quantify the error in the maximum stress failure theory.

\subsection{Data Needed}

Data are needed to determine the reduction in the uniaxial strength of core support graphite due to multiaxial stress conditions. The data are needed for bi- and triaxial tension and tension/compression combinations. The data base must be adequate to show with [95]\% confidence that the mean value of the uniaxial strength is not reduced by more than:

$[15] \%$ in a biaxial stress field

[20]\% in a triaxial stress field

The above statistical data base is needed only for unirradiated graphite at room temperature in air. An additional small number of data points are needed on the effects of the service conditions. Quality assurance must be in accordance with the requirements for Quality Assurance Level I. 
1.4 Data Parameters/Service Conditions

a. Specified minimum ul timate

strength, psi

Tensile Compressive

Small cylindrical billet

[7 in.] diam $x$ [48 in.] long

[2400]

[3000]

for core support posts

Large cylindrical billet

[17 in.] diam $x$ [48 in.] long

[2400]

$[3000]$

for core support blocks

b. Maximum point stress, psi

In core support post

[800]

[1000]

In core support block

[800]

[1000]

C. Service temperature range, ${ }^{\circ} \mathrm{C} /{ }^{\circ} \mathrm{F}$

Minimum

$[120 / 248]$

Maximum

d. Operating environment

Primary coolant

Helium

Pressure range

1 to 63 atmos

e. Radiation environment

Maximum fast fluence $(E>29 \mathrm{fJ}, \operatorname{HTGR})\left[1 \times 20^{20}\right] \mathrm{n} / \mathrm{cm}^{2}$

2. DESIGNER'S ALTERNATIVES

The following alternatives are available:

2.1 Continue to use the maximum stress failure theory without further vaidation.

2.2 Use the maximum stress failure theory, estimate the error on the basis of the existing data and include sufficient design margin to account for the uncertainties.

3. SELECTED APPROACH AND EXPLANATION

The selected approach is to obtain a multiaxial strength data base sufficient to bound the error in the simple maximum stress theory. If the error is unacceptably large, a more accurate failure theory will then be developed. 
Alternative 2.1 was rejected due to the risk of not being acceptable for licensing.

Alternative 2.2 would resuli in unnecessarily large structural cross sections.

4. SCHEDULE REQUIREMENTS

The final data are needed at the start of the final design phase (9/90).

5. PRIORITY

$3[\mathrm{M}]$

6. FALLBACK POSITION AND CONSEQUENCES OF NON-EXECUTION

Designer's alternative 2.2 would be used. The consequences would be increased structural sizes. This would cause additional primary coolant loop pressure drop which would reduce plant operating efficiency and increase operating costs. In addition, licensing difficulties may be encountered when trying to convince the NRC that the approach has adequate safety margin in light of limited data.
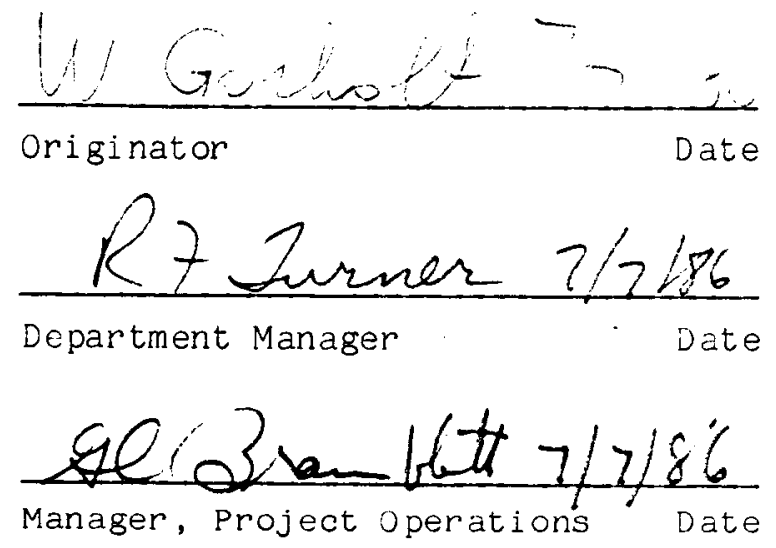


\author{
MULT IAXIAL STRENGTH OF GRAPHITE FOR PERMANENT REFLECTOR \\ DDN M.10.17.04 \\ PROJECT NUMBER 6300
}

PLANT: $4 \times 350 \mathrm{MW}(\mathrm{t})$ Modular HTGR/System: 10

1. REQUIREMENT OR DESIGN FEATURE REQUIRING EXPERIMENTAL DATA OR VALIDATION TESTING

The conceptual design of the permanent side reflector has been done on the basis of the maximum stress failure theory which is a simplified approximation whose uncertainty needs to be quantified. If the uncertainty is large, a more accurate theory will then be developed.

Associated data needs: DDN M.10.17.02.

\title{
1.1 Summary of Function/Title/Assumptions
}

F1.1.1.1.2.2.1.3.2, "Maintain Integrity of Side Reflector."

Assumption 2. The maximum stress failure theory is a reasonable

approximation for 2020 graphite under a multiaxial state of stress.

1.2 Current Data Base Summary

Exploratory biaxial stress tests were performed in 1980 on permanent reflector graphite. The tests yielded a limited number of biaxial stress data points. These are not sufficient to quantify the error in the maximum stress failure theory.

\subsection{Data Needed}

Data are needed to determine the reduction in the uniaxial strength of permanent reflector graphite due to multiaxial stress conditions. The data are needed for bi- and triaxial tension and tension/ compression combinations. The data base must be adequate to show with [95]\% confidence that the mean value of the uniaxial strength is not reduced by more than:

$$
\begin{aligned}
& {[15] \% \text { in a biaxial stress field }} \\
& {[20] \% \text { in a triaxial stress field }}
\end{aligned}
$$

The data base must be valid for 2020 graphite in a large rectanguler billet of dimensions [20.5 in. $x 20.5$ in. $x 39$ in.]. Quality assurance must be in accordance with the requirements for Quality Assurance Level I. 
The above statistical data base is needed only for unirradiated graphite at room temperature in air. An additional small number of data points are needed on the effects of the service conditions.

1.4 Data Parameters/Service Conditions

a. Specified minimum uItimate strength, psi

Tensile

Compressive

b. Maximum point stress in PSR, psi

Tensile

Compressive

c. Service temperature range, ${ }^{\circ} \mathrm{C} /{ }^{\circ} \mathrm{F}$

Minimum

Maximum
$[1950]$

[2400]

[650]

$[800]$

[120/248]

[500/932]

d. operating environment

Primary coolant

Hel ium

Pressure range

1 to 63 atmos

e. Radiation environment

Fast neutron fluence ( $E>29 \mathrm{fJ}, \mathrm{HTGR})\left[2 \times 10^{20}\right] \mathrm{n} / \mathrm{cm}^{2}$

2. DESIGNER'S ALTERNATIVES

The following alternatives are available:

2.1 Continue to use the maximum stress failure theory without further vali dation.

2.2 Use the maximum stress failure theory, estimate the error on the basis of the existing data and include sufficient design margin to account for the uncertainties.

3. SELECTED APPROACH AND EXPLANATION

The selected approach is to obtain a multiaxial strength data base sufficient to bound the error in the simple maximum stress theory. If the error is unacceptably large, a more accurate failure theory will then be developed.

Alternative 2.1 was rejected due to the risk of not being acceptable for licensing. 
Alternative 2.2 would result in unnecessarily large structural cross sections.

4. SCHEDULE REQUIREMENTS

The final data is needed at the start of the final design phase (9/90).

5. PRIORITY

$3[\mathrm{M}]$

6. FALLBACK POSITION AND CONSEQUENCES OF NON-EXECUTION

Designer's alternative 2.2 would be used. The consequences would be increased structural sizes. This would cause the outer diameter of the permanent side reflector to increase resulting in a larger core cavity diameter and increased plant construction costs. In addition, licensing difficulties may be encountered when trying to convince the NRC that the approach has adequate safety margin in 1 ight of limited data.

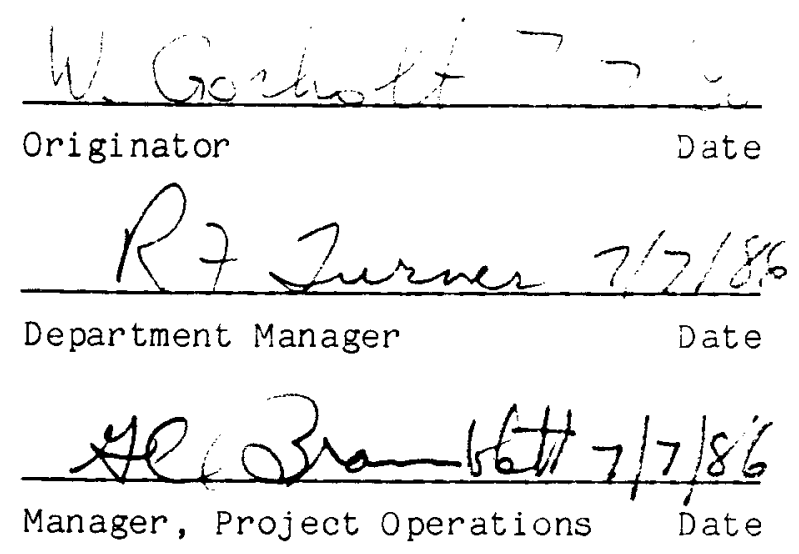




\section{FATIGUE STRENGTH OF GRAPHITE FOR CORE SUPPORT COMPONENTS}

DDN M.10.17.05

PROJECT NUMBER 6300

PLANT: $4 \times 350 \mathrm{MW}(\mathrm{t})$ Modular HTGR/System 10

1. REQUIREMENT OR DESIGN FEATURE REQUIRING EXPERIMENTAL DATA OR VALIDATION TESTING

To establish structural integrity of the core supports under cyclic loadings (e.g., plant transients, flow-induced vibration, and seismic vibration), fatigue analysis is required by the ASME Code. For this analysis, the fatigue strengths of core support component graphites must be determined.

\subsection{Summary of Function/Title/Assumptions}

F1.1.2.1.2.2.2.2.2.2 "Maintain Integrity of Graphite Core Support." Assumption 12: The cycle fatigue endurance limits for 2020 graphite specified in the Graphite Design Data Manual are valıd.

\subsection{Current Data Base Summary}

Some uniaxial push-pull fatigue preliminary tests in air at ambient temperature have been made on axial and radial specimens of standard production grade 2020 graphite. In each case the tests were made on specimens from a single billet. The stress ratio, $R$ (ratio between the minimum stress and the maximum stress during a cycie), varied between -2 and 0 . Forty or fifty specimens were tested for each orientation and stress ratio, to a maximum of $10^{5}$ cycles.

\subsection{Data Needed}

A fatigue strength data base sufficient to construct a Design Fatigue Diagram* is needed. The data base must be sufficient to establish a [95]\% confidence that the mean values of the data base do not differ from the mean values of the population by more than $[10] \%$. The data base must include:

a) Up to $10^{5}$ cycles.

b) Stress ratio, $\mathrm{R}$ (ratio between the minimum and maximum stress during a cycle) ranging from $[-1]$ to $[+1]$.

c) Dependence on orientation and location in billet and on variation from billet to billet.

*As defined in the draft of Subsection CE of the ASME Code. 
In addition, a small number of data points are needed to determine the effects of the operating environment. Quality assurance must be in accordance with the requirements for Quality Assurance Level I.

\subsection{Data Parameters/Service Conditions}

a. Specified minimum ultimate strength, tensile/compressive, psi

Small cylindrical billet for core support posts [2400]/[3000] Large cylindrical billet for core support blocks L2400]/[3000]

b. Data range from 1 cycle to $10^{5}$ cycles

c. Operating Environment

$\begin{array}{ll}\text { Primary coolant } & \text { Hel ium } \\ \text { Pressure } & 1 \text { to } 63 \text { atms }\end{array}$

d. Service Temperature Range, ${ }^{\circ} \mathrm{C} /{ }^{\circ} \mathrm{F}$
Minimum
$[120 / 248]$
Maximum

e. Irradiation

Maximum fast fluence ( $\mathrm{E}>29 \mathrm{fJ}, \mathrm{HTCR}$ )

$$
\left[1 \times 10^{20}\right] \mathrm{n} / \mathrm{cm}^{2}
$$

2. DESIGNER'S ALTERNATIVES

2.1. Use currently available fatigue data of standard production 2020 graphite and include additional design margin to cover uncertainties.

\section{SELECTED APPROACH AND EXPLANATION}

The selected approach is to complete the fatigue strength data base for grade 2020 graphite billets including data on the effects of the operating environment.

This will negate the need to invoke design alternative 2.1 which would result in large structural sizes leading to a reduced plant operating efficiency and higher operating cost due to increased primary coolant loop pressure drop.

4. SCHEDULE REQUIREMENTS

Final data base is needed by [9/91] one year after start of final design $[9 / 90]$.

\section{PRIORITY}




\section{FALLBACK POSITION AND CONSEQUENCES OF NONEXECUTION}

Design Alternative 2.1 would be used. The resulting increased structural cross section sizes would cause additional primary coolant loop pressure drop reducing plant operating efficiency and increasing operating costs. In addition, licensing difficulties may be encountered when trying to convince the NRC that the approach has adequate safety margin in light of limited data.
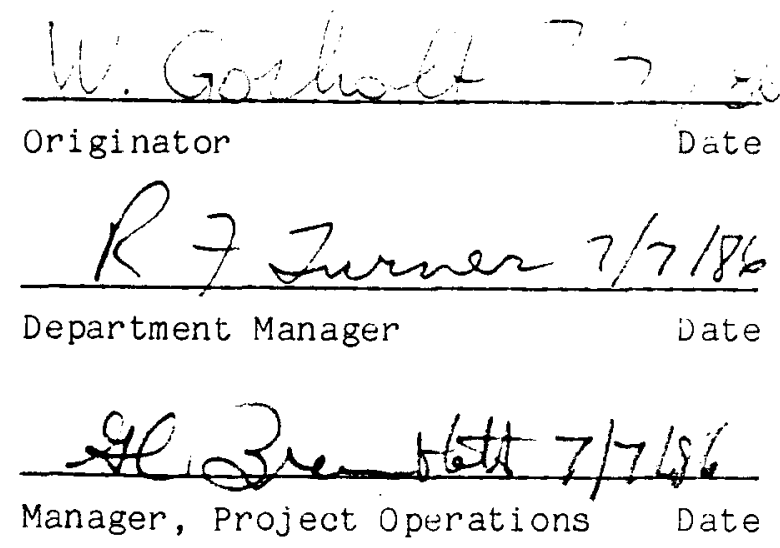


\title{
DATE : $7 / 3 / 86$
}

\author{
FATIGUE STRENGTH OF GRAPHITE FOR PERMANENT REFLECTORS \\ DDN M.10.17.06 \\ PROJECT NUMBER 6300
}

PLANT: $4 \times 350 \mathrm{MW}(t)$ Modular HTGR/System 10

\section{REQUIREMENT OR DESIGN FEATURE REQUIRING EXPERIMENTAL DATA OR VALIDATION TESTING}

To establish structural integrity of the permanent side reflectors under cyclic loadings (e.g., plant transients, flow-induced vibration, and seismic vibration), fatigue analysis is required by the ASME Code. For. this analysis, the fatigue strengths of the permanent reflector componen: graphite must be determined.

\subsection{Summary of Function/Title/Assumptions}

Function F.1.1.1.1.2.2.1.3.2, "Maintain Integrity of side Reflector," Assumption 12: The cycle fatigue endurance limits for' 2020 graphite specified in the Graphite Design Data Manual are valid.

\subsection{Current Data Base Summary}

Some uniaxial push-pull preliminary fatigue tests in air at ambient temperature have been made on axial and radial specimens of standard production grade 2020 graphite. In each case the tests were made on specimens from a single billet. The stress ratio, $\mathrm{R}$ (ratio between the minimum stress and the maximum stress during a cycle), varied between -2 and 0 . Forty or fifty specimens were tested for each orientacion and stress ratio to a maximum of $10^{5}$ cycles.

\subsection{Data Needed}

A fatigue strength data base sufficient to construct a Design Fatigue Diagram* is needed. The data base must be sufficient to establish a [95]\% confidence that the mean values of the data base do not differ from the mean values of the population by more than $[10] \%$. The data base must include:

a) Up to $10^{5}$ cycles.

b) Stress ratio, $R$ (ratio between the minimum and maximum stress during a cycle) ranging from $[-1]$ to $[+1]$. As defined in the draft of Subsection CE of the ASME Code. 
c) Dependence on orientation and location of billet and on variation from billet to billet.

In addition, a small number of data points are needed to determine the effects of the operating environment. Quality assurance must be in accordance with the requirements for Quality Assurance Level I.

1.4 Data Parameters/Service Conditions

a. Specified minimum ultimate strength, psi

Tensile [1950]

Compressive [2400]

b. Data range from 1 cycle to $10^{5}$ cycles.

c. Operating environment

Primary coolant Helium

Pressure 1 to 63 atmos

d. Service temperature range, ${ }^{\circ} \mathrm{C} /{ }^{\circ} \mathrm{F}$

Minimum $\quad[120 / 248]$

Maximum [500/932]

f. Irradiation

Maximum fast fluence ( $\mathrm{E}>29 \mathrm{fJ}, \mathrm{HTGR}$ ) $\left[2 \times 10^{20}\right] \mathrm{n} / \mathrm{cm}^{2}$

2. DESIGNER'S ALTERNATIVES

The following alternative is available:

2.1. Use currently available fatigue data of standard production 2020 graphite and include additional design margin to cover uncertainties.

3. SELECTED APPROACH AND EXPLANATION

The selected approach is to complete the fatigue strength data base for grade 2020 graphite billets including data on the effects of the operating environment. This will negate the need to invoke design alternative 2.1 which would result in large structural sizes leading to a reduced plant operating efficiency and higher operating cost due to increased primary coolant loop pressure drop.

4. SCHEDULE REQUIRMENTS

Final data base is needed by [9/91] one year after start of final design $[9 / 90]$. 


\section{PRIORITY}

$3 \mathrm{M}$

6. FALLBACK POSITION AND CONSEQUENCES OF NON-EXECUTION

Design Alternative 2.1 would be used. The resulting increased structural cross section sizes would cause the outer diameter of the permanent side reflector to increase resulting in a larger core cavity diameter and increased capital costs. In addition, licensing difficulties may be encountered when trying to convince the NRC that the approach has adequate safety margin in light of 1 imited data.
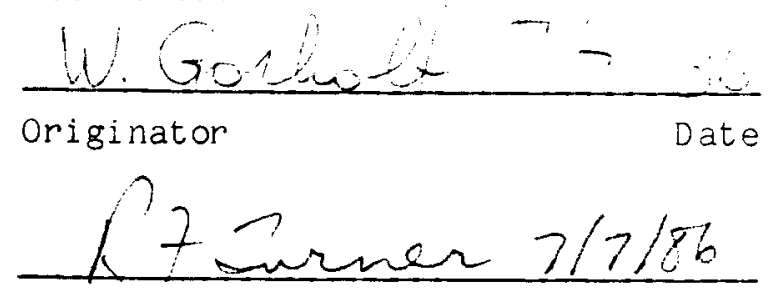

Department Manager Date

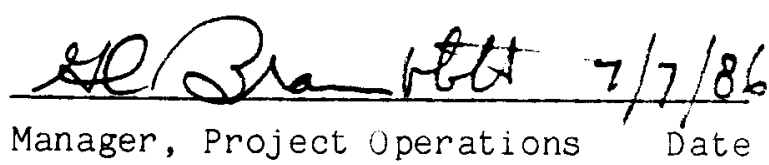


MINER'S LAW FOR GRAPHITE FOR CORE SUPPORT COMPONENTS

DDN M.10.17.07

PROJECT NUMBER 6300

PLANT: $4 \times 350 \mathrm{MW}(\mathrm{t})$ Modular HTGR/System 10

1. REQUIREMENT OR DESIGN FEATURE REQUIRING EXPERIMENTAL DATA OR VALIDATION TESTING

Miner's rule is used in the graphite-component fatigue analysis for combining the fatigue damage from different stress amplitudes. Miner's rule is used in metallic structures but has not been validated for graphite.

Associated data needs: DDN M.10.17.05.

1.1 Summary of Function/Title/Assumptions

Function F1.1.2.1.2.2.2.2.2.2, "Maintain Integrity of Graphite Core Support," Assumption 6: Miner's rule for estimating the cumularive fatigue is applicable to 2020 graphite.

\subsection{Current Data Base Summary}

No data is available on the applicability of Miner's rule to graphite.

\subsection{Data Needed}

Data are needed on the cumulative fatigue strength of core support graphite subjected to sequential series of stress cycles with different amplitude. The number of. cases (i.e., combinations of stress amplitudes) shall be selected such that a valid comparison can be made between the measured cumulative fatigue life and the cumulative fatigue 1 ife predicted by applying Miner's rule to the constant amplitude fatigue data established in DDN M.10.17.05.

A sufficient data base is needed to determine the difference betwe n constant amplitude fatigue life and varying amplitude fatigue life with $[95] \%$ confidence. Quality assurance must be in accordance with the requirements for Quality Assurance Level I. 
1.4 Data Parameters/Service Conditions

a. Specified minimum ultimate strength, tensile/compressive, psi

Small cylindrical billet for core support posts [2400]/[3000]

Large cylindrical billet for core support blocks [2400]/[3000]

b. Data range from 1 cycle to $10^{5}$ cycles with stress amplitudes of [Later].

c. Operating environment

Primary coolant Helium

Pressure 1 to 63 atmos

d. Service temperature range, ${ }^{\circ} \mathrm{C} /{ }^{\circ} \mathrm{F}$

$\begin{array}{ll}\text { Minimum } & {[120 / 248]} \\ \text { Maximum } & {[900 / 1652]}\end{array}$

e. Irradiation

Maximum fast fluence ( $\mathrm{E}>29 \mathrm{fJ}, \mathrm{HTGR}$ ) $\left[1 \times 10^{2} 0\right] \mathrm{n} / \mathrm{cm}^{2}$

2. DESIGNER'S ALTERNATIVES

2.1 Assume Miner's rule to be applicable without validation and design the core support components on this basis.

3. SELECTED APPROACH AND EXPLANATION

The selected approach is to obtain data on cumulative fatigue damage and verify Miner's rule for grade 2020 graphite at room temperatures. The selected approach would allow the structural elements to be sized with confidence to the requirements of the ASME Code reducing the risk of licensing difficulties.

4. SCHEDULE REQUIRMENTS

Final data base is needed by [9/91], one year after start of final design $(9 / 90)$.

5. PRIORITY

$4 \mathrm{~L}$ 
6. FALLBACK POSITION AND CONSEQUENCES OF NON-EXECUTION

Alternative 2.1 would be used. The consequences would be licensing difficulties in trying to convince the NRC that Miner's rule can safely be used for graphite in spite of the lack of validation.

If the data should show Miner's rule is not suitable for graphite, another design rule must be found. In that event additional testing and theoretical studies may be necessary.
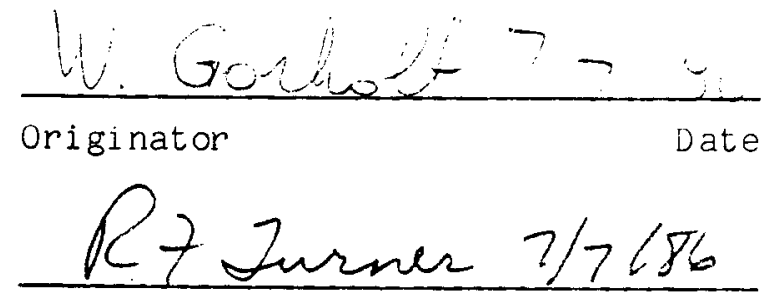

Department Manager

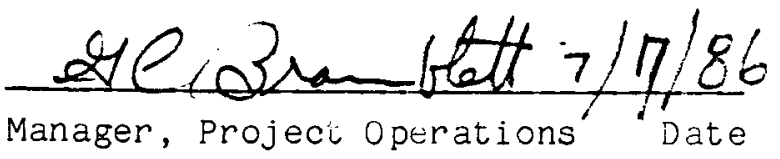




\section{DATE : $7 / 3 / 86$}

MINER'S LAW FOR GRAPHITE FOR PERMANENT SIDE REFLECTORS

DDN M.10.17.08

PROJECT NUMBER 6300

PLANT: $4 \times 350 \mathrm{MW}(t)$ Modular HTGR/System 10

1. REQUIREMENT OR DESIGN FEATURE REQUIRING EXPERIMENTAL DATA OR VALIDATION TESTING

Miner's rule is used in the graphite-component fatigue analysis for combining the fatigue damage from different stress amplitudes. Miner's rule is used in metallic structures but has not been validated for graphite.

Associated data needs: DDN M.10.17.06.

1.1 Summary of Function/Title/Assumptions

Function F.1.1.1.1.2.2.1.3.2 "Maintain Integrity of Side Reflector." Assumption 2: Miner's rule for estimating the cumulative fatigue is applicable to 2020 graphite.

\subsection{Current Data Base Summary}

No data is available on the applicability of Miner's rule to graphite.

1.3 Data Needed

Data are needed on the cumulative $f a t i g u e ~ s t r e n g t h$ of permanent reflector graphite subjected to sequential series of stress cycles with different amplitude. The number of cases (i.e., combinations of stress amplitudes) shall be selected such that a valid comparison can be made between the measured cumulative fatigue life and the cumulative fatigue 1 ife predicted by applying Miner's rule to the constant amplitude fatigue data established in DDN M.10.10.06.

A sufficient data base is needed to determine the difference between constant amplitude fatigue $l$ ife and varying amplitude fatigue 1 ife with $[95] \%$ confidence. Quality assurance must be in accordance with the requirements for Quality Assurance Level I. 
1.4 Data Parameters/Service Conditions

a. Specified minimum ul timate strength, psi

Tensile

[1950]

Compressive

b. Data range from 1 cycle to $10^{5}$ cycles with stress amplitudes of [Later]

c. Operating Environment

Primary coolunt Helium

Pressure 1 to 63 atms

d. Service Temperature Range, ${ }^{\circ} \mathrm{C} /{ }^{\circ} \mathrm{F}$

$\begin{array}{ll}\text { Minimum } & {[120 / 218]} \\ \text { Maximum } & {[500 / 932]}\end{array}$

e. Irradiation

Maximum fast fluence ( $E>29 \mathrm{fJ}, \mathrm{HTGR}$ )

$\left[2 \times 10^{20}\right] \mathrm{n} / \mathrm{cm}^{2}$

2. DESIGNER'S ALTERNATIVES

2.1 Assume Miner's rule to be applicable without validation and design the permanent reflector components on this basis.

3. SELECTED APPROACH AND EXPLANATION

The selected approach is to obtain data on cumulative fatigue damage and verify Miner's rule for grade 2020 graphite at room temperature. The selected approach would allow the structural elements to be sized with confidence to the requirements of the ASME Code reducing the risk of Iicensing difficulties.

4. SCHEDULE REQUIRMENTS

Final data base is needed by [9/91] one year after start of final design $(9 / 90)$.

5. $\quad$ PRIORITY

$4 \mathrm{~L}$

6. FALLBACK POSITION AND CONSEQUENCES ON NON-EXECUTION

Alternative 2.1 would be used. The consequences would be licensing difficulties in trying to convince the NRC that Miner's rule can safeiy be used for graphite in spite of the lack of validation. 
If the data should show that Miner's rule is not suitable for graphite, another design rule must be found. In that event additional testing and theoretical studies may be necessary.
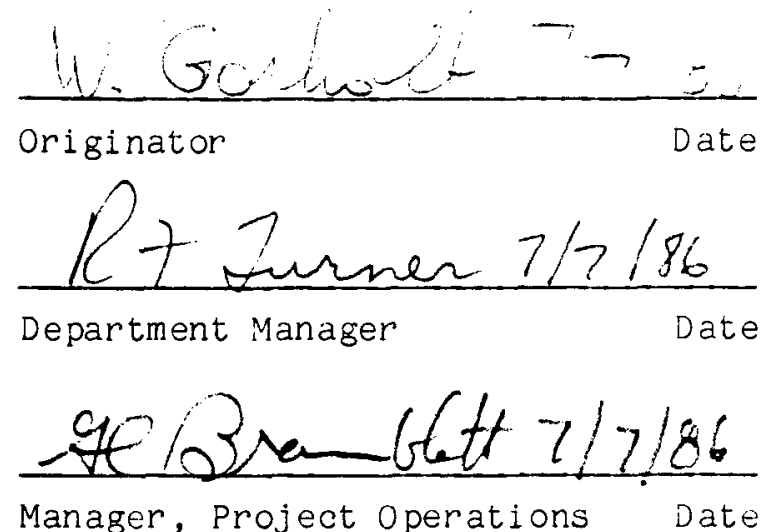


\author{
ELASTIC PROPERTIES DATA BASE FOR CORE SUPPORT GRAPHITE \\ DDN M.10.17.09 \\ PROJECT NUMBER 6300
}

PLANT: $4 \times 350 \mathrm{MW}(t)$ Modular HTGR/System 10

1. REQUIREMENT OR DESIGN FEATURE REQUIRING EXPERIMENTAL DATA OR VALIDATION TESTING

The graphite core support (CS) structure is designed to meet the allowable stress limits specified by the ASME Code Section III, Div. 2, Subsection CE. The code requires an adequate data base for the elastic properties.

Associated data needs: DDN M.10.17.11.

1.1 Summary of Function/Title/Assumptions

F1.1.2.1.2.2.2.2.2.2, "Maintain Integrity of Graphite Core Support."

Assumption 3: The mean values for the elastic properties of Young's modulus and Poisson's ratio given in the Graphite Design Data Manual for 2020 graphite are vailid.

\title{
1.2 Current Data Base Summary
}

The current reference material is 2020 graphite. Uniaxial tensile and compressive Young's moduli data has been obtained in air at room temperature on axial and radial specimens from 49 standardproduction billets, $254 \mathrm{~mm}$ (10 in.) in diameter and $1.98 \mathrm{~m}$ (78 in.) long. A few measurements have been made of Young's modulus at elevated temperatures.

A purified grade of 2020 graphite has been investigated to improve corrosion resistance. For the purified grade 2020 graphite, Young's modul us measurements have been made in air at ambient temperature on axial and radial specimens from two standard-production billets and one large rectangular billet of dimensions $660 \mathrm{~mm} \times 660 \mathrm{~mm} \times 1.00 \mathrm{~m}$ (26 in. $x 26$ in. $x 39$ in.).

The current data base is judged adequate for conceptual design but needs to be increased for preliminary and final design.

\subsection{Data Needed}

The required data must be valid for 2020 graphite in two different sizes of billtts: 
a. Small cylindrical billet, $[178 \mathrm{~mm}$ ( 7 in.) $]$ in diameter and [1.22 $\mathrm{m}$ ( $48 \mathrm{in.})]$ long for core support posis.

b. Large cylindrical billet, $[432 \mathrm{~mm}(17 \mathrm{in.})]$ in diameter and [1.22 $\mathrm{m}$ (48 in.)] long for core support blocks.

The data base must be sufficient to establish the mean values of Young's Modulus and Poisson's Ratio within $+[10] \%$ and $+[25] \%$, respectively, at [95]\% confidence. Some ad̄̄itional data points are needed to determine the effects of the operating environment (Note that irradiation effects are covered under DDN M.10.17.11). Quality assurance must be in accordance with the requirements for Quality Assurance Level I.

\subsection{Data Parameters/Service Conditions}

a. Specified minimum ultimate strength, psi

Tensile

Compressive

[2400]

$[3000]$

b. Maximum point stress in components, psi

Tensile

Compressive

c. Service temperature range, ${ }^{\circ} \mathrm{C} /{ }^{\circ} \mathrm{F}$

Minimum

Maximum

$[120 / 248]$

[900/1652]

d. Operating environment

Primary coolant

Pressure range

HeI i um

1 to 63 atmos

e. Radiation environment

Fast neutron fluence ( $E>29 \mathrm{fJ}, \mathrm{HTGR}$ )

$\left[1 \times 10^{20}\right] \mathrm{n} / \mathrm{cm}^{2}$

\section{DESIGNER'S ALTERNATIVES}

The following alternative has been considered:

2.1 Complete the design on the basis of the currently available data. 
3. SELECTED APPROACH AND EXPLANATION

The selected approach is to complete the Young's modul us and Poissons's ratio data base on grade 2020 graphite including data to reflect the conditions expected in a modular HTGR to reduce uncertainties in the predicted structural response of the core support structure.

The use of design alternative 2.1 would resuit in a weakened licensing position.

4. SCHEDULE REQUIRMENTS

The final data are needed by [9/91], one year after the start of the final design phase $(9 / 90)$.

5. PRIORITY

$1 \mathrm{~L}$

\section{FALLBACK POSITION AND CONSEQUENCES OF NUN-EXECUTION}

Design alternative 2.1 would be used. The consequences would be a risk of rejection during licensing resulting in a crash technology program and possibly schedule delays.
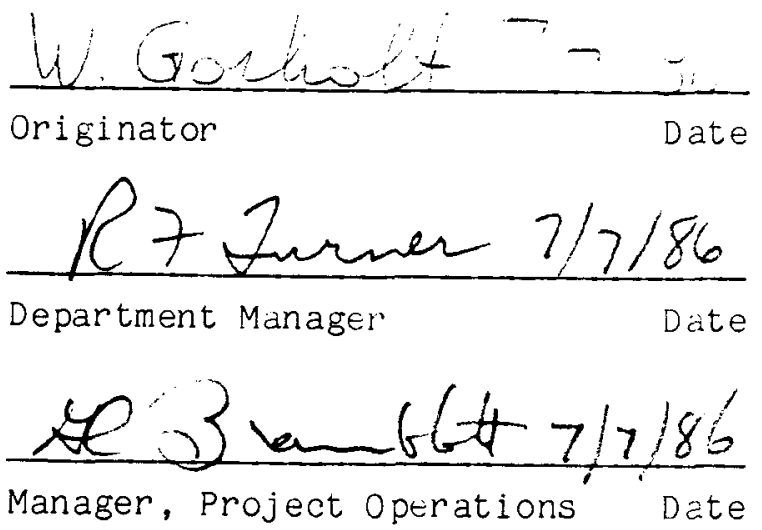
DATE : $\quad 7 / 3 / 86$

\author{
ELASTIC PROPERTIES DATA BASE FOR PERMANENT REFLECTOR GRAPHITE \\ DDN M.10.17.10 \\ PROJECT NUMBER 6300
}

PLANT: $4 \times 350 \mathrm{MW}(t)$ Modular HTGR/System 10

1. REQUIREMENT OR DESIGN FEATURE REQUIRING EXPERIMENTAL DATA OR VALIDATION TESTING

The graphite permanent side reflectors (PSR) are designed to meet the allowable stress limits specified by the ASME Code Section III, Div. 2, Subsection $\mathrm{CE}$. The code requires an adequate data base for the elastic properties.

Associated data needs: DDN M.10.17.12.

1.1 Summary of Function/Title/Assumptions

F1.1.1.1.2.2.1.3.2, "Maintain Integrity of Side Reflector."

Assumption 3: The mean values for the elastic properties of Young's modulus and Poisson's ratio given in the Graphite Design Data Manual for 2020 graphite are valid.

\title{
1.2 Current Data Base Summary
}

The current reference material is 2020 graphite. Uniaxial tensile and compressive Young's modul us data has been obtained in air at room temperature on axial and radial specimens from 49 standardproduction billets, $254 \mathrm{~mm}$ ( $10 \mathrm{in.}$ ) in diameter and $1.98 \mathrm{~m}$ (78 in.) long. A few Young's modulus measurements have been made at temperatures up to $1500^{\circ} \mathrm{C}$. No measurements have been made from large billets.

A purified grade of 2020 graphite has been investigated to improve corrosion 'sidiciance. I'vi the purified grade 2020 graphite, Young's modulus measurements have been made in air at ambient temperature on axial and radial specimens from two standard-production billets and one large rectangular biliet of dimensions $660 \mathrm{~mm} \times 660 \mathrm{~mm} \times 1.00 \mathrm{~m}$ (26 in. $x 26$ in. $x 39$ in.).

Current data base is judged adequate for conceptuai design but needs to be increased for preliminary and final design, especially in the large sizes appropriate to the permanent reflectors. 
1.3 Data Needed

A Young's moduius and Poisson's ratio data base is required. The data base must be valid for 2020 graphite in the $[0.52 \mathrm{~m} \times 0.52 \mathrm{~m} \times$ $1.00 \mathrm{~m}$ (20.5 in. $x 20.5$ in. $x 39$ in.) ] billet selected for the permanent side reflector blocks. The data base must be sufficient to establish the mean values of Young's Modulus and Poisson's Ratio within $\pm[10] \%$ and $\pm[25] \%$, respectively, at $[95] \%$ confidence. Some additional data points are needed to determine the effects of the operating environment. (Note that irradiation effects are covered under DDN M.10.17.12.) Quality assurance must be in accordance with the requirements for Quality Assurance Level I.

\subsection{Data Parameters/Service Conditions}

a. Specified minimum ultimate strength, psi

Tensile

[1950]

Compressive

[2400]

b. Maximum point stress in PSR, psi

Tensile

$[650]$

Compressive

c. Service temperature range, ${ }^{\circ} \mathrm{C} /{ }^{\circ} \mathrm{F}$

Minimum

Maximum

d. Operating environment

Primary coolant

Pressure range

e. Radiation environment

Fast neutron fluence ( $\mathrm{E}>29 \mathrm{fJ}, \mathrm{HTGR}$ )
Hel ium

1 to 63 atmos

$$
\left[2 \times 10^{2} 0\right] \mathrm{n} / \mathrm{cm}^{2}
$$

\section{DESIGNER'S ALTERNATIVES}

The following alternative has been considered:

2.1 Complete the design on the basis of the currently available data.

3. SELECTED APPROACH AND EXPLANATION

The selected approach is to complece the Young's modulus and Poisson's ratio data base on grade 2020 graphite including data to reflect the conditions expected in a modular HTGR to reduce uncertainties in the predicted structural response of the permanent side reflector. 
The use of design alternate 2.1 would result in a weakened licensing position.

4. SCHEDULE REQUIRMENTS

The final data are needed by $[9 / 91]$, one year after the start of final design phase $(9 / 90)$.

5. PRIORITY

$1 \mathrm{~L}$

6. FALLBACK POSITION AND CONSEQUENCES ON NON-EXECUTION

Design alternative 2.1 would be used. The consequences would be a risk of rejection during licensing resulting in a crash technology program and possibly schedule delays.
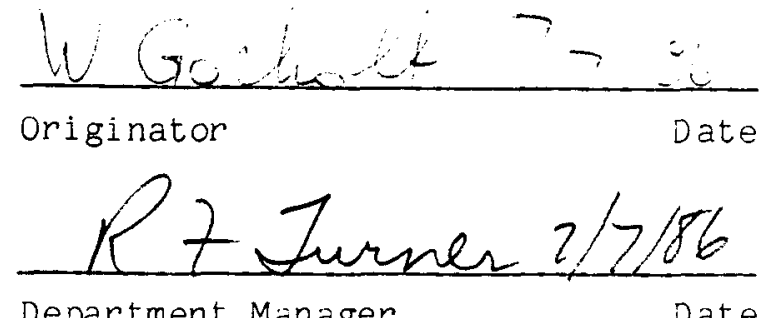

Department Manager

Date

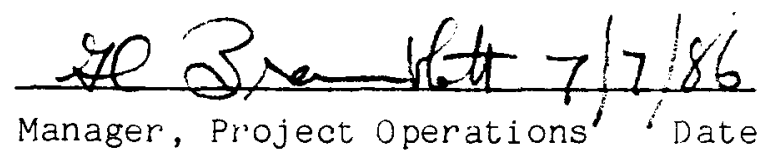


IRRADIATIUN EFFECTS ON MECHANICAL PROPERTIES OF CORE SUPPORT GRAPHITE DDN M.10.17.11

PROJECT NUMBER 6300

PLANT: $4 \times 350 \mathrm{MW}(\mathrm{t})$ Modular HTGR/System 10

1. REQUIREMENT OR DESIGN FEATURE REQUIRING EXPERIMENTAL DATA OR VALIDATION TESTING

The graphite core support components are required to satisfy the stress limits specified by the ASME Code Section III, Div. 2, Subsection CE. In showing compliance with the stress limits, the effects of the low level irradiation must be included.

Associated data needs are DDNs: M.10.17.01, M.10.17.09.

1.1 Summary of Function/Title/Assumptions

F1.1.2.1.2.2.2.2.2.2, "Maintain Integrity of Graphite Core Support."

Assumption 5: The effects of radiation on 2020 graphite mechanical properties are negligible.

1.2 Current Data Base Summary

A limited amount of irradiation test data are available on grade 2020 graphite but only at a fluence greater than $1.3 \times 10^{21}$ neutrons $/ \mathrm{cm}^{2}$.

1.3 Data Needed

Data are needed to def ine the effect of low levels of fast fluence on the Young's modulus, Poisson's ratio, and strength of 2020

graphite. The data base must be sufficient to establish with [95]\% confidence that the effects of irradiation are to 1) increase the minimum ultimate strength (see DDN M.10.17.01) and 2) change the mean values of Young's modulus and Poisson's ratio by less than $[10] \%$ (see DDN M.10.17.9). If the changes to Young's Modulus and Poisson's ratio exceed $10 \%$ the changes must be determined within $\pm[5] \%$ for Young's Modul us and $\pm[20] \%$ for Poisson's ratio. The required data must be valid for 2020 graphite in two sizes:

a. Small cylindrical billet, [178 mm (7 in.) ] in diameter and $1.22 \mathrm{~m}$ (48 in.)] long for core support posts.

b. Large cylindrical billet, $[432 \mathrm{~mm}$ (17 in.)] in diameter and $1.22 \mathrm{~m}$ ( 48 in.)] long for core support blocks. 
Quality assurance must be in accordance with the requirements for Quality Assurance Level I.

1.4 Data Parameters/Service Conditions
a. Specified minimum ul timate strength, psi
Tensile Compressive
Small cylindrical billet for
[2400]
$[3000]$
core support posts
Large cylindrical billet for
core support blocks
[2400]
$[3000]$
b. Point stress, psi
In core support post
In core support block
[800]
[800]
$[1000]$
c. Service temperature range, ${ }^{\circ} \mathrm{C} /{ }^{\circ} \mathrm{F}$
Minimum
$[120 / 248]$
Maximum
d. Operating environment
Primary coolant
Pressure range
$\mathrm{H} \in \mathrm{l}$ i um
1 to 63 atmos
e. Fast fluence range, neuirons $/ \mathrm{cm}^{2}$ (E > $29 \mathrm{fJ}, \mathrm{HTGR}$ )
Minimum
0
Maximum
$\left[1 \times 10^{20}\right]$

2. DESIGNER'S ALTERNATIVES

The following alternatives are available:

2.1 Complete the design on the assumption that the irradiation effects are negligible without further validation.
2.2 Increase the depth of the replaceable reflector so as to reduce the exposure of the core support structure to negligible levels of fast fluence.

3. SELECTED APPROACH AND EXPLANATION

The selected approach is to establish a data base for quantifying the effects of low level irradiation. 
Design Alternative 2.1 would weaken the licensing position. An increased depth of the bottom reflector (Alternative 2.2) would lead to reduced plant efficiency through increased core pressure drop and increased capital costs through the consequential increase in the size of the core cavity.

4. SCHEDULE REQUIREMENTS

The data are needed by [9/91] one year after the start of the final design phase $(9 / 90)$.

5. PRIORITY

$2 \mathrm{~L}$

6. FALLBACK POSITION AND CONSEQUENCES OF NUNEXECUTION

Design alternative 2.1 would be used. The consequences would be a risk of rejection during licensing, resulting in a crash technology program and possible schedule delays.
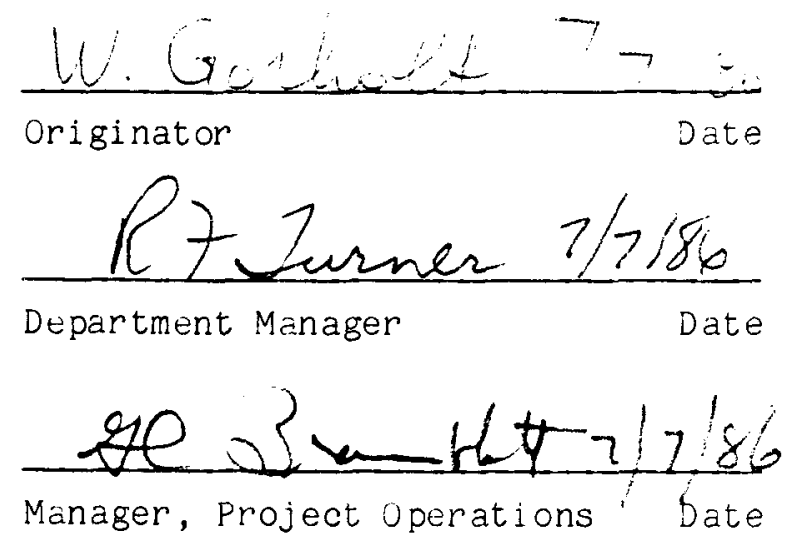
IRRADIATION EFFECTS ON MECHANICAL PROPERTIES OF PERMANENT REFLECTOR GRAPHITE DDN M.10.17.12

PROJECT NUMBER 6300

PLANT: $4 \times 350 \mathrm{MW}(\mathrm{t})$ Modular HTGR/System 10

i. REQUIREMENT OR DESIGN FEATURE REQUIRING EXPERIMENTAL DATA OR VALIDATION TESTING

Permanent side reflectors (PSR) are required to satisfy the stress 1 imits specified by the ASME Code Section III, Div. 2, Subsection CE. In showing compliance with the stress limits, the effects of the low level irradiation must be included.

Associated data needs: DDN's M.10.17.02 and 10.17.10.

1.1 Summary of Function/Title/Assumptions

F1.1.1.1.2.2.1.3.2, "Maintain Integrity of Side Reflector."

Assumption 5: The effects of radiation on 2020 graphite mechanical properties are negligible.

1.2 Current Data Base Summary

A limited amount of irradiation test data are available on grade 2020 graphite but only at a fluence greater than $1.3 \times 10^{21}$ neutrons $/ \mathrm{cm}^{2}$.

\subsection{Data Needed}

Data are needed to define the effect of low leveis of fast fluence on the Young's modulus, Poisson's ratio, and strength of 2020 graphite. The data base must be sufficient to establish with L95]\% confidence that the effects of irradiation are to 1) increase the minimum ultimate strength (see DDN M.10.17.01) and 2) change the mean values of Young's modulus and Poisson's ratio by less than [10]\% (see DDN M.10.17.10). The required data must be valid for 2020 graphite in the billet size selected for the permanent reflector blocks $[0.52 \mathrm{~m} \times 0.52 \mathrm{~m} \times 1.00 \mathrm{~m}$ (20.5 in. $x 20.5$ in. $x$ 39 in.)]. Quality assurance must be in accordance with the requirements for Quality Assurance Leve $\perp$. 
1.4 Data Parameters/Service Conditions
a. Specified minimum ul timate strength, psi
Tensile
[1950]
Compressive
$[650]$
[2400]
b. Point stress, psi
$[800]$
c. Service temperature range, ${ }^{\circ} \mathrm{C} /{ }^{\circ} \mathrm{F}$
Minimum
Maximum
$[120 / 248]$
$[500 / 932]$

d. Operating environment

Primary coolant

Helium

Pressure range

[1 to 65 atmos]

e. Fast fluence range, neutrons $/ \mathrm{cm}^{2}$ ( $E>29 \mathrm{fJ}, \mathrm{HTGR}$ )

Minimum

0

Maximum

$\left[2 \times 10^{20}\right]$

\section{DESIGNER'S ALTERNATIVES}

The following alternatives are available:

2.1 Complete the design on the assumption that the irradiation effects are negligible without further validation.

2.2 Increase the number of replaceable side reflectors so as to reduce the exposure of the permanent side reflectors to negligible levels of fast fluence.

\section{SELECTED APPROACH AND EXPLANATION}

The selected approach is to establish a data base for quantifying the effects of low level irradiation.

Design Alternative 2.1 would weaken the licensing position. Additional replaceable reflectors (Alternative 2.2) would lead to a larger core diameter and consequent increases in the diameters of the core barrel and of the reactor vessel. The consequence would be a substantial increast in the capital cost.

4. SCHEDULE REQUIRMENTS

The final data are needed by [9/91], one year after the start of the final design phase (9/90).

5. PRIORITY

$2 \mathrm{~L}$ 
6. FALLBACK POSITION AND CONSEQUENCES OF NONEXECUTION

Design alternative 2.1 would be used. The consequences would be a risk of rejection during licensing, resulting in a crash technology program and possible schedule delays.
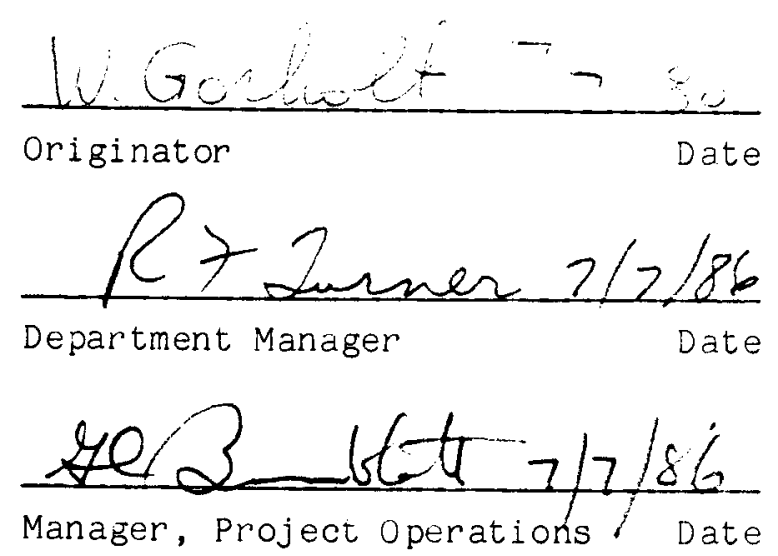


\section{THERMAL PROPERTIES OF CORE SUPPORT GRAPHITE}

DDN M.10.17.13

PROJECT NUMBER 6300

PLANT: $4 \times 350 \mathrm{MW}(\mathrm{t})$ Modular HTGR/System 10

1. REQUIREMENT OR DESIGN FEATURE REQUIRING EXPERIMENTAL DATA OR VALIDATION TESTING

To calculate the coolant and graphite temperatures and the associated size changes and thermal stresses in the core support components, a thermal properties data base is needed.

Associated data needs: DDN 10.17.15.

1.1 Summary of Function/Title/Assumptions

F1.1.2.1.2.2.2.2.2.2, "Maintain Integrity of Graphite Core Support."

Assumption 3: The mean values of thermai expansivity, thermai conductivity, and specific heat given in the Graphite Design Data Manual for 2020 graphite are valid.

Assumption 4: The lower bound for the emissivity of 2020 graphite is 0.8 .

1.2 Current Data Base Summary

Some thermal property data (e.g. specific heat, thermal expansivity, and thermal conductivity) of Grade 2020 graphite have been obtained from a very limited number of logs (or billets). The existing data base includes the mean value of the tested population, the withinlog standard deviation (for a particular orientation and location) and the log-to-log standard deviation. The uncertainty in the estimates of the population mean values and standard deviation is felt io be large because of the limited size of the data base. The current data base for grade 2020 graphite is limited to specimens from ten [7 in.] diameter logs and one billet [ 24 in. $x 24$ in. $x$ 39 in.]

\subsection{Data Needed}

Data are needed for thermal expansivity, thermal conductivity, emissivity, and specific heat. The data base must be sufficient to establish with [95]\% confidence that the mean values of the data base do not differ from the mean values of the population by more than $[10] \%$. 
The data base must be valid for two different billet sizes:

a. Small cylindrical billet, $[178 \mathrm{~mm}(7 \mathrm{in.})]$ in diameter and

[1.22 $\mathrm{m}$ (48 in.)] long for core support posts.

b. Large cylindrical billet, $[432 \mathrm{~mm}$ (17 in.)] in diameter and [1.22 $\mathrm{m}$ (48 in.)] long for core support blocks.

The data base must include data on:

a. Dependence on orientation, location in billet.

b. Variation from lot to lot, billet to billet.

c. Effects of the reactor operating conditions (Note that

irradiation effects are covered under DDN M.10.17.15.

Quality assurance must be in accordance with the requirements for Quality Assurance Level I.

1.4 Data Parameters/Service Conditions

a. Temperature range, ${ }^{\circ} \mathrm{C} /{ }^{\circ} \mathrm{F}$

Minimum service [120/248]

Maximum service $\quad[900 / 1652]$

b. Operating environment

Primary coolant Helium

Fast neutron fluence ( $\mathrm{E}>29 \mathrm{fJ}, \mathrm{HTGR}$ )

$\left[1 \times 10^{20} \mathrm{n} / \mathrm{cm}^{2}\right]$

2. DESIGNER'S ALTERNATIVES

The following alternatives are available:

2.1 Use currently available data and add design margin to account for the uncertainties.

2.2 Eliminate the need for additional thermal properties by reducing the thermal stresses such that the existing data base could be supplemented with conservative assumptions without needing additional design margin.

\section{SELECTED APPROACH AND EXPLANATION}

The selected approach is to complete the thermal properties data base for use in the design. 
Alternative 2.1 would require components of larger cross sections resulting in higher core pressure drop and increased capital and operating costs.

Alternative 2.2 would require slower shutdown transients which could only be achieved through a complete redesign of the plant control system and was thus rejected as being unrealistic.

4. SCHEDULE REQUIREMENTS

The data is required by [9/91], one year after the start of final design $[9 / 90]$.

5. PRIORITY

$3 M$

6. FALLBACK POSITION AND CONSEQUENCES OF NON-EXECUTION

Design alternative 2.1 would be used resulting in larger structural sizes. This would cause additional primary coolant loop pressure drop which would reduce plant operating efficiency and increase operating costs. In addition, licensing difficulties may be encountered when trying to convince the NRC that the approach has adequate safety margin in light of the limited data.
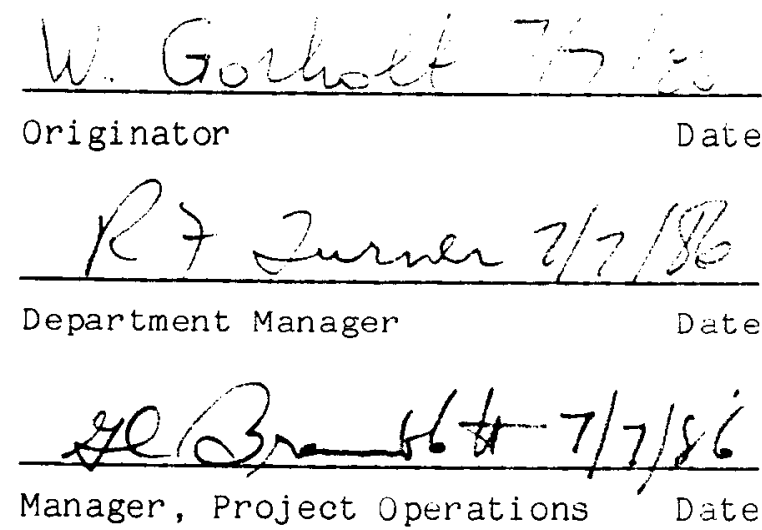


\section{THERMAL PROPERTIES OF PERMANENT REFLECTOR GRAPHITE \\ DDN M.10.17.14 \\ PROJECT NUMBER 6300}

PLANT: $4 \times 350 \mathrm{MW}(\mathrm{t})$ Modular HTGR/Sysiem 10

1. REQUIREMENT OR DESIGN FEATURE REQUIRING EXPERIMENTAL DATA OR VALIDATION TESTING

To calculate the coolant and graphite temperatures and the associated size changes and thermal stresses in the permanent reflector components, a thermal properties data base is needed.

Associated data needs are: DDN M.10.17.16.

1.1 Summary of Function/Title/Assumptions

F1.1:1.1.2.2.1.3.2, "Maintain Integrity of Side Reflectors."

Assumption 1: The mean value of thermal expansivity, thermal conducrivity, and specific heat given in the Graphite Design Data Manual for 2020 graphite are valid.

Assumption 2: The lower bound for the emissivity of 2020 graphite is 0.8 .

E3.1.1.2.1.1.2.2.1.1.2, "Conduct Heat Through Reflector."

Assumption 1: The mean values of thermal expansivity, thermal conductivity, and specific heat given in the Graphite Design Data Manual for 2020 graphite are valid.

Assumpition 2: The lower bound for the emissivity of 2020 graphite is 0.8 .

\subsection{Current Data Base Summary}

Some thermal property data (e.g. specific heat, thermal expansivity, and thermal conductivity) of Grade 2020 graphite were obtained from a very limited number of logs (or billets). The existing data base includes the mean value of the tested population, the within-log standard deviation (for a particular orientation and location) and the log-to-log standard deviation. The uncertainty in the estimates of the population mean values and standard deviation is felt to be large because of the limited size of the data base. The current data base for grade 2020 graphite is Iimited to specimens from cen [ 7 in.] diameter logs and one billet [24 in. $x 24$ in. $x 39$ in. ]. 


\subsection{Data Needed}

Data are needed for thermal expansivity, thermal conductivity, emissivity, and specific heat. The data base must be sufficient to establish with $[95] \%$ confidence that the mean values of the data base do not differ from the mean values of the popuiation by more than $[10] \%$.

The data base must be valid for a billet size of $[0.52 \mathrm{~m} \times 0.52 \mathrm{~m} \times$ $1.0 \mathrm{~m}$ (20.5 in. $\times 20.5$ in. $\times 39$ in.)] and must include data on:

a. Dependence on orientation, location in billet.

b. Variation from lot to lot, billet to billet.

c. Effects of the reactor operating condition (Note that irradiation effects are covered under DDN M.10.17.16).

Quality assurance must be in accordance with the requirements for Quality Assurance Level I.

1.4 Data Parameters/Service Conditions

a. Temperature range, ${ }^{\circ} \mathrm{C} /{ }^{\circ} \mathrm{F}$
Minimum service
[120/248]

Meximum service

$[500 / 932 j$

b. Operating environment

Primary coolant Helium Fast neutron fluence ( $E>29 \mathrm{fJ}$, HTGR)

$$
\left[2 \times 10^{20} \mathrm{n} / \mathrm{cm}^{2}\right]
$$

\section{DESIGNER'S ALTERNATIVES}

The following alternatives are available:

2.1 Use currently available data and add design margin to account for the uncertainties.

2.2 Eliminate the need for additional thermal properties by reducing the thermal stresses such that the existing data base could be supplemented with conservative assumptions without needing additional design margin.

3. SELECTED APPROACH AND EXPLANATION

The selected approach is to complete the thermal properties data base for use in the design. 
Alternative 2.1 would require components of larger cross sections resulting in increased capital cost.

Alternative 2.2 would require the slower shutdown transients which could only be achieved through a complete redesign of the plant control system and was thus rejected as being unrealistic.

4. SCHEDULE REQUIRMENTS

The data is required by [9/91], one year after the start of final design $(9 / 90)$.

5. PRIORITY

$3 M$

6. FALLBACK POSITION AND CONSEQUENCES OF NON-EXECUTION

Design alternative 2.1 would be used resulting in larger structural sizes. This would require an increase in the diameters of the core barrel and of the reactor vessel and, consequently, higher capital cost. In addition, licensing difficulties may be encountered when trying to convince the NRC that the approach has adequate safety margin in light of the limited data.

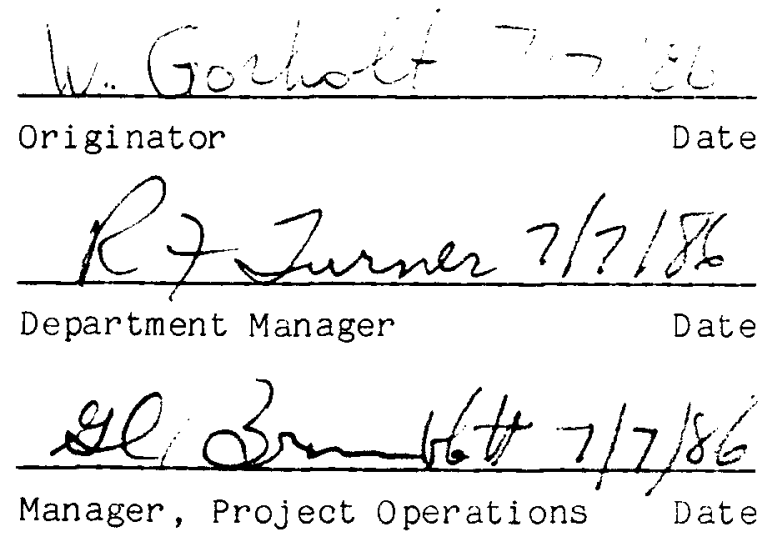


IRRADIATION EFFECTS UN THERMAL PROPERTIES OF CORE SUPPORT GRAPHITE

DDN M.10.17.15

PROJECT NUMBER 6300

PLANT: $4 \times 350 \mathrm{MW}(\mathrm{t})$ Modular HTGR/System 10

1. REQUIREMENT OR DESIGN FEATURE REQUIRING EXPERIMENTAL DATA OR VALIDATION TESTING

To calculate the temperature gradients and the associated thermal stresses in the core support components, the effects of low level irradiation on the thermal properties must be established.

Associated data needs are DDNs: M.10.17.13.

1.1 Summary of Function/Title/Assumptions

F1.1.2.1.2.2.2.2.2.2, "Maintain Integrity of Graphite Core Support."

Assumption 5: The effects of radiation on 2020 graphite thermal properties are negligible.

1.2 Current Data Base Summary

There is no existing data on the effects of low levels of neutron irradiation on the thermal properties of graphite grade 2020 .

1.3 Data Needed

Data are needed to define the effects of low levels of fast fluence on the thermal expansivity, thermal conductivity, and specific heat of graphite grade 2020. The data base must be sufficient to establish with [95]\% confidence that the irradiation effects do not change the mean value of the above properties by more than [10]\%. If the change is greater than $[10] \%$, the change must be determined within $+L 5] \%$. The required data base must be valid for graphite grade $2 \overrightarrow{0} 20$ in two sizes:

a. Small cylindrical billets [7] in. diameter $x$ [48] in. iong for core support posts.

b. Large cylindrical billets [17] in. diameter $x$ [48] in. long for core support blocks.

Quality assurance must be in accordance with the requirements for Quality Assurance Level I. 
1.4 Data Parameters/Service Conditions

a. Graphite temperature range, ${ }^{\circ} \mathrm{C} /{ }^{\circ} \mathrm{F}$

Minimum service $\quad[120 / 248]$

Maximum service [900/1652]

b. Primary coolant temperature range, ${ }^{\circ} \mathrm{C} /{ }^{\circ} \mathrm{F}$

Minimum [600/1112]

Maximum [800/1472]

Core exit temperature (rated) [687/1268]

c. Operating environment

Primary coolant Helium

Fast neutron fluence ( $\mathrm{E}>29 \mathrm{fJ}, \mathrm{HTGR}$ )

$\left[1 \times 10^{20} \mathrm{n} / \mathrm{cm}^{2}\right]$

2. DESIGNER'S ALTERNATIVES

2.1 Complete the design on the basis that the irradiation effects are negligible without further validation.

2.2 Reduce the exposure of the core support structure to negligibic levels of fast fluence by increasing the depth of the bottom reflector.

3. SELECTED APPROACH AND EXPLANATION

The selected approach is to establish a data base for quantifying the effects of low level irradiation.

Alternative 2.1 would weaken the 1 icensing position.

Alternative 2.2 would increase the core cavity and also the core pressure drop and thus would result in larger capital and operating costs.

4. SCHEDULE REQUIRMENTS

The data are required by [9/91], one year after the start of final design $(9 / 90)$.

5. PRIORITY

$2 \mathrm{M}$ 
6. FALLBACK POSITION AND CONSEQUENCES ON NON-EXECUTION

Alternative 2.1 would be used. The consequences would be a risk of rejection during licensing, resulting in a crash technology program and possible schedule delays.
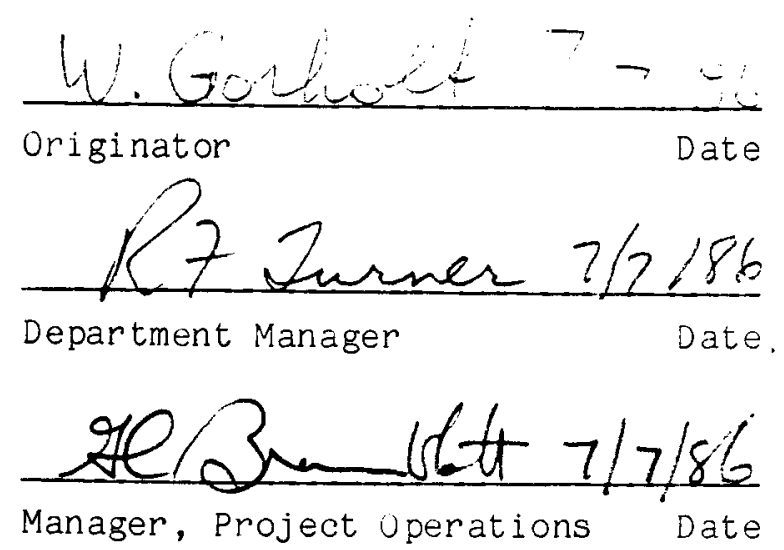
IRRADIATION EFFECTS ON THERMAL PROPERTIES OF PERMANENT SIDE REFLECTOR GRAPHITE DDN M.10.17.16

PROJECT NUMBER 6300

PLANT: $4 \times 350 \mathrm{MW}(\mathrm{t})$ Modular HTGR/System 10

1. REQUIREMENT OR DESIGN FEATURE REQUIRING EXPERIMENTAL DATA OR VALIDATION TESTING

To calculate the temperature gradients and the associated thermai stresses in the permanent side reflector components, the effects of low level irradiation on the thermal properties must be established.

Associated data needs are DDNs: M.10.17.14.

1.1 Summary of Function/Title/Assumptions

F1.1.1.1.2.2.1.3.2, "Maintain Integrity of Side Reflectors." Assumption 5: The effects of radiation on 2020 graphite thermal. properties are negligible.

1.2 Current Data Base Summary

There is no existing data on the effects of low levels of neutron irradiation on the thermal properties of graphite grade 2020 .

\subsection{Data Needed}

Data are needed to define the effects of low levels of fast fluence on the thermal expansivity, thermal conductivity, and specific heat of graphite grade 2020. The data base must be sufficient to extablish a [95]\% confidence that the irradiation effects do not change the mean value of the above properties by more than [10]\% . If the change is greater than $[10] \%$, the change must be determined within $+[5] \%$. The required data base must be valid for graphite grade $2 \overline{0} 20$ in a billet size of $[0.52 \mathrm{~m} \times 0.52 \mathrm{~m} \times 1.0 \mathrm{~m}(20.5 \mathrm{in} . \mathrm{x}$ 20.5 in. $x 39$ in.)]. Quality assurance must be in accordance with the requirements for Quality Assurance Level I. 
1.4 Data Parameters/Service Conditions

a. Temperature range, ${ }^{\circ} \mathrm{C} /{ }^{\circ} \mathrm{F}$

Minimum service $\quad$ [120/248]

Maximum service $\quad$ [900/1652]

b. Primary coolant temperature range, ${ }^{\circ} \mathrm{C} /{ }^{\circ} \mathrm{F}$

$\begin{array}{ll}\text { Maximum } & {[600 / 1112]} \\ \text { Minimum } & {[800 / 1472]} \\ \text { Core exit temperature (rated) } & {[687 / 1268]}\end{array}$

c. Operating environment

Primary coolant Helium

Fast neutron flux ( $>20 \mathrm{fJ}$, HTGR)

$\left[2 \times 10^{20} \mathrm{n} / \mathrm{cm}^{2}\right]$

2. DESIGNER'S ALTERNATIVES

The following alternatives are available:

2.1 Complete the design on the basis that the irradiation effects are negligible without further validation.

2.2 Reduce the exposure of permanent side reflectors to negligible levels of fast fluence by adding replaceable reflector elements.

3. SELECTED APPROACH AND EXPLANATION

The selected approach is to establish a data base for quantifying the effects of low level irradiation.

Alternative 2.1 would weaken the licensing position.

Alternative 2.2 would increase the core cavity resulting in a larger reactor vessel and thus higher capital cost.

4. SCHEDULE REQUIRMENTS

The data are required by [9/91], one year after the start of final design $(9 / 90)$.

5. PRIORITY

$2 \mathrm{M}$ 
6. FALLBACK POSITION AND CONSEQUENCES ON NON-EXECUTION

Alternative 2.1 would be used. The consequences would be a risk of rejection during licensing, resulting in a crash technology program and possible schedule delays.
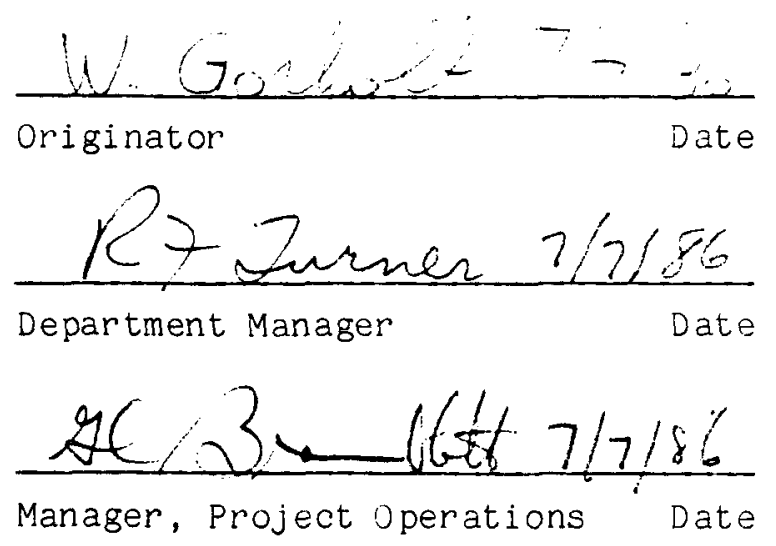


\author{
CORROSION CHARACTERISTICS OF CORE SUPPORT GRAPHITE \\ DDN M.10.17.17 \\ PROJECT NUMBER 6300
}

PLANT: $4 \times 350 \mathrm{MW}(\mathrm{t})$ Modular HTGR/System: 10

1. REQUIREMENT OR DESIGN FEATURE REQUIRING EXPERIMENTAL DATA UR VALIDATION TESTING

The core support components are designed with a corrosion allowance on the basis that the graphite corrosion due to impurities in the helium is limited to a skin effect. The adequacy of the corrosion allowance needs confirmation.

1.1 Summary of Function Number/Title/Assumptions

F1.1.2.1.2.2.2.2.2.2 "Maintain Integrity of Graphite Core Support."

Assumption 10: Graphite corrosion is limited to a maximum depth of [2] $\mathrm{mm}$.

\title{
1.2 Current Data Base Summary
}

The corrosion of core support graphite (Stackpole 2020) by coolant impurities $\left(\mathrm{H}_{2} \mathrm{O}\right.$ and $\left.\mathrm{O}_{2}\right)$ may be mass-transfer limited, chemicalreaction limited, or a combination of both; consequently, both processes must be characterized. The transport of coolant impurities in core support graphite is by pore diffusion; the transport rates increase with increasing graphite burnoff. The process is characterized by an effective diffusion coefficient; the reference correlation was obtained for $\mathrm{H}_{2} \mathrm{O}$ uransport in 4451 graphite with 1\% burnoff.

The reference correlations for the kinetics of 2020 corrosion by coolant impurities are based upon laboratory measurements on other nuclear graphites. The reaction rate of $\mathrm{H}_{2} \mathrm{O}$ with 2020 is taken to be three times higher than inat derived for 4451 fuel element graphite (see DDN M.10.18.08, Section 1.2). For oxidation of core support graphite by air, the rate expression derived from $l \leqslant b$ measurements on H327 graphite is used. 
1.3 Data Needed

Data are needed to confirm with [95\%] confidence that any significant corrosion of the graphite core support components is limited to a maximum depth of [2] mm below the exposed surface. (Significant corrosion is defined as a reduction in strength by more than [10\%].) The confirmation must include the effects of the operating environment, both for normal operation and for the specified moisture ingress conditions. Quality assurance must be in accordance with the requirements for Quality Assurance Level I.

\subsection{Data Parameters/Service Conditions}

The service conditions of interest are given below.

Normal Operation

Environment

Maximum fast fluence ( $\mathrm{E}>29 \mathrm{fJ}$, HTGR)

Maximum gamma flux

Primary coolant temperature range

Graphite temperature range

Maximum time averaged coolant impurity levels

Helium coolant pressure

Moisture Ingress Conditions

Environment

Coolant pressure range

Range of coolant impurity Levels

Graphite temperature range
Hel ium

$\left[1 \times 10^{20}\right] \mathrm{n} / \mathrm{cm}^{2}$

$[\mathrm{TBD}] \mathrm{MeV} / \mathrm{cm}^{2}-\mathrm{s}$

$[300-750]{ }^{\circ} \mathrm{C}$

$[120-900]{ }^{\circ} \mathrm{C}$

[2] $\mathrm{ppm} \mathrm{H}_{2} \mathrm{O}$

[5] $\mathrm{ppm} \mathrm{CO}$

[2] $\mathrm{ppm} \mathrm{CO} \mathrm{CO}_{2}$

[TBD j $\mathrm{ppm} \mathrm{O}$

[TBD] ppm $\mathrm{H}_{2}$

Total Oxidants $<[10] \mathrm{ppm}$

maximum, but not to

exceed [600] ppm days

per year

1 to 63 atms
Heli um

$\left[\begin{array}{lll}1 & \text { to } & 65\end{array}\right]$ atms

[TBD] $\mathrm{ppm} \mathrm{H}_{2} \mathrm{O}$

[TBD] ppm $\mathrm{CO}$

[TBD] ppm CO

Total Oxidants [TBD] ppm

$[120$ to 900$]{ }^{\circ} \mathrm{C}$ 


\section{DESIGNER'S ALTERNATIVES}

The following alternatives have been considered:

2.1 Use current data base with associated uncertainties and add margin.

2.2 Impose tighter tech specs on primary coolant oxidant levels.

2.3 Use a higher purity, more corrosion resistant graphite.

3. SELECTED APPROACH AND EXPLANATION

The selected approach is to confirm that the corrosion of 2020 graphite under normal operating and $\mathrm{H}_{2} \mathrm{O}$ ingress conditions is limited to a skin effect. Design Alternative 2.1 is rejected because the uncertainties in the current data base would require a large corrosion allowance and might also result in licensing difficulties. Design Alternative 2.2 is rejected because imposition of tighter tech spec limits on coolant impurities is expected to adversely impact availability. Design Alternative 2.3 is rejected because development and qualification of a higher purity core support graphite would add significant development costs.

\section{SCHEDULE REQUIREMENTS}

Prel iminary data by [3/89], six months prior to PSSAR submittal (9/89) and final data by [9/92], one year prior to FSSAR submittal (9/93).

5. PRIORITY

$2 \mathrm{M}$

\section{FALLBACK POSITION AND CONSEQUENCES OF NONEXECUTION}

Alternalive 2.1 would be used. The acceptable thickness of the corrosion allowance is, however, limited by the dimensional requirements, and it may not be possible to add enough margin to cover all the uncertainties. The consequences are therefore a weakened licensing position in addition to cost increases resulting from larger component sizes.

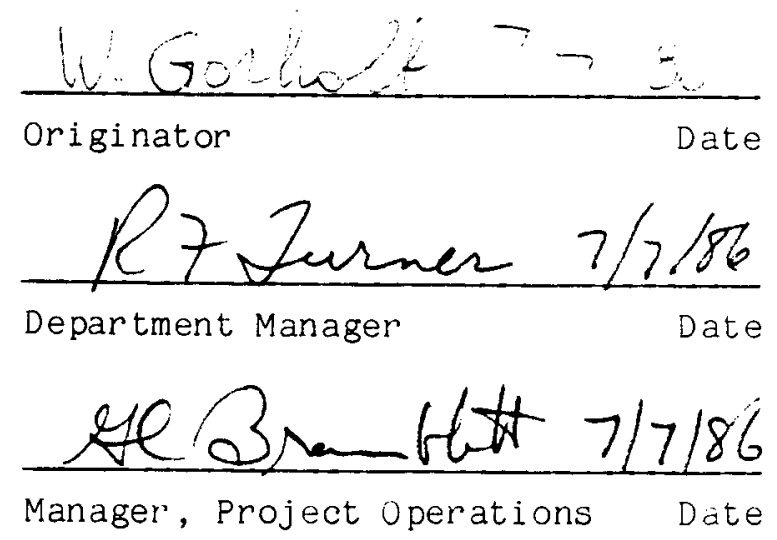




\section{CORROSION CHARACTERISTICS OF PERMANENT REFLECTOR GRAPHITE}

DDN M.10.17.18

PROJECT NUMBER 6300

PLANT: $4 \times 350 \mathrm{MW}(\mathrm{t})$ Modular HTGR/System: 10

1. REQUIREMENT OR DESIGN FEATURE REQUIRING EXPERIMENTAL DATA OR VALIDATION TESTING

The permanent reflector components are designed with a corrosion allowance on the basis that the graphite corrosion due to impurities in the helium is limited to a skin effect. The adequacy of the corrosion allowance needs confirmation.

1.1 Summary of Function Number/Title/Assumptions

F1.1.1.1.2.2.1.3.2 "Maintain Integrity of Side Reflectors."

Assumption 10: Graphite corrosion is limited to a maximum depth of [2] $\mathrm{mm}$.

\subsection{Current Data Base Summary}

The corrosion of permanent reflector graphite (Stackpole 2020) by coolant impurities $\left(\mathrm{H}_{2} \mathrm{O}\right.$ and $\left.\mathrm{O}_{2}\right)$ may be mass-transfer limited, chemical-reaction limited, or a combination of both; consequently, both processes must be characterized. The transport of coolant impurities in core support graphite is by pore diffusion; the transport rates increase with increasing graphite burnoff. The process is characterized by an effective diffusion coefficient; the reference correlation was obtained for $\mathrm{H}_{2} \mathrm{O}$ transport in $\mathrm{H} 451$ graphite with $1 \%$ burnoff.

The reference correlations for the kinetics of 2020 corrosion by coolant impurities are based upon laboratory measurements on other nuclear graphites. The reaction rate of $\mathrm{H}_{2} \mathrm{O}$ with 2020 is taken to be three times higher than that derived for $H 451$ fuel element graphite (see DDN M.10.18.08, Section 1.2). For oxidation of core support graphite by air, the rate expression derived from lab measurements on H327 graphite is used.

\subsection{Data Needed}

Data are needed to confirm with [95\%] confidence that any significant corrosion of the permanent reflector components is 
limited to a maximum depth of [2] mm below the exposed surface. (Significant corrosion is defined as a reduction in strength by more than [10\%].) The confirmation must include the effects of the operating environment, both for normal operation and for the specified moisture ingress conditions. Quality assurance must be in accordance with the requirements for Quality Assurance Level II.

1.4 Data Parameters/Service Conditions

The service conditions of interest are given below.

Normal Operation

Environment

Maximum fast fluence ( $\mathrm{E}>29 \mathrm{fJ}, \mathrm{HTCR}$ )

Maximum gamma flux

Primary coolant temperature range

Graphite temperature range

Maximum time averaged coolant impurity levels

Helium coolant pressure

Moisture Ingress Conditions

Environment

Coolant pressure range

Range of coolant impurity Levels

Graphite temperature range
Helium

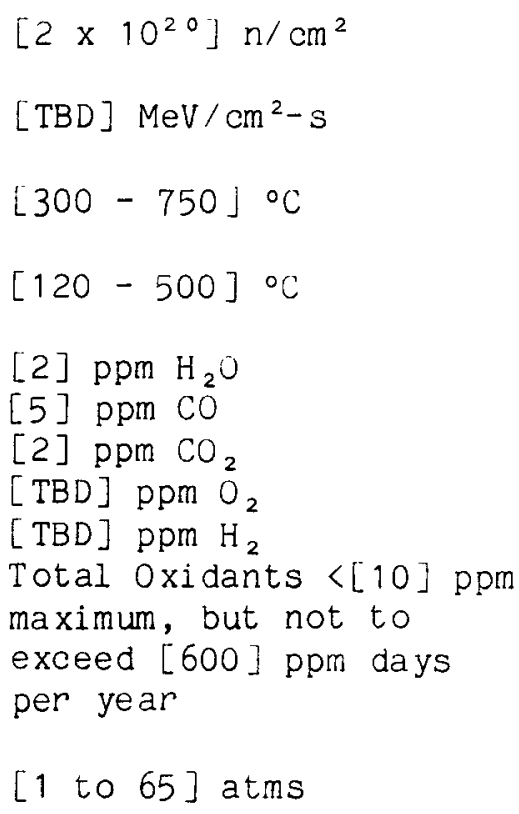

[1 to 65] atms

Heli um

[1 to 65] atms

[TBD] $\mathrm{ppm} \mathrm{H}_{2} \mathrm{O}$

[TBD] ppm $\mathrm{CO}$

$[\mathrm{TBD}] \mathrm{ppm} \mathrm{CO}_{2}$

Total Oxidants [TBD] ppm

$[120 \text { to } 900]^{\circ} \mathrm{C}$ 


\section{DESIGNER'S ALTERNATIVES}

The following alternatives have been considered:

2.1 Use current data base with associated uncertainties and add margin.

2.2 Impose tighter tech specs on primary coolant oxidant levels.

2.3 Use a higher purity, more corrosion resistant graphite.

\section{SELECTED APPROACH AND EXPLANATION}

The selected approach is to confirm that the corrosion of 2020 graphite under normal operating and $\mathrm{H}_{2} \mathrm{O}$ ingress conditions is limited to a skin effect. Design Alternative 2.1 is rejected because the uncertainties in the current data base would require a large corrosion allowance and might also result in licensing difficulties. Design Alternative 2.2 is rejected because imposition of tighter tech spec limits on coolant impurities is expected to adversely impact availability. Design Alternative 2.3 is rejected because development and quai ification of a higher purity permanent reflector graphite would add significant development costs.

4. SCHEDULE REQUIREMENTS

Preliminary data by [9/87], at the start of the preliminary design and final data by [9/92], one year prior to FSSAR submittal (9/93).

5. PRIORITY

$2 \mathrm{M}$

6. FALLBACK POSITION AND CONSEQUENCES OF NONEXECUTION

Alternative 2.1 would be used. The acceptable thickness of the corrosion allowance is, however, 1 imited by the dimensional requirements, and it may not be possible to add enough margin to cover all the uncertainties. The consequences are therefore a weakened licensing position in addition to cost increases resulting from larger component sizes.

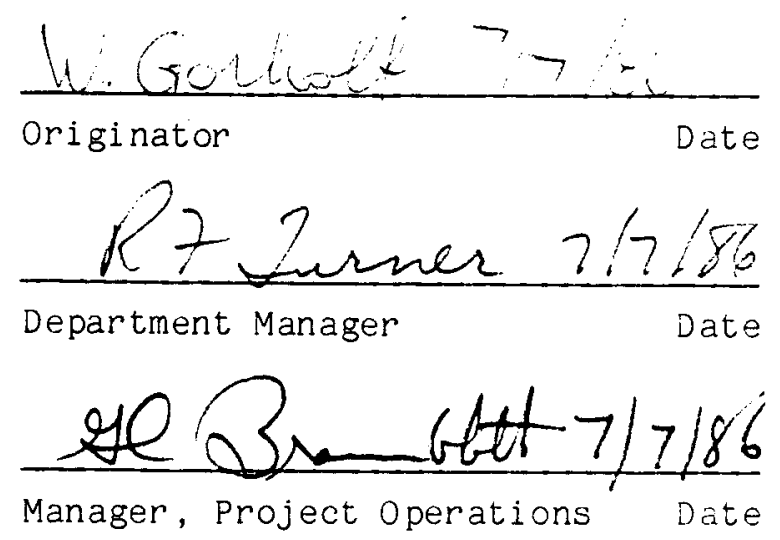




\section{CONEIRM LARGE SIZE GRAPHITE FOR PERMANENT REFLECTOR}

DDN M.10.17.21

PROJECT NUMBER 6300

PLANT: $4 \times 350 \mathrm{MW}(\mathrm{t})$ Modular HTGR/System 10

1. REQUIREMENT OR DESIGN FEATURE REQUIRING EXPERIMENTAL DATA OR VALIDATION TESTING

The permanent side reflector (PSR) is designed to be made from large blocks of grade 2020 graphite. The ability to manufacture blocks of this size with consistent properties needs confirmation.

Associated Data Needs: DDN M.10.17.02.

1.1 Summary of Function/Title/Assumptions

F.1.1.2.1.2.1.2.2.1 "Limit Flow in Horizontal Gaps" F.1.1.2.1.2.1.2.2.2 "Limit Flow in Vertical Gaps" Assumption 1: Large grade 2020 graphite blocks are available.

1.2 Current Data Base Summary

Large billets of 2020 graphite of the size needed for the PSR blocks are not routinely produced. One large block of grade $2020,0.66 \mathrm{~m} \mathrm{x}$ $0.66 \mathrm{~m} \times 0.99 \mathrm{~m} \mathrm{(26}$ in. $\times 26$ in. $\times 39$ in.), was produced in 1983 and was used for characterization tests at GA.

\subsection{Data Needed}

The process for producing graphite grade 2020 in a billet size of [0.52 $\mathrm{m} \times 0.52 \mathrm{~m} \times 1.00 \mathrm{~m}(20.5 \mathrm{in.} \times 20.5$ in. $\times 39$ in.)] is needed so that the ability to supply permanent side reflector blocks in sufficient quantities and with consistent properties can be ensured. The process must be such that all the billets produced have the required minimum ultimate strength (see DDN M.10.17.02). If grade 2020 in the large billet size does not have the required properties, an alternative material must be developed. Quality assurance must be in accordance with the requirements for Quality Assurance Level II.

\subsection{Data Parameters/Service Conditions}
a. Specified minimum ul timate strength, psi
Tensile
[1950]
Compressive
b. Point stress, psi
[650]
[800] 
c. Service temperature range, ${ }^{\circ} \mathrm{C} /{ }^{\circ} \mathrm{F}$

Minimum

[120/248]

Maximum

[500/932]

d. Operating environment

Primary coolant

Hel ium

Pressure range

1 to 63 atmos

e. Fast fluence range, neutrons $/ \mathrm{cm}^{2}$ (E > $29 \mathrm{fJ}, \mathrm{HTGR}$ )

Minimum

Maximum

$$
\left[2 \times 10^{20}\right]
$$

\section{DESIGNER'S ALTERNATIVES}

2.1 Decrease the size of the permanent reflector blocks to that selected for the largest core support component.

2.2 Assume that large blocks with consistent properties can be produced with an existing process.

3. SELECTED APPROACH AND EXPLANATION

The selected approach is to develop a controlled and reproducible grade 2020 graphite (or an equivalent material) in a size of $0.52 \mathrm{~m} \times 0.52 \mathrm{~m} \times$ $1.0 \mathrm{~m}$ (20.5 in. $x 20.5 \mathrm{in.} \times 39 \mathrm{in.}$ ). The use of smaller blocks (Alternative 2.1) would impact the efficiency of the core by increasing the bypass flow through the larger number of gaps. Capital cost would also increase because of the need to machine and install a larger number of components. Alternative 2.2 would result in a greater billet to billet strength variation than assumed in the data base and thus an unnecessarily high rejection rate.

4. SCHEDULE REQUIRMENTS

Preliminary confirmation that the large blocks can be manufactured from grade 2020 is needed at the start of preliminary design [9/87] and the final confirmation one year later [9/88].

\section{PRIORITY}

$1 \mathrm{~L}$ 
6. FALLBACK POSITION AND CONSEQUENCES OF NONEXECUTION

Design Alternative 2.1 would be used. The consequences of smaller permanent side reflector blocks would be 1) a higher capital cost due to the need to machine a larger number of blocks, and 2) a reduced plant efficiency due to more core bypass flow.
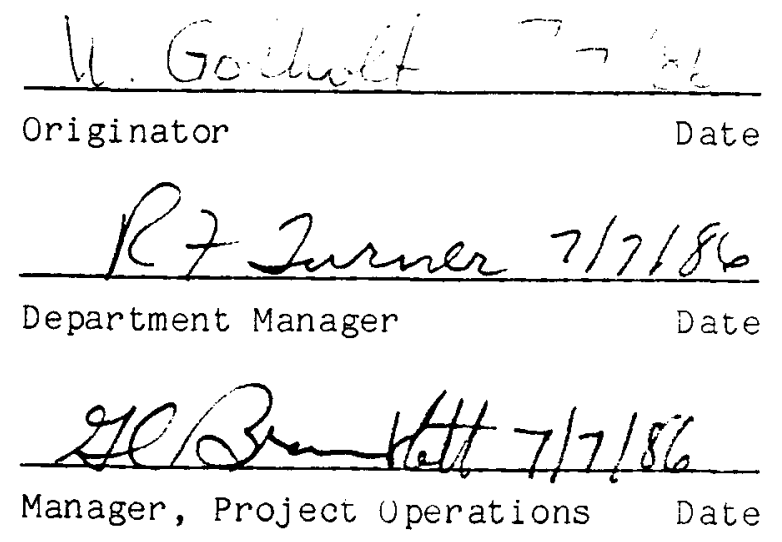
NDE DATA FOR REACTOR INTERNALS GRAPHITE SPECIFICATIONS

DDN M.10.17.22

PROJECT NUMBER 6300

PLANT: $4 \times 350 \mathrm{MW}(t)$ Modular HTGR/System 10

1. REQUIREMENT OR DESIGN FEATURE REQUIRING EXPERIMENTAL DATA OR VALIDATION TESTING

Nondestructive testing techniques are required for product control during procurement of graphite for the reactor internal structures.

1.1 Summary of Function/Title/Assumptions

F1.1.2.1.2.2.2.2.2.2, "Maintain Integrity of Graphite Core Support." Assumption 4: The production graphite will have the same properties as the design data base.

F1.1.1.1.2.2.1.3.2, "Maintain Integrity of Side Reflectors." Assumption 4: The production graphite will have the same properties as the design data base.

1.2 Current Data Base Summary

Oak Ridge National Laboratory has developed nondestructive techniques and produced dara on their accuracy and limitations using Stackpole Carbon Company's grade 2020 graphite. The data base is too small to validate these techniques so they can be used in material NDE specifications to control the product of mass produced graphite.

\subsection{Data Needed}

Data are needed to validate NDE techniques and write material control specifications for the procurement of graphite for reactor internal structures. The NDE techniques must be sufficiently accurate to (1) detect flaws in the largest billets used for the reactor internal structures, and (2) determine the tensile strength of smaller specimens with an error no greater than [10\% j. Quality assurance must be in accordance with the requirements for Quality Assurance Level II.

\subsection{Data Parameters/Service Conditions}

NDE will be conducted at room temperature conditions. 
2. DESIGNER'S ALTERNATIVES

2.1 Control the strength of the production material by destructive strength testing only. This would require destructive tesing of several tensile test coupons from each billet in addition to more extensive mapping of at least one billet from each lot.

2.2 Reduce the need for product control by accepting a greater uncertainty in the strength of the production material. This would, however, result in a lower minimum ultimate strength (which is statistically defined) and hence lower allowable stresses.

\section{SELECTED APPROACH AND EXPLANATION}

The selected approach is to use nondestructive examination in combination with a minimum of destructive testing to ensure that the production graphite satisfies the specifications. This approach is the most cost effective since NDE is less expensive than conventional destructive testing (Alternative 2.1). Alternative 2.2 would cause structural cross sections to be larger resulting in an increased size envelope and higher primary coolant pressure drop. This would reduce plant operating efficiency and cause higher capital and operating costs.

4. SCHEDULE REQUIREMENTS

The data is needed by [9/92], before start of production of graphite for the permanent graphite components. This is assumed to be one year before the end of the final design phase (9/93).

\section{PRIORITY}

$6 \mathrm{M}$

6. FALLBACK PUSITION AND CONSEQUENCES OF NONEXECUTION

Alternative 2.1 would be used. The consequences will be higher cost of the graphite material.
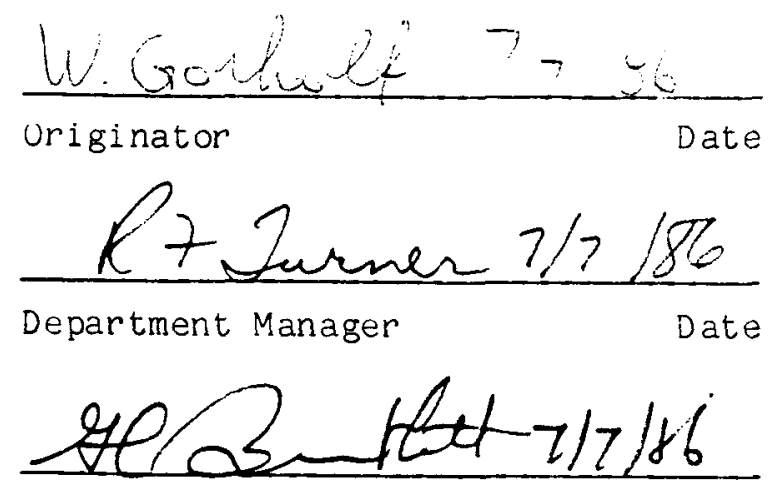

Manager, Project operations Date 


\author{
CONEIRM STRENGTH OF GRAPHITE CURE SUPPORT \\ DDN M.10.17.23 \\ PROJECT NUMBER 6300
}

PLANT: $4 \times 350 \mathrm{MW}(t)$ Modular HTGR/System: 10

1. REQUIREMENT OR DESIGN FEATURE REQUIRING EXPERIMENTAL DATA UR VALIDATION TEST ING

Graphite core support components are required to meet the stress Iimits specified by the ASME Code Section III, Div. 2, Subsection CE. Stress analysis using linear elastic methods was selected as the method for showing compliance with these limits.

\title{
1.1 Summary of Function/Title/Assumptions
}

F1.1.2.1.2.2.2.2.2.2, "Maintain Integrity of Graphite Core Support." Assumption ?. The use of simplified linear eiastic stress anatysis methods to show compliance with required stress 1 imits can be val idated.

\subsection{Current Data Base Summary}

Full-scale testing of FSV core support structure modules (1968) confirmed adequate safety factors against vertical loads. A series of tests on LHTGR core support posts and seats (1976 and 1977) did not correlate well with analytical predictions. Specifically, in the first tests premature failure of the seats was experienced. In the second tests (after redesign of the seats), the experimental ultimate load exceeded the analytical predictions. Subsequently, more detailed three dimensional analysis improved the correlations but resulted in a requirement to validate future designs.

\subsection{Data Needed}

Data are required to confirm that the analytically predicted ultimate load of the graphite core support structure under vertical loads is adequate. The design to be confirmed will be that selected and shown to meet the required stress limits by analysis during conceptual and preliminary design. Data are also required on the load at which initial cracking occurs, if different from the ul timate load. Quality assurance must be in accordance with the requirements for Quality Assurance Level I. 
1.4 Data Parameters/Service Conditions

a. Maximum vertical design loads per core column, lb

Deadweight [4500]

Pressure drop [1100]

Operating basis earthquake [4500]

Differential expansion loads [TBD]

b. Service temperature range, ${ }^{\circ} \mathrm{C} /{ }^{\circ} \mathrm{F}$

$\begin{array}{ll}\text { Minimum } & {[120 / 248]} \\ \text { Maximum } & {[900 / 1652]}\end{array}$

c. Operating environment

Primary coolant Helium

Pressure range 1 to 63 atmos

d. Radiation environment

Maximum fast fluence ( $E>29 \mathrm{fJ}, \mathrm{HTGR}$ )

$\left[1 \times 10^{20}\right] \mathrm{n} / \mathrm{cm}^{2}$

\section{DESIGNER'S ALTERNATIVES}

The following alternatives are available:

2.1 Decrease the stress Iimits employed compared with those required by the ASME Code, to allow for uncertainties in the analysis.

2.2 Employ more sophisticated stress analysis methods to reduce the uncertainties in predicted stresses.

3. SELECTED APPROACH AND EXPLANATION

The selected approach is:

a. To design the core support to the stress limits required by the ASME Code with the relatively simple linear elastic material model in a finite element stress analysis method allowed by that code.

b. Confirm the analysis by validating the ultimate load capacity of prototype core support components.

The use of decreased siress limits (2.1) is judged to be significantly less attractive; since the question of the degree of uncertainty being covered by the decrease would remain unanswered. More sophisticated analysis (2.2) would also leave uncertainty remaining unless it also is validated. In that case, in addition to increased analysis cost, there would be significant method development costs and the cost of validation. 
4. SCHEDULE REQUIRMENTS

Validate the preliminary design by [3/90], six months before the start of the final design phase $(9 / 90)$.

5. PRIORITY

$4 \mathrm{M}$

6. FALLBACK POSITION AND CONSEQUENCES ON NON-EXECUTION

Design alternative 2.1 would be employed with increased risk that a satisfactory position on the structural integrity and reliability of this component might not be developed in time for the final design.
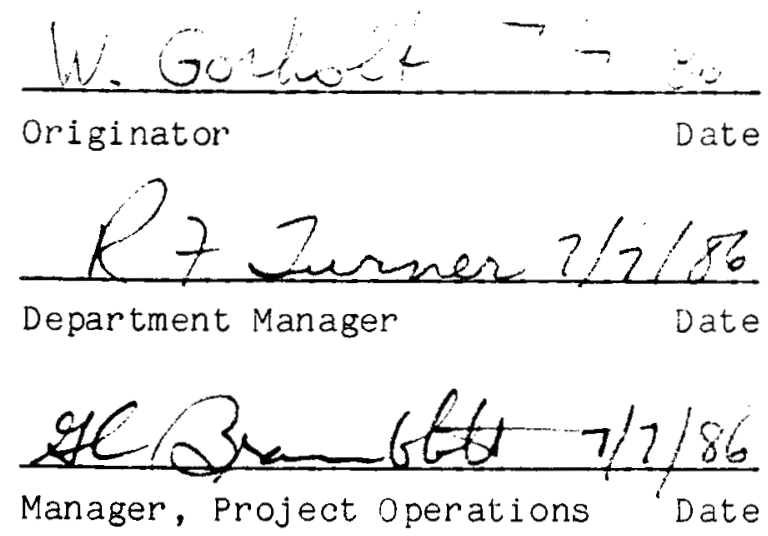
CONEIRM LATERAL STRENGTH OF PERMANENT REFLECTOR

DDN M.10.17.24

PROJECT NUMBER 6300

PLANT: $4 \times 350 \mathrm{MW}(\mathrm{t})$ Modular HTGR/System: 10

1. REQUIREMENT OR DESIGN FEATURE REQUIRING EXPERIMENTAL DATA OR VALIDATION TESTING

The permanent side reflector (PSR) is is required to meet the stress limits specified by the ASME Code Section III, Div. 2, Subsection CE. Stress analysis, using 1 inear elastic methods, was selected as the primary method of showing compliance with these limits.

\subsection{Summary of Function/Title/Assumptions}

F1.1.1.1.2.2.1.3.2, "Maintain Integrity of Side Reflector." Assumption 1. The use of simplified linear elastic stress analysis methods to show compliance with required stress limits can be val idated.

\subsection{Current Data Base Summary}

No tests have been performed to confirm that the permanent side reflector components have adequate safety factors against lateral seismic loads. However, shear tests on a component with a related function, namely, the fuel element flange connection (1983) did not correlate well with analytical predictions. The experimental ultimate load exceeded the analytical prediction which indicated that the analysis is conservative. The remaining uncertainty, however, resulted in a requirement to validate future designs.

\subsection{Data Needed}

Data are required to confirm that the analytically predicted ul timate shear load of the graphite keyway in the PSR under lateral shear loads is adequate. The design to be confirmed will be that selected and shown to meet the required stress limits by analysis during conceptual and preliminary design. Data are also required on the load at which initial cracking occurs, if different from the ultimate load. Quality assurance must be in accordance with the requirements for Quality Assurance Level I. 
1.4 Data Parameters/Service Conditions

a. Maximum lateral design loads per block $=[5,0001 \mathrm{~b}]$ at a relative impact velocity of $[40 \mathrm{in./s}]$.

b. Service temperature range, ${ }^{\circ} \mathrm{C} /{ }^{\circ} \mathrm{F}$

Minimum

$[120 / 248]$

Maximum

[500/932]

c. Operating environment

Primary coolant

Helium

Pressure range

1 to 63 atm

d. Radiation environment

Maximum fast fluence ( $\mathrm{E}>29 \mathrm{fJ}, \mathrm{HTGR}$ )

$\left[2 \times 10^{20}\right] \mathrm{n} / \mathrm{cm}^{2}$

2. DESIGNER'S ALTERNATIVES

The following alternatives are available:

2.1 Decrease the stress limits employed compared with those required by the ASME Code, to allow for uncertainties in the analysis.

2.2 Employ more sophisticated stress analysis methods to reduce the uncertainties.

\section{SELECTED APPROACH AND EXPLANATION}

The selected approach is:

a. To design the PSR to the stress 1 imits required by the ASME Code with the relatively simple linear elastic material model in a finite element stress analysis method allowed by that code.

b. Confirm the analysis by validating the ultimate load capacity of prototype PSR components.

The use of decreased stress limits (2.1) is judged to be significantly less attractive; since the question of the degree of uncertainty being covered by the decrease would remain unanswered. More sophisticated analysis (2.2) would also leave uncertainty remaining unless it also is validated. In that case, in addition to increased analysis cost, there would be significant method development costs and the cost of validation.

\section{SCHEDULE REQUIRMENTS}

Validate the preliminary design by [3/90], six months before the start of the final design phase $(9 / 90)$. 


\section{PRIORITY}

$4 \mathrm{M}$

6. FALLBACK POSITION AND CONSEQUENCES OF NON-EXECUTION

Design alternative 2.1 would be employed with increased risk that a satisfactory position on the structural integrity and reliability of this component might not be developed in time for the final design.
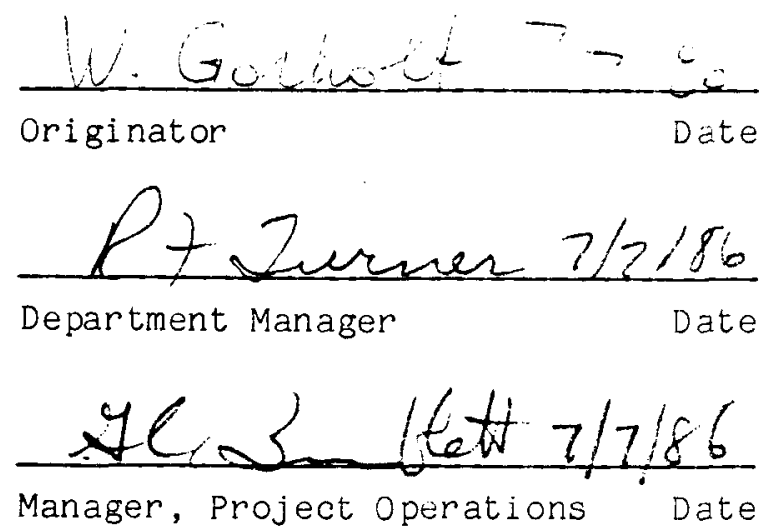


\author{
MULT IAXIAL STRENGTH OF GRAPHITE FOR CORE COMPONENTS \\ DDN M.10.18.01 \\ PROJECT NUMBER 6300
}

PLANT : 4 × $350 \mathrm{MW}(\mathrm{t})$ Modular HTGR/System 10

1. REQUIREMENT OR DESIGN FEATURE REQUIRING EXPERIMENTAL DATA OR VALIDATION TESTING

The failure surface defined by the maximum stress failure theory is a simplified approximation whose uncertainty needs to be quantified and included in the probabilistically based stress criteria which are being developed for showing compliance with the Goals 2 and 3 reliability requirements.

\title{
1.1 Summary of Function/Title/Assumptions
}

F2.1.2.1.2.4, "Protect the Capability to Maintain Fuel Element Structural Integrity."

Assumption 1: The maximum stress failure theory is a reasonable approximation for $\mathrm{H}-451$ graphite under multiaxial state of stress.

\subsection{Current Data Base Summary}

Biaxial data are available on unirradiated ATJ, ATJ-S, Graphite-G, JTA, PGX, and 2020 graphites. No biaxial or triaxial strength tests have as yet been performed on $\mathrm{H}-451$ graphites.

\subsection{Data Needed}

Data are needed to determine the reduction in the uniaxial strength of core component graphite due to multiaxial stress conditions. The data are needed for bi- and triaxial tension and tension/compression combinations. The data base must be adequate to show with [95]\% confidence that the mean value of the uniaxial strength is not reduced by more than:

$[15] \%$ in a biaxial stress field

$[20] \%$ in a triaxial stress field

The above statistical data base is needed only for unirradiated graphite at room temperature in air. An additioinal small number of data points are needed on the effects of the service conditions. Quality assurance must be in accordance with the requirements for Quality Assurance Level I. 


\subsection{Data Parameters/Service Conditions}

Service Temperature Range: $120^{\circ} \mathrm{C}-950^{\circ} \mathrm{C}\left(248^{\circ} \mathrm{F}-1742^{\circ} \mathrm{F}\right)$

Maximum Fast Fluence: $5 \times 10^{25} \mathrm{n} / \mathrm{m}^{2}$ (E $>29 \mathrm{fJ}, \mathrm{HTGR}$ )

Operating Environment: Helium at $1-63$ atm pressure

\section{DESIGNER'S ALTERNATIVES}

The following alternatives are available:

2. 1 Estimate the error in the maximum stress failure theory on the basis of existing data.

2.2 Eliminate the need for detailed quantification of the errors in the stress analysis by using stress limits with deterministicaily selected high safety factors from which the Goal 2 reliabilities can be conservatively estimated.

3. SELECTED APPROACH AND EXPLANATION

The selected approach is to establish a "mean value" failure surface such that the error in the simplified maximum stress failure theory can be quantified and the effects on the reliabilities calculated. Alternative 2.1 was rejecied because an estimate would be difficult to defend. Alternative 2.2 would require a lower power density and a corresponding increase in core volume and hence cost.

4. SCHEDULE REQUIREMENTS

Data are required by [9/91], one year after the start of the final design phase $(9 / 90)$.

\section{PRIORITY}

$4 M$

6. FALLBACK POSITION AND CONSEQUENCES OF NONEXECUTION

Design alternative 2.1 would be used with the risk of rejection during licensing resulting in either a crash technology program or a belated design change.
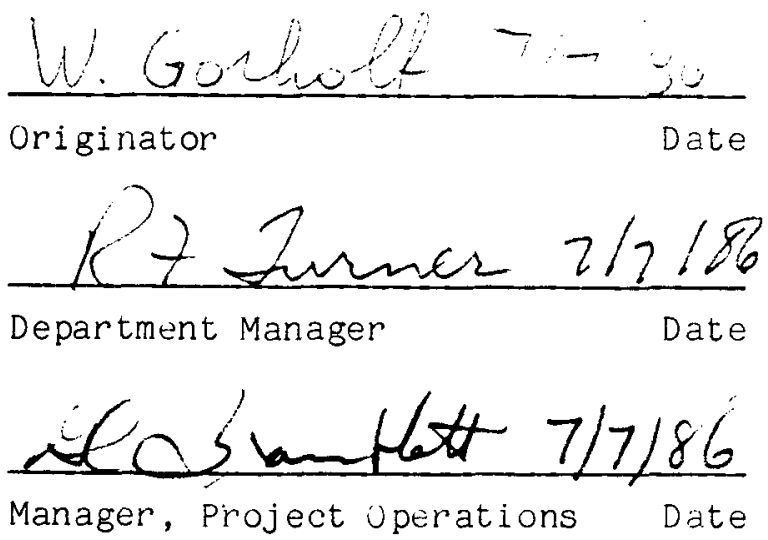


\section{DATE : $\quad 7 / 3 / 86$}

FATIGUE DATA FOR GRAPHITE FOR CORE COMPONENTS

DDN M.10.18.02

PROJECT NUMBER 6300

PLANT: $4 \times 350 \mathrm{MW}(\mathrm{t})$ Modular HTGR/System 10

1. REQUIREMENT OR DESIGN FEATURE REQUIRING EXPERIMENTAL DATA OR VALIDATION TESTING

Fatigue analysis is required for the graphite core components. In this analysis, the cumulative effects of varying stress amplitudes must be accounted for.

\subsection{Summary of Function/Title/Assumptions}

F1.1.2.1.2.2.4, "Maintain Fuel Element Structural Integrity." Assumption 3: Miner's rule for estimating the cumulative fatigue is applicable to $\mathrm{H}-451$ graphite.

\subsection{Current Data Base Summary}

Some uniaxial push-pull fatigue tests in air at ambient temperature have been made on axial and radial specimens of $\mathrm{H}-451$ graphite from a single billet. The stress amplitude was held constant during each test. The stress ratio, $R$ (ratio between the minimum stress and the maximum stress during a cycle), varied between -1 and 0 , and tests were conducted to a maximum of $10^{5}$ cycles. No tests in which the stress amplitude was changed have been conducted.

\subsection{Data Needed}

The following fatigue data are required:

a. Fatigue 1 ife as a function of stress amplitude for $\mathrm{H}-451$ graphite under constant amplitude cyclic loading for two conditions:

1) Cycling between tension and equal compression (stress ratio of -1 ).

2) Cycling between tension and zero stress (stress ratio of 0 ).

The data base must be sufficient to determine the mean value of the fatigue strength within $\pm[6] \%$ at $[95] \%$ confidence. 
b. Eatigue life for H-451 graphite subjected to sequential series of cycles with different amplitude. Enough data are needed to establish the difference between constant amplitude fatigue life and varying amplitude fatigue 1 ife with $[95] \%$ confidence.

The above data are needed for unirradiated graphite at room temperature. In addition, a limited number of data points are needed to determine the effects of the operating environment. Quality assurance must be in accordance with the requirements for Quality Assurance Level I.

\subsection{Data Parameters/Service Conditions}

Service Temperature Range: $120^{\circ} \mathrm{C}-950^{\circ} \mathrm{C}\left(248^{\circ} \mathrm{F}-1742^{\circ} \mathrm{F}\right)$

Maximum Fast Fiuence: $5 \times 10^{25} \mathrm{n} / \mathrm{m}^{2}$ (E>29 $\mathrm{fJ}, \mathrm{HTGR}$ )

Operating Environment: Helium at $1-63$ atm pressure

Maximum Number of Load Cycles from Plant Cycles: $\left[10^{2}<\mathrm{TBD}<10^{5}\right]$

Maximum Number of Cycles from Seismic Vibrations: $\left[10^{2}<\mathrm{TBD}<10^{5}\right]$

2. DESIGNER'S ALTERNATIVES

The following alternatives are available:

2.1 Decrease the allowable tensile stress of the graphite below the fatigue endurance limit, in which case an adequate fatigue strength is ensured without any fatigue analysis.

2.2 Complete the fatigue analysis on the basis of the existing data base and assume Miner's ruie to be valid without validation.

\section{SELECTED APPROACH AND EXPLANATION}

The selected approach is to perform fatigue analysis using Miner's rule and to validate the applicability of this rule to H-451 graphite.

The use of decreased allowable stress (2.1) is judged to be significantly less attractive since it requires lower core power densities, which result in increased capital and operating costs. Alternative 2.2 would incur the risk of rejection during licensing.

4. SCHEDULE REQUIRMENTS

Data are required by [9/91], one year. after the start of the $f$ inal design phase $(9 / 90)$. 
$[D C-D D N-80-74]$

$\mathrm{PC}-000213 / 1$

5. PRIORITY

$4 \mathrm{~L}$

6. EALLBACK POSITION AND CONSEQUENCES OF NONEXECUTION

Design alternative 2.2 would be used with the risk of rejection during licensing resulting in either a crash technology program or a belated design change.
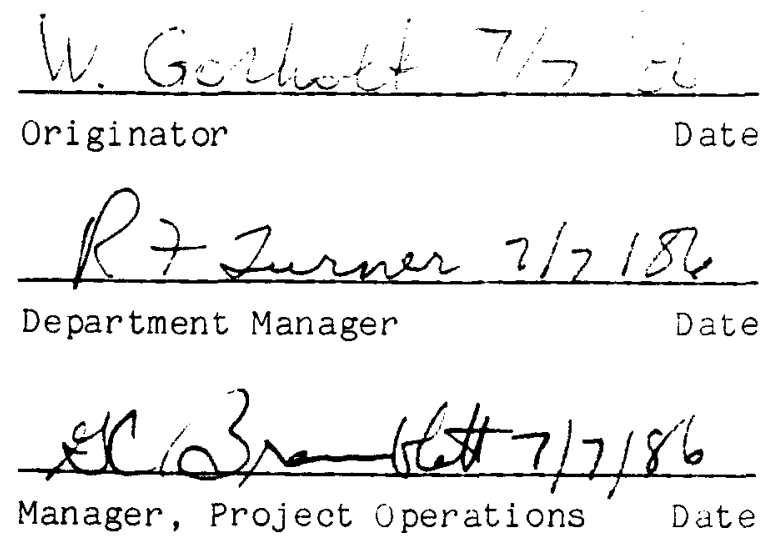
STAT ISTICS OF MECHANICAL PROPERTIES OF GRAPHITE CORE COMPONENTS DDN M.10.18.03

PROJECT NUMBER 6300

PLANT: $4 \times 350 \mathrm{MW}(\mathrm{t})$ Modular HTGR/System 10

1. REQUIREMENT OR DESIGN FEATURE REQUIRING EXPERIMENTAL DATA OR VALIDATION TESTING

Probabilistically based stress criteria are used to ensure compliance with the Goals 2 and 3 reliability requirements. The statistical variability of the mechanical properties of the graphite core components is needed for the development of these criteria.

\subsection{Summary of Function/Title/Assumptions}

F2.1.2.1.2.4, "Protect the Capability to Maintain Fuel Element Structural Integrity."

Assumption 2: The coefficients of variation given in the Graphite Design Data Manual are accurate to within [25]\%.

Assumption 3: Confidence limits on the mean value and standard deviation can be sufficiently determined through the $t$ and Chi-Square distributions, respectively.

Assumption 4: Uncertainty in the estimation of the skewness of a distribution can be estimated by the uncertainty in the coefficient of variation.

\subsection{Current Data Base Summary}

Tensile, compressive, and flexural strengths in air at ambient temperature have been measured on axial and radial specimens on approximately 100 billets of preproduction and production $\mathrm{H}-451$ graphite from six fabrication lots. For one billet, specimens were taken throughout the whole volume; for 12 billets, specimens were taken from four locations; and for the remainder of the billets specimens were taken from two locations. No strength tests have been made at elevated temperatures. Analysis of the currently available statistical data indicates a strong negative skewness, which is being interpreted as a bimodal normal discribution on the basis of flaw analysis.

A considerable body of data exists on the effects of irradiation on Young's modulus and tensile strength of H-451 graphite specimens 
irradiated in the Oak Ridge Reactor at $550^{\circ} \mathrm{C}$ through $1300^{\circ} \mathrm{C}$ to fluences between $1 \times 10^{21}$ neutrons $/ \mathrm{cm}^{2}$ and $1 \times 10^{22}$ neutrons $/ \mathrm{cm}^{2}$. Specimens were taken from five billets selected from three different production lots. Additional sonic modulus data on $\mathrm{H}-451$ graphite irradiated at $600^{\circ} \mathrm{C}$ and $900^{\circ} \mathrm{C}$ to fluences up to $4 \times 10^{22}$ neutrons $/ \mathrm{cm}^{2}$ are available from $H F I R$ capsule irradiations.

1.3 Data Needed

Data are needed to def ine the tensile and compressive strengths, Poisson's ratio, and stress-strain relationship in accordance with appropriate ASTM standards for H-451 graphites, including the effects of:

a. Orientation and location in billet.

b. Variation from billet to billet and from lot to lot.

c. Temperature ranging from shutdown conditions to the maximum service temperature.

d. Fast neutron fluence.

The data base must be sufficient to establish at [95]\% confidence that the mean values of the required properties lie within the following bounds:

$\begin{array}{ll}\text { Tensile strength: } & \pm[3] \% \\ \text { Compressive strength: } & \pm[10] \% \\ \text { Stress-Strain relationship: } & \pm[8] \% \\ \text { Poisson's Ratio: } & \pm[20] \%\end{array}$

In addition to the above statistical data base, information is also needed on the effects of volume and of a pressurized helium environment. Quality assurance must be in accordance with the requirements for Quality Assurance Level I.

\subsection{Data Parameters/Service Conditions}

$$
\begin{aligned}
& \text { Service Temperature Range: } 120^{\circ} \mathrm{C}-950^{\circ} \mathrm{C}\left(248^{\circ} \mathrm{F}-1742^{\circ} \mathrm{F}\right) \\
& \text { Operating Environment: Helium at } 1-63 \text { atm pressure } \\
& \text { Maximum Fluence: } \left.5 \times 10^{25} \mathrm{n} / \mathrm{m}^{2} \text { (E }>29 \mathrm{fJ}, \mathrm{HTGR}\right)
\end{aligned}
$$

\section{DESIGNER'S ALTERNATIVES}

The following alternatives are available:

2.1 Use the existing data base. 


\subsection{Eliminate the need for a detailed statistical data base by using stress limits with deterministically selected high safety factors from which the Goals 2 and 3 reliabilities can be conservatively estimated.}

3. SELECTED APPROACH AND EXPLANATION

The selected approach is to show compliance with the Goals 2 and 3 requirements through detailed probabilistic methods. This requires an adequate statistical data base.

Alternative 2.1 was rejected because the existing data base is inadequate for a probabilistic design approach. Alternative 2.2 would require a significantly lower power density and, consequently, a larger core. The effects on capital and operating cost would be large.

4. SCHEDULE REQUIRMENTS

Data are required by [9/91], one year after the start of the final design phase $(9 / 90)$.

5. PRIORITY

$2 \mathrm{H}$

6. FALLBACK POSITION AND CONSEQUENCES OF NONEXECUTION

Design alternative 2.2 would be used. The consequences would be a reduced power density and a corresponding increase in core size resulting in higher capital and operating cost.
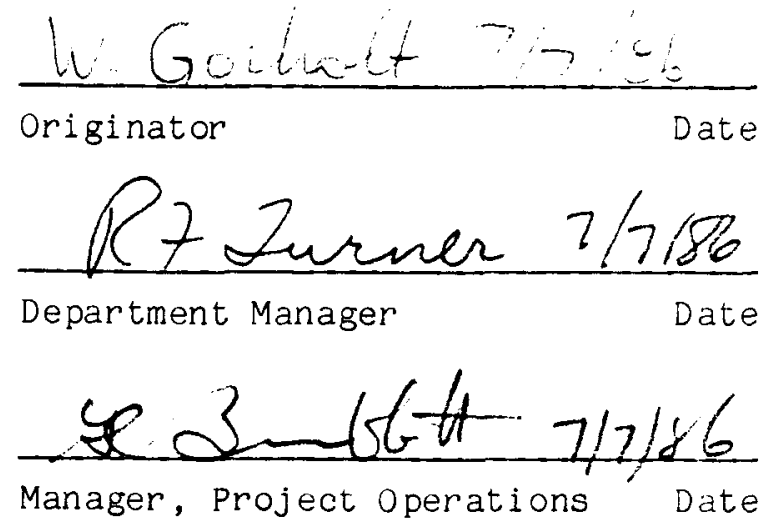


\author{
STATISTICS OF IRRADIATION-INDUCED STRAIN OF GRAPHITE CURE COMPONENTS \\ DDN M.10.18.04 \\ PROJECT NUMBER 6300
}

PLANT: $4 \times 350 \mathrm{MW}(\mathrm{t})$ Modular HTGR/System 10

1. REQUIREMENT OR DESIGN FEATURE REQUIRING EXPERIMENTAL DATA OR VALIDATION TESTING

Probabilistically based stress oriteria are used to ensure compliance with the Goals 2 and 3 reliability requirements. The statistical variability of the irradiation induced strain of the core component graphite is needed for the development of these criteria.

\title{
1.1 Summary of Function/Title/Assumptions
}

F1.1.2.1.2.2.4, "Maintain Fuel Element Structural Integrity."

F2.1.2.1.2.4, "Protect the Capability to Maintain Fuel Element Structural Integrity."

Assumption 1: The mean values of the irradiation-induced dimensional changes given in the Graphite Design Data Manual for H-451 graphite are valid.

Assumption 2: The coefficients of variation given in the Graphite Design Data Manual are accurate to within [25]\%.

Assumption 3: Confidence limits on the mean value and standard deviation can be sufficiently determined through the $t$ and Chi-Square distributions, respectively.

Assumption 4: Uncertainty in the estimation of the skewness of a distribution can be estimated by the uncertainty in the coefficient of variation.

\subsection{Current Data Base Summary}

A considerable body of data exists on the effects of irradiation on dimensional changes of $\mathrm{H}-451$ graphite specimens irradiated in the Oak Ridge Reactor at $550^{\circ} \mathrm{C}$ through $1300^{\circ} \mathrm{C}$ to fluences between $1 \times 10^{21}$ neutrons $/ \mathrm{cm}^{2}$ and $1 \times 10^{22}$ neutrons $/ \mathrm{cm}^{2}$. Specimens were taken from five billets selected from three different production lots. Additional dimensional change data for $\mathrm{H}-451$ graphite irradiated at $600^{\circ} \mathrm{C}$ and $900^{\circ} \mathrm{C}$ to fluences up to $4 \times 10^{22}$ neutrons $/ \mathrm{cm}^{2}$ are available from HFIR capsule irradiations. 
1.3 Data Needed

Data are needed to def ine the irradiation-induced dimensional changes of graphite $\mathrm{H}-451$ as a function of fluence and temperature, including:

a. Dependence on orientation and location in billet.

b. Variation from billet to billet and lot to lot.

The data base must be sufficient to determine the mean values of the irradiation strains within $\pm[0.05] \%$ strain at $[95] \%$ confidence. Some additional data are needed to establish the within billet correlation. Quality assurance must be in accordance with the requirements for Quality Assurance Level I.

1.4 Data Parameters/Service Conditions

Service Temperature Range: $\quad 300^{\circ} \mathrm{C}-950^{\circ} \mathrm{C}\left(572^{\circ} \mathrm{F}-1742^{\circ} \mathrm{F}\right)$

Operating Environment: Helium at 1 - 63 atm pressure

Maximum Fast Fluence: $5 \times 10^{25} \mathrm{n} / \mathrm{m}^{2}$ (E $>29 \mathrm{fJ}, \mathrm{HTGR}$ )

\section{DESIGNER'S ALTERNATIVES}

The following alternatives are available:

2.1 Use the existing data base.

2.2 Eliminate the need for a detailed statistical data base by using stress limits with deterministically selected high safety factors from which the Goal 2 and 3 reiliabilities can be conservatively estimated.

3. SELECTED APPROACH AND EXPLANATION

The selected approach is to show compliance with the Goals 2 and 3 reliability requirements through detailed probabilistic methods. This requires an adequate statistical data base.

Alternative 2.1 was rejected because the existing data base is inadequate for a probabilistic design approach. Alternative 2.2 would require a significantly lower power density and, consequently, a larger core.

4. SCHEDULE REQUIRMENTS

Data are required by $[9 / 91]$, one year after the start of the $f$ inal design phase $(9 / 90)$. 
5. PRIORITY

$2 \mathrm{H}$

6. FALLBACK POSITION AND CONSEQUENCES OF NONEXECUTION

Design alternative 2.2 would be used. The consequences would be a reduced power density and a corresponding increase in core size resuiting in higher capital and operating costs.
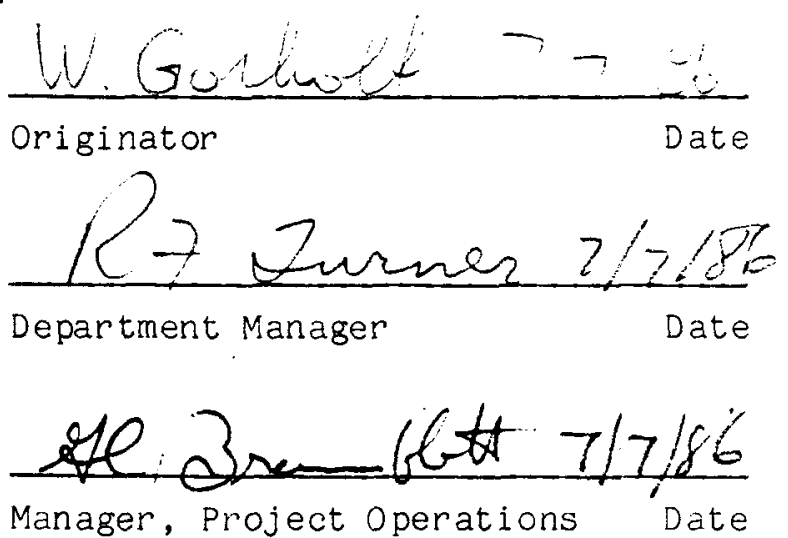
STATISTICS OF IRRADIATION-INDUCED CREEP OF GRAPHITE CORE COMPONENTS DDN M.10.18.05

PROJECT NUMBER 6300

PLANT: $4 \times 350 \mathrm{MW}(t)$ Modular HTGR/System 10

1. REQUIREMENT OR DESIGN FEATURE REQUIRING EXPERIMENTAL DATA OR VALIDATION TESTING

Probabilistically based design oriteria are being used for showing compliance with the Goals 2 and 3 reliability requirements. The statistical variability of the creep properties of the core component graphite is needed for the development of these criteria.

\subsection{Summary of Function/Title/Assumptions}

F2.1.2.1.2.4, "Protect the Capability to Maintain Fuel Element Structural Integrity."

Assumption 1: The coefficients of variation given in the Graphite Design Data Manual are accurate to within [25]\%.

Assumption 2: Confidence limits on the mean value and standard deviation can be sufficiently determined through the $t$ and Chi-Square distributions, respectively.

Assumption 3: Uncertainty in the estimation of the skewness of a distribution can be estimated by the uncertainty in the coefficient of variation.

\subsection{Current Data Base Summary}

Two compressive creep capsules without continuous strain registration operating at $600^{\circ} \mathrm{C}$ and three compressive creep capsuies operating at $900^{\circ} \mathrm{C}$ have been completed at ORNL. Each capsule contained eight creep specimens of $\mathrm{H}-451$ graphite stressed to $13.8 \mathrm{MPa}$ (2000 psi) or $20.7 \mathrm{MPa}$ (3000 psi) in compression. Two specimens of $\mathrm{H}-451$ graphite were irradiated in tensile creep assemblies with continuous strain registration at petten. The temperature was $820^{\circ} \mathrm{C}$ to $850^{\circ} \mathrm{C}$ and the stress was $6 \mathrm{MPa}$ ( $870 \mathrm{psi}$ ). The ORNL experiments included measurements for the effect of creep strain on Young's modulus, Poisson's ratio, and thermal expansivity. 


\subsection{Data Needed}

The following data are needed for $\mathrm{H}-451$ graphite as function of fluence and temperature:

a. Steady state creep strain in tension and compression up to $1 \%$ creep strain.

b. Transient (primary) creep strain.

c. Transverse-to-longitudinal strain ratios.

The data base must be sufficient to establish the mean value of the steady state creep strain within $\pm[8] \%$ and the mean values of the other creep properties within $\pm[20] \%$ both with $[95] \%$ confidence. In defining the required creep properties, the following effects need to be included.

a. Dependence on orientation and location in billet.

b. Variation from billet to biliet and from lot to lot.

In addition to the statistical data base, some data are al so needed to establish the effect of creep on tensile strength, Young's modulus, chermal expansivity and thermal conductivity. Furthermore, data are needed to validate that the creep strain is not significantly affected by the flux level. Quality assurance must be in accordance with the requirements for Quality Assurance Level I.

1.4 Data Parameters/Service Conditions

Service Temperature Range: $300^{\circ} \mathrm{C}-950^{\circ} \mathrm{C}\left(572^{\circ} \mathrm{F}-1742^{\circ} \mathrm{F}\right)$

Operating Environment: Helium at $1-63$ atm pressure

Maximum Fast Fluence: $5 \times 10^{25} \mathrm{n} / \mathrm{m}^{2}$ (E > $29 \mathrm{fJ}, \mathrm{HTGR}$ )

2. DESIGNER'S ALTERNATIVES

The following alternatives are available:

2.1 Use the existing data base.

2.2 Eliminating the need for a detailed statistical data base by using stress limits with deterministically selected high safety factors from which the Goals 2 and 3 reliabilities can be conservatively estimated.

3. SELECTED APPROACH AND EXPLANATION

The selected approach is to show compliance with the Goals 2 and 3 reliability requirements through detailed probabilistic methods. This requires an adequate statistical data base. 
Alternative 2.1 was rejected because the existing data base is inadequate for a probabilistic design approach. Alternative 2.2 would require a significantly lower power density and, consequently, a larger core.

4. SCHEDULE REQUIRMENTS

Data are required by [9/91], one year after the start of the final design phase $(9 / 90)$.

5. PRIORITY

$1 \mathrm{H}$

6. FALLBACK POSITION AND CONSEQUENCES OF NONEXECUTIUN

Design alternative 2.2 would be used. The consequences would be a reduced power density and a corresponding increase in core size resulting in higher capital and operating costs.
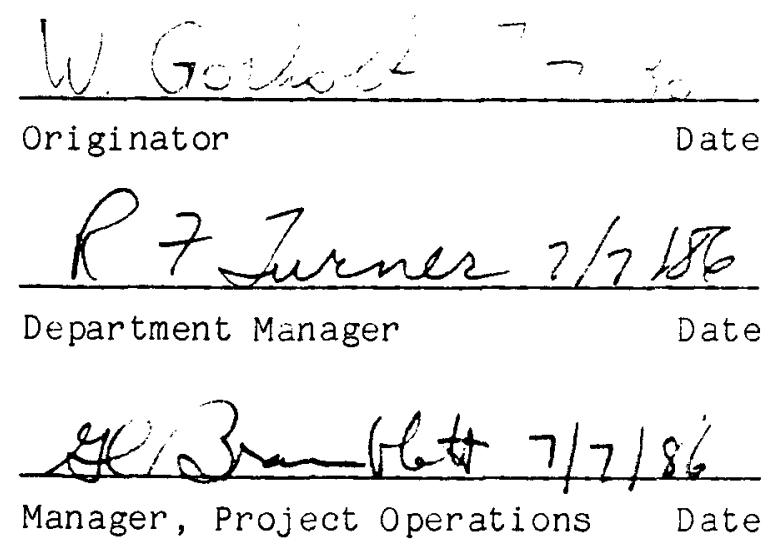
STATISTICS OF THERMAL PROPERTIES OF GRAPHITE FUR CORE COMPONENTS

DDN M.10.18.06

PROJECT NUMBER 6300

PLANT: $4 \times 350 \mathrm{MW}(t)$ Modular HTGR/System 10

1. REQUIREMENT OR DESIGN FEATURE REQUIRING EXPERIMENTAL DATA OR VALIDATION TESTING

The thermal properties are needed to complete the thermal-hydraul ic design of the graphite core components. The statistical variability of these properties is needed to develop probabilistically based stress criteria for showing compliance with the Goals 2 and 3 reliability requirements.

\subsection{Summary of Function/Title/Assumptions}

F1.1.2.1.1, "Transfer Heat from Fuel to Heat Transfer surface."

Assumption 1: The mean values of thermal expansivity, thermal conductivity, and specific heat given in the Graphite Design Data Manual for $\mathrm{H}-451$ graphite are valid.

Assumption 2: The lower bound for the emissivity of $\mathrm{H}-451$ graphite is 0.8 .

F2.1.2.1.2.4, "Protect the Capability to Maintain Fuel Element Structural Integrity."

Assumption 1: The coefficients of variation given in the Graphite Design Data Manual are accurate to within $[25] \%$.

Assumption 2: Confidence limits on the mean value and standard deviation can be sufficiently determined through the $t$ and Chi-Square distributions, respectively.

Assumption 3: Uncertainty in the estimation of the skewness of a distribution can be estimated by the uncertainty in the coefficient of variation.

\subsection{Current Data Base Summary}

Axial and radial thermal expansion measurements have been made on specimens from ten billets of production $\mathrm{H}-451$ graphite. In most cases, specimens have been from four locations in the billet. Measurements were made between ambient temperature and $500^{\circ} \mathrm{C}$. 
Thermal diffusivity measurements in the axial and radial direction have been made on seven billets of production H-451 graphite between room temperature and $800^{\circ} \mathrm{C}$. Specimens were taken from one or two locations in the billet.

Data exists on the effects of irradiation on thermal diffusivity and thermal expansivity of $\mathrm{H}-451$ graphite specimens irradiated in the Oak Ridge Reactor at $550^{\circ} \mathrm{C}$ through $1300^{\circ} \mathrm{C}$ to fluences between $1 \times 10^{21}$ neutrons $/ \mathrm{cm}^{2}$ and $1 \times 10^{22}$ neutrons $/ \mathrm{cm}^{2}$. Specimens were taken from five billets selected from three different production lots. Additional thermal expansivity data on $\mathrm{H}-451$ graphite and some data on early subsize prototype H-451I graphite irradiated at $600^{\circ} \mathrm{C}$ and $900^{\circ} \mathrm{C}$ to fluences up to $4 \times 10^{22}$ neutrons $/ \mathrm{cm}^{2}$ are available from HFIR capsule irradiations.

1.3 Data Needed

Thermal expansivity, conductivity, emissivity, and specific heat are needed for graphite $\mathrm{H}-451$, including:
a. Dependence on orientation and location in billet.
b. Variation of within and between billets and from lot to lot.
c. Temperature dependence.
d. Dependence on neutron fluence and irradiation temperature.

The data base must be sufficient to establish a [95]\% confidence that the mean values of the required thermal properties are within the following bounds:
Expansivity:
Conductivity:
Specific Heat:

$$
\begin{aligned}
& \pm[5] \% \\
& \pm[5] \% \\
& \pm[10] \%
\end{aligned}
$$

For emissivity, [95]\% confidence is needed that the lower bound of the property is $[0.80]$. Quality assurance must be in accordance with the requirements for Quality Assurance Level I.

1.4 Data Parameters/Service Conditions

Service Temperature Range: $120^{\circ} \mathrm{C}-950^{\circ} \mathrm{C}\left(248^{\circ} \mathrm{F}-1752^{\circ} \mathrm{F}\right)$

Operating Environment: Helium at $1-63 \mathrm{~atm}$ pressure

Maximum Fluence: $5 \times 10^{25} \mathrm{n} / \mathrm{m}^{2}$ (E > $29 \mathrm{fJ}$, HTGR) 
2. DESIGNER'S ALTERNATIVES

The following alternatives are available:

2.1 Use the existing data base.

2.2 Eliminate the need for a detailed statistical data base by using stress limits with deterministically selected high safety facturs from which the Goals 2 and 3 reliabilities can be conservatively estimated.

3. SELECTED APPROACH AND EXPLANATION

The selected approach is to show compliance with the Goals 2 and 3 reliability requirements through detailed probabilistic methods. Alternative 2.1 was rejected because the existing data base is inadequate for a probabilistic design approach. Alternative 2.2 would require a significantly lower power density and, consequently, $\exists$ larger core.

4. SCHEDULE REQUIRMENTS

Data are required by $9 / 91$, one year after the start of the final design phase $(9 / 90)$.

5. PRIORITY

$3 \mathrm{H}$

6. FALLBACK POSITION AND CONSEQUENCES OF NONEXECUTION

Design alternative 2.2 would be used. The consequences would be a reduced power density and a corresponding increase in core sizt resulting in higher capital and operating costs.
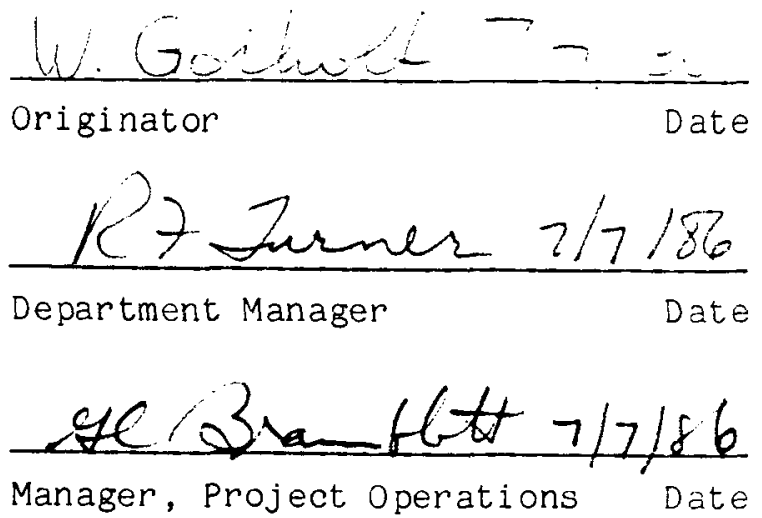
STATISTICS OF FRACTURE MECHANICS PROPERTIES OF GRAPHITE FOR CORE COMPONENTS DDN M.10.18.07

PROJECT NUMBER 6300

PLANT: $4 \times 350 \mathrm{MW}(t)$ Modular HTGR/System 10

1. REQUIREMENT OR DESIGN FEATURE REQUIRING EXPERIMENTAL DATA OR VALIDATIUN TEST ING

To meet the Goals 2 and 3 reliability requirements for the core components, it is necessary to calculate the probability of functional damage. Functional damage has been defined as a crack extending a-l the way across a fuel or reflecior element or at least a significant distance into the element. So far, only vertical cracks have been addressed using existing continuum mechanics methods. Fracture mechanics methods are needed to address horizontal cracks and also to validate the continuum mechanics methods.

\subsection{Summary of Function/Title/Assumptions}

F2.1.2.1.2.4, "Protect the Capability to Maintain Fuel Element Structural Integrity."

Assumption 3: The progression of vertical cracks (due to radial stresses) can be analyzed with continuum mechanics methods.

Assumption 4: Horizontal cracks which need fracture mechanics methods are less probable than vertical cracks due to (1) lower stresses in the axial direction, and (2) only vertical cracks have been observed in FSV fuel elements.

\subsection{Current Data Base Summary}

Some static $\mathrm{K}_{I C}$ measurements have been made on production $\mathrm{H}-451$ graphite using the chevron-notched short-rod specimen geometry. A few measurements have also been made on specimens from early subsize prototype $\mathrm{H}-451 \mathrm{I}$ biliets. Changes in the static $\mathrm{K}_{\mathrm{IC}}$ have been measured on $\mathrm{H}-451$ graphite specimens irradiated at $600^{\circ} \mathrm{C}$ and $900{ }^{\circ} \mathrm{C}$ to fluences of $1.6 \times 10^{22} \mathrm{n} / \mathrm{cm}^{2}$ in $\mathrm{HFIK}$. 
1.3 Data Needed

A data base is needed to define the critical stress intensity factors $\left(K_{I C}\right)$ and strain energy release rates $\left(G_{I C}\right)$ for crack initiation, stable crack growth, and crack arrest for graphite H-451 at room temperature in air, including:

a. The effects of orientation and location in billet.

b. Variation from billet to billet and from lot to lot.

The data base must be sufficient to establish the mean values of the above fracture mechanics properties within $\pm[10] \%$ at $[95] \%$ confidence.

A limited number of additional data points are needed to establish the effects of the operating environment on the fracture mechanics properties. The environmental conditions whose effects need to be established are:

a. The effect of irradiation.

b. The effect of temperature within the service temperature range.

c. The effect of pressurized helium.

Quality assurance must be in accordance with the requirements for Quality Assurance Level I.

\subsection{Data Parameters/Service Conditions}

Service Temperature Range: $300^{\circ} \mathrm{C}-950^{\circ} \mathrm{C}\left(572^{\circ} \mathrm{F}-1652^{\circ} \mathrm{F}\right)$

Operating Environment: Helium at $1-63$ atm pressure

Maximum Fast Fluence: $5 \times 10^{25} \mathrm{n} / \mathrm{m}^{2}$ (E $>29 \mathrm{fJ}, \mathrm{HTGR}$ )

\section{DESIGNER'S ALTERNATIVES}

The following alternatives are available:

2.1 Use the existing finite element codes to examine cracking initiation and progression based upon the maximum principal stress failure theory for vertical and also for crack initiation for horizontal cracks.

2.2 Eliminate the need for fracture mechanics methods by designing the core graphite components with high safety factors from which the Goals 2 and 3 reliabilities can be conservatively estimated. 
3. SELECTED APPROACH AND EXPLANATION

The selected approach is to develop fracture mechanics methods and use these to study crack propagation as part of the analysis for showing compliance with Goals 2 and 3 reliability requirements. Alternative 2.1 was rejected because it is theoretically unsound and thus would have been difficult to defend to the NRC. Alternative 2.2 wouid require a significantly lower power density and, consequently a larger core. The effects on capital and operating cost would be large.

4. SCHEDULE REQUIRMENTS

Data are required by $9 / 92$, two years after the start of the final design phase $(9 / 90)$.

5. PRIORITY

$4 M$

6. FALLBACK POSITION AND CONSEQUENCES OF NONEXECUTION

Design alternative 2.2 would be used. The consequences would be a reduced power density and a corresponding increase in core size resulting in nigher capital and operating cost.
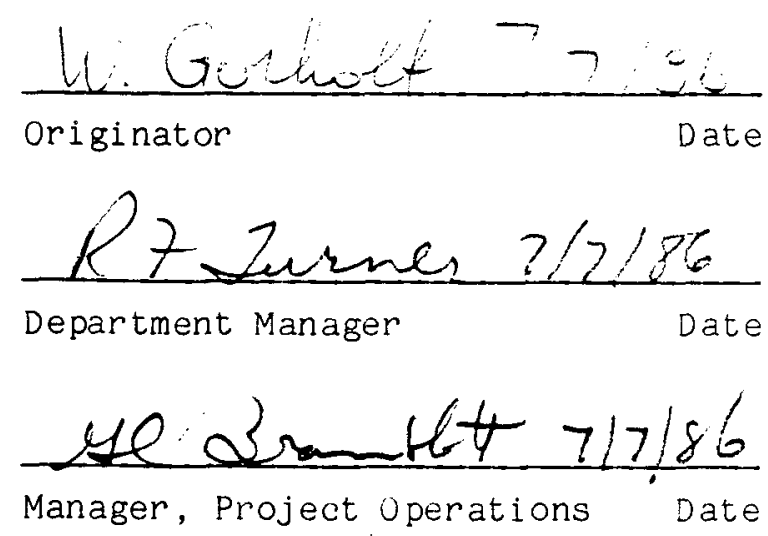
PLANT: $4 \times 350 \mathrm{MW}(t)$ Modular HTGR/System 10

1. REQUIREMENT OR DESIGN FEATURE REQUIRING EXPERIMENTAL DATA OR VALIDATION TEST ING

The graphite core components may be corroded by coolant impurities, principally $\mathrm{H}_{2} \mathrm{O}$, with consequent deterioration of their integrity. Associated data needs are DDNs: M.10.01, M.10.18.09.

\subsection{Summary of Function Number/Title/Assumptions}

F1.1.2.1.2.2. 4 "Maintain Fuel Element Structural Integrity." Assumption 4: The existing correlations for $\mathrm{H}-451$ graphite corrosion are accurate within a factor of [2] at $95 \%$ confidenci.

\subsection{Current Data Base Summary}

The corrosion of core component graphite (H451) by coolant impurities $\left(\mathrm{H}_{2} \mathrm{O}, \mathrm{O}_{2}\right.$, and $\left.\mathrm{CO}_{2}\right)$ may be mass-transf $\mathrm{er}$ limited, chemical-reaction limited, or a combination of both; consequently, both processes must be characterized. The transport of coolant impurities is a combination of pore diffusion and permeation flow due to pressure gradients; the transport rates increase with increasing graphite burnoff. The former process is characterized by an effective diffusion coefficient; the reference correlation was obtained for $\mathrm{H}_{2} \mathrm{O}$ transport in $\mathrm{H} 451$ graphite with $1 \%$ burnoff. The permeability of $\mathrm{H} 451$ has not been well characterized.

The reference correlations for the kinetics of 4451 corrosion by coolant impurities are based primorily upon laboratory measurements on small unirradiated specimens in helium with high impurity levels at or near atmospheric pressure. Some daca were obtained at elevated pressures $(-20 \mathrm{~atm})$ in the $\mathrm{High}$ Pressure Test Loop. Since the measurements were all made on unirradiated graphite, the effects of radiolysis and catalysis by fission metais on the graphite corrosion rate were not systematically investigated. The reaction of $\mathrm{H}_{2} \mathrm{O}$ with $\mathrm{H} 451$ exhibits Langmuir $\mathrm{Hinshel}$ wood type kinetics with significant product inhibition by $\mathrm{H}_{2}$ but not by $\mathrm{CO}$. The reference correlation for oxidation of $\mathrm{H}_{4} 51$ by air was derived from lab measurements on H327 graphite. 


\subsection{Data Needed}

Correlations describing the corrosion of 4451 graphite by coolant impurities during normal operation and $\mathrm{H}_{2} \mathrm{O}$ ingress events are needed. Data are needed to characterize both the transport of coolant impurities and graphite corrosion products in 4451 graphite and the intrinsic kinetics for the reaction of water and oxygen with H451 graphite. To characterize the transport of coolant impurities in graphite, the porosity, tortuosity, and permeability of the graphite must be determined. To characterize the reaction kinetics, the reaction rate must be determined as a function of temperature, impurity concentrations, system pressure, and time. In addition, the effects of radiolysis and catalysis by graphite impurities and by $f$ ission metals on the reaction kinetics must be determined. Finally, the effects of partial graphite burnoff on both the mass transfer processes and the intrinsic reaction kinetics must be quantified.

Sufficient data are needed to predict the burnoff within an accuracy of [2] with [95]\% confidence. Quality assurance must be in accordance with the requirements for Quality Assurance Level I.

\subsection{Data Parameters/Service Conditions}

The service conditions of interest are given below.

a. Normal Operation

Environment

Maximum fast fluence $(E>29$ fJ, HTGR)

Maximum gamma Flux

Primary coolant temperature range

Graphite temperature range

Maximum time averaged coolant impurity levels

Helium coolant pressure
Helium

$$
\begin{aligned}
& {\left[5 \times 10^{21}\right] \mathrm{n} / \mathrm{cm}^{2}} \\
& {[\mathrm{TBD}] \mathrm{MeV} / \mathrm{cm}^{2}-\mathrm{s}} \\
& {[120 \text { co } 700]^{\circ} \mathrm{C}} \\
& {[120-950]^{\circ} \mathrm{C}} \\
& {[2] \mathrm{ppm} \mathrm{H}_{2} \mathrm{O}} \\
& {[5] \mathrm{ppm} \mathrm{CO}} \\
& {[2] \mathrm{ppm} \mathrm{CO}} \\
& {[\mathrm{TBD}] \mathrm{ppm} \mathrm{O}_{2}} \\
& \text { Total oxidants }<10 \mathrm{ppm} \\
& {[10] \mathrm{ppm} \mathrm{H} \mathrm{H}_{2}} \\
& 1 \text { to } 63 \text { atms }
\end{aligned}
$$


b. Moisture Ingress Conditions

$\begin{array}{ll}\text { Environment } & \text { Helium } \\ \text { Coolant pressure range } & {[1 \text { to 65] atms }} \\ \text { Maximum time average coolant } & {[\mathrm{TBD}] \mathrm{ppm} \mathrm{H}_{2} \mathrm{O}} \\ \text { impurity levels } & {[\mathrm{TBD}] \mathrm{ppm} \mathrm{CO}} \\ & {[\mathrm{TBD}] \mathrm{ppm} \mathrm{CO}_{2}} \\ & \text { Total } 0 x i d a n t s[\mathrm{TBD}] \\ \text { Graphite temperature range } & {[120-1200]^{\circ} \mathrm{C}}\end{array}$

2. DESIGNER'S ALTERNATIVES

The following alternatives are available:

2.1 Use the current data base and add more margin to account for the uncertainties.

2.2 Impose tighter tech specifications on primary coolant oxidant levels.

2.3 Use a higher purity, more corrosion resistant graphite.

3. SELECTED APPROACH AND EXPLANATION

The selected approach is to determine the corrosion characteristics of $\mathrm{H} 451$ graphite under normal operating and $\mathrm{H}_{2} \mathrm{O}$ ingress conditions. Design alternative 2.1 is rejected because the uncertainties in the current data base would necessitate unacceptably large design margins. Design alternative 2.2 is rejected because imposition of tighter tech spec limits on coolant impurities is expected to adversely impact plant availability. Design alternative 2.3 is rejected because development and qualification of a higher purity graphite would add significant development costs. (H-451 is already a graphite with high oxidation resistance.)

4. SCHEDULE REQUIREMENTS

Preliminary data by $3 / 89,6$ months prior to PSSAR submittal (9/89) and final data by $9 / 91$, one year after the start of final design (9/90).

5. PRIORITY

$2 \mathrm{H}$ 
6. FALLBACK POSITION AND CONSEQUENCES OF NONEXECUTION

A combination of Alternatives 2.1 and 2.2 with the necessity of added margins in the design to compensate for uncertainties in the extent of core component corrosion. The consequence would be unnecessarily

restrictive tech specs on primary coolant impurity levels which could have a very adverse impact on plant availability.
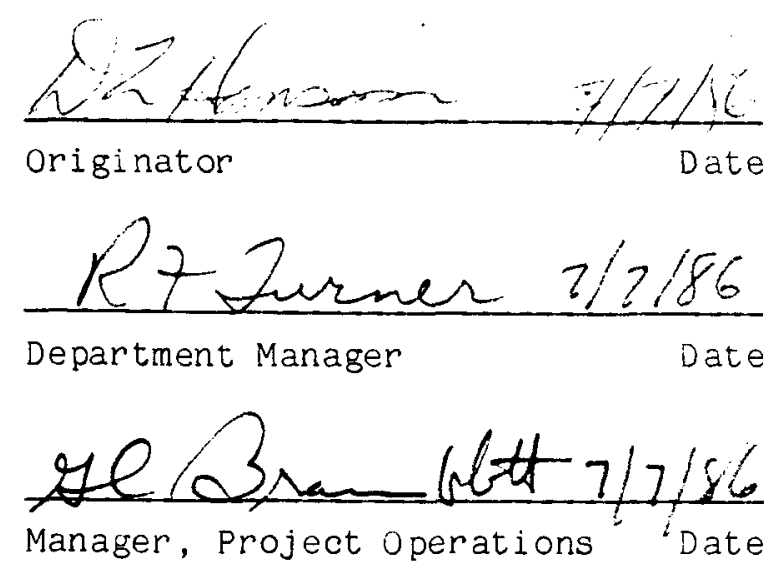
CORROSION EFFECTS ON CORE COMPUNENT GRAPHITE DESIGN PROPERTIES

DDN M.10.18.09

PROJECT NUMBER 6300

PLANT: $4 \times 350 \mathrm{MW}(\mathrm{c})$ Modular HTGR/Sys tem 10

1. REQUIREMENT OR DESIGN FEATURE REQUIRING EXPERIMENTAL DATA OR VALIDATION TESTING

The graphite core components must withstand the loads imposed on them without exceeding the stress limits of Goal 1 and the reliability limits of Goal 2 including degradation due to corrosion effects. Thus, the relationship between the design properties and the amount and distribution of oxidation is needed.

Associated data needs are DDNs M.10.01 and M.10.18.08.

\subsection{Summary of Function/Title/Assumptions}

F2.1.2.1.2.4, "Protect the Capability to Maintain Fuel Element Structurai Integrity."

Assumption 5: The existing data base is sufficient to predict the corrosion effects on H-451 graphite within a factor of [2] at [95]: conf idence.

F1.1.2.1.2.2.4, "Maintain Fuel Element structural Integrity."

Assumption 8: The existing data base is sufficient to predict the corrosion effects on H-451 graphite within a factor of [2] at [95]\% confidence.

\subsection{Current Data Base Summary}

Changes in the tensile strength and Young's modul us of $\mathrm{H}-451$ graphite uniformly oxidized up to $20 \%$ burnoff at $800^{\circ} \mathrm{C}$ and $1000^{\circ} \mathrm{C}$ have been reported. The effect of steam oxidation at $900^{\circ} \mathrm{C}$ and $1000^{\circ} \mathrm{C}$ on the static elastic fracture toughness has been measured for H-451 graphite. No thermal properties of $\mathrm{H}-451$ have been determined for oxidized material. The measurements have all been made on unirradiated graphite.

\subsection{Data Needed}

The data base shall be sufficient to define the following for $\mathrm{H}-451$ graphite: 
a. Effects of uniform burnoff on Young's modulus, tensile strength, compressive strength, irradiation-induced creep and dimensional change, fracture toughness, thermal conductivity, thermai expansivity, and specific heat.

b. The effects of nonuniform burnoff on these mechanicai and thermal properties.

Data are needed to predict the degradation of the design properties due to graphice corrosion within an accuracy of [2] with [95]\% confidence. Quality assurance must be in accordance with the requirements for Quality Assurance Level $I$.

\subsection{Data Parameters/Service Conditions}

The reactor operating or service conditions are given below.

Normal Operation

$\begin{array}{ll}\text { Maximum fast fluence }(E>29 \mathrm{fJ}) & {[5.0] \times 10^{21 \mathrm{n} / \mathrm{cm}^{2}}} \\ \text { Primary coolant temperature range } & {\left[120^{\circ} \mathrm{C} \mathrm{to} 700^{\circ} \mathrm{C}\right]} \\ \begin{array}{l}\text { Core component graphite temperature } \\ \text { range }\end{array} & {\left[120^{\circ} \mathrm{C} \mathrm{to} 950^{\circ} \mathrm{C}\right]} \\ \text { Maximum time averaged coolant } & \\ \text { impurity levels } & {[2] \mathrm{ppm} \mathrm{H}_{2} \mathrm{O}} \\ & {[5] \mathrm{ppm} \mathrm{CO}} \\ & {[2] \mathrm{ppm} \mathrm{CO} 2} \\ \text { Helium coolant pressure } & \text { Total oxidants }<10 \mathrm{ppm} \\ \end{array}$

Moisture Ingress Conditions

Coolant pressure range

[1 to 63] atms

Range of coolant impurity levels

[TBD] $\mathrm{ppm} \mathrm{H}_{2} \mathrm{O}$

[TBD] $\mathrm{ppm} \mathrm{CO}$

[TBD] $\mathrm{ppm} \mathrm{CO}_{2}$

Total oxidants < [TBD] ppm

Core component graphite temperature range

$\left[120^{\circ} \mathrm{C}\right.$ to $\left.1200^{\circ} \mathrm{C}\right]$

\section{DESIGNER'S ALTERNATIVES}

The following alternatives are available:

2.1 Use the current data base in the thermal and stress analysis and add more margin to account for uncertainties. 
2.2 Impose tighter tech specifications on the primary coolant oxidant levels.

2.3 Use a higher purity, more corrosion resistant graphite.

3. SELECTED APPROACH AND EXPLANATION

The selected approach is to obtain an improved materials data base on the effects of corrosion of the core component graphite. Design alternative 2.1 is rejected because the uncertainties in the current data base would necessitate unacceptably large design margins. Design alternative 2.2 is rejected because imposition of tighter tech spec limits on coolant impurities is expected to adversely impact plant availability. Design alternative 2.3 is rejected because development and qualification of a higher purity graphite would add significant development costs. (H-451 is al ready a graphite with high corrosion resistance).

4. SCHEDULE REQUIREMENTS

Preliminary data by [3/89.], six months prior to PSAR submittal (9/39) and final data by [9/91] one year after the start of the final design.

\section{PRIORITY}

$2 \mathrm{H}$

6. FALLBACK POSITION AND CONSEQUENCES OF NONEXECUTION

A combination of alternatives 2.1 and 2.2 with the necessity of added margins in the design to compensate for uncertainties in the degradation of the core components due to corrosion. The consequence would be unnecessarily restrictive tech specs on primary coolant impurity levels which could have a very adverse impact on-plant availability.
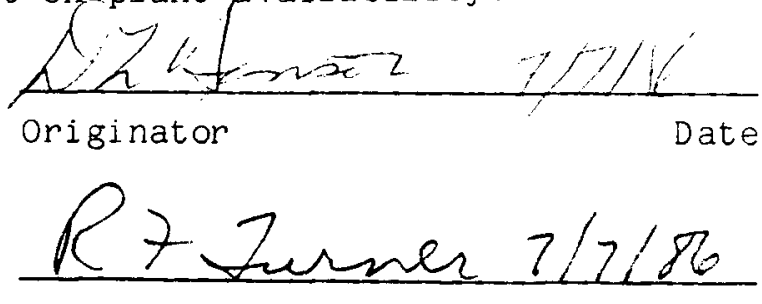

Department Manager

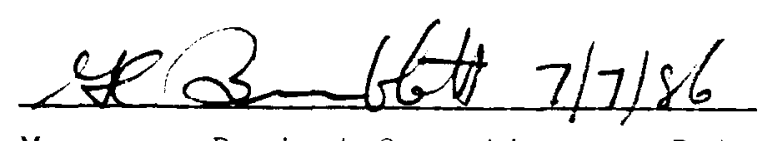

Manager, Project operations 
PLANT: $4 \times 350 \mathrm{MW}(\mathrm{t})$ Modular HTGR/System 10

1. REQUIREMENT OR DESIGN FEATURE REQUIRING EXPERIMENTAL DATA OR VALIDATION TESTING

Nondestructive testing techniques are needed for product control during procurement of graphite for the core components.

Associated data needs are DDNS: M.10.18.01 and M.10.18.03.

1.1 Summary of Function/Title/Assumptions

F1.1.2.1.2.2.4 "Maintain Fuel Element Structural Integrily."

Assumption 2: The production graphite will have the same properties as the design data base.

\subsection{Current Data Base Summary}

ORNL has developed nondestructive testing techniques and produced data on their accuracy and limitations for graphite grade H-451. The data base is too small to sufficientiy validate these techniques for use in product control of mass produced graphite.

\subsection{Data Needed}

Data are needed to validate NDE techniques and write materiai control specifications for the procurement of graphite for core components. The NDE techniques must be sufficiently accurate to 1) detect unacceptable flaws in the billets, and 2) determine the tensile strength of smaller specimens with an error no greater than [10]\%. Quality assurance must be in accordance with the requirements for Quality Assurance Level II.

1.4 Data Parameters/Service Conditions

NDE will be conducted at room temperature conditions.

\section{DESIGNER'S ALTERNATIVES}

These alternatives were considered:

2.1 Control the strength of the production material by conventional strength testing only. This would require several tensile test coupons from each billet in addition to more extensive mapping of at least one billet from each lot. 
2.2 Include additional design margin to account for uncertainties in the production material.

3. SELECTED APPROACH AND EXPLANATION

The selected approach is to use nondestructive examination in combination with a minimum of destructive testing to ensure that the production graphite satisfies the specifications. This is the most cost effective approach since NDE is less expensive than conventional destructive testing (Alternative 2.1). Alternative 2.2 would lead to a reduction in allowable stresses and hence a reduced power density and a larger core with a large increase in both capital and operating costs.

4. SCHEDULE REQUIREMENTS

The data is needed before the start of production of the graphite for the core components. This is assumed to be by $9 / 92$, one year before the end of the final design phase (9/93).

5. PRIORITY

$6 \mathrm{~L}$

6. FALLBACK POSITION AND CONSEQUENCES OF NONEXECUTION

Alternatives 2.1 would be used resulting in higher cost of the graphite material.
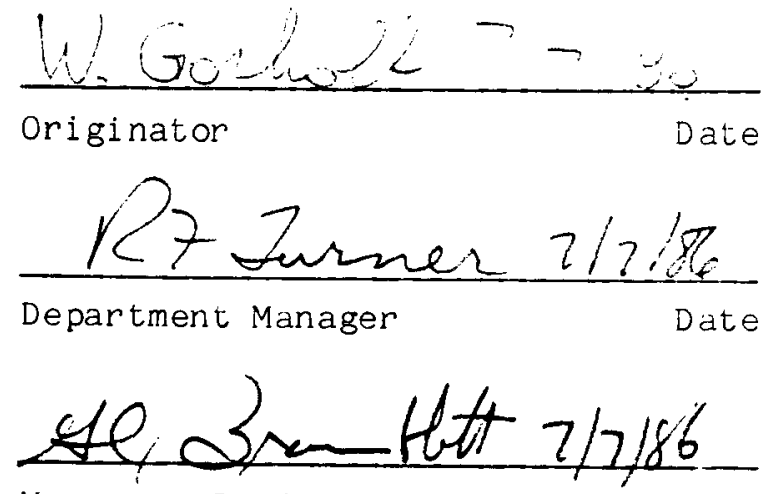

Manager, Project Operations Date 
VALIDATE FUEL ELEMENT DYNAMIC STRENGTH PREDICTIONS

DDN M.10.18.11

PROJECT NUMBER 6300

PLANT: $\quad 4 \times 350 \mathrm{MW}(\mathrm{t})$ Modular HTGR/System 10

1. REQUIREMENT OR DESIGN FEATURE REQUIRING EXPERIMENTAL DATA OR VALIDATION TESTING

The graphite core components (fuel and replaceable reflector elements) must withstand dynamic stresses due to seismic loads in combination with thermal/irradiation induced stresses.

\subsection{Summary of Function/Title/Assumption}

F1.1.2.1.2.2.4, "Maintain Fuel Element Structural integrity."

Assumption 9: The dynamic strength can be predicted with static finite element methods.

Assumption 10: Thermal/irradiation stresses and seismic stresses can be linearly combined.

\subsection{Current Data Base Summary}

To address the issue in Assumption 9, a series of dynamic tests of unirradiated FSV fuel elements was performed in 1976 in a pendulum rig. Those tests indicated that the dynamic strength can reasonably well be predicted with static finite element methods. However, all the test specimens were control fuel elements which are not used in the $350 \mathrm{MW}(t)$ core and most of them were made of graphite grade $\mathrm{H}-327$. Only two specimens were from $\mathrm{H}-451$ which is the $350 \mathrm{MiN}(\tau)$ reference material. No data exist on the mechanical strength (static or dynamic) of irradiated fuel elements.

\subsection{Data Needed}

The failure load of $\mathrm{H}-451$ fuel elements subjected to dynamically applied forces are needed. The nature of the forces and their duration must be representative for the type of loads imposed on the fuel elements during earthquakes. Data points are needed for both virgin fuel elements and irradiated fuel elements with residual stresses resulting from long time exposure to temperatures and fluences comparable to the conditions in an HTGR core.

The data base must be sufficient to establish with [95\%] confidence that the analytical methods are conservative, i.e., the mean values 
of the experimentally determined failure loads are higher than the corresponding analytical predictions. Quality assurance must be in accordance with the requirements for Quality Assurance Level I.

1.4 Data Parameters/Service Conditions

Material: Graphite Grade H-451

Service Temperature Range: $120^{\circ} \mathrm{C}-950^{\circ} \mathrm{C}\left(248^{\circ} \mathrm{F}-1742^{\circ} \mathrm{F}\right)$

Maximum Fast Fluence: $5 \times 10^{25} \mathrm{n} / \mathrm{m}^{2}$ (E $>29 \mathrm{fJ}, \mathrm{HTGR}$ )

Operating Environment: Helium a $1-63$ atm pressure

\section{DESIGNER'S ALTERNATIVES}

These alternatives were considered:

2.1 Redesign the core to eliminate the seismic impact loads on the fuel and reflector elements. This would require keying or clamping of the core.

2.2 Proceed on the basis of the present assumptions (static methods, linear combination) without validation.

3. SELECTED APPROACH AND EXPLANATION

The selected approach is to validate the dynamic strength predicted on the basis of static methods and linear load combinations. This was seen as the most cost effective approach. Alternative 2.1 would resuit in a costlier design and more complicated refueling. Alternitive 2.2 would incur the risk of rejection during licensing.

4. SCHEDULE REQUIREMENTS

Data are required by $3 / 90$, six months before the start of final design $(9 / 90)$.

5. PRIORITY

$1 M$

6. FALLBACK POSITION AND CUNSEQUENCES OF NONEXECUTION

Design Alternative 2.2 would be used with the risk of rejection during licensing resulting in either a crash technology program or a belated design change.

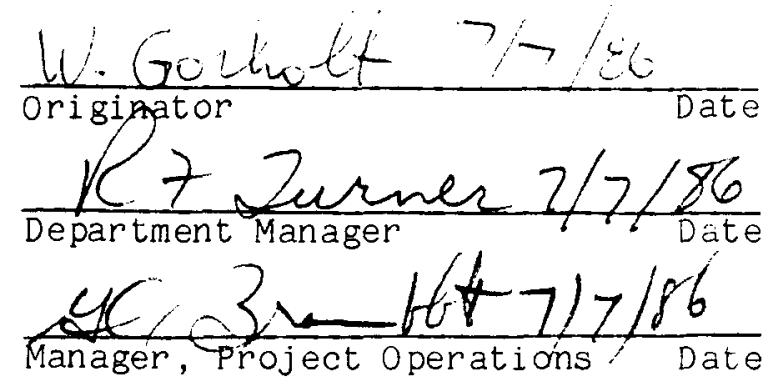




\author{
VALIDATE FUEL ELEMENT FAILURE MODE PREDICTIONS \\ DDN M.10.18.12 \\ PROJECT NUMBER 6300
}

PLANT: $\quad 4 \times 350 \mathrm{MW}(t)$ Modular HTGR/System 10

1. REQUIREMENT OR DESIGN FEATURE REQUIRING EXPERIMENTAL DATA UR VALIDATION TESTING

The steps in the design process for showing compliance with the Goals 2 and 3 reliability requirements includes calculations of how a crack, if initiated, would progress until the fuel element is functionally damaged. The methods for performing these calculations need validation.

\title{
1.1 Summary of Function/Title/Assumption
}

F.2.1.2.1.2.4, "Protect the Capability to Maintain Fuel Element Structurai Integrity."

Assumption 6: The failure mode, i.e., the crack progression can be predicted with the TWOD finite element code.

\subsection{Current Data Base Summary}

The failure load and failure mode of virgin fuel elements under mechanical loads were determined in two test programs: first for FSV elements in 1976, then for the $2240 \mathrm{MW}(\mathrm{i})$ elements in 1983. Some analytical correlations were performed, but these did not include crack progression analyses. Limited cracking under thermal/ irradiation stresses have been observed in two FSV fuel elements, and reasonably good analytical correlations were achieved. The cracking was, however, far from extensive enough to represent failure in a functional sense. No data exist for failure under combined thermal/irradiation and mechanical loads.

\subsection{Data Needed}

The failure loads and failure modes are needed for fuel elements subjected to the combination of mechanical and thermal/irradiation loads. The thermal/irradiation stresses must be comparable to those developed in a typical fuel element at shutdown conditions (due to creep there are residual stresses at shutdown of the same magnitude as the operating stresses).

The specific data needed are:

a. Mechanical load at crack initiation

b. Location of crack initiation

c. Mechanical load at ultimate failure

d. Crack path from initiation to ultimate failure 
The data base must establish with [90\%] confidence that the analytical methods are conservative, i.e., the mean values of the experimental data is higher than the corresponding analytical predictions. Quality assurance must be in accordance with the requirements for Quality Assurance Level $I$.

1.4 Data Parameters/Service Conditions

Material: $\mathrm{H}-451$

Service Temperature Range: $120^{\circ} \mathrm{C}-950^{\circ} \mathrm{C}\left(248^{\circ} \mathrm{F}-1742^{\circ} \mathrm{F}\right)$

Maximum Fast Fluence: $5 \times 10^{25} \mathrm{n} / \mathrm{m}^{2}$ (E $>29 \mathrm{fJ}$, HTGR)

Operating Environment: Helium at 1-63 atm pressure

\section{DESIGNER'S ALTERNATIVES}

These alternatives were considered:

2.1 Validate the analytical predictions on the basis of the existing data.

2.2 Design the core components with a large margin from where the reliabilities can be conservatively estimated without detailed predictions of failure loads and failure modes.

3. SELECTED APPROACH AND EXPLANATION

The selected approach is to perform cracking analysis with the TwOD code as a part of the design process for showing compliance with the Goal 2 reliability requirements and to validate the analytical methods by correlation with an expanded data base. Alternative 2.1 would incur the risk of rejection during licensing. Alternative 2.2 would lead to an uneconomical design.

4. SCHEDULE REQUIREMENTS

The data are needed by $9 / 89$, one year before the start of final design $(9 / 90)$.

5. PRIORITY

$1 \mathrm{M}$ 
6. FALLBACK POSITION AND CONSEQUENCES OF NONEXECUTION

Design Alternative 2.1 would be used with the risk that the validation would be deemed unacceptable resuiting in either a crash technology program or a belated design change.
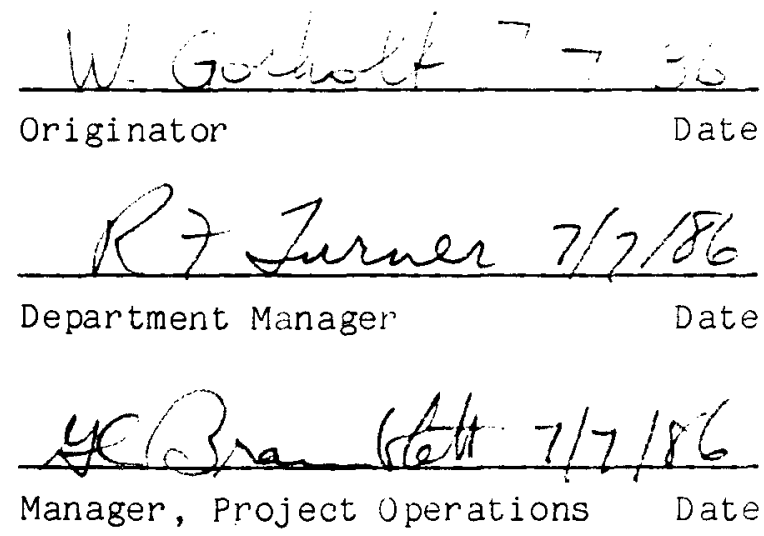


\author{
VALIDATE CORE COMPONENT SEISMIC LOAD PREDICTIONS \\ DDN M.10.18.13 \\ PROJECT NUMBER 6300
}

PLANT: $4 \times 350 \mathrm{MW}(\mathrm{t})$ Modular HTGR/System 10

1. REQUIREMENT OR DESIGN FEATURE REQUIRING EXPERIMENTAL DATA OR VALIDATION TESTING

The seismic loads imposed on the graphite core components are predicied with the MCOCO computer code which uses the excitation at the core boundary as input. These load predictions must be validated.

\title{
1.1 Summary of Function/Title/Assumptions
}

F1.1.2.1.2.2.4 "Maintain Fuel Element Structural Integrity."

Assumption 11: The seismic loads are correctly predicted by the MCUCO computer code.

\subsection{Current Data Base Summary}

Tests were run in 1974 on a scaled model of a large HTGR core. These tests validated the MCUCO code in general, i.e., the frequency characteristics and the overall core response. A satisfactory validation of the load predictions was not achieved, however, partly due to instrumentation limitations, partly due to an unresolved question about the scaling laws.

\subsection{Data Needed}

Data are needed on the structurai integrity of the fuel elements, i.e., whether the elements break or are otherwise structurally damaged after having been subjected to a simulated earthquake of an intensity for which the analytical methods would predict damage. Data are also needed on the relative impact velocities between the pairs of elements experiencing the highest impact loads.

The data base must be sufficient to establish a [90\%] confidence that the analytical methods are conservative; i.e., the analytically predicted loads are higher than the actual loads. Quality assurance must be in accordance with the requirements for Quality Assurance Level I.

\subsection{Data Parameters/Service Conditions}

Material: Graphite Grade $\mathrm{H}-451$

Service Temperature Range: $120^{\circ} \mathrm{C}-950^{\circ} \mathrm{C}\left(248^{\circ} \mathrm{F}-1742^{\circ}\right)$

Maximum Fast Fluence: $5 \times 10^{25} \mathrm{n} / \mathrm{m}^{2}$ (E $>29 \mathrm{fJ}, \mathrm{HTGR}$ ) 
Operating Environment: Helium at 1-63 atm pressure

Seismic Excitation at Core Boundary: [0.5 g OBE]

$[0.75 \mathrm{~g}$ SSE $]$

2. DESIGNER'S ALTERNATIVES

These alternatives were considered:

2.1 Redesign the core to eliminate the seismic impact loads on the fuel and reflector elements. This would require keying or clamping of the core.

2.2 Continue to use the existing methods without further validation.

3. SELECTED APPROACH AND EXPLANATION

The selected approach is to supplement the data base to complete the validation of the seismic design. Alternative 2.1 would result in a costlier design and more complicated refueling. Alternative 2.2 would incur the risk of rejection during licensing.

4. SCHEDULE REQUIREMENTS

The data are needed by 9/92, one year before PSAR submittal (9/93).

5. PRIORITY

$3 \mathrm{M}$

6. FALLBACK POSITION AND CONSEQUENCES OF NONEXECUTION

Design alternative 2.2 would be used with the risk of rejection during licensing resulting in a crash technology program and possibly also schedule delays.
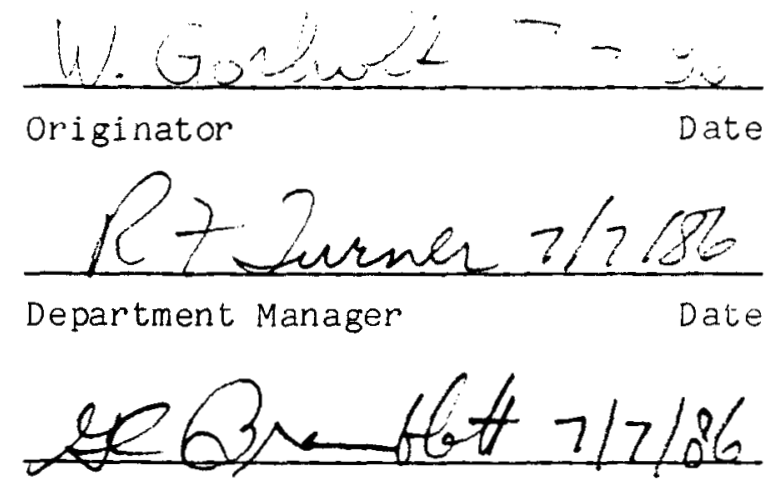

Manager, Project operations Date 
VALIDATE CONTROL ROD SHOCK ABSORBER CHARACTERISTICS

DDN M.10.18.14

PROJECT NUMBER 6300

PLANT: $4 \times 350 \mathrm{MW}(\mathrm{t})$ Modular HTGR/System 10

1. REQUIREMENT OR DESIGN FEATURE REQUIRING EXPERIMENTAL DATA OR VALIDATIUN TESTING

Crushable graphite shock absorbers are installed at the bottom of the control rod channel to protect the graphite core support structure in the event of an accidentally dropped control rod.

1.1 Summary of Function/Title/Assumptions

F2.1.2.1.2.2.2.2.2.2.4 "Absorb Energy from Dropped Control Rod"

Assumption 1: A crushable graphite insert can absorb sufficient energy to protect the core support structure.

\subsection{Current Data Base Summary}

No data is available on the shock absorption characteristics of graphite in crushable form (e.g., perforated, honeycombed, etc.).

\subsection{Data Needed}

Data are needed to establish the absorption characteristics for three different variants, as specified by the designer, of a crushable graphite shock absorber. (The absorption characteristic is the energy absorbed in crushing action, expressed as a percentage of the cotal kinetic energy in the falling body). For each of the three variants, a sufficient data base must be established to provide $90 \%$ confidence that the mean value of the data base is at most [20\%] different from the true mean vaiue. (Provided the data confirms that all three variants are adequate, the designer will select the most cost effective of the variants). Quality assurance must be in accordance with the requirements for Quality Assurance Level I.

\subsection{Data Parameters/Service Conditions}

Material: Graphite Grade $\mathrm{H}-451$

Service Temperature Range: $21^{\circ} \mathrm{C}-700^{\circ} \mathrm{C}\left(70^{\circ} \mathrm{F}-1300^{\circ} \mathrm{F}\right)$

Maximum Fast Fluence: $\left[\begin{array}{lll}1 & \times 10^{25}\end{array}\right] \mathrm{n} / \mathrm{m}^{2}$ ( $\mathrm{E}>29 \mathrm{fJ}, \mathrm{HTGR}$ )

Operating Environment: Helium at 1-65 atm pressure

Characteristics of Dropped Control Rod:

Weight of Rod: [180] ib

Max Drop Height: [32] ft 


\section{DESIGNER'S ALTERNATIVES}

These alternatives were considered:

2.1 Improve the reliabilicy of the control rod such that the unscheduled outage due to a dropped rod meets the allocations even without any shock absorbing features.

2.2 Use a FSV type metallic shock absorber connected to the lower end of the control rod.

2.3 Eliminate the shock absorber and accept the unscheduled outage resulting from a dropped rod.

\section{SELECTED APPROACH AND EXPLANATION}

The selected approach is to use shock absorbers of crushable graphite with validated characteristics. Validation is necessary because of the uncertainties in making analytical predictions. This approach was found to be more cost effective than the alternatives. Alternative 2.1 would increase the cost of the control rods and would also introduce the difficulties and expenses of proving that their reliabilities were adequate. Alternative 2.2 would require periodic replacements of the shock absorber due to embrittlement of the thin-walled metal structure. Irradiation testing would also be necessary to determine the degradation of the shock absorption characteristics as function of the fast fluence. Alternative 2.3 would require an increase in the unscheduled outage allocation due to the extended shutdown for replacing potentially damaged core support components.

4. SCHEDULE REQUIREMENTS

The data are needed by 9/92, one year before PSAR submittal (9/93).

5. PRIORITY

$4 M$

6. FALLBACK POSITION AND CONSEQUENCES OF NONEXECUTION

Alternative 2.2 would be used. This would increase operating costs and also technology cost due to the need for irradiation testing.

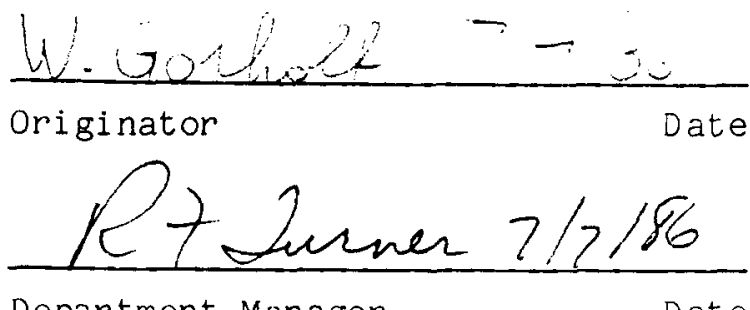

Department Manager

Date

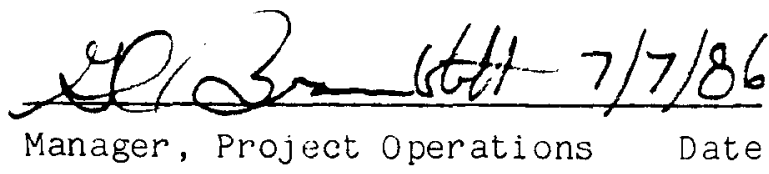

